\title{
Service quality in customer-employee relationships
}

\author{
Citation for published version (APA):
}

Wetzels, M. G. M. (1998). Service quality in customer-employee relationships: an empirical study in the after-sales services context. [Doctoral Thesis, Maastricht University]. Universiteit Maastricht. https://doi.org/10.26481/dis.19980706mw

Document status and date:

Published: 01/01/1998

DOI:

10.26481/dis.19980706mw

Document Version:

Publisher's PDF, also known as Version of record

\section{Please check the document version of this publication:}

- A submitted manuscript is the version of the article upon submission and before peer-review. There can be important differences between the submitted version and the official published version of record.

People interested in the research are advised to contact the author for the final version of the publication, or visit the DOI to the publisher's website.

- The final author version and the galley proof are versions of the publication after peer review.

- The final published version features the final layout of the paper including the volume, issue and page numbers.

Link to publication

\footnotetext{
General rights rights.

- You may freely distribute the URL identifying the publication in the public portal. please follow below link for the End User Agreement:

www.umlib.nl/taverne-license

Take down policy

If you believe that this document breaches copyright please contact us at:

repository@maastrichtuniversity.nl

providing details and we will investigate your claim.
}

Copyright and moral rights for the publications made accessible in the public portal are retained by the authors and/or other copyright owners and it is a condition of accessing publications that users recognise and abide by the legal requirements associated with these

- Users may download and print one copy of any publication from the public portal for the purpose of private study or research.

- You may not further distribute the material or use it for any profit-making activity or commercial gain

If the publication is distributed under the terms of Article $25 \mathrm{fa}$ of the Dutch Copyright Act, indicated by the "Taverne" license above, 


\title{
Service Quality in Customer-Employee Relationships
}

\author{
An Empirical Study in the After-Sales Services Context
}


(C) 1998, Martin G.M. Wetzels, Maastricht.

All rights reserved. No part of this publication may be reprinted or utilized in any form or by any electronic, mechanical or other means, now known, or hereafter invented, including photocopying and recording, or in any information storage or retrieval system, without written permission from the copyright owner.

ISBN: 90-9011771-7

Printed by: DATAWYSE, Maastricht. 


\title{
Service Quality in Customer-Employee Relationships
}

\author{
An Empirical Study in the After-Sales Services Context
}

\section{PROEFSCHRIFT}

\author{
ter verkrijging van de graad van doctor \\ aan de Universiteit Maastricht, \\ op gezag van de Rector Magnificus, Prof. Dr. A.C. Nieuwenhuijzen Kruseman, \\ volgens het besluit van het College van Decanen, \\ in het openbaar te verdedigen \\ op maandag 6 juli 1998 om 14:00 uur
}

door

Martin G.M. Wetzels 
Promotor:

Prof. Dr. J.D.P. Kasper

Co-promotor:

Dr. J.G.A.M. Lemmink

Beoordelingscommissie:

Prof. Dr. F.Ch. Palm (voorzitter)

Prof. R.A. Feinberg, Ph.D. (Purdue University, West-Lafayette, USA)

Prof. Dr. J. Hagedoorn 
Non scholae, sed vitea discimus.

SENECA 



\section{Preface and Acknowledgements}

Service quality is probably the single most important concept in services marketing to date. It therefore features prominently in this thesis. It becomes apparent from this thesis that service quality can be improved by empowering customer-contact service employees. Empowerment decreases role ambiguity and thus increases job satisfaction and performance. Furthermore, service quality and customer satisfaction positively affect the relationship between service provider and service customer.

The undertaking of writing a dissertation is probably the ultimate service experience both for the Ph.D. candidate as well as for his advisors. As a result, a lot of the conclusions of this dissertation also apply to the "Ph.D. service experience". Being empowered by my advisors I have strolled about the field of marketing. However, I always returned to my dissertation. My advisors gave me the opportunity to explore new and interesting paths. The quality of their coaching played a pivotal role in the completion of this dissertation. Apart from increasing my job satisfaction and performance, it instilled me with great confidence in the ultimate outcome of this project and left me with a feeling of both personal and professional accomplishment.

This dissertation is the result of a study, which started approximately four years ago. Many persons have contributed to this dissertation in one way or another. I would like to take the opportunity to thank them. To begin with, I would like to thank my advisors, Jos Lemmink and Hans Kasper for their unrelenting support, valuable ideas and the effort and energy they expended on the completion of this dissertation. Especially, I would like to thank Jos Lemmink, from whom the idea for this dissertation originated. It was Jos Lemmink who showed me the wonderful world of science. It was under his inspiring and enthusiastic supervision I wrote my Master Thesis and decided to become a Ph.D. Candidate. He was always willing to listen to my ideas, to make remarks, to suggest alternatives and to divert my energy to the completion of this dissertation. A person who he needs to be mentioned in this respect as well is Ko de Ruyter. He once referred to the author of this dissertation as being a "true procrastinator". Ko and Jos never failed to focus my attention on the completion of this dissertation. Knowing myself and my interest in everything else except my dissertation that must have been a tremendous job. Although I turned my attention to my dissertation only grudgingly at that time, I feel an immense gratitude for their actions now. Without them this dissertation could have remained die Unvollendete. I also wish to express my sincere thanks to Hans Kasper. Being one of the founding fathers of services marketing in the Netherlands, he taught me to step back from the empirical results of my study and take a more comprehensive view. Furthermore, his remarks and suggestions were always stimulating and constructive and have considerably improved the quality of this manuscript.

I would like to express my feelings of gratitude towards the members of my graduation committee, Prof. Dr. F. Ch. Palm, Prof. R.A. Feinberg, Ph.D. and Prof. Dr. J. Hagedoorn for reading the manuscript and providing me with valuable suggestions.

Furthermore, the contributions of the Department of Marketing and Marketing Research have to be recognized and are appreciated by the author of this dissertation. Without the resources, energy and effort of the department this dissertation would have remained a latent thought by the author. Every member of the department contributed to this dissertation in one way or another. Thanks to you all! I hope we can continue our cooperation in the future. However, one person in particular needs to be mentioned. That person is Ko de Ruyter. We started with the department of Marketing and Marketing Research in 1993. Little did we know then that we know now. I am deeply indebted to him for stimulating me to write and publish papers. Since then our personal and professional relationships have prospered and I consider him to be an esteemed and respected colleague and fellow academician as well as a very dear and close personal friend. Ko, live long and prosper (Traditional Vulcan greeting)! Finally, I would like to thank Mieke Donders, our secretary for all the work she did for my dissertation. 
The financial support by the Faculty of Economics and Business Administration to this dissertation is also gratefully acknowledged. Without the resources set apart by the Faculty of Economics and Business Administration this dissertation would have remained merely a reflection of a concept.

Moreover, I would like to thank my fellow Ph.D. candidates who participated in the Ph.D. courses. Our conversations were always interesting and have stimulated my mind. In particular, I would like to thank Joost Pennings. His contributions to this thesis are well appreciated. Finally, I would like to thank all faculty on the Ph.D. courses as well.

I would like to thank my student-assistants, Louise Rijk and Klaas Fleischmann for their assistance in collecting the data for this dissertation. They have done a wonderful job in taking care of the data collection process. Their professional attitude and competence should be a role model for students to come.

I also would like to thank the sponsoring organization, which choose to remain unnamed, for the resources they provided for this study, both intellectual and financial. One person in particular needs to be mentioned. Without René Sprenkels' firm support and tenacity this project would never have resulted in a longitudinal study. The discussions with him and his colleagues were always a source of inspiration. Their contributions to the managerial implications of this dissertation are invaluable. Having recognized the contribution of all the above, I need to emphasize that all the remaining weaknesses are my sole responsibility.

I would like to thank my parents and sister for fostering the flame of learning. My parents have always done the utmost to stimulate my interest in studying and learning. Ultimately, their efforts culminated in this dissertation. Without them this dissertation would have remained unwritten. I also would like to thank my sister for the intellectual sparring. I hope it was as stimulating for her as it was for me.

Finally, I would like to thank Katja. She stood by my side and provided me with the support I needed to complete this dissertation. Her love and caring were an essential input for this study. Katja, thank you! 


\section{Table of Contents}

\section{Preface and Acknowledgments}

1. Introduction

1.1 The Service Economy: Fact or Fiction?........................................................................3

1.2 The Service Encounter: Games between People............................................................5

1.3 The Service Encounter: A Marketing Perspective .................................................................7

1.4 The Service Encounter: An Organizational Perspective ................................................10

1.5 Relevance of the Thesis .......................................................................................12

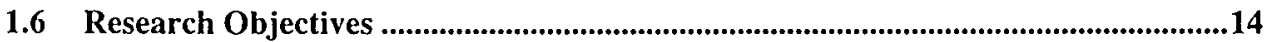

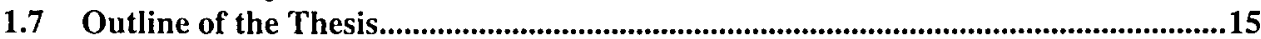

2. Service Quality: The Focal Construct................................. 17

2.1 Introduction ..............................................................................................................................18

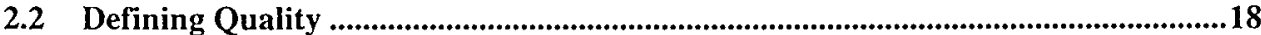

2.3 The Conceptual Model of Service Quality ........................................................................22

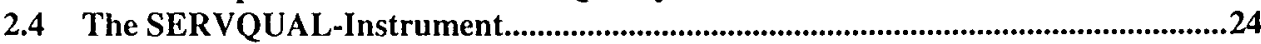

2.5 Conceptual Concerns regarding the SERVQUAL-Instrument ..................................29

2.5.1 The "Gap" (P-E) Conceptualization of Service Quality........................................29

2.5.2 Is Service Quality an Attitude? ............................................................................30

2.5.3 The Multidimensional Nature of Service Quality..................................................31

2.5.4 Service Quality and Customer Satisfaction: Identical Twins or Siamese Twins

2.5.5 Service Value: A Contender to the Throne?........................................................34

2.5.6 The Static Nature of the Conceptual Model of Service Quality...........................35

2.5.7 Consequences of Service Quality ..............................................................................36

2.6 Measurement Concerns pertaining to SERVQUAL .....................................................39

2.6.1 Dimensionality of the SERVQUAL-Instrument .......................................................39

2.6.2 Use of Importance Weights ...........................................................................4

2.6.3 Use of Difference Scores...................................................................................4I

2.6.4 The Distribution of Service Quality .....................................................................44

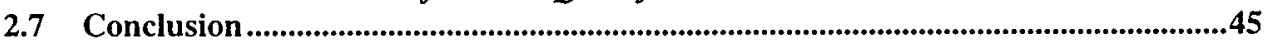

3. Organizational Antecedents to Service Quality .................... 47

3.1 Introduction ........................................................................................................................48

3.2 The Extended Model of Service Quality.....................................................................49

3.2.1 Research Design.............................................................................................51

3.2.2 Model Specification..................................................................................................51

3.2.3 Measurement Properties..........................................................................................53

3.3 Testing the Extended Model of Service Quality: A Pre-Study ....................................54

3.3.1 Research Setting.................................................................................................54

3.3.2 Sampling Procedure...............................................................................................5

3.3.3 Measurement Instruments.........................................................................54

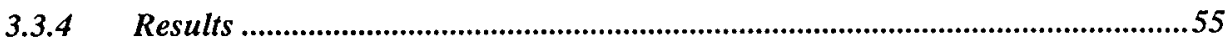

3.3.5 Discussion ..............................................................................................................59

3.4 The Need for an Alternative Model ............................................................................59

3.5 Role Stress .................................................................................................................61

3.5.1 Role Theory ................................................................................................62 
3.5.2 Defining Role Conflict and Role Ambiguity.................................................62

3.5.3 The Dynamics of Role Ambiguity and Role Conflict .......................................64

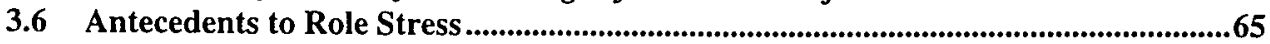

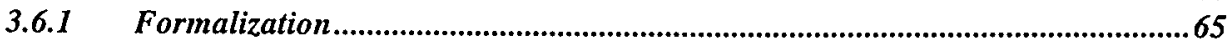

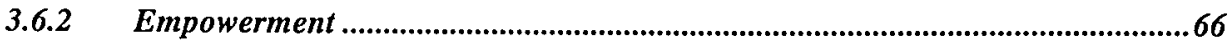

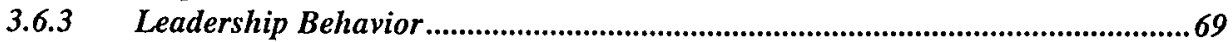

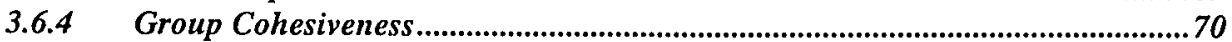

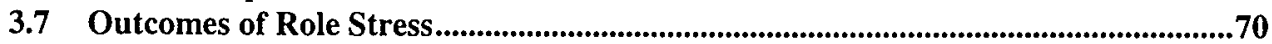

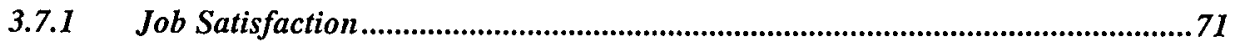

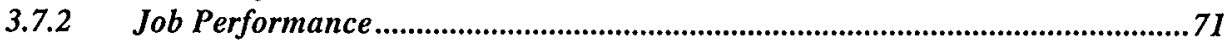

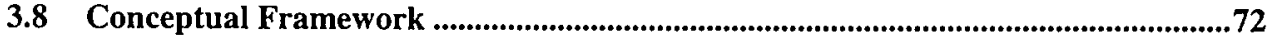

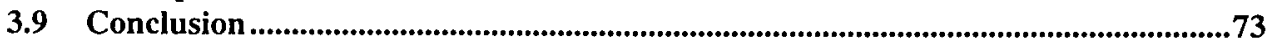

4. Service Quality and the Relationship Paradigm.................. 75

4.1 Introduction ................................................................................................................76

4.2 Quality and Business Performance..........................................................................76

4.3 Relationship Marketing in Services ........................................................................8

4.4 Conceptualization of Commitment ..............................................................................83

4.5 Antecedents of Commitment ........................................................................................8

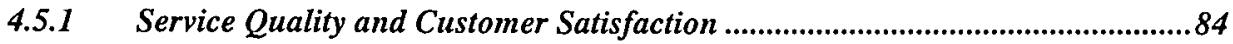

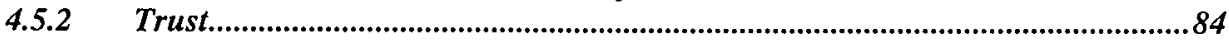

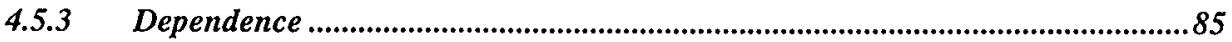

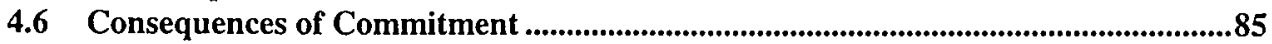

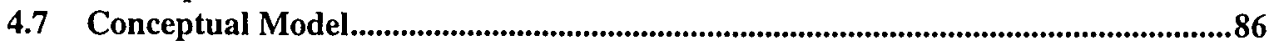

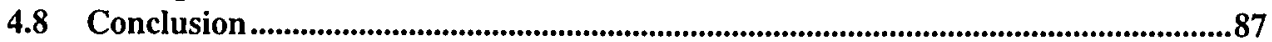

5. Role Stress in After-Sales Service Management: Its Antecedents and Consequences ....................................................... 88

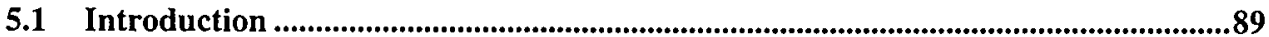

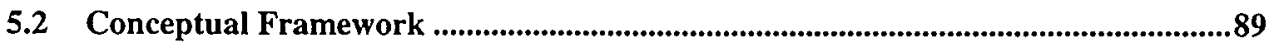

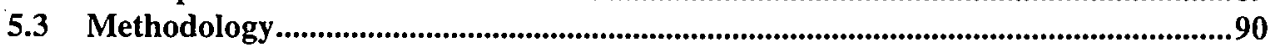

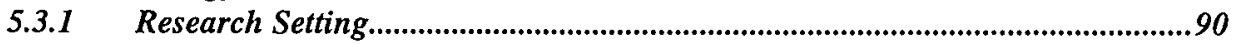

5.3.2 Sampling Design and Data Collection ..............................................................91

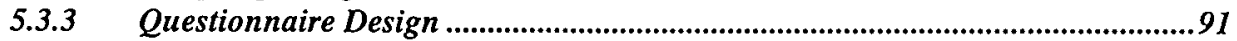

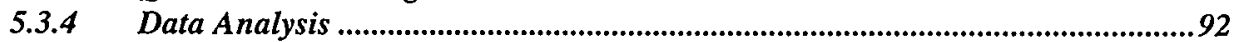

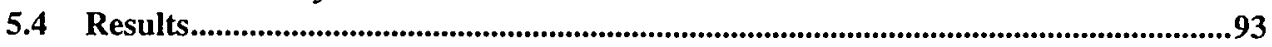

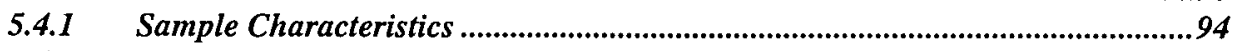

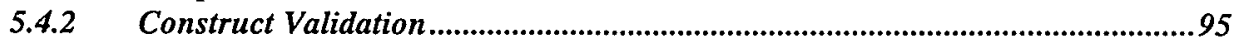

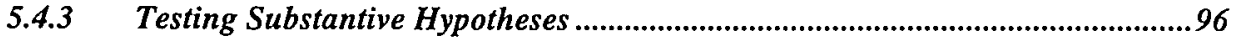

5.4.4 A Longitudinal Approach .................................................................................99

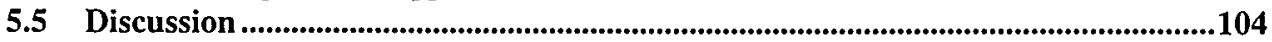

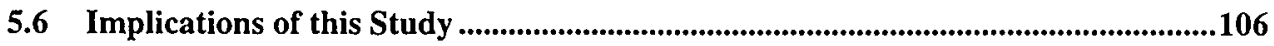

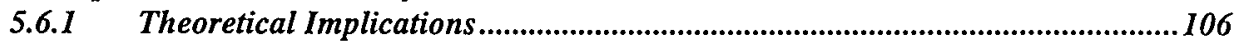

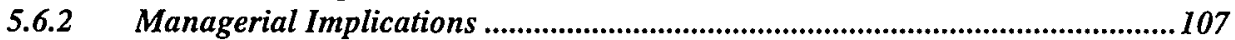

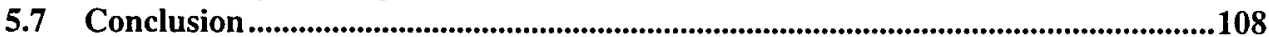

6. Commitment in Service Relationships: An Empirical Test of Its Antecedents and Consequences.................................................... 110

6.1 Introduction .....................................................................................................................111

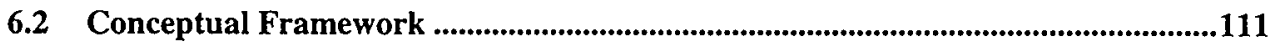

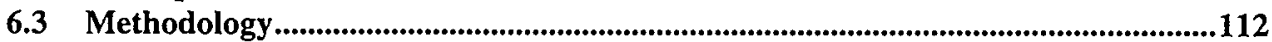

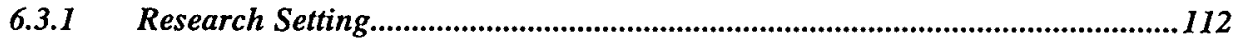


6.3.2 Sampling Design and Data Collection .........................................................112

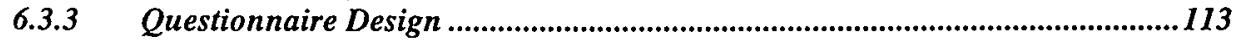

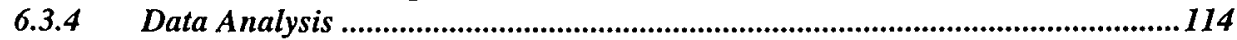

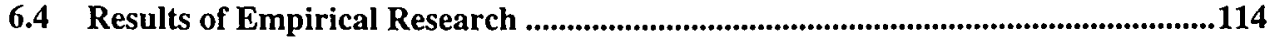

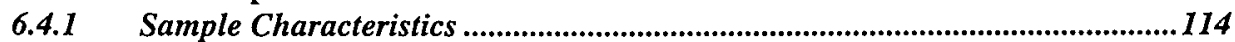

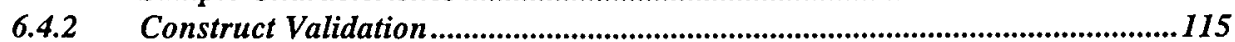

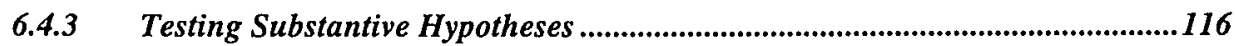

6.5 Discussion ..................................................................................................................119

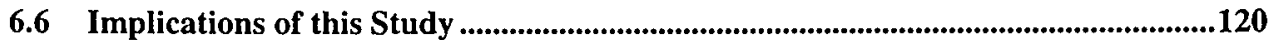

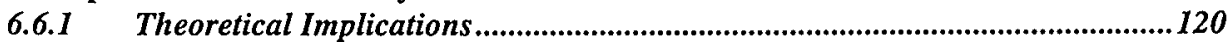

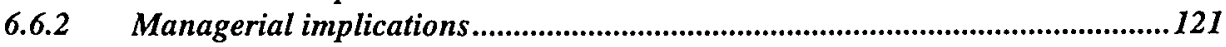

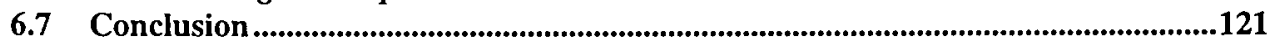

7. Conclusions ............................................................................. 123

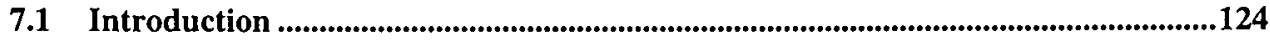

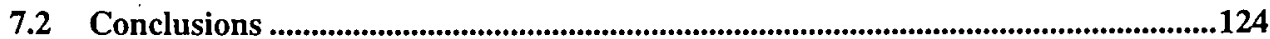

7.2.1 Research Question 1: Organizational Antecedents to Service Quality............124

7.2.2 Research Question 2: Service Quality and the Relationship Paradigm .......... 127

7.3 Implications.............................................................................................................130

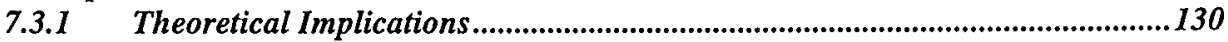

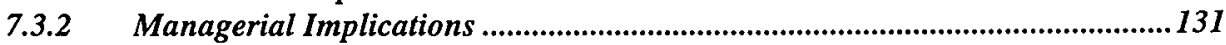

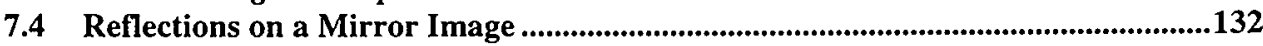

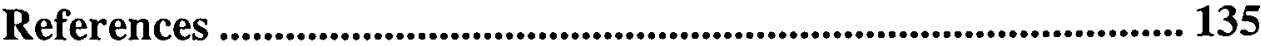

Appendix I: Original SERVQUAL-Instrument.............................. 156

Appendix II: Modified SERVQUAL-Instrument .......................... 158

Appendix III: Behavioral Intentions Battery .................................. 160

Appendix IV: Measures for Extended Model of Service Quality

Appendix V: Measurements Scales Used in Empirical Study Chapter 5 .

Appendix VI: Detailed Results of Confirmatory Factor Analyses for Cross-Sectional Study ...................................................................... 166

Appendix VII: Measurements Scales Used in Empirical Study Chapter 6.......................................................................................... 168 
Nederlandse Samenvatting .............................................................. 172

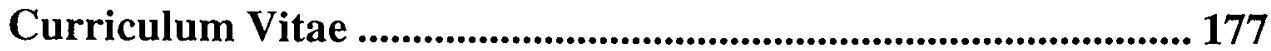




\section{Chapter 1 Introduction}

\section{Outline of the Chapter}

1.1 The Service Economy: Fact or Fiction?

1.2 The Service Encounter: Games between People

1.3 The Service Encounter: A Marketing Perspective

1.4 The Service Encounter: An Organizational Perspective

1.5 Relevance of the Thesis

1.6 Research Objectives

1.7 Outline of the Thesis 


\section{Introduction}

Since the turn of this century most economically advanced, western societies have evolved from being predominantly manufacturing-based to being predominantly service-based (Bateson 1989, 1992; Bell 1973; Fitzsimmons \& Fitzsimmons 1994; Grönroos 1990a; Heskett 1986, 1987; Mills 1986; Riddle 1986; Rust et al. 1996; Zeithaml \& Bitner 1996). Currently, the service sector contributes about $58 \%$ to Gross National Product (GNP) on average worldwide. Furthermore, over half of all fixed capital formation has been occurring in the service sector. Finally, services represent about $20 \%$ of world trade (Riddle 1986). The increased importance of services in world trade was acknowledged by the inclusion of services in the Uruguay Round, which was held under auspices of the General Agreement on Tariffs and Trade (GATT) ${ }^{1}$.

The importance of world trade in services was rather pronounced for the United States. The positive trade balance for services has helped to offset the negative trade balance for goods (Heskett 1986; Henkoff 1994). Ginsberg \& Vojta (1981) present a dramatic shift from goods to services in the United States. From 1948 to 1978 the service sector increased from $54 \%$ of GNP to $66 \%$ of GNP. Regarding employment, a similar development can be discerned. From 1948 to 1977 , employment in the service sector has risen from 27.2 million to 54.4 million, more than the total number of people employed in 1948. Koepp (1987) indicates that the service sector in the United States will be continuing to grow, as 85 percent of all new jobs since 1982 have been created in service industries. The impact of services on a national economy is not only reflected by the size of its service sector. Heskett (1987) reports that the service sector in the United States apart from accounting for about $70 \%$ of the National Income and three-fourths of the nonfarm jobs, also generated 44 million jobs in the past three decades, softened the effects of every post-World War II recession and fueled every recent economic recovery. Normann (1991) depicts a similar development for Sweden. From 1870 to 1990 , the percentage of active labor force in the service sector has increased form $5 \%$ to $75 \%$. Therefore, one might agree with Grönroos (1990a) who argues that the Western World is already experiencing a "service economy". According to Fuchs (1968), a "service economy" is characterized by a service sector, which contributes more than fifty percent to GNP.

Two fields are extremely relevant for the study of the management of service organizations: (1) marketing and (2) organizational theory (Bowen 1990; Bowen \& Schneider 1988; Mindak \& Folger 1990). The Journal of Business Research even devoted an entire issue to the roles of these two fields with regard to the management of service organizations (Bowen 1990; Czepiel 1990; George 1990; Grönroos 1990b; Hensel 1990; Jones 1990; Mills 1990; Mindak \& Folger 1990; Tansik 1990). Mindak \& Folger $(1990,1)$ illustrate the importance of these two fields for the management of service organizations as follows:

\footnotetext{
"In striving for the competitive edge, service providers learn early that marketing's basic role is to make promises and to build expectations for a service's performance. The task then remains for the organization's operations support system to deliver on these promises in the most efficient way possible. The need to integrate the 'one-rwo punch' of marketing and organizational behavior in the service economy' is paramount."
}

However, Bowen \& Schneider (1988) indicate that the perspective of both fields is rather different. The marketing literature has focused on the customer, whereas the organizational behavior literature has mainly concentrated on the employee.

The increased importance of the service sector regarding both national economies and international trade has led to an increased attention by marketers towards the marketing of 
services during the last three decades (Lovelock 1984; Grönroos 1990a; Parasuraman et al. 1985; Rust et al. 1996; Zeithaml \& Bitner 1996). The marketing field quite rapidly moved beyond mere definitional issues (Grönroos 1983; Lovelock 1983; Rathmell 1966; Regan 1963; Shostack 1977a; Zeithaml 1981) to the development of models of service management and organization (Grönroos 1990a; Langeard et al. 1981; Parasuraman et al. 1985, 1988; Zeithaml et al. 1990) ${ }^{2}$.

A major research topic in the marketing field currently is service quality (Berry \& Parasuraman 1993; Cronin \& Taylor 1992, 1994; Fisk et al. 1993; Grönroos 1990a; Lewis \& Booms 1983; Parasuraman et al. 1985, 1988, 1991, 1994a,b,c; Rust \& Oliver 1994; Swartz et al. 1992; Teas 1993, 1994; Zeithaml et al. 1990, 1996). This emphasis on service quality in marketing can be explained to a large extent by the fact that several authors have demonstrated a positive relationship between quality and economic performance (Anderson et al. 1994; Anderson 1993; Buzzel \& Gale 1987; Buzzel \& Wiersema 1981a,b; Capon et al. 1990; Fornell 1992; Jacobson \& Aaker 1987; Oliver 1997; Phillips et al. 1983; Reichheld \& Sasser 1990, 1996; Rust \& Zahorik 1993; Rust et al. 1995; Szymanski et al. 1993; Zahorik \& Rust 1992). Organizational theory, on the other hand, is still primarily concerned with manufacturing organizations (Grönroos 1990a; Mills 1986; Schneider 1985). However, some organizational theorists have provided valuable contributions to the study of service organizations (e.g., Bowen 1986; Bowen \& Schneider 1985, 1988; Schneider et al. 1980; Schneider \& Bowen 1985).

It is the purpose of this thesis to address two issues. To begin with, it is the performance of the customer-contact service employees, which is essential to the ultimate success of the service organization. Hence, we will attempt to uncover organizational factor, which affect customer-contact service employee performance. Secondly, although, several authors have found indications for a positive relationship between (service) quality and business performance in terms of profitability, this relationship needs a more in-depth study. It has been proposed that initiating and maintaining long-term relations between service organizations and customers might be the key factor in this relationship.

Before we turn to the contributions of the marketing field and the organization theory field to the study of service organizations, we will first discuss the importance of the service sector in Western Economies. Furthermore, we will introduce the "service encounter" between customer-contact service employee and customer as a vehicle to structure our discussion regarding the contribution of marketing and organization theory. Subsequently, we will address the relevance of this thesis and present the research objectives of this thesis. Finally, the structure of this thesis will be briefly highlighted.

This chapter is structured as follows. Section 1.1 examines the evolution of the service sector in national economies and international trade. In section 1.2, we will be concerned with the service encounter. The service encounter is at the core of quality management in services both from a marketing perspective and from an organizational perspective. In section 1.3, attention will be paid to the marketing perspective and in section 1.4 , attention will be focused on the organizational perspective. Furthermore, in section 1.5 we will discuss the relevance of this thesis based on both theoretical and practical considerations. In section 1.6, the research objectives of this thesis will be presented and subsequently the research questions will be formulated. Finally, section 1.7 will deal with the structure of this thesis.

\subsection{The Service Economy: Fact or Fiction?}

The service sector exhibits a substantial impact on national economies and world trade. Therefore, it seems obvious that the answer to this question would be "Fact" rather than "Fiction". There are some scholars who question this assumption. To begin with, the figures 
which support the existence of a dominant service sector, might be deceptive. Normann (1991) indicates that we might simply be looking at the illusory trick of accounting with respect to national statistics. Normann $(1991,1)$ provides the following example:

"When a housewife sends her children to mursery school so that she can take a job with a big cleaning company (one of whose clients may be the nursery school), the accountant can point proudly at an increase in economic activity; but what has really happened is that certain activities which were previously performed outside the marketplace have now come into the market and have therefore appeared in the books."

According to Norman (1991), this is just a shift of service activity from the informal to the formal economy. The formal economy is that part of the economy which is officially part of the GNP and therefore national statistics. However, a myriad of service activities has always been carried out outside the formal economy and has, therefore, never been recorded in the accounts of national economies. Hence, it can be concluded that the expansion of the service sector in national economic statistics is to some extent due to an accounting reorganization of existing services instead of the emergence of a new services economy.

Grönroos (1990a), on the other hand, argues that the accounting principles for the national statistics might also exhibit a deflationary effect on the size of the service sector. Essentially, the currently used national statistics are based on yesterday's society, when manufacturing was still the main activity in most societies. The "service sector" is in fact much larger than it would appear on the basis of the currently employed national statistics, as only so-called "pure services", such as banks, financial institutions, hotels, restaurants, cleaning firms, are included in the service sector. Services related to goods, such as after sales services are thus excluded from the services sector. Grönroos $(1990 \mathrm{a}, 6)$ uses the following example to clarify this issue:

"...if, say a manufacturer of elevators takes care of the service, the repair, and maintenance of their elevators, this increases the industrial sector's contribution to GNP. If, however, an outside service firm provides the owners of the elevators with same service, it is the senvice sector that grows!"

Thus, it can be concluded that it is highly questionable to refer to "service industries" or "manufacturing industries", because most companies in the manufacturing sector offer their customers a bundle of benefits, which includes both goods and services. Following Evans \& Berman (1987), Grönroos (1990a) contends that there is substantial "hidden service sector" alongside the "official service sector", as defined by the currently employed accounting principles for the national statistics. Giarini (1991) exemplifies the importance of the "hidden service sector" by indicating that even in the case of "pure" goods a substantial proportion $(70 \%-80 \%)$ of the price is represented by services. This has caused Grönroos $(1990 \mathrm{a}, 4)$ to acclaim that:

\section{"Everybody" is in the service economy."}

Furthermore, it needs to be realized that the rise of the services sector is largely based on the increased productivity in the agricultural and manufacturing sectors (Bell 1973; Grönroos 1983, 1990a; Fitzsimmons \& Fitzsimmons 1994; Normann 1991). There is a close historical parallel with the transition from agriculture to manufacturing during the Industrial Revolution. This transition was only possible, because of the increase in agricultural productivity, which freed agricultural workers to take up jobs in the emerging manufacturing sector (Normann 1991). This parallel led Regan (1963) to coin the transition from manufacturing to services as the Service Revolution. The notion that employment moves from one sector into another sector, as productivity increases in one sector is known as the Clark-Fisher hypothesis (Clark 1957).

However, the importance of the service sector has not been universally recognized (Riddle 1986; Shelp 1981). Services were referred to as "tertiary" (Fisher 1935, 1939), as "residual" 
(Clark 1940) or "post-industrial" (Bell 1973) leading to the misconception that services are only of minor importance. Riddle $(1986,4)$, on the other hand, noted that:

"The service sector plays a seldom recognized role as a necessary and critical ingredient in all economic growth."

Although the service sector is a "necessary" and "critical" component of an economy, so are the extractive sector (agriculture and mining) and the manufacturing sector. All three sectors are important and more in particular the interplay between the sectors. However, nations can survive using mainly imported agricultural products or manufactured products, but no modern economy can survive without a service sector (Riddle 1986).

The dominance of the service sector is often attributed to the so-called "post-industrial society" (Bell 1973). Using the term post-industrial society implicitly assumes there has been an "industrial" and "pre-industrial" society. To put the transition from manufacturing to services into perspective, we will have to discuss the evolution of society from pre-industrial to industrial to post-industrial (Bell 1973). In pre-industrial societies, life essentially consists of a "game against nature". Economic activities are concentrated in the primary sector of the economy - mining, forestry and fishing. The pace of time is dependent on the elements. In industrial societies, the secondary sector plays a pivotal role in the economy. Life can be described as a "game against fabricated nature". Energy and machines have replaced raw muscle. The artisan of pre-industrial society is replaced by the engineer and the semi-skilled worker. Ultimately, the engineer will device a machine which will even replace the semiskilled worker. Productivity - making more with less - is the main indicator of economic activity. In post-industrial societies, life can be viewed as a "game between people". The majority of economic activities are based on services (tertiary, quaternary, and quinary sectors). Information has replaced raw muscle, energy and machines. Machine technology developed in the industrial era has been complemented by "intellectual technology". The central person in the post-industrial society is the "professional". Productivity is replaced by quality as the predominant indicator of economic activity (Fornell 1992, 1995; Kasper \& Schreuder 1985). Fornell $(1992,1995)$ argues that the existing measures of economic performance are not sufficient to reflect economic advancement. Fornell (1995) contends that economic advancement may be contingent on both productivity - quantity of output - and quality of the output. Fornell $(1992,7)$ provides the following example illustrate his line of reasoning:

"According to the OECD Productivity" Index, both Japan and (west) Germany are below the average productivity level for developed countries. Nevertheless, they are countries with a positive balance of trade, strong economy, and reputation for quality products."

Hence, the use of alternative measures of economic advancement should be considered. For example, Fornell (1992) proposes the use of a national satisfaction barometer

In the next section, we will focus on the service encounter, which is at the core of most services (Czepiel et al. 1985; Solomon et al. 1985). The service encounter essentially is the key to success or failure of a service organization.

\subsection{The Service Encounter: Games between People}

Findings from the American Customer Satisfaction Index and other national indexes reveal that services are consistently the lowest scoring sector on customer satisfaction with public services scoring lowest (Anderson et al. 1994). In service organizations, customer satisfaction is often determined by the quality of individual encounters - the service encounter (Bitner 1990; Czepiel et al. 1985; Solomon et al. 1985; Surprenant \& Solomon 1987). The service encounter has been defined as (Shostack 1985, 243): 
I "A service encounter is a period of time during which a consumer directly interacts with a service."

This definition emphasizes that the service encounter encompasses all elements of the interaction between consumer and service organization: the intangible as well as the tangible elements. Others, however, indicate that the service encounter is mainly conceived as interpersonal interaction between service provider and customer (Chase 1978; Czepiel et al. 1985; Solomon et al. 1985; Surprenant \& Solomon 1987). Solomon et al. $(1985,100)$ define the service encounter as the:

"... the face-to-face encounter between a buyer and a seller in a service setting."

Although we acknowledge the importance of the personal elements in the service encounter, we feel that tangible elements need to be included in the service encounter (cf. Bitner 1990). For instance, the use of advanced technology and equipment may bestow a feeling of trust and a connotation of high quality on the customer.

The nature of the service encounter is succinctly depicted in Figure 1-1. Essentially, the service organization consists of two parts: a visible and an invisible part (Chase 1978, 1986; Langeard et al. 1981; Shostack 1985). The invisible part is concerned with all organizational processes in the service organization that support the visible part in delivering the service to the customer. The visible part consists of the tangible elements (Bitner 1990, 1992; Wener 1985) and the service provider - intangible elements.

The evaluation of the service encounter can be approached from several perspectives (Bateson 1985; Czepiel et al. 1985): (1) an organizational perspective, (2) a customer perspective and (3) a customer-contact service employee perspective. The service organization is mainly interested in the performance of the service provider or service employee, as it allows the service organization to attain its objectives. It is, therefore, essential for the service organization to identify organizational factors, which affect the performance of service employees. The customer is mainly interested in the service quality and customer satisfaction

Figure 1-1: The Service Encounter ${ }^{2}$

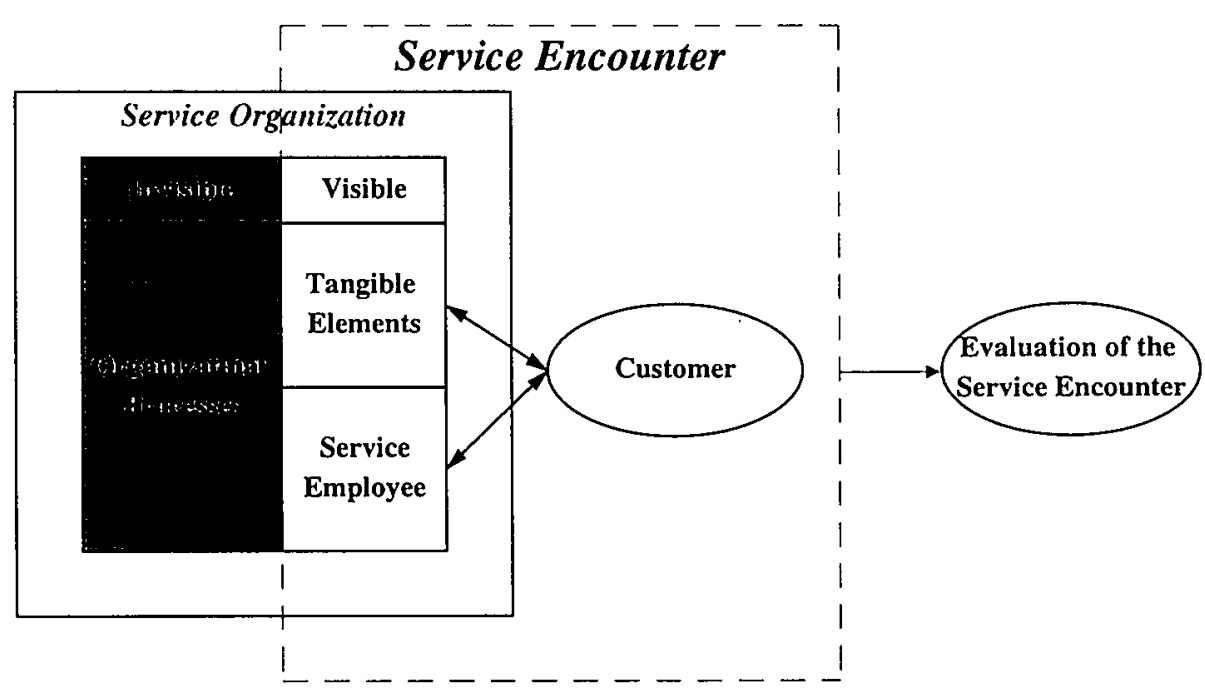

a This model is partly based on the SERVUCTION system model developed by Langeard et al. (1981). 
derived from the service encounter. If the evaluation of service quality and customer satisfaction is positive, the customer may decide to remain loyal to the service organization (Bateson 1985; Czepiel et al. 1985). The customer-contact service employee perspective is mainly concerned with the primary rewards of the service encounter, such as pay, promotion, job satisfaction and recognition from his colleagues and his/her supervisor. These primary rewards are mainly contingent on his/her performance in the service encounter. However, it should be noted that customer-contact personnel generally really cares about the customer and is willing to exert the greatest possible effort to satisfy the customer's needs (Schneider 1980; Schneider \& Bowen 1985; Schneider et al. 1979).

Bateson (1985) proposes that the service encounter can also be viewed as a three-cornered fight for control. The relationship between the service organization and the customer is characterized by a trade-off between customer-contact service employee autonomy and efficiency. The relationship between the service organization and the service customer is characterized by a trade-off between customer satisfaction and efficiency. If the service encounter is controlled by the service organization need for efficiency, the service encounter will be dominated by rules and procedures (Bateson 1985; Schneider 1980; Schneider et al. 1979). Both the customer-contact service employee and the service customer are confronted by the "rule book" of the service organization and have lost control over the service encounter. However, the service organization can only remain profitable by satisfying both the needs of the customer and the customer-contact service employee. The ideal service encounter needs to achieve a balance in which the need for control by the customer, the customercontact service employee and the service organization are taken into account.

The marketing field has mainly concentrated on the service customer. The customer contact service employee has been relatively neglected in marketing academia (Boles \& Babin 1996; Hartline \& Ferrell 1996; Hartline \& Jones 1996). One notable exception is the Conceptual Model of Service Quality (Parasuraman et al. 1985). In this model perceived service quality is determined by four organizational gaps. This model was later extended by adding organizational control and communication processes (Zeithaml et al. 1988). In the next two sections, we will first discuss the marketing perspective on the service encounter and subsequently the organizational perspective on the service encounter.

\subsection{The Service Encounter: A Marketing Perspective}

Initially, in the marketing field it was assumed that the marketing of goods and services were essentially identical (Enis \& Roering 1981; Wyckham et al. 1975). However, increasingly marketers realized that the marketing of services is separated from the marketing of goods by a number of attributes (Berry 1980; Grönroos 1978; Lovelock 1981, 1980; Shostack 1977a,b; Thomas 1978; Zeithaml 1981). Generally, the following four attributes, which distinguish goods from services, are distinguished (Zeithaml et al. 1985):

(1) Intangibility. Services are much less tangible than physical goods. Services are experiences rather than objects, which can be possessed.

(2) Inseparability of production and consumption. Goods are first produced and then consumed. Services, on the other, hand, are characterized by simultaneous production and consumption.

(3) Heterogeneity. The quality of a service may vary from service provider to service provider, from consumer to consumer and from day to day.

(4) Perishability. As services are experiences rather than objects, they cannot be stored. As a result, service providers may find it difficult to synchronize supply and demand.

It is generally recognized that intangibility is critical to the dichotomy between goods and services (Bateson 1977; Zeithaml 1985). The other three attributes can be viewed as consequences of intangibility. Each attribute leads to specific problems for service marketers, which on their turn, necessitate special marketing strategies to solve them. For instance, 
intangibility may affect the marketing communications of an organization, since services cannot be easily communicated to consumers (Rathmell 1974).

Especially, quality management in service organizations is strongly affected by these attributes of services vis-à-vis goods. First, since services are performances rather than objects, service organizations might find it difficult to understand how consumers perceive and evaluate service quality. Consequently, uniform and consistent quality standards can rarely be set (Bateson 1977; Berry 1980; Zeithaml 1981). Secondly, services are characterized by simultaneous production and consumption. Thus, services are not manufactured at a plant, but are generally the result of the interaction between customer and service provider. Consequently, quality control will be rather difficult to assure (Grönroos 1978; Lehtinen \& Lehtinen 1982). Several authors have addressed the issue of the role of service outcome and service process as determinants of service quality (Czepiel et al. 1985; Lytle \& Mokwa 1992; Parasuraman et al. 1985; De Ruyter \& Wetzels 1998a; Venetis 1997). Thirdly, services, especially those with a high labor content, are heterogeneous. As a consequence, consistent and uniform quality will be a serious problem, as it is contingent on the interaction between customer and employee (Bitner et al. 1985, 1990; Booms \& Bitner 1981; Czepiel et al. 1985). Finally, perishability means that services cannot be stored and hence quality cannot be verified in advance of the sale (Lovelock 1981; Shostack 1977a).

As was already mentioned, service quality constitutes an important theme in the marketing field regarding services. Service quality may be approached from several different perspectives (Holbrook \& Corfman 1985; Garvin 1988; Klaus 1985; Lemmink 1991; Steenkamp 1989). Initially, the concept of service quality borrowed heavily from the objectivistic view of quality employed in the goods sector (Crosby 1979; Garvin 1984a,b; Gummesson 1991). However, the above mentioned attributes of services (intangibility, inseparability, heterogeneity and perishability) suggest that a straightforward adaptation of the objectivistic quality concept from the goods sector would not be feasible; a more subjectivistic concept of quality was called for. As a result, the concept of perceived service quality was developed. Perceived quality is a concept of quality, which can be characterized as a customer-oriented approach to quality. Perceived service quality is generally described as the discrepancy between a customer's expectation regarding a service and the perception of the actual service provided (Jacoby \& Olson 1985; Grönroos 1984; Lehtinen \& Lehtinen 1982; Lewis \& Booms 1983).

This is in correspondence with Parasuraman et al. (1985), who distinguish three underlying themes concerning service quality:

(1) Service quality is more difficult for the consumer to evaluate than goods quality.

(2) Service quality perceptions result from a comparison of consumer expectations with the actual service performance.

(3) Quality evaluations are not made solely on the outcome of a service; they also involve evaluations of the process of service delivery.

Taking this as a starting point, Parasuraman et al. (1985) developed a conceptual model of service quality applicable to all service industries based on executive interviews and focus group interviews. At the core of their model is the concept of perceived service quality. According to them perceived service quality can be viewed as a gap between expected service and the actual service delivery. The magnitude and direction of this gap (GAP5) is determined by four orgänizational gaps, viz.:

(1) GAP1. The difference between consumer expectations and management perceptions of consumer expectations.

(2) GAP2. The difference between management perceptions of consumer expectations and service quality specifications.

(3) GAP3. The difference between service quality specifications and the service actually delivered.

(4) GAP 4. The difference between service delivery and what is communicated about the service to customers. 
On the basis of their conceptual model of service quality, Parasuraman et al. (1988) developed a measurement instrument, SERVQUAL, to assess perceived service quality. The SERVQUAL instrument has been applied to a variety of services such as after sales services (Kasper \& Lemmink 1989), professional services (Bojanic 1991; Brown \& Swartz 1989) and physical distribution services (Koelemeijer et al. 1993; Lemmink et al. 1997). The Conceptual Model was later extended to the Extended Model of Service Quality, which introduced organizational antecedents, mainly control- and communication-oriented variables, to the Conceptual Model of Service Quality.

The SERVQUAL-instrument has developed into the mainstay of service quality measurement (Lemmink 1992; Parasuraman 1995; Vriens et al. 1997; De Vries et al. 1997). However, various other techniques have been developed to measure service quality. To begin with, several authors have proposed conjoint analysis as an alternative (Bremer et al. 1994; DeSarbo et al. 1994; Vriens et al. 1997; De Vries et al. 1997; Wetzels et al. 1995). Conjoint analysis allows the researcher to determine the importance of the different service attributes and the gain (loss) in utility among the levels of an attribute. Alternatively, the Critical Incident Technique (CTT) has also been used a method to measure service quality (Bitner et al. 1985, 1990; De Ruyter et al. 1995; Vriens et al. 1997; De Vries et al. 1997). The CIT requires respondents to report an extremely satisfying and/or an extremely dissatisfying service experience. The incidents can then be analyzed using qualitative techniques, such as content analysis, and/or quantitative techniques, such as cross-tabulations and log-linear analysis (cf. Bitner et al. 1990; De Ruyter et al. 1995). However, the nature of these methods has caused them to be hardly used in structural or substantive models.

Moreover, both academics and practitioners have realized that the service encounter should not be seen as a discrete and static phenomenon (Berry 1995; Bitner \& Hubbert 1994; Bolton \& Drew 1991a, Crosby \& Stevens 1987; Czepiel 1990; Dwyer et al. 1987; Ganesan 1994; Grönroos 1993, 1994, 1995; Gummesson 1984; Liljander \& Strandvik 1994, 1995a,b; Morgan \& Hunt 1994; De Ruyter \& Wetzels 1998c; De Ruyter et al. 1997c; Sheaves and Barnes 1996; Sheth \& Parvatiyar 1994; Shemwell et al. 1994; Storbacka et al. 1994). Or as Czepiel (1990, 15) puts it eloquently:

\footnotetext{
"As service encounters accumulate over time, a buyer and a seller have the opportunity to transform from a collection of individual transactions into a relationship. In an exchange relationship, an individual exchange is viewed not so much as an entity unto itself as it is a continuation of a past series of exchanges likely to continue into the future."
}

In order to introduce dynamics several authors have proposed to shift the focus from the individual service encounter to a chain of service encounters or episodes (Bitner \& Hubbert 1994; Bolton \& Drew 1991a; Liljander \& Strandvik 1994, 1995a,b; De Ruyter \& Wetzels 1998c; De Ruyter et al. 1997c). Bolton \& Drew (1991a) propose a longitudinal design, which attempts to capture the effect of service improvements over different time periods. Other authors distinguish between, essentially, two levels of analysis: (1) the individual service encounter and (2) the service relationship conceptualized as chain of interrelated service encounters or episodes (Bitner \& Hubbert 1994; Liljander \& Strandvik 1994, 1995á,b; De Ruyter \& Wetzels 1998c; De Ruyter et al. 1997c). This train of thought has been elaborated into the relationship paradigm or relationship marketing (Czepiel 1990; Dwyer et al. 1987; Liljander \& Strandvik 1995a; Morgan \& Hunt 1994; Storbacka et al. 1994; De Ruyter \& Wetzels 1998d; De Ruyter et al. 1997c; Venetis 1997). In the relationship paradigm the focus is on the relationship per se, not a chain of individual encounters, but interrelated service encounters episodes. The relationship is more than the sum of its parts, the individual services encounter or episodes. Although the importance of the service encounter is generally acknowledged there is a only limited evidence for the effect of service quality and/or customer satisfaction on the development of relationships between the service organization and its customers (Czepiel 1990; Liljander \& Strandvik 1995a; Storbacka et al. 1994; De Ruyter \& 
Wetzels 1998d; De Ruyter et al. 1997c; Venetis 1997). We will continue in section 1.4. using an organizational perspective on the service encounter using.

\subsection{The Service Encounter: An Organizational Perspective}

Similarly as the attributes of service lead to specific problems for service marketers, they also lead to problems, organizational contingencies, for organizational theorists. Every organizational contingency, on its turn, necessitates organizing principles. For instance, simultaneous production and consumption will negatively affect the coordination of supply and demand of services (Sasser 1976). Services cannot be inventoried. It is the service manager's task to match supply and demand for service. For instance, if an airline seat is not taken, money is lost. An organizing principle, which might be applied in response to this organizational contingency, is the use of customers as "partial employees". Increasing customer participation in service delivery offers service providers a mechanism for adjusting supply to demand in service organizations, e.g. the use of ATMs can reduce the work load of bank tellers during peak hours (Sasser 1976; Sasser et al. 1978).

As was already indicated the service attributes strongly affect quality management in service organizations. The marketing field proposed a framework for quality management in service organizations, the Extended Model of Service Quality, in which perceived service quality is ultimately determined by organizational causes, the antecedents with respect to the four organizational gaps (Zeithaml et al. 1988; Parasuraman et al. 1990). Although no explicit framework for quality management in service organizations was conceived, in the organizational theory field some valuable contributions to the quality management in service organizations may still be provided (Bowen \& Schneider 1988). In the remainder of this section, the potential contributions of the organizational theory field to quality management in service organizations will be briefly discussed.

A major contribution of organizational theory to services research consists of systems theory (Chase 1978; Kahn et al. 1964; Katz \& Kahn 1978; Lawrence \& Lorsch 1967; Thompson 1967). Thompson (1967) actually proposes that organizations are averse to uncertainty originating from their technology choice and their organizational environment. Therefore, organizations will try to insulate their technical core in order to achieve more efficient operations. Mills \& Moberg (1982) argue that sealing off the technical core may be impossible for service operations. Services are produced through the interaction of customers and customer-contact service employees and therefore the technical core of service operations needs to be an open system (Argote 1982; Chase \& Tansik 1983; Larsson \& Bowen 1989; Mills 1986). Although it may be tenuous to attempt to seal off the technical core or front-office from customer-created uncertainties, it may be an alternative to seal off the uncertainties created at the administrative sector or back-office (Chase 1978, 1981; Chase \& Tansik 1983). More generally, Larsson \& Bowen $(1989,217)$ define customer-created uncertainty as:

"...the organization's incomplete information about, what, where, when and how customer input is going to be processed to produce the desired outcomes."

Essentially, customer-created uncertainty emanates from two sources (Larsson \& Bowen 1989): (1) the diversity of customer demand and (2) the tendency of customers to participate in the production of the service. It is the customer-contact service employee who is confronted with this customer-created uncertainty, or as Larsson \& Bowen $(1989,217)$ put it:

"Bridging environmental and task uncertainty is the essence of boundary operations in service production."

Boundary operations or boundaries spanning activities are another important exponent of systems theory. If we perceive organizations as open systems, it is essential that some members of the organization operate at the periphery or boundary of the system (Adams 1976, 1980; 
Aldrich 1971; Kahn et al. 1964; Katz \& Kahn 1978; Thompson 1967). Their activities are referred to as boundary spanning activities (Leifer \& Delbecq 1978; Wall \& Adams 1974). More recently, the importance of boundary spanning activities has been emphasized concerning organizational learning (Day 1994; Fiol \& Lyles 1985; Slater \& Narver 1995; De Vries et al. 1997). Organizational learning is both beneficial to the (service) organization and to its customers (Day 1994; Slater \& Narver 1995). The ability to learn faster than the competitors may be considered the only real sustainable competitive advantage for (service) organizations. In service organizations, it is the customer-contact service employees, which are the key assets, since they are the boundary spanners, which actually acquire the information from the customers (Boles \& Babin 1996; De Vries et al. 1997).

Although, boundary spanning persons are essential for all organization, and more in particular service organizations, they are extremely susceptible to role stress (Churchill et al. 1985; Goolsby 1992; Kahn et al. 1964; Katz \& Kahn 1978; Keller et al. 1976; Keller \& Holland 1975; Lysonski 1985). Most of the research on the effect of role stress on boundary spanning positions has focused on managerial levels and manufacturing organizations (Boles \& Babin 1996; Hartline \& Ferrell 1996). Role stress exhibits a negative effect on such outcome variables as job satisfaction, organizational commitment, job performance and intention to stay with the organization (Brown \& Peterson 1993; Churchill et al. 1985; Fisher \& Gitelson 1983; Goolsby 1992; Jackson \& Schuler 1985; Kahn et al. 1964; Katz \& Kahn 1978; Parkington \& Schneider 1979; Van Sell et al. 1981). Research has identified a host of factors influencing role stress: personal characteristics, such as age, education, locus of control, interpersonal characteristics, such as supervisory behavior, communication, and organizational characteristics, such as formalization and organizational level (e.g., Fisher \& Gitelson 1983; Jackson \& Schuler 1985; Van Sell et al. 1981).

Employees play a major part in service delivery; sometimes employees are even equated with the service (Bitner et al. 1990; Boles \& Babin 1996; Czepiel et al 1985; Grönroos 1983, 1990; Hartline \& Ferrell 1996; Heskett 1987, 1995; Parkington \& Schneider 1979; De Vries et al. 1997). Their performance is, therefore, of the utmost importance to service organizations. Performance of service employees is generally hard to assess given the characteristics of services. Therefore, service organizations have resorted to objective performance measures, such as number of transactions or mean time spent on transactions (Bommer et al. 1995; Levy \& Sharma 1993). However, the use of such performance measures may not take into account the quality of the service encounter (Mills \& Moberg 1982; Parasuraman et al. 1985; Parkington \& Schneider 1979). Recently, researchers found that self-evaluation by employees may be superior to manager evaluation and objective measures (Mabe \& West 1982; Levy \& Sharma 1995). The success of self-evaluation suggests that the exploration of innovative evaluation procedures might be fruitful in service relationships. Since service relationships have as their nexus the customer, it might well be that the customer should be the source of the employee evaluation in a service organization. There are a number of potential problems in having customers evaluate service employees. Sometimes customers are unable to evaluate the performance of individual service employees. It is the service unit or branch, or even the service organization as a whole they evaluate (Hartline \& Ferrell 1996). Finally, a research design using customer evaluations will require large numbers of units; and subsequently customer and service employees (Hartline \& Ferrell 1996; Parasuraman et al. 1990). Subsequently, data analysis will have to be conducted using aggregated data and the aggregation may actually confound relationships, if the variables are conceptualized on individual levels (Rousseau 1978, 1985; Klein et al. 1994).

Moreover, several authors suggest that a service-oriented culture can be generated by treating contact personnel as "partial customers", i.e. employees deserve the same treatment that management wants the organization's customers to receive (Bowen 1986; Bowen \& Schneider 1985; Schneider \& Bowen 1984). Viewing employees as "partial customers" and customers as "partial employees" indicates the physical and psychological closeness between customers and employees. Schneider \& Bowen (1984) suggest therefore that customer-contact personnel should participate in the decision making with regard to the development and delivery of new services. 
Employing participative decision making in service organizations is in correspondence with the preconditions generally assumed necessary for the use participative decision making, namely: (1) employees possess relevant information that management lacks and (2) employee acceptance of the decision is critical for its implementation (Vroom \& Yetton 1973). It has been illustrated that customers and contact personnel share similar views of service quality and service climate (Schneider et al. 1980; Schneider \& Bowen 1985), whereas management often has been unable to accurately identify. customer needs (Langeard et al. 1981; Kasper \& Lemmink 1989). Several researchers from the marketing field proposed "internal marketing" as a means to create and maintain a service climate (Berry 1981; George 1984, 1986, 1990; Grönroos 1983, 1990a; De Vries et al. 1997).

\subsection{Relevance of the Thesis}

The management of customer-contact service employees has been relatively "underresearched" (Boles \& Babin 1996; Hartline \& Ferrell 1996). In the marketing field it was mainly in sales that management of customer-contact personnel was focused on (Brown \& Peterson 1993; Churchill et al. 1985; Suchanek 1998). In organizational theory, the management of service organization remained the field of a limited number of researchers (Bowen \& Schneider 1988; Mills 1986). The marketing field took up the challenge of services and rapidly generated a huge amount of literature on services (Berry \& Parasuraman 1993; Fisk et al. 1993; Swartz et al. 1992). However, the majority of this literature focuses on the evaluation of the service encounter by the customer in terms of customer satisfaction, service quality or value. Although Zeithaml et al. (1988) developed a model for the management of customer-contact service employees (the Extended Model of Service Quality), they found the majority of their hypotheses not supported by their empirical work (Parasuraman et al. 1990). In their study, however, they found the pivotal role of role stress for the management of customer-contact personnel. Role stress does not only affect job satisfaction and customer-contact service employee performance, it also may lead to service employee turnover (Bluedorn 1982; King \& King 1990; Mathieu \& Zajac 1990; Mobley et al. 1979; Parkington \& Schneider 1979). Role stress is one of the focal constructs in role theory (Kahn et al. 1964; Katz \& Kahn 1978; King \& King 1990). The services marketing field mainly used role theory for the dyadic interaction between customer-contact service employees and customers (Grove et al. 1992; Solomon et al. 1985). The use of role theory for management of customer contact service employees has been relatively underresearched (Boles \& Babin 1996; Hartline \& Ferrell 1996), especially vis-à-vis salespeople.

More recently, Heskett and colleagues have proposed that there may be a relationship between service employee job satisfaction, service employee loyalty (intention to stay with the service organization), on the one hand, and customer satisfaction, customer loyalty and service organization profitability, on the other hand (Heskett 1995; Heskett et al. 1994, 1997; Schlesinger \& Heskett 1992). This causal chain is referred to by them as the service profit chain (Heskett et al. 1994, 1997). Essentially, they posit that service employee job satisfaction and service employee loyalty or intention to stay with the service organization is positively related to customer satisfaction and customer loyalty and ultimately service organization profitability. Role stress, on its turn, is one of the major determinants of job satisfaction (Brown \& Peterson 1993; Fisher \& Gitelson 1983; Jackson \& Schuler 1985; Van Sell et al. 1981).

The importance of customer service for creating a competitive advantage has been increasingly realized by manufacturing organizations as well (Bowen et al. 1989; Cunningham \& Röberts 1974; Grönroos 1990a; Jackson \& Cooper 1988; Kasper \& Lemmink 1989; Kyj 1989, Lele 1986; Lele \& Sheth 1987; Levitt 1969; Rakowski 1982; De Vries et al. 1997). Companies operating in the business-to-business markets have increasingly recognized the importance of customer service. With the advent of generic products in these markets, the incremental value of customer service has increasingly gained importance (Kyj 1989; Lele 1986; Lele \& Sheth 1987; De Vries et al. 1997). Competitive advantages based on technological innovations may not be sufficient for long-term success. In fact, technological advances may be 
easily matched by competitors once the product is on the market (Bowen et al. 1989; Lele 1986; Lemmink 1991). Alternatively, as the service manager of the organization which participated in our empirical study puts it:

"All competitors in this market essentially sell the same hardware, it is the customer service that really" matters in obtaining a competitive advantage."

Furthermore, Bowen et al. (1989) argue that customer service is not only the key to competitive advantage it may be a prerequisite for competition (cf. Cunningham \& Roberts 1974). Consequently, customer service may be used as entry barrier to the market, as new entrants will have to provide a customer service level matching the customer service level of the incumbents (Porter 1980). Gummesson (1994) even observes a shift from goods-focused to a servicefocused paradigm, in which services provide the core benefits to customers and goods are considered peripherals.

The concept of customer service originated in logistics (Kyj 1989; LaLonde \& Zinszer 1976; Perrault \& Russ 1974; Rakowski 1982; Tucker 1983). However, LaLonde \& Zinszer (1976, 2) provide a more comprehensive definition of customer service as:

"... those activities that occur at the interface between the customer and the corporation which enhance or facilitate the sale and use of the corporation's products or services."

This definition clearly expanded the view on customer service in a temporal level, attribute level and functional level (Rakowski 1982). The expansion in temporal level is related to the issue that customer service starts beyond the interface between the customer and the organization. In fact, it already starts when the organization can show the benefits of its products and services to the customer. Furthermore, customer service expands beyond the mere delivery of the product: the post sale or after-sales services, including repairs, complaints and training. Expansion of the attribute level is concerned with the issue that logistics services focus only on a limited amount of service attributes (LaLonde \& Zinszer 1976; Perrault \& Russ 1974; Wetzels et al. 1995). The expansion on the functional level is concerned with the issue that it is not only the logistics/physical distribution department, which should be solely responsible for customer service (Lemmink et al. 1997). Customer service should be a cross-functional effort including marketing, sales, logistics/physical distribution and product support (Rakowski 1982; De Vries et al. 1997).

As we already mentioned above role stress exhibits a pervasive effect on customer-contact service employees. This also extends to service employees rendering customer services. Miller et al. (1988) report that customer service employee is one of the ten most stressful jobs in the United States. Consequently, we need to study the relevant literature and formulate a conceptual framework, which includes role stress as a focal construct. To advance knowledge of the management of customer-contact service employees we need to acknowledge the fragmented nature of the relevant literature. A number of fields have notably contributed to the understanding of the management of service employees: marketing, organizational theory, human resource management and (social) psychology. We will use this literature in an integrative fashion and developed a model in which role stress is linked to customer-contact service employee performance conceptualizing job satisfaction as a mediator. Finally, most of the research in this field has employed a cross-sectional research design, thus neglecting the potentially dynamic nature of service management. Therefore, we will both use a cross-sectional and a longitudinal design.

However, the service employee is only one part of the dyadic relationship within the service encounter. It is the customer, which ultimately decided on organizational performance by remaining loyal to the service organization. Relationship marketing is not only beneficial to the service organization, but also to its customers (Berry 1995; Czepiel 1990; Grönroos 1995). However, for the influence of service/quality customer satisfaction duo on relationships between customers and service organizations there is only limited evidence (Storbacka et al. 1994; 
Liljander \& Strandvik 1995a,b; De Ruyter \& Wetzels 1998c,d; De Ruyter et al. 1997c; Venetis 1997). Therefore, we will attempt to link service quality and customer satisfaction with the relationship paradigm using a review of the extant literature.

\subsection{Research Objectives}

The research objectives of this thesis are twofold. To begin with, we will concentrate on organizational factors, which affect customer-contact service employee performance. The performance of customer-contact service employees is quintessential for the success of service organizations. Therefore, we will attempt to address the following research question in this thesis:

Research Question 1:

Which organizational factors affect the performance of customer-contact service employees?

Using literature from a variety of disciplines, such as marketing, organizational theory, human resource management, (social) psychology, we will first formulate a conceptual framework. Subsequently, the substantive relationships in this framework will be tested using empirical research in an after-sales service setting.

Although several authors have reported a positive relationship between quality and profitability (e.g., Buzzel \& Gale 1987; Rust et al. 1995), there is still no clear view on the intervening process which leads from (service) quality to profitability. Recently, it has been proposed that the maintenance of long-term relationships might clarify this relationship; this is referred to as the relationship paradigm (Berry 1995; Dwyer et al. 1987; Morgan \& Hunt 1994; De Ruyter et al.1997c; Venetis 1997; Webster 1992). Recently, several authors have explored frameworks, which have identified factors contributing to the creation and maintenance of long-term relationships. However, the following question remains:

\section{Research Question 2:}

\section{How can service quality be related to the relationship paradigm? How does service quality} affect the intention of customers to remain loyal in a long-term service relationship?

We will review the extant literature and conceptualize a framework, which relates service quality to constructs developed in the relationship paradigm. Subsequently, the substantive relationships in our conceptual framework will be tested in an after-sales service setting.

The research objectives of this thesis can be summarized graphically in Figure 1-2. From this figure it can be observed that service quality is the focal construct in this study. Concerning the first research question service quality will be used as a performance measure for customer-contact service employees. With regard to the second research question service quality will be used from the perspective of the customer. Although the unit of analysis is different in the two research questions, service quality is still the common denominator in this thesis. 


\section{Figure 1-2: Overview of the Research Objectives of the Thesis}

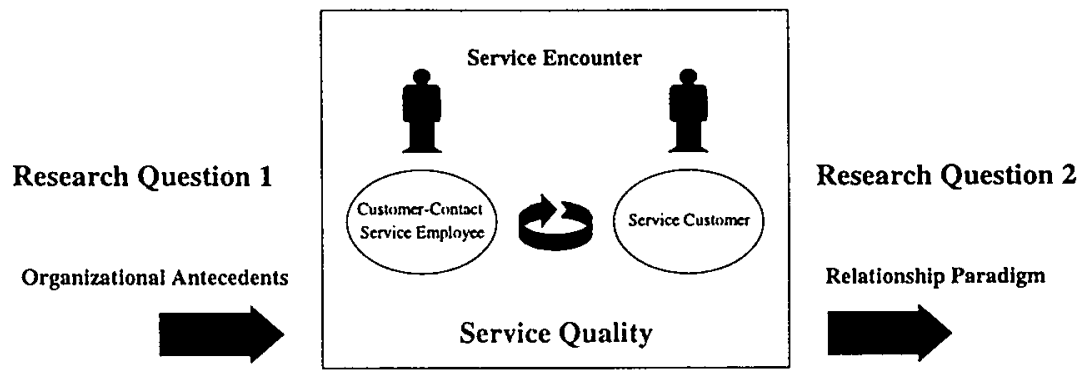

\subsection{Outline of the Thesis}

The structure of this thesis can be described as follows. After this introductory chapter in which we sketched the research objectives, we will continue with Chapter 2. Chapter 2 will be concerned with an in-depth review of the focal construct of this study: service quality. We will first review different perspectives on defining qaulity. Furthermore, the Conceptual Model of Service Quality and its accompanying SERVQUAL-instrument will be discussed. Both conceptual concerns and measurement concerns will be addressed regarding the Conceptual Model of Service Quality and the SERVQUAL-instrument.

In Chapter 3 the first research question will be addressed conceptually. We will first discuss the Extended Model of Service Quality. Subsequently, the Extended Model of Service Quality will be tested in a pre-study. Our pre-study revealed only limited empirical support for the relationships in the Extended Model of Service Quality. Next, we will be concerned with the need for an alternative model using role stress as the focal construct. We will briefly discuss role theory and its main exponents, role ambiguity and role conflict. Furthermore, several antecedents to role stress and the several outcomes of role stress will be identified. Finally, we will present our conceptual framework.

Chapter 4 will be concerned with the second research question in a conceptual fashion. We will first focus on the relationship between quality and business performance. As the relationship between quality and business performance is based on the loyalty of service customer, we will next address the relationship marketing in services. At the core of relationship paradigm, commitment can be found. With regard to commitment, we will both identify antecedents and outcomes in our conceptual model.

Chapter 5 and Chapter 6 contain the empirical part of this thesis. In these two chapters, we will test the substantive relationships, which were laid down in the conceptual models based on our two research questions. In Chapter 5 , we will be concerned with organizational antecedents to service quality (research question 1), while Chapter 6 will be concerned with the role of service quality and customer satisfaction with respect to the relationship paradigm (research question 2). A graphical representation of the structure of this thesis is shown in Figure 1-3. 


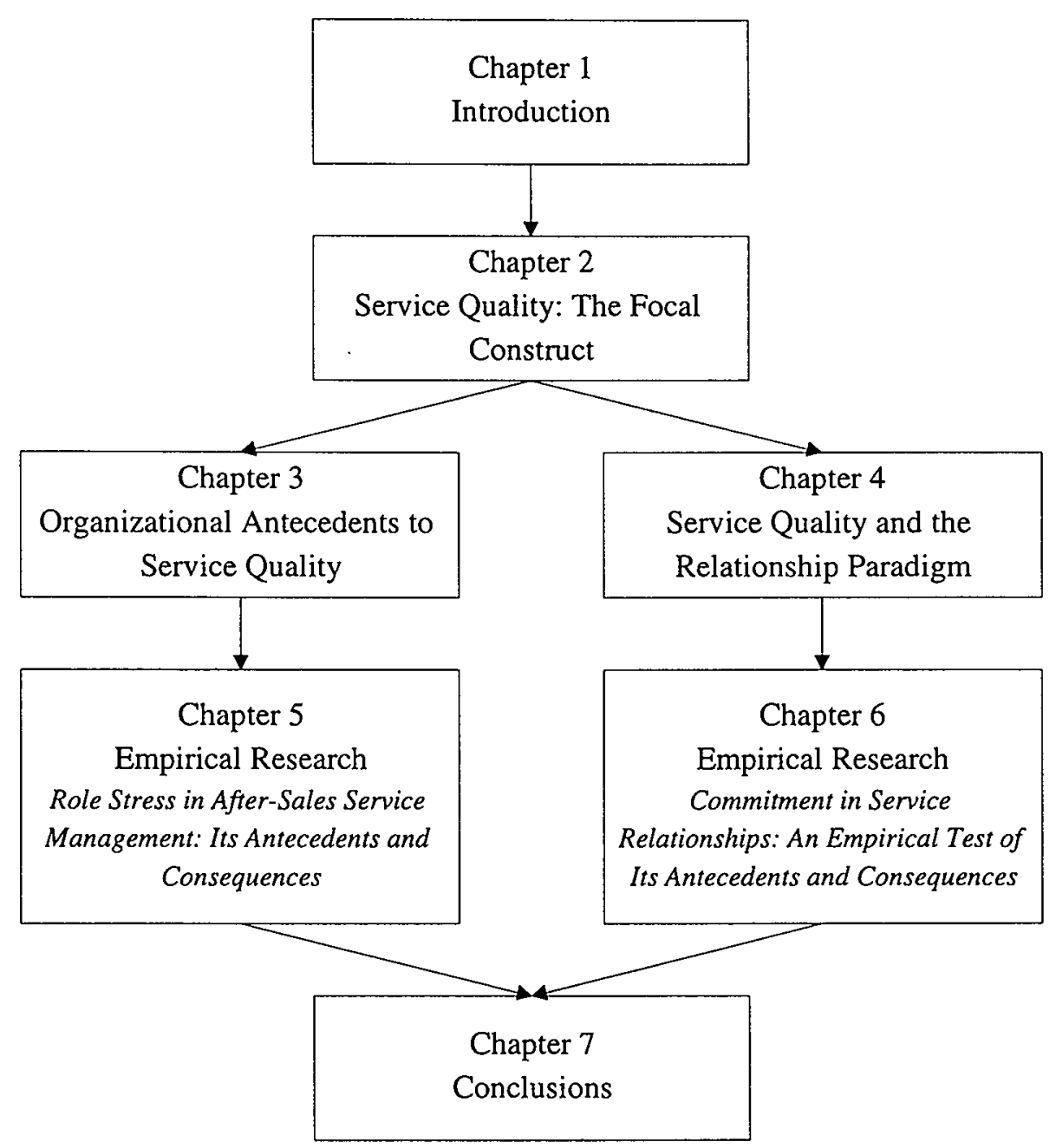




\section{Chapter 2 Service Quality: The Focal Construct}

\section{Outline of the Chapter}

2.1 Introduction

2.2 Defining Quality

2.3 The Conceptual Model of Service Quality

2.4 The SERVQUAL-Instrument

2.5 Conceptual Concerns regarding the SERVQUAL-Instrument

2.5.1 The "Gap" (P-E) Conceptualization of Service Quality

2.5.2 Is Service Quality an Attitude?

2.5.3 The Multidimensional Nature of Service Quality

2.5.4 Service Quality and Customer Satisfaction: Identical Twins or Siamese Twins

2.5.5 Service Value: A Contender to the Throne?

2.5.6 The Static Nature of the Conceptual Model of Service Quality

2.5.7 Consequences of Service Quality

2.6 Measurement Concerns pertaining to SERVQUAL

2.6.I Dimensionality of the SERVQUAL-Instrument

2.6.2 Use of Importance Weights

2.6.3 Use of Difference Scores

2.6.4 The Distribution of Service Quality

2.7 Conclusion 


\section{Service Quality: The Focal Construct}

\section{$2.1 \quad$ Introduction}

Although several conceptual frameworks have been proposed for service quality (Bitner 1990; Bolton \& Drew 1991a, 1991b; Brown \& Swartz 1989; Grönroos 1983, 1990a; Parasuraman et al. 1985; Zeithaml et al. 1988) and some extent, if even implicitly, all these frameworks incorporate an internal perspective, i.e. organizational, factors or antecedents. However, the majority of the empirical work based on these frameworks focuses on external factors or outcomes, such as (perceived) service quality, customer satisfaction or service value.

It is the aim of this chapter to present service quality as the focal construct of this study. In this thesis service quality is both antecedent and outcome. In this chapter we will explore the origins of service quality. Several perspectives on quality will be discussed and their relation to service quality will be clarified. Furthermore, the Conceptual Model of Service Quality will be dealt with. The Conceptual Model of Service Quality to date still is the most comprehensive model of service quality available to both academics and practitioners. However, most of its appeal is related to the accompanying measurement instrument, SERVQUAL.

SERVQUAL will feature prominently in this chapter of the thesis. We will both approach the instrument from a conceptual as well as an empirical perspective. With regard to the conceptual concerns the "gap" conceptualization of the SERVQUAL-instrument will be dealt with. Furthermore, we will be concerned with the question whether service quality can be viewed as attitude. Subsequently, the multidimensional nature of service quality will be explored. Service quality, customer satisfaction and service value are closely related. However, we will show that these constructs, though empirically related, are conceptually distinct. The Conceptual Model of Service Quality (and thus SERVQUAL) is essentially static of nature. Several dynamic approaches have been proposed for service quality and will be briefly reviewed. More recently, several authors have attempted to relate service quality (via customer satisfaction) to behavioral intentions as outcome variable.

With regard to measurement concerns with respect to SERVQUAL attention will be focused on several issues. First, the generalizabilty or universality of the model will be discussed. Replications of SERVQUAL have resulted in mixed results regarding the generalizability of the instrument. In addition, the use of importance weights has been suggested for SERVQUAL. Empirical results suggest that the inclusion of importance weights does not lead to substantial improvements of empirical results. Furthermore, the operationalization of SERVQUAL employs difference scores. A review on the use of difference scores casts severe doubts on their reliability and validity. Finally, the observed distribution of service quality will be reviewed. Empirical findings indicate that the SERVQUAL measure is negatively skewed.

This chapter proceeds as follows. To begin with, in section 2.2 the different perspectives on quality will be briefly discussed. In section 2.3 the Conceptual Model of Service Quality will be dealt with. In section 2.4 we will be concerned with the SERVQUAL-instrument, which was developed on the basis of this framework. Section 2.5 will focus on the conceptual concerns pertaining to SERVQUAL. In section 2.6 the measurement concerns regarding SERVQUAL will be concentrated on. Finally, in section 2.7 a conclusion to chapter 2 will be provided.

\subsection{Defining Quality}

Quality is an elusive and fuzzy concept and as a result is extremely hard to define (Garvin 1984a,b; Gummesson 1991; Lemmink 1991; Parasuraman et al. 1985; Reeves \& Bednar 1994; Steenkamp 1989). This may partly be caused by the different perspectives taken by 
scholars from different disciplines in defining quality (Garvin 1984a,b; Reeves \& Bednar 1994; Steenkamp 1989). Or as Cowan (1969, ix) formulates it eloquently:

"Quality is a jewel with many facets, and it is important when using the term, to define, explicitly or implicitly, with which facet one is concerned."

Multiple approaches to defining quality have been identified by various authors (Garvin 1984a,b; Reeves \& Bednar 1994). Garvin (1984b) distinguishes five major approaches to define quality:

(1) The transcendent approach to defining quality. This approach defines quality as (Garvin 1984b, 25):

"innate excellence."

Proponents of the transcendent view of quality contend that quality cannot be precisely defined, but rather is absolute and universally recognizable (Pirsig 1974, 1992; Tuchman 1980). This approach finds its origins in philosophy, and more in particular in metaphysics (Reeves \& Bednar 1994; Steenkamp 1989). However, its practical applicability is rather limited, as quality cannot be defined precisely using this perspective (Garvin 1984a,b; Lemmink 1991; Reeves \& Bednar 1994; Steenkamp 1989)

(2) The product-based approach to defining quality. This approach posits that quality differences amount to differences in the quantity of a particular desired attribute of the product (Abbott 1955; Brems 1948; Leffler 1982; Leland 1977; Lemmink 1991; Steenkamp 1989). Garvin $(1984 \mathrm{~b}, 26)$ provides the following illustration of this approach:

"... high-quality ice cream has a high butterfat content, just as fine rugs have a large number of knots per square inch."

The assumption underlying this approach suggests two corollaries (Garvin 1984b). Firstly, higher quality products can only be obtained at higher cost, as quality is reflected in the quantity of a particular desired attribute. Secondly, quality can be evaluated against an objective standard, viz.: quantity.

(3) The user-based approach to defining quality. The user-based approach to defining quality is based on the notion that (Garvin 1984b, 27):

"quality lies in the eye of the beholder."

In essence, this approach contends that different consumers have different needs. High quality is attained by designing and manufacturing products, which meet the specific needs of consumers. As a result, this approach reflects a highly idiosyncratic and subjective view of quality. Juran $(1974,2-2)$ as a proponent of this approach defines quality as:

"fitness for use."

This approach is rooted in the demand-side of the market (cf. Dorfman \& Steiner 1954). Two issues should be addressed with regard to this user-based approach (Garvin 1984b):

(1) The first issue concerns the aggregation of individual preferences at the higher level of the market.

(2) The second issue deals with the fact that this approach essentially equates quality with (a maximization) of satisfaction. In other words, as Garvin (1984b, 27) puts it: 
"A consumer may enjoy a particular brand because of its unusual taste or features, yet may still regard some other brand as being of higher quality."

(4) The manufacturing-based approach to defining quality. As opposed to the user-based approach, the manufacturing-based approach to quality originates from the supply-side of the market, the manufacturer. This approach is based on the premise that meeting specifications connotes high quality (Crosby 1979; Luchs 1986). The essence of this approach boils down to: quality is (Crosby 1979,15 )

"...conformance to requirements."

This approach to defining quality is quite elementary, as it is based on an objective standard or specification (Reeves \& Bednar 1994).

A critical comment on this approach is articulated by Garvin (1984b). He finds that although a product may conform to certain specifications or standards, the content and validity of those specifications and standards are not questioned. The perspective taken by this approach is predominantly inward (Garvin 1984b; Gummesson 1991). As a result, firms may be unaware of shifts in customer preferences and competitors' (re)actions (Reeves \& Bednar 1994).

The ultimate consequence of this approach is that quality improvement will lead to cost reduction (Crosby 1979; Garvin 1983, 1984b; 1987, Luchs 1986). Cost reduction is achieved by lowering internal failure costs (e.g., scrap, rework and spoilage) and external failure costs (e.g., warranty costs, complaint adjustments, service calls, and loss of goodwill and future sales) through prevention and inspection (Feigenbaum 1983; Garvin 1983; Garvin 1987; Lundvall \& Juran 1974; Steenkamp 1989).

(5) The value-based approach to defining quality. The value-based approach presumes that quality can be defined in terms of costs and prices (Abbott 1955; Broh 1982; Feigenbaum 1961). Garvin (1984b, p. 28) uses the following example to clarify this perspective:

“... $\$ 500$ running shoe, no matter how well constructed, could not be a quality product, for it would find few buyers."

Clearly, this approach to defining shows promise, as both price and quality enter into the customer's decision-making process (Curry 1985). Reeves \& Bednar (1994) emphasize that this definition of quality forces firms to concentrate on internal efficiency ("internal conformance to specifications") and external effectiveness ("the extent to which external customer expectations are met").

However, this approach mixes two distinct, though related, concepts: quality and value (Bolton \& Drew 1991b, Garvin 1984b; Stahl \& Bounds 1991; Reeves \& Bednar 1994). This leads to a hybrid concept of (Garvin 1984b, 28):

"affordable excellence."

Because of its hybrid nature this concept lacks definitional clarity and might result in incompatible designs when implemented in practice.

Bednar \& Reeves (1994) propose one additional approach to quality: quality is meeting and/or exceeding customers' expectations. This approach is based on the definition of perceived service quality by (Parasuraman et al. 1988, 17): 
"Perceived service quality is therefore viewed as the degree and direction of discrepancy between consumers' perceptions and expectations."

This definition was initially conceived in the services marketing literature and as such takes an extremely user-based perspective (Holbrook \& Corfman 1985; Grönroos 1983, 1984, 1990a; Lehtinen \& Lehtinen 1982; Lewis \& Booms 1983; Parasuraman et al. 1985; Sasser et al. 1978; Zeithaml et al. 1990). Grönroos (1990a, 37) in this respect emphasizes:

"It should always be remembered that what counts is quality as it is perceived by the customers [emphasis in original text in italics]."

Due to the growing importance of the service sector in the global economy (As discussed in Chapter 1) this definition of quality has widely found acceptance (Gummeson 1991; Reeves \& Bednar 1994).

Relying on only a single approach might seriously impede the successful introduction of high-quality products (Garvin 1984a,b; Gummesson 1991); a synthesis of the above approaches is clearly needed. Garvin (1984b) proposes a temporal synthesis, in which emphasis shifts from the user-based approach, to the product-based approach and finally to the manufacturing-based approach, as products move from design to manufacturing and to the market. The user-based approach is the starting point, as market information must be obtain using marketing research to determine the features that connote high-quality. Next, these features must be translated into product attributes (the product-based approach). Finally, the manufacturing-approach will need to ensure that products are manufactured according to specifications laid down in the design of the product. The transcendent approach and the value approach are omitted from his synthesis, since they would lead to definitional problems.

Gummesson (1991) concurs in the integrative "quality" of the quality concept. Essentially, he reduces the above approaches to defining quality into two categories:

(1) the objective, technology-driven and production-oriented definition of the manufacturing-based approach ("Do things right") and

(2) the subjective, market-driven and customer-oriented definition of the user-based approach ("Do the right things").

Furthermore, he proposes that customer-perceived quality might integrate these two approaches, as it focuses the efforts of both manufacturing (operations management) and marketing (marketing management). Or as it is expressed by Gummesson $(1991,5)$ :

"[Customer-Perceived] Quality is the integrating concept between production-orientation and marketing orientation, between technology and customer satisfaction."

This notion is readily recognizable in the Conceptual Model of Service Quality conceived by Parasuraman et al. (1985). In section 2.3 the Conceptual Model of Service Quality will be discussed into quite some detail.

\section{Conclusion}

Garvin (1984b) distinguishes five major approaches to define quality: (1) the transcendent approach, (2) the product-based approach, (3) the user-based approach, (4) the manufacturingbased approach and the value-based approach. A sixth approach identified by Reeves \& Bednar (1994) is defining quality as meeting and/or exceeding customers' expectations. This approach was initially conceived in the services marketing literature and takes the user-based approach ad extremis. Relying on one definition may hinder the introduction of high-quality products. Therefore, a temporal synthesis of user-based approach, the product-based approach 
and the manufacturing-based approach may be warranted. Such a synthesis is laid down in the Conceptual Model of Service Quality.

\subsection{The Conceptual Model of Service Quality}

The Conceptual Model of Service Quality as conceived by Parasuraman and colleagues (Parasuraman et al. 1985) has achieved the status of the "standard" service quality model. This might be due to its inherent simplicity, the relationship between perceived service quality and internal factors, and the ready-to-use SERVQUAL measurement instrument for perceived service quality (Lemmink 1992). Essentially, the model consists of two components:

(1) perceived service quality (GAP5) and

(2) four internal gaps (GAP1-GAP4).

The Conceptual Model of Service Quality is depicted in Figure 2-1. In this model GAP5 (perceived service quality) is determined by the magnitude and direction of GAP1-GAP4. Parasuraman et al. (1985) posit the following relationship:

$$
\text { GAP5 = f(GAP1, GAP2, GAP3, GAP4) }
$$

The four internal gaps can be described as follows:

(1) Marketing Information Gap (GAP1): The difference between actual customer expectations and management perception of customer expectations.

(2) Standards Gap (GAP2): The difference between management perception of customer expectation and service quality specifications.

(3) Service Performance Gap (GAP3): The difference between service quality specifications and the service actually delivered.

(4) Communication Gap (GAP4): The difference between the service delivered and what is communicated about the service to customers.

GAP5 (perceived quality) is of a multidimensional nature. Parasuraman et al. (1985) distinguish ten underlying dimensions of perceived service quality. These dimensions are summarized in Table 2-1. Using these original ten dimensions Parasuraman et al. (1988) developed a measurement instrument for perceived service quality - SERVQUAL.

\section{Conclusion}

This section of chapter 2 is concerned with the Conceptual Model of Service Quality as conceived by Parasuraman et al. (1985). In essence, this model posits that perceived service quality (or GAP5 in terms of the model) is conceptualized as the comparison between perceptions and expectations. The magnitude and direction of perceived service quality, on its turn, is an influenced by four internal or organizational gaps. 
Figure 2-1: The Conceptual Model of Service Quality

\section{Consumer}

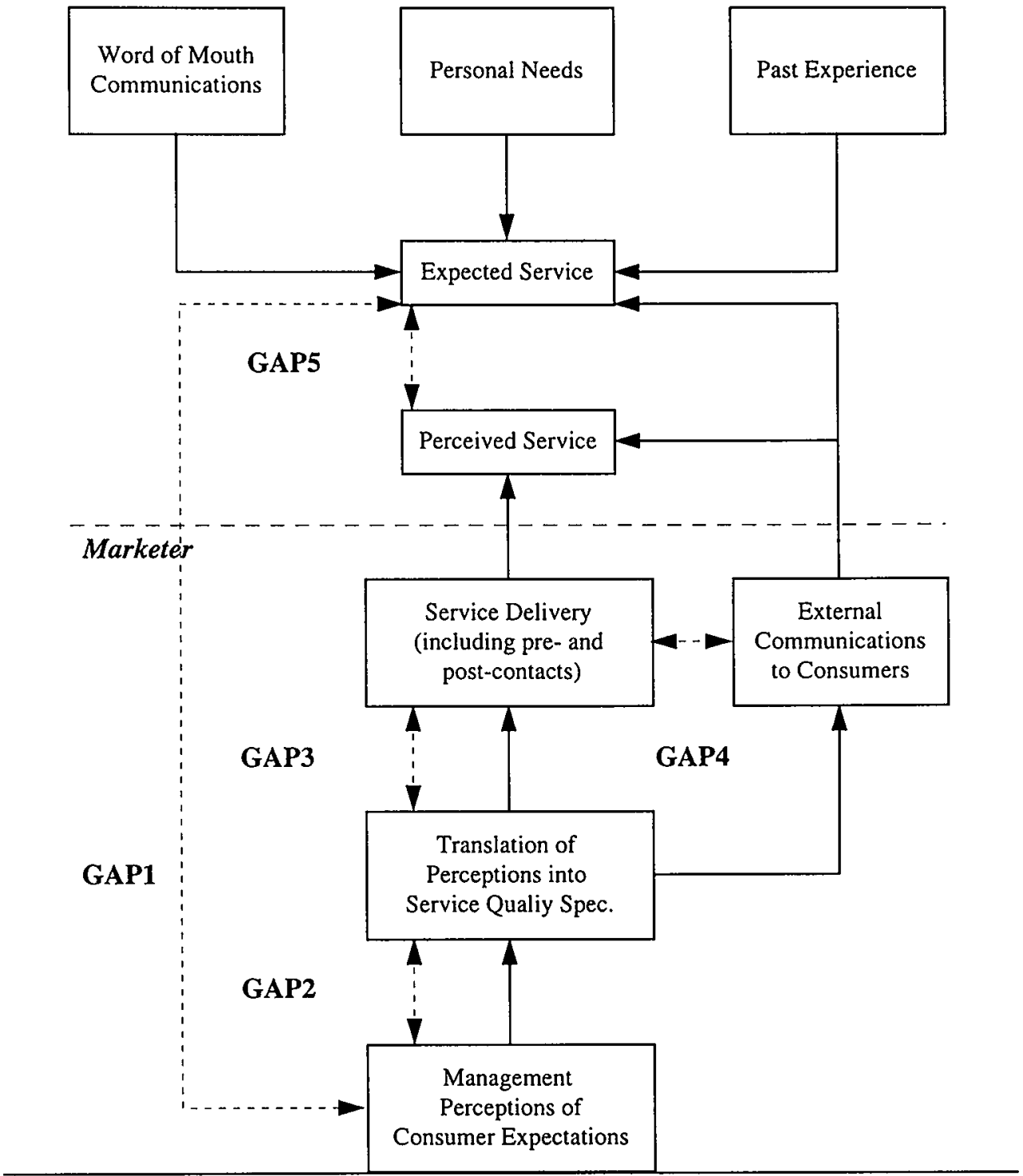

Source: Parasuraman et al. $(1985,44)$ 


\section{Table 2-1: Dimensions of Service Quality}

1. Reliability involves the consistency of performance and dependability.
2. Responsiveness concerns the willingness or readiness of employees to provide service.
3. Competence means possession of the required skills and knowledge to perform the service.
4. Access involves approachability and ease of contact.
5. Courtesy involves politeness, respect, consideration and friendliness of contact personnel.
$6 . \quad$ Communication means keeping customers informed in language they understand and
7. Credibility involves trustiness, believability and honesty.
8. Security is freedom from danger, risk or doubt.
9. needs.
10. Tangibles include the physical evidence of the service.

Adapted from: Parasuraman et al. $(1985,47)$.

\section{$2.4 \quad$ The SERVQUAL-Instrument}

The SERVQUAL-instrument for measuring service quality has evolved into a kind of gospel for academics and practitioners in the field of service quality. SERVQUAL has been applied in a myriad of settings, such as: banking, credit cards, repair and maintenance, telecommunication (Parasuraman et al. 1988); a dental school patient clinic, a business school placement center, a tire store, an acute care hospital (Carman 1990); telecommunication, banking, insurance (Parasuraman et al. 1991); banking, pest control, dry cleaning and fast food restaurants, (Cronin \& Taylor 1992); an electric and gas utility company (Babakus \& Boller 1992), hospitals (Babakus \& Mangold 1992; Reidenbach \& Sandifer-Smalllwood 1990); recreational services (Fick \& Ritchie 1991); after-sales services (Kasper \& Lemmink 1989); physical distribution services (Wetzels et al. 1995).

Using scale development procedures suggested by Churchill (1979), Parasuraman et al. (1988) developed the SERVQUAL-instrument for perceived service quality. Using the ten dimensions in Table 2-1 as a starting point 97 items were generated. Each item consisted of two components: one component reflected perceived service or perceptions and the other component reflected expected service or expectations. Both components were measured on $7-$ point Likert scale with only the ends of scale anchored by "Strongly disagree" (1) and "Strongly agree" (7). The items were presented in a two consecutive parts. The first part contained the expectation components for the items, while the second part contained the perception components for the items. In order to prevent distortion of the responses by acquiescence bias or "yea-saying or nay-saying" tendencies about half of the items was negatively worded and the other half was positively worded - reverse statement polarization (Churchill 1979; Bagozzi 1994; Belson 1984; Herche \& Engelland 1996; Pedhazur \& Pedhazur Schmelkin 1991; Schmitt \& Stults 1985).

Two stages of data collection and scale purification were subsequently carried out (cf. Churchill 1979; Nunnally \& Bernstein 1994). The first stage of data collection and scale purification using coefficient $\alpha$, item-to-total correlations and principal components analysis resulted in a reduction of the number of factors to seven. Five of the original factors were retained in this configuration (See Table 2-1):
(1) Tangibles;
(2) Reliability;
(3) Responsiveness; 
(4) Understanding/knowing the customer and

(5) Access.

The remaining five dimensions, communication, credibility, security, competence and courtesy, were collapsed into-two dimensions. The number of factors was further reduced in the second stage of data collection and scale purification. The results of principal components analysis suggested an overlap between the dimensions understanding/knowing the customer and access, and the dimensions communication, credibility, security, competence and courtesy. Consequently, the overlapping dimensions were combined to form two separate dimensions:

(1) Assurance and

(2) Empathy.

The development of the SERVQUAL-instrument as described in Parasuraman et al. (1988) is summarized in Figure 2-2.

Parasuraman et al. (1991) present a replication and extension of their 1988 study. More in particular, they propose a number of modifications to the original SERVQUAL-instrument (Parasuraman et al. 1988). The first modification was concerned with the expectations section of SERVQUAL. Confronted with extremely high scores on the expectations components of the individual statements, Parasuraman et al. (1991) decided to revise the expectation part of the instrument (cf. Vogels et al. 1989). Whereas the original scale reflected normative or ideal expectations, the revised instrument reflected predictive expectations relative to an excellent firm in the industry. For example, with regard to statement no. 5 the expectation item (E5) of the original instrument $s$ formulated as follows (Parasuraman et al. 1988, 38):

"When these firms promise to do something by a certain time, they should do so."

In the revised SERVQUAL-instrument the wording of expectation item no. 5 (E5) has been changed in (Parasuraman et al. $(1991,446)$ :

"When excellent telephone companies promise to do something by a certain time, they will do so."

Both the original SERVQUAL-instrument and the modified SERVQUAL-instrument are included in the appendices. Appendix I contains the original instrument and Appendix II contains the modified instrument.

A second modification was. related to use of negatively worded items for the responsiveness and empathy dimensions in the original instrument. For the modified instrument all negatively worded items were replaced by positively worded items. Parasuraman et al. (1991) present three reasons for this alteration:

(1) The standard deviations were consistently higher for the negatively worded items;

(2) Managers perceived that respondents might find negatively formulated items awkward and not as meaningful as positively formulated items;

(3) Reliability in terms of coefficient $\alpha$ may be adversely affected by the use of negatively worded items.

The findings of a study by Vogels et al. (1989) support this modification. They report bimodal distributions for the negatively worded items in their study, which lead to lower means and higher standard deviations. Schmitt \& Stults (1985) observe similar results were found in such diverse areas as interview impressions, personality research and work stress. In general, it can be hypothesized that a majority of the negatively worded items load on a single "negative" factor. The used simulated data to assess the effect of negatively worded items on the factor 
structure of three measurement instruments each consisting of 30 items. Their design varied on two factors:

(1) Percentage of "careless" respondents $(0 \%, 5 \%, 10 \%, 15 \%, 20 \%)$ and

(2) the number of negatively worded items $(4,8,12)$.

Their results reveal that the effect of the number of negatively worded items did not substantially affect their results. However, for all three instruments at only $10 \%$ "careless" respondents a "negative" factor, i.e. consisting mainly of negative items, could be clearly discerned. Schmitt \& Stults $(1985,367)$ define "careless" respondents as a respondent that:

"...is simply reading a few of the items in the measuring instrument, inferring what it is the items are asking of the respondent, and then responding in like manner to the remainder of the items in the instrument."

Herche \& Engelland (1996) reproduced similar finding with empirical data on three marketing scales:

(1) SOCO scale (Saxe \& Weitz 1982);

Figure 2-2: Development of Dimensionality of SERVQUAL-Instrument

\section{Original 10 Dimensions}

Tangibles

Reliability

Responsiveness

Communication

Credibility

Security

Competence

Courtesy

Understanding/knowing the customer Access
SERVQUAL Dimensions

Topoles

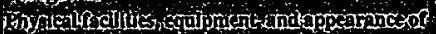
iponiongit

Relibititity

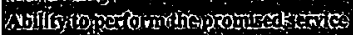

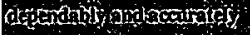

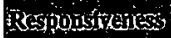

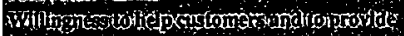

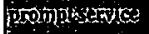

Bisuring

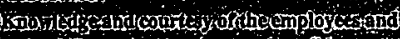

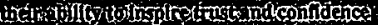


(2) ADAPTS scale (Spiro \& Weitz 1990) and

(3) CETSCALE (Shimp \& Sharma 1987).

All three instruments have been frequently applied and have shown favorable psychometric properties in terms of reliability and validity. The CETSCALE is the only instrument without negatively worded items. A revised version of the CETSCALE including seven negatively worded items was developed by the authors. Moreover, a fourth measurement instrument was especially developed for this study; the instrument was developed to evaluate the degree of innovativeness. The instrument consists of two forms. Form A consists only of positive items and Form B consists of both positive and negative factors. Using confirmatory factor analysis the authors find that the inclusion of a "negative" factor significantly improves the fit over a one factor model for all three mentioned marketing scales. Babakus \& Boller (1992) report the emergence of a "negative" factor using exploratory factor analysis using the original SERVQUAL-instrument.

Furthermore, with regard to the fourth scale they report that the fit of Form B, the mixedpolarity instrument is worse than the fit of the Form A consisting only of positively worded items. As Herche \& Engelland (1996) point out the inclusion of negatively worded items might not only lead to "negative" factor artifact, it my also pose a serious threat to measure unidimensionality. Unidimensionality has recently been advanced as a fundamental assumption underlying measurement theory (Anderson et al. 1987; Gerbing \& Anderson 1988; Hattie 1985; Kumar \& Dillon 1987; Steenkamp \& van Trijp 1991). This threat to unidimensionality may be rooted in the asymmetry between positive and negative items, since these need not necessarily been located on the same continuum (Kanouse \& Hanson 1971).

In sum, we can see that negatively worded items may exhibit two types of effects on the dimensionality of a measurement instrument. First, inclusion of negative items may lead to the emergence of a "negative". factor using factor analytic techniques. If a dimension is solely operationalized by negative items, this might make it particularly susceptible to the emergence of a "negative" factor. Second, the use of mixed-polarity items for a dimension might result in a reduction of the performance of the scale regarding unidimensionality tests. Therefore, Herche \& Engelland $(1996,373)$ conclude:

“...caution is advised when employing scales with mixed-item polarity."

Moreover, in their 1991 study Parasuraman and his colleagues suggest to add an importance measure to instrument in order to be able to calculate (Parasuraman et al. 1991, 424):

"...a composite, weighted estimate of overall service quality."

Perceived service quality can now be defined as (cf. Teas 1993):

$$
P S Q_{i}=\sum_{j=I}^{k} W_{j}\left(P_{i j}-E_{i j}\right)
$$

$P S Q_{i}=$ Perceived service quality of stimulus $i$

$P_{i j}=$ Perception of service of stimulus $i$ with regard to attribute $j$

$E_{i j}=$ Expected service of stimulus $i$ with regard to attribute $j$

$W_{j}=$ Weighting factor if the attributes have different weights

$k=$ Number of attributes 
Parasuraman et al. (1991) propose that $\mathrm{W}_{\mathrm{j}}$ is measured by allocating 100 points to the individual dimensions of service quality in accordance with their perceived importance. The measure they propose is a constant sum scale (Bagozzi 1994; Lodge 1981). Self-estimated importance weights or explicit importance weights have been extensively used in the social sciences (Brannick \& Darling 1991; Doyle et al. 1997; Jaccard et al. 1986; Taylor 1995; Zhu \& Anderson 1991). Their use, however, has also been criticized for several reasons. The most important shortcoming is the lack of convergent validity (Jaccard et al. 1986; Taylor 1995; Zhu \& Anderson 1991).

The two most popular approaches for determining explicit importance weights are: (1) a direct rating of the perceived importance and (2) an allocation of a budget of points between attributes in accordance with their perceived importance (Doyle et al. 1997). Intuitively one would expect that these approaches would yield similar results. However, research indicates that the two methods are not equivalent (Doyle et al. 1997; Zhu \& Anderson 1991). Using Anderson's (1981) averaging model Zhu and Anderson (1991) find that the point allocation method produces seriously biased estimates as compared to the rating method. Doyle et al. (1997) comment that the results of Zhu \& Anderson (1991) are based on the assumption that global judgments are intrinsically correct. Furthermore, the theoretical weights were obtained using rating rather than point allocation. Consequently, the use of only one method to obtain importance weights may be highly suspect. For example, Zeithaml et al. (1990) find quite divergent important weights using rating and point allocation. The validity of importance weights is important, since invalid weight estimates may lead to wrong conclusions regarding overall perceived service quality (Zhu \& Anderson 1991).

In their 1988 paper (Parasuraman et al. 1988) the authors used a different approach to determine the importance of the individual dimensions. This method entailed regressing a global measure of service quality on the average perceived service quality scores of the individual dimensions of service quality (Brannick \& Darling 1991). However, this method is rather problematic when the dimensions are correlated, since multicollinearity affects the magnitude and direction of the regression coefficients (Darlington 1990; Neter et al. 1990; Pedhazur \& Pedhazur Schmelkin 1991). Pedhazur \& Pedhazur Schmelkin $(1991,450)$ even suggest that:

"In the face of high multicollinearity, it may turn out that most, even all, of the b's are statistically not significant, despite the fact that $R^{2}$ may be relatively high and statistically significant."

Parasuraman et al. (1988) find that in three out of four organizations only two (reliability and assurance) of the five dimensions have a statistically significant effect on a global measure of service quality. For the fourth organization only one of the dimensions, reliability, exhibits a significant effect on the global measure of service quality. The authors themselves admit that the results are (Parasuraman et al. 1988, ):

"...somewhat masked by possible multicollinearity."

However, they do not provide any diagnostic measures to assess the severity of the multicollinearity threat. Several diagnostic measures, such as the variance inflation factor (VIF) or tolerance are available for the detection of multicollinearity (Darlington 1990; Neter et al. 1990; Ofir \& Khuri 1986; Pedhazur \& Pedhazur Schmelkin 1991). Parasuraman et al. (1988) do not even provide the matrix of zero-order correlations between the service quality dimensions.

More recently, two methods have been advanced to estimate implicit importance weights: (1) conjoint analysis and (2) multidimensional scaling. Conjoint analysis is a technique which allows a set of overall responses to factorially designed stimuli to be decomposed, so that the utility of each stimulus attribute can be inferred from the respondent's overall evaluations of 
the stimuli (Carroll \& Green 1995; Green \& Srinivasan 1978, 1990). On the basis of the partworth utilities implicit importance weights can then be determined. Several authors have applied conjoint analysis in service settings (DeSarbo et al. 1994; De Ruyter \& Wetzels 1995; Wetzels et al. 1995). Its most important shortcoming is that only a limited number of attributes or dimensions can be included without making the task unmanageable for the respondents.

Multidimensional scaling is a second approach, which has recently been advanced as an alternative to derive implicit importance weights. Multidimensional scaling uses proximities between objects or subjects to be translated into spatial distances in a number of dimensions (Carroll \& Green 1997; Cooper 1983; Green 1975). More specifically, Taylor (1995) proposes that weighted multidimensional scaling can be used to derive importance weights for each individual. The major limitation of this approach is that dimensions cannot be explicitly named.

\section{Conclusion}

On the basis of the Conceptual Model of service Quality a measure instrument, SERVQUAL, was developed by Parasuraman et al. (1988). The instrument consists of two components: (1) perceptions and (2) expectations. The instrument has been modified by the original authors in 1991 (Parasuraman et al. 1991). The modification was concerned with expectations component. Expectations were changed from ideal ("should") expectations to predictive ("would") expectations. Moreover, an importance weight using a constant sum scale on attribute level was added to the original instrument. However, the use of importance weights may be problematic, as the most popular methods, rating and point allocation may not lead to consistent results. Multidimensional scaling and conjoint analysis have been proposed as more valid techniques for obtaining importance weights.

\subsection{Conceptual Concerns regarding the SERVQUAL-Instrument}

Section 2.5 is aimed at reviewing conceptual concerns regarding the SERVQUAL-instrument. This discussion will therefore focus on conceptual issues regarding GAP5. GAP1 to GAP4 will be dealt with in more detail in chapter 3 .

\subsubsection{The "Gap" (P-E) Conceptualization of Service Quality}

The single most important strength of the conceptual model underlying the SERVQUALinstrument is its inherent parsimony (Iacobucci et al. 1994; Lemmink 1992). However, Iacobucci et al. (1994) that this strength simultaneously is its major shortcoming. More in particular, they argue (Iacobucci et al. 1994, 3):

"...it is too [emphasis in original text in italics] simple to provide a general understanding of customer evaluation or to be useful in empirical prediction."

The Conceptual Model of Service Quality is based on relative evaluations (See equation 2.2). The absolute level of perceptions $\left(P_{i j}\right)$ expectations $\left(E_{i j}\right)$ does not enter the equation. The ultimate consequence of this definition is that service quality will be evaluated favorably as long as expectations are met or exceeded. The absolute level of either perceptions or expectations is not explicitly taken into consideration (Bolton \& Drew 1991b; Churchill \& Surprenant 1982; Oliver 1980; Oliver 1993a,b; Tse \& Wilton 1988). Iacobucci et al. (1994, 16) use the example of Joe's Diner, a truck-stop restaurant with very low expectations, to illustrate the importance of absolute levels of expectations: 
“...the customer who enters Joe's Diner with appropriately low expectations and indeed experiences poor food and rude service. It is unlikely that predicting a favorable evaluation is valid, even though the customer's prior expectations had been met."

Another consequence of this conceptualization of service quality is that services exceeding expectations in the same magnitude (and direction) are predicted to lead to similar levels of perceived service quality. For example, assume that a 7-point Likert-type rating scale is used to capture both perceptions and expectations. Further, assume service A scores 2 on expectations and service $B$ scores a 6 on expectations. The corresponding perception scores are a 3 for service $A$ and a 7 for service $B$. This results in the same perceived service quality score for both service $A(7-6=1)$ and Service B $(3-2=1)$. However, it would be rather unrealistic to assume that both services result in the same level of perceived service quality, since service B exhibited both a higher level of perceptions and expectations.

\subsubsection{Is Service Quality an Attitude?}

The early work in service quality research strongly focused on embedding service quality in the customer satisfaction framework (e.g., Oliver 1980, 1981; Iacobucci et al. 1994, 1996; Cronin \& Taylor 1992, 1994). More in particular, several authors raised the question whether service quality is an attitude (Bitner 1990; Bolton \& Drew 1991a,1991b; Parasuraman et al. 1988). Taking up this challenge Cronin \& Taylor (1992) proposed that service quality could indeed be considered an attitude. Therefore, they question the expectations-performance gap definition of service quality. They indicate that the expectancy disconfirmation model should be reserved for customer satisfaction. This assumption leads them to the following two conclusions:

(1) The "adequacy-importance" model is the most effective operationalization of attitude (Mazis et al. 1975) and

(2) the performance component adequately captures attitude without including the importance weight in the model.

Consequently, they develop an adapted version of the SERVQUAL-instrument, SERPERF, which only incorporates the perception component. SERVPERF can be represent by the following equation:

$$
\begin{aligned}
& \operatorname{PSQ}_{i}=\sum_{j=1}^{k} W_{j}\left(P_{i j}\right) \\
& \mathbf{P S Q}_{i}=\text { Perceived service quality of stimulus } i \\
& \text { (2.3) } \quad \mathbf{P}_{\mathbf{i} j}=\text { Perception of service of stimulus } \mathbf{i} \text { with regard to attribute } \mathbf{j} \\
& W_{j}=\text { Weighting factor if the attributes have different weights } \\
& k=\text { Number of attributes }
\end{aligned}
$$

To test SERVPERF Cronin \& Taylor (1992) used both a weighted and unweighted version of SERVQUAL and SERVPERF. From their empirical study it can be concluded that discriminant validity of the new instrument is adequate, as the intercorrelations between the service quality measures exceed the correlations with satisfaction and purchase intentions (cf. Churchill 1979). Furthermore, the unweighted SERVPERF measure outperformed the weighted SERVPERF version and the two SERVQUAL measures in explaining a global measure of service quality in all four industries included in the study. The superior performance of perceptions in explaining global measures of quality has been corroborated by other authors as well (Babakus \& Boller 1992 ; Parasuraman et al. 1993, 1994a,b,c), 
The discussion whether or not service quality constitutes an "attitude" is closely related to the distinction between service quality and customer satisfaction (Cronin \& Taylor 1992, 1994; Oliver 1980, 1981; Parasuraman et al. 1988). Iacobucci et al. (1994) more recently advanced that both service quality and customer satisfaction can be distinguished as "attitudes". However, they propose that in line with Fishbein (1967) the meanings of each of the two constructs should limited. The conceptual definition service quality should reflect a more cognitive evaluation, while the conceptual definition of customer satisfaction should reflect a more affective evaluation. This also might lead to clearer view on the "service quality is an attitude" discussion.

\subsubsection{The Multidimensional Nature of Service Quality}

The multidimensional nature of service quality has been acknowledged in the European as well as in the North American research traditions in services marketing (Garvin 1987; Grönroos 1984, 1990; Gummesson 1991; Lapierre 1996; Lapierre \& Filiatrault 1996; Lehtinen et al. 1996; Liljander and Strandvik 1995a; Parasuraman et al. 1988, 1991,1994a,b,c; Zeithaml et al. 1996). Although the exact number of dimensions remains open to discussion, the general notion of multidimensionality seems to be generally accepted. The most popular exponent of this perspective is the Conceptual Model of Service Quality and the accompanying SERVQUAL-instrument developed by Parasuraman et al. (1988) and further refined in Parasuraman et al. (1991). The generalizability of the five SERVQUAL dimensions in other than the original industries (Parasuraman et al. 1988, 1991) is still rather problematic (Carman 1990; Babakus \& Boller 1992; Paulin \& Perrien 1996).

Furthermore, it could be argued that a service encounter consists of two major components: (1) the service process and (2) the service outcome (Grönroos 1984, 1990a; Lapierre 1996; Lapierre \& Filiatrault 1996; De Ruyter \& Wetzels 1998a). The five dimensions identified in the Conceptual Model of service Quality are directed towards the interaction between customer and service provider; and therefore focus on the service process (Lapierre 1996; Lapierre \& Filiatrault 1996).

An additional problem with the Conceptual Model of Service is its implicit assumption that each service encounter consists of only of single stage (Carman 1990; Lemmink et al. 1998; Liljander \& Strandvik 1995a; De Ruyter et al. 1997a,b). More in particular, if a service encounter or service episode consists of multiple stages the dimensions of the Conceptual Model of Service Quality would require a subscript to identify them. Factor analytic procedures might result in factors based on stages rather than dimensions (cf. Carman 1990).

Rust and his colleagues (Kordupleski et al. 1993; Rust et al. 1995) take this train of thought even to a more extreme position. They propose to structure service quality to be structures around the business process. The business process would than be used to derive the first-order factors leading to service quality, the second-order factor. Subsequently, items or indicators need to be generated within each process or first-order factor. Apart from modeling the stages into the model such an approach also ensures for managerial relevance. This approach has also been applied in services value research. De Ruyter and his colleagues (Lemmink et al. 1998; De Ruyter et al. 1997a,b) similarly used business processes in their framework of service value. In Lemmink et al. (1998) they found a good fit for their second-order confirmatory factor model. In this second-order model they used three indicators (emotional dimension of service value, practical dimension of service value and the logical dimension of service value) for each stage of the service process (first-order factor) leading to satisfaction with the service encounter or service episode (second-order factor).

\subsubsection{Service Quality and Customer Satisfaction: Identical Twins or Siamese'Twins}

An issue, which has received ample attention in academia in this respect, is the differentiation between service quality and customer satisfaction (Bitner 1990; Bitner \& Hubbert 1994; 
Bolton \& Drew 1991a,b; Cronin \& Taylor 1992; Jacobucci et al. 1994; Oliver 1993, 1997; Taylor \& Baker 1994). The confusion surrounding these two constructs in services research can be accounted for by the fact that both are based on the same "canonical" model (lacobucci et al. 1996). Service quality and customer satisfaction models share the following characteristics (Iacobucci et al. 1996):

(1) Customers are thought to hold the expectations prior to their purchases;

(2) Customers make perceptions regarding their purchases;

(3) Customers compare their perceptions to their expectations; and

(4) This comparative process results in evaluations of quality and/or satisfaction (and subsequent effects, e.g. future purchase intentions).

This "canonical" model is shown in Figure 2-3.

Oliver (1993a) proposes that service quality and customer satisfaction differ on four fundamental characteristics. To begin with, the dimensions underlying quality are quite specific, while customer satisfaction can result from any dimension related to the service encounter. Secondly, service quality is based on ideals or "excellence" (Parasuraman et al. 1988, 1991, 1994a,b,c; Zeithaml et al. 1993), whereas customer satisfaction can be based on a host of alternative standards, such as predictive norms and experience-based norms (Iacobucci et al. 1994, 1996; Zeithaml et al. 1993). Iacobucci et al. $(1994,15)$ following a similar reasoning propose a similar approach:

"Perhaps satisfaction is indeed judged by consumers against their own internal standards, whereas quality is would be better defined as judgment relative to managerial or competitive standards."

In fact, they propose that service quality is based on external standards and customers satisfaction on internal standards.

This classification of standards is closely related to the following third characteristic suggested by Oliver (1993a). It is contended that service quality does not require experience with service or service provider. Customer satisfaction, on the other hand, is an experiential construct. Customer satisfaction can only be evaluated by actually experiencing the service encounter (Anderson et al. 1994; Iacobucci et al. 1994). Anderson et al. (1994) suggest that in general customer satisfaction is influenced by price, whereas service quality is viewed as independent form price. Price or costs incurred are often modeled using value; value is thus operationalized as the ration of perceived quality relative to price (cf. Zeithaml 1988).

Finally, service quality and customer satisfaction are based on different sets of antecedents. The antecedents of service quality are mainly limited to communication, both personal and impersonal, and situational characteristics (Zeithaml et al. 1993). Customer satisfaction has been hypothesize to be influenced by a number of cognitive and affective processes (Oliver 1993a,b,1997), such as disconfirmation (Anderson \& Sullivan 1993; Oliver 1993a; Oliver \& DeSarbo 1988) equity (Oliver \& Swan 1989a,b), attribution (Folkes 1984; Oliver \& DeSarbo 1988; Richins 1983), mood states (Gardner 1985) and emotions (Mano \& Oliver 1993; Price et al. 1995; Westbrook \& Oliver 1991). 
Figure 2-3: A Canonical Model for Consumer Evaluations

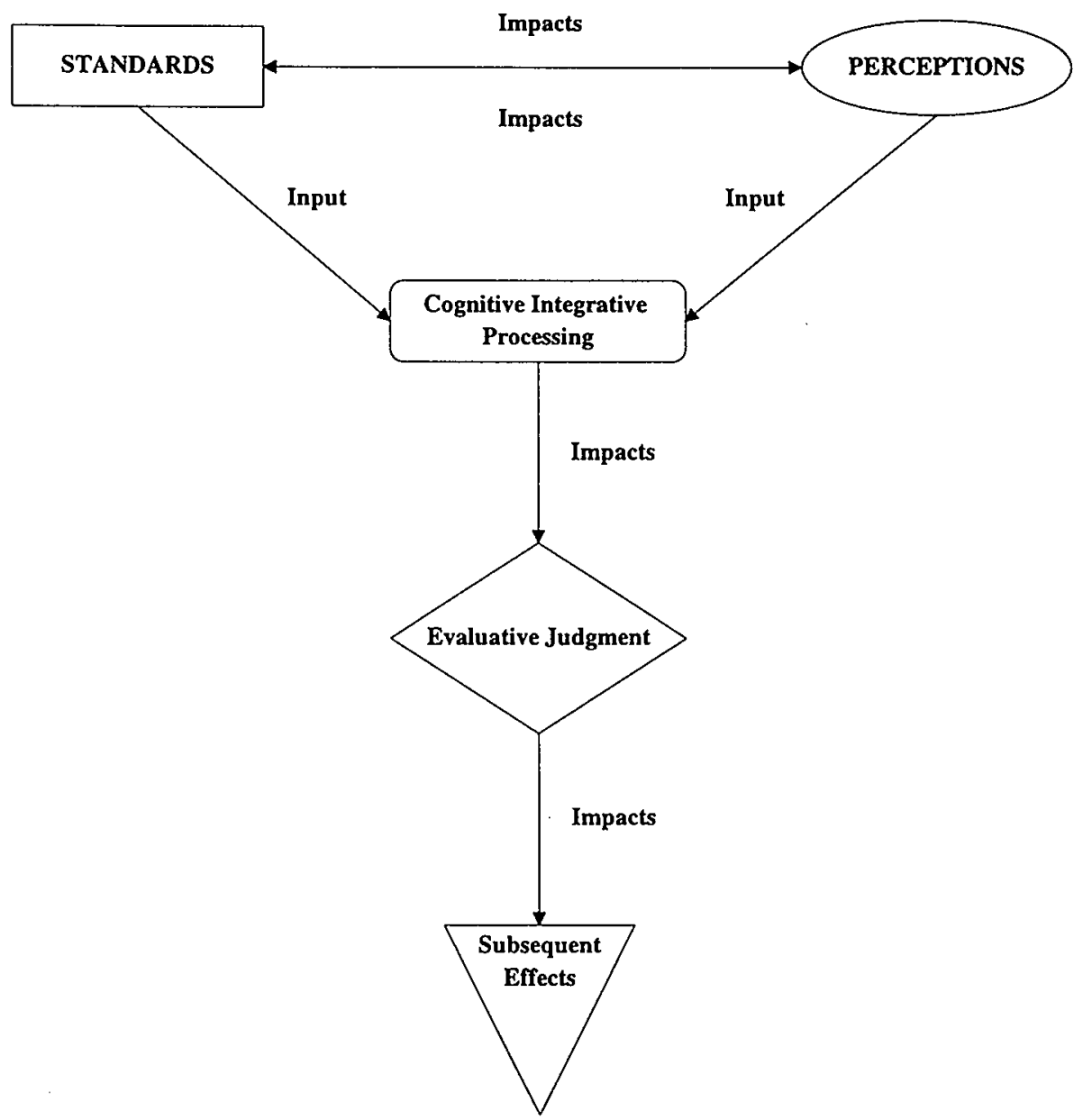

Adapted from lacobucci et al. $(1996,3)$

Moreover, Iacobucci et al. (1994) propose that the conceptual definition of service quality should reflect a more cognitive evaluation, while the conceptual definition of customer satisfaction should reflect a more affective evaluation. Oliver $(1993 \mathrm{~b}, 1994,1997)$ finds that service quality has a greater cognitive content than customer satisfaction. Customer satisfaction showed to be both cognitive and affective in content.

There is a growing consensus on the sequential order of service quality and satisfaction. The latter is increasingly regarded as the superordinate construct based on conceptual work by Oliver, Rust, Fornell and his colleagues (Anderson et al. 1994; Fornell et al. 1996; Oliver 1993a, 1997; Rust \& Oliver 1994) and empirical evidence provided by Woodside et al. (1989), Cronin and Taylor (1992) Anderson \& Sullivan (1993), Taylor \& Baker (1994), Fornell cum suis (Anderson et al. 1994; Fornell et al. 1996) and De Ruyter et al. (1997d).

Woodside et al. (1989) further propose that customer satisfaction on its turn affects behavioral intentions. Their model assumes the following causal chain: service quality $\rightarrow$ customer satisfaction $\rightarrow$ behavioral intentions. Cronin \& Taylor (1992) find empirical support 
for this model using structural equation modeling. However, their application of structural equation modeling is not flawless (Iacobucci et al. 1994). Bitner (1990) finds empirical support for the reverse causal ordering between service quality and customer satisfaction. This leads to the following causal chain: customer satisfaction $\rightarrow$ service quality $\rightarrow$ behavioral intentions. Taylor \& Baker (1994) suggest an alternative conceptualization of the relationship between service quality, customer satisfaction and behavioral intentions. They propose that satisfaction moderates the relationship between service quality and behavioral intentions. Using moderated regression analysis (cf. Sharma et al. 1981) they find support for the hypothesis that customer satisfaction might be a moderator for the relationship between service quality and behavioral intentions for three of the four industries in their study.

Although service quality and customer satisfaction can be conceptually distinguished as different constructs, it might be rather difficult to find empirical differences. It is likely that measures of either concept will be empirically correlated (Iacobucci et al. 1994). Therefore, we can conclude that service quality and customer satisfaction do not relate to each other as identical twins, but rather as Siamese twins: a striking resemblance, but hard to tease apart.

\subsubsection{Service Value: A Contender to the Throne?}

Another major weakness of the Conceptual model of Service Quality is its omission of financial factors (Anderson et al. 1994; Fornell et al. 1996; Iacobucci et al. 1994; Lemmink 1998; De Ruyter et al. 1997a,b; Zeithaml 1988). During the past decade, various competing models have been advanced to explain consumer evaluations of services (Iacobucci et al. 1996). Many of these models include service quality and satisfaction as their basic focal constructs, departing from a comparison between customer expectations and service provider performance (Iacobucci et al. 1994, Parasuraman et al. 1994b). Recently, however, it has been argued that the concept of value is a (Zeithaml \& Bitner 1996, 32):

"...key competitive factor defining the way services are bought and sold".

It has even been argued that value can be considered as the basis for service quality (Garvin 1987). Although the conceptualization of value in a services setting has received some attention (e.g., Holbrook 1994), evidence is scarce with respect to the relationship between theoretical definitions and corresponding empirical measures. Likewise, the conceptual interrelationship between value and satisfaction as competitive evaluative judgments has not been dealt with in the services marketing literature (Rust \& Oliver 1994). These issues have been largely overlooked in the literature and merit further clarification.

Value has frequently been conceptualized as the outcome of a price/quality ratio or the comparison of what one receives with the cost of acquisition (Anderson 1995; Anderson et al. 1994; Fornell et al. 1996; Oliver 1997; Zeithaml 1988). According to this point of view, service customers will attempt to maximize the level of quality in relation to the disutility of price. Price in this case may be interpreted as a psychological price in terms of time and distance. It has been argued that service providers that maximize quality minus the disutility from prices will be favored by customers. Therefore, while the quality of a service may be conceived of as good, its net or marginal value may still be rated poor is the price of that service is perceived to be too high (Rust \& Oliver 1994). This conceptualization of value as a proxy for the quality price ratio may be labeled the value-for-money approach. This approach very much focuses our attention to value as a cognitive construct as an explicit comparison between price and quality is made by consumers. However, it has been emphasized recently that affect should also be considered in determining postpurchase responses (Oliver 1993b, 1997). If value is perceived as a summary cognitive and affective response then an affective component should also be incorporated in a conceptualization of value.

On the basis of writings in the realm of axiology, Hartman $(1967,1973)$ has proposed a generic and formal model of value that takes both affective and cognitive aspects into account. 
This model consists of three dimensions; (1) extrinsic, (2) intrinsic and (3) systemic. The distinction between extrinsic and intrinsic is one of the few undisputed issues in the area of axiology. The extrinsic value dimension reflects that the use of a particular service can be regarded as a means to a specific end. This dimension has also been termed the utilitarian or instrumental component of the value construct (Holbrook 1994). Intrinsic value on the other hand, represents the emotional evaluation of a service. It reflects the affective part of the consumer response to a service offering or the service delivery as end in itself (Hirschman \& Holbrook 1982). Finally, systemic value pertains to the inherent relationship between concepts in their systematic interaction, e.g., the relationship between what one gives and what one gets. It points to rational or logical aspects of a service episode. Hartman's threedimensional model reflects the basic three-partite conceptualization that is often made in axiology (e.g., Lewis 1946; Taylor 1961; Olson 1967), although different terminology is frequently used. Similarly, Mattsson (1991) who was the first to use Hartman's model in a services marketing context, introduced new labels: emotional (E), practical (P) and logical (L), with $\mathrm{E}>\mathrm{P}>\mathrm{L}$ in terms of richness of content. By using these three dimensions, Hartman attempts to establish a matching of concrete and abstract properties of a concept. The emotional dimension refers to the 'Gestalt experience' of an encounter. The practical dimension refers to concrete objects in the physical world, which can be grasped. The logical dimension encompasses the formal world, the rationality of a sequence of events. In relation to the service delivery process, the emotional dimension reflects the hedonic experience of the service episode, the practical dimension represents its functional elements and the logical elements pertain to the rational aspects. Hartman's model was used by Danaher \& Mattsson (1994) in order to explain satisfaction with the hotel visit. Hence, service satisfaction is treated as the superordinate construct. Consumer value judgments, therefore, contribute to satisfaction, which has been viewed as a summary cognitive and affective response to all elements of the service delivery process (Rust \& Oliver 1994). Holbrook $(1994,27)$ defines value as an

"...interactive relativistic consumption preference experience".

This posits value not only as an evaluative customer judgment regarding the service object, but also focuses our attention to the subject-object interaction in the process of service delivery. Thus, value - by definition - is associated with the service delivery process. Several empirical studies have been conducted using the Hartman-Mattsson framework (Mattsson 1991). Empirical research showed that the framework could be applied to different service industries, such as museums (De Ruyter et al. 1997a), hotels (De Ruyter et al. 1997b) and restaurants (Lemmink et al. 1998).

\subsubsection{The Static Nature of the Conceptual Model of Service Quality}

Another major conceptual flaw in the Conceptual Model of Service Quality is its static nature. It has been recognized that time plays an essential role when modeling service quality and customers satisfaction (Boulding et al. 1993; Iacobucci et al. 1994, 1996; Liljander \& Strandvik 1994; Oliver 1980). For instance, customers may change their attitude, intentions and/or behavior following a (positive or negative) service experience (Boulding et al. 1993; Liljander \& Strandvik 1994). Alternatively, service improvements may alter the perceived quality of relationships over time (Bolton \& Drew 1991a). Therefore, a dynamic approach for conceptualizing of service quality seems preferable and might bring theory development in services marketing more in line with the relationship marketing school of thought. Several dynamic approaches have been suggested in the literature on services marketing recently.

One approach to measuring dynamic service quality focuses on the so-called actual dynamics of a relationship over time. An example of this approach is the longitudinal model by Bolton \& Drew (1991a). This model measures service quality at various sequential points in time. In 
essence, this is a repetition of static models (such as the Conceptual Model of Service Quality) within a limited time frame. There are conceptual as well as practical drawbacks to this approach. In the first place, actual dynamic models suffer from the same drawbacks as the static Conceptual Model of Service Quality. Secondly, the whole is not always the same as the sum of its parts, i.e., the relative weight that customers attach to the quality of different service episodes remains unknown (Liljander \& Strandvik 1995a). Often it is assumed that a negative disconfirmation of expectations will lead to a decrease in satisfaction. Bitner (1990) has shown that such an assumption is disputable due to the role that customer attribution plays. Furthermore, the zone of tolerance may impact a service episode evaluation in a similar manner (Liljander \& Strandvik 1993; Parasuraman et al. 1994a,c; Zeithaml et al. 1991, 1996). A practical disadvantage is that Bolton \& Drew's actual dynamics model has been tested for a socalled continual service (telecommunications) only. Results may differ for discrete services, i.e., service where the decision whether or not to continue relationships is made separately each time (Liljander \& Strandvik 1994). Finally, panel attrition may easily occur in the longitudinal design (Menard 1991). For instance, at $t_{3}$ in the Bolton \& Drew study only a $56 \%$ response could be obtained as a result of panel attrition.

A second attempt at modeling the actual dynamics of the quality of a relationship was conducted by Boulding et al. (1993). The basic notion of their dynamic process model is that perceptions as well as expectations are "updated" by individual service encounters, word-ofmouth and competitor action. On the basis of Tse \& Wilton (1988), Boulding et al. (1993) make a distinction between will and should expectations. Finally, the model also has a number of practical disadvantages similar to Bolton \& Drew's (1991a) longitudinal design. Its operationalization is complex, expensive, time-consuming, and also runs the risk of panel attrition. In order to deal with these drawbacks, models of perceived dynamics have been developed recently.

An alternative to measuring the actual quality of customer-supplier relationships is an approach that models the perceived dynamics of service quality. This approach invites respondents to reflect on individual episodes as well as to make an overall assessment of the quality of the relationship over time. Bitner \& Hubbert (1994) distinguish between overall and encounter specific satisfaction. Encounter satisfaction relates to a discrete experience, while overall satisfaction is related to the total satisfaction of a customer with an organization. Satisfaction is treated as an antecedent of service quality. Service quality is treated as an attitudinal concept and defined as the (global) impression of the relative inferiority/superiority of an organization. However, this model is limited in the sense that no antecedents of aforementioned concepts are measured and no causal link to actual consumer behavior is explicitly made.

A more comprehensive approach to measuring perceived relationship quality is the dynamic service quality model developed by Liljander \& Strandvik (1994). According to this model, an explicit distinction is made between episode and relationship performance. In this model too, a distinction is made between service quality and satisfaction. Only in this case, service quality is treated as an antecedent of satisfaction. Both quality and satisfaction are measured at the episodic and at the relationship level. It is argued that perceived performance at the episode level may influence perceived quality through the disconfirmation of a comparison standard. Finally, both episodic and relationship variables are linked to intentions.

\subsubsection{Consequences of Service Quality}

It is obvious that service quality is not the ultimate objective of a service organization. It is through service quality and subsequently customer satisfaction that will result in organizational effectiveness and profitability. More recently, it has been proposed in services marketing to study a more intermediate construct than organizational effectiveness or 
profitability: service loyalty (Bitner 1990; Cronin \& Taylor 1992; Taylor \& Baker 1994; Woodside et al. 1989; Parasuraman et al. 1994a,c; Zeithaml et al. 1996).

Research into customer loyalty has focused primarily on product-related or brand loyalty, whereas loyalty to service organizations has remained underexposed (Gremler \& Brown 1996). Frequently, a high positive correlation between the constructs of satisfaction and product loyalty is reported. With regards to service loyalty, perceived service quality is often viewed as a key antecedent (Dick \& Basu 1994). However, there are a number of reasons why findings in the field of product loyalty cannot be generalized to service loyalty (Keaveney 1995; Gremler \& Brown 1996). Service loyalty is more dependent on the development of interpersonal relationships as opposed to loyalty with tangible products (Berry 1983), for person-to-person interactions form an essential element in the marketing of services (Bateson 1985; Czepiel \& Gilmore 1987; Surprenant \& Solomon 1987; Crosby et al. 1990; Czepiel 1990). Furthermore, the influence of perceived risk is greater in the case of services, as customer loyalty may act as a barrier to customer switching behavior (Zeithaml 1981; Klemperer 1987; Guiltinan 1989). Indeed, it has been demonstrated that loyalty is more prevalent among service customers than among customers of tangible products (Snyder 1986). In a services context, intangible attributes such as reliability and confidence may play a major role in building or maintaining loyalty (Dick \& Basu 1994).

As most research originated from the field of packaged consumer goods (Jacoby \& Chestnut 1978), a strong emphasis has been on behavioral measures. In a services context, loyalty is frequently defined as observed behavior (Liljander \& Strandvik 1995a,b). Ultimately it is actual behavior that drives a service organization's performance. However, behavioral measures, such as repeat purchasing and purchasing sequence, have been criticized for a lack of a conceptual basis and for having a narrow, i.e., outcome-focused view of what is in fact a dynamic process (Day 1969). For instance, a low degree of repeat purchasing of a particular service may very well be the result of situational factors such as non-availability, variety seeking and lack of provider preference. Therefore, the behavioral approach to loyalty may not yield a comprehensive insight into the underlying reasons for loyalty, instead it is a consumer's disposition in terms of preferences or intentions that plays an important role in determining loyalty (Jain et al. 1987; Bloemer \& Kasper 1995). Furthermore, repeat purchasing behavior may not even be based on a preferential disposition but on various bonds that act as switching barriers to consumers (Storbacka et al. 1994; Liljander \& Strandvik 1995a). During the past decades, therefore, customer loyalty has also been approached as an attitudinal construct (Biong 1993; Hallowell 1996). This is reflected, for instance, in the willingness to recommend a service provider to other consumers (Selnes 1993).

In addition to the behavioral and attitudinal approach to customer loyalty, it has been argued that there is also a cognitive side to customer loyalty (Lee \& Zeiss 1980). In this sense, customer loyalty is frequently operationalized as the product or service that first comes to mind when making a purchase decision (Newman \& Werbel 1973; Bellenger et al. 1976; Dwyer et al. 1987); the product or service that is a customer's first choice among alternatives (Ostrowski et al. 1993) or price tolerance (Anderson 1996; Fornell et al. 1996). Therefore, operationalization of service loyalty would have to consider behavioral, attitudinal and cognitive aspects in the development of a composite index. These elements are present in the behavioral intentions battery that was developed by Zeithaml et al. (1996) with regards to services loyalty.

Little empirical research has focused explicitly on the relationship between service quality perceptions and customer loyalty. With regards to behavioral intentions in a services setting, Zeithaml et al. (1996) proposed a comprehensive, multi-dimensional framework of customer behavioral intentions in services. This framework was initially comprised of the following four main dimensions: (1) word-of-mouth communications, (2) purchase intention, (3) price sensitivity and (4) complaining behavior.

On the basis of factor analysis on the 13-item scale, five dimensions were identified by 
Zeithaml et al. (1996):

(1) loyalty to company;

(2) propensity to switch;

(3) willingness to pay more;

(4) external response to problem and

(5) internal response to problem.

The instrument is included in Appendix MI. Conceptually, however, the five factor solution does not appear to provide an unambiguous and consistent factor pattern. In the first place, the so-called loyalty dimension is in essence comprised of both word-of-mouth as well as customer preference, represented by three scale items each. Furthermore, various expressions of customer complaining behavior or response to a dissatisfactory service encounter are distributed over two factors ("external response to problem" and "internal response to problem"). External response to a problem also contains an item that relates to customer disloyalty. Likewise, inter-dimensional overlap applies to pricing-related loyalty intentions, which are placed under two factors ("propensity to switch" and "willingness to pay more").

Empirically, a number of problems present themselves as well. The results of a reliability analysis reveal that particularly the two-item factors have coefficient $\alpha$ 's falling below 0.6 , possibly due to the limited number of items. Moreover, the correlations between (overall) service quality and the factor "internal response to problem" for the four service settings, turn out to be non-significant. Furthermore, it can be argued that customer preference and positive word-of-mouth or recommendation are two distinct dimensions of customer loyalty in services. Loyalty regardless of pricing or price tolerance can be viewed as a third dimension of customer loyalty in relation to customer perceived service quality. Also, the use of a single item measure ("external response to problem") should be avoided as suggested by Churchill (1979). Finally, a distinction can be made between a general evaluation of service quality and the evaluation of a specific negative service encounter (Bitner \& Hubbert 1994).

The relationship between overall service quality and individual service loyalty dimensions has also been examined empirically by Boulding et al. (1993) and Cronin \& Taylor (1992)! Cronin \& Taylor (1992) focused solely on repurchase intentions, whereas Boulding et al. (1993) focused on both repurchase intentions and willingness to recommend. In the study by Cronin \& Taylor (1992) service quality did not appear to have a significant (positive) effect on intentions to purchase again, while Boulding et al. (1993) found positive relationships between service quality and repurchase intentions and willingness to recommend. Loyalty under varying pricing conditions, i.e., willingness to pay a premium price and to remain loyal even when prices go up, has not received much attention in the service quality literature. Only Zeithaml et al. (1990) reported a positive relationship between service quality and the two aforementioned loyalty dimensions. Woodside et al. (1989) use customer satisfaction as a mediating construct between service quality and behavioral intentions. Special attention should be given to the study of Zeithaml et al. (1996). These authors offer a conceptual framework of the impact of service quality on particular behaviors that signal whether customers remain with or defect from a company. The results of a multi-company study show different relationships between (overall) service quality and service loyalty dimensions. For the four companies included in the study, service quality is positively related to (within the zone of tolerance ${ }^{2}$ ) loyalty and the willingness to pay more, while service quality is negatively related to switching behavior and the external response to a problem.

Finally, with regards to the response to a negative service experience, it has been suggested that the majority of customers simply remain inactive and do not undertake any action (Day 
1984). Furthermore, it has been argued that actually responding to dissatisfaction (e.g., by switching, complaining directly to the company or complaining to a third party) is negatively related to the level of perceived service quality (Singh, 1991; Kelley et al. 1993). In addition, personal (e.g., attribution (Folkes 1994) and situational variables determine to a large extent behavioral intentions in response to dissatisfaction.

The Conceptual Model of Service Quality focuses on a single service encounter or service episode (Boulding et al. 1993; Iacobucci et al. 1994; Strandvik \& Liljander 1995a; De Ruyter \& Wetzels 1997). More recently, the initiation and more in particular maintenance of existing relationship has received more attention. It could be very insightful to link up the service quality - customer satisfaction framework with the relationship framework. The next section will deal with measurement issues regarding the SERVQUAL-instrument accompanying the Conceptual Model of Service Quality.

\section{Conclusion}

In this section we raised several conceptual concerns. with respect to the SERVQUALinstrument. To begin with, the "gap" conceptualization of service quality in the Conceptual Model of Service is based on a relativistic comparison of perceptions versus, while absolute values of perceptions and expectations do not enter the equation. Furthermore, perceptions exceeding expectations at a similar magnitude and direction are assumed to lead to the same amount of service quality. Next, service quality has been defined as attitude by some authors to differentiate it from customer satisfaction. Consequently, a service quality has been operationalized as perceptions-only score in the SERVPERF-instrument (Cronin \& Taylor 1992). Iacobucci et al. (1994) propose that both service quality and satisfaction can be viewed as an attitude, but that the meaning of each construct should be limited conceptually. Thus reducing the question "Is service quality an attitude?" to a rhetorical one. Service quality is a multidimensional construct. However, the number and nature of the dimensions remain open to discussion. Recently, Rust and his colleagues (Kordupleski et al. 1993; Rust et al. 1995) have proposed a framework on the different stages in the business process of a service organization. Although both customer satisfaction and service value are related to service quality, they have been found conceptually different form service quality. The Conceptual Model of Service Quality and consequently SERVQUAL are static of nature. Several frameworks have been proposed to incorporate dynamics. The use of perceived dynamics links the static SERVQUAL-instrument to relationship quality and thus to the relationship paradigm (Bitner \& Hubbert 1994; Strandvik \& Liljander 1994). On a different plane of conceptualization service quality has been related to the more short-term concept of behavioral intentions. In general, a positive relationship has been established between service quality and behavioral intentions.

\subsection{Measurement Concerns pertaining to SERVQUAL}

In this section attention will be focused on measurement issues with regard to the SERVQUAL-instrument. More in particular, we will briefly discuss the dimensionality of the instrument, the use of importance weights, the use of a difference score and the empirical distribution of service quality.

\subsubsection{Dimensionality of the SERVQUAL-Instrument}

Both the conceptual and empirical foundations of the SERVQUAL-instrument were laid in the financial services sector (Parasuraman et al. 1985: retail banking, (2) credit card, (3) securities brokerage, (4) product repair and maintenance; Parasuraman et al. 1988: (1) bank, (2) credit card company, (3) repair and maintenance company, (4) long-distance telephone company; Parasuraman et al. 1991: (1) telephone company, (2) insurance company, (3) bank). 
On the basis of this "financial services" descent the claim to universality may already be slightly doubtful (Brown et al. 1993; Lapierre 1996). However Parasuraman et al. $(1988,19)$ contend that it was the purpose of SERVQUAL to:

"...produce a scale that would have general applicability."

In their initial study Parasuraman et al. (1988) report relatively high values of coefficient $\alpha$ for the individual dimensions of SERVQUAL. Moreover, using exploratory factor analysis to assess the convergent and discriminant validity they find that each item loads high only on the hypothesized factor for the four participating companies.

These favorable results, however, seemed not to replicate in their 1991 study (Parasuraman et al. 1991). Although the reliabilities in terms of coefficient $\alpha$ were still relatively high, their factor-analytic results seemed somewhat problematic. More in particular, the tangibles dimension loaded on two dimensions (one representing equipment and facilities and one representing personnel and communication materials); thus casting considerable doubt on the unidimensionality of this dimension. Furthermore, responsiveness and assurance (and to some degree reliability) loaded on the same factor, while in general interfactor correlations were somewhat higher than in their 1988 study. These divergent results might be caused by an artifact; restraining the factor solution to five factors. Therefore, Parasuraman et al. (1991) advanced that six-factor solution might lead to a more plausible result. Although, responsiveness and assurance seemed to be slightly more distinct, tangibles, however, still loaded on two factors, whereas the inter-factor correlations remained high.

Replication studies by other authors have even fared less well than the studies by the original authors. Carman (1990) carried out a study using an adapted version of SERVQUAL in four settings: (1) a dental school patient clinic, (2) a business school placement center, (3) a tire store and (4) an acute care hospital. Carman (1990) finds similar factors (although not an equal number) as compared to Parasuraman et al (1988, 1991), however the item-to-factor stability appears to be less than in the original studies. Carman (1990) also notes that the applicability in some of the settings requires quite substantial adaptations in terms of dimensions and items. Babakus \& Boller (1992) report on a study in which they applied the original SERVQUAL to a gas utility company. Using both exploratory and confirmatory (first-order and second-order) factor analysis Babakus \& Boller (1992) were unable to replicate the hypothesized five dimensional structure of the original SERVQUAL-instrument. Finally, Cronin \& Taylor $(1992,1994)$ used confirmatory factor analysis and found that a five factor structure did not provide an adequate fit to the data. Subsequently, they carried out exploratory factor analysis and a unidimensional factor structure was confirmed.

Authors using a more meta-analytic approach have reports similar results (Asubonteng et al. 1996; Buttle 1996; Parasuraman et al. 1991; Paulin \& Perrien 1996). In general, they report relatively high reliabilities in terms of coefficient $\alpha$ for the individual dimensions. However, results differ considerably when looking at different service quality dimensions. Paulin \& Perrien (1996) find that for the studies included in their overview that coefficient $\alpha$ varies from 0.50 to 0.87 for the empathy dimension and from 0.52 to 0.82 for the tangibles dimension. However, the number of factors extracted and factor loading patterns are inconsistent across studies. Furthermore, inter-factor correlations among the responsiveness, assurance and reliability dimensions are quite high (Buttle 1996; Parasuraman et al. 1991; Spreng \& Singh 1993). Finally, Paulin \& Perrien (1996) suggest that the limited replicability of the SERVQUAL instrument may be causes by contextuality (cf. Cronbach 1986). They find that studies applying SERVQUAL differ in terms of units of study, the study observations and the type of study.

The opportunities for generalizability of the SERVQUAL-instrument seem to be limited. Carman (1990) suggests that the number of dimensions of service quality for industries may 
be related to the importance of the dimensions and the number of stages in the business process. More important factors tend to break up into several factors. For example, Carman (1990) suggests that in retail setting tangibles are especially important and therefore the dimension might break up into two or more subdimensions. Parasuraman et al. (1991) observe a similar phenomenon. As we have already seen also the number of stages affects the dimensionality, as the stages of the business process emerge as factors. This is due to the "financial services" descent of the SERVQUAL-instrument. In financial services the number of service encounters or stages is often limited to one.

A different approach to generalizability of service quality over different industries might be the application of second-order factor analysis (Babakus \& Boller 1992). Assuming that service quality is a second order factor provides the opportunity to differentiate first-order factor per industry. Dabholkar et al. (1996) formulate such a model for a retail setting using (1) physical aspects, (2) reliability, (3) personal interaction, (4) problem solving and (5) policy as first-order factors loading on the second-order factor, (retail) service quality. This model is confirmed by the data and provides a good fit using second-order confirmatory factor analysis.

\subsubsection{Use of Importance Weights}

Both SERVQUAL (see equation 2.1) and SERVPERF (see equation 2.2) incorporate importance weights $\left(\mathrm{W}_{\mathbf{j}}\right)$. Empirical research, however, has found that the inclusion of an importance weight may only introduce redundancy (Churchill \& Surprenant 1982; Cronin \& Taylor 1992; Teas 1993; Woodruff et al. 1983). Therefore, the use of importance weights is not recommended; it increases questionnaire length and does not add explanatory power. Especially, given the difficulties associated with deriving importance weights, as outlined above.

\subsubsection{Use of Difference Scores}

From equation (2.1) it can be observed that perceived service quality is defined as a relative evaluation $\left(\mathrm{P}_{\mathrm{ij}}-\mathrm{E}_{\mathrm{ij}}\right)$. Such an approach is not conceptually unsound per se, as it has a firm theoretical foundation in adaptation level theory (Helson 1959) and comparison level theory (Thibaut \& Kelley 1959). The problem is rooted in the operationalization of SEVQUAL quality score as a difference score. More formally, difference scores can be defined as (Peter et al. 1993,655$)$ :

\section{"...the subtraction of one measure from another to create a measure of a distinct construct."}

Various authors have pointed out the psychometric problems involved in the use of difference or deficiency scores (Babakus \& Boller 1992; Brown et al. 1993; Carman 1990; Johns 1981; Lord 1963; Parasuraman et al. 1993; Peter et al. 1993; Prakash 1984; Prakash \& Lounsbury 1984; Wall \& Payne 1973; Werts \& Linn 1970). Peter cum suis (Brown et al. 1993; Peter et al. 1993) in a recent treatise of the subject identify four potential problems:

(1) Difference scores per se are less reliable than their component scores. This follows directly form the formula for calculating the reliability coefficient for difference scores $\left(r_{D}\right)$ presented by Peter et al. $(1993,655)$ : 
$\mathbf{r}_{\mathrm{D}}=\frac{\sigma_{1}^{2} \mathbf{r}_{11}+\sigma_{2}^{2} \mathrm{r}_{22}-2 \mathrm{r}_{12} \sigma_{1} \sigma_{2}}{\sigma_{1}^{2}+\sigma_{2}^{2}-2 \mathbf{r}_{12} \sigma_{1} \sigma_{2}}$

$r_{11}$ : reliability coefficient of the first component score

$r_{22}$ : reliability coefficient of the second component score

$r_{12}$ : the correlation between the component scores

$\sigma_{1}^{2}$ : variance of the first component score

$\sigma_{2}^{2}$ : variance of the second component score

From equation (2.4) it can be inferred that the reliability coefficient for difference scores decreases, if the reliability coefficient of the component scores decreases and/or the correlation between the component scores increases. Prakash (1984) for instance reports that three measures of disconfirmation showed low to mediocre reliabilities $(0.19$ to 0.48 ) in terms of the reliability coefficient exhibited in equation (2.4). These results are corroborated in a follow-up study by Prakash \& Lounsbury (1984). They report a median reliability of 0.48 .

(2) As reliability places an upper bound on validity, this will undoubtedly lead to validity problems (Bagozzi 1994; Nunnally \& Bernstein 1994). Peter et al. (1993) indicate that low reliability might lead to attenuation of correlation between measures. Consequently, the lack of correlations between measures might be mistaken as evidence of discriminant validity. Prakash (1984) and Prakash \& Lounsbury (1984) report low correlations between three confirmation measures and a global satisfaction measure (ranging from 0.08 to 0.50 ) and intention to repurchase (ranging from 0.05 to 0.32 ). A second problem with validity is related to the correlation between the component scores. If the component scores are highly correlated, which is not altogether uncommon (Johns 1981; Wall \& Payne 1973), the difference score cannot be distinguished from its components. As a result, difference scores are not able to demonstrate construct validity (Peter et al. 1993).

(3) Difference scores are closely related to their component scores. Any correlation between the difference score and another variable may be spurious (Wall \& Payne 1973). Partial correlations or part correlations may be needed to uncover the true relationship (Cohen \& Cohen 1983; Wall \& Payne 1973). The high correlations are especially problematic when both the component scores and the difference score are used in correlational techniques, such as regression analysis (Darlington 1990; Neter et al. 1990; Ofir \& Khuri 1986; Pedhazur \& Pedhazur Schmelkin 1991) or structural equation modeling (Bollen 1989).

(4) The fourth problem that can be distinguished is the possibility of restricting the variance of the difference score. For example, in the case of service quality $\left(P_{i j}-E_{i j}\right)$ it can be assumed that expectations often equal or exceed perceptions. As a result, the possible variance of difference scores will be more restricted at higher levels of perceptions than at lower levels of perceptions. Brown et al. (1993, 131-132) provide the following example the clarify the variance restriction in this instance:

\footnotetext{
"Respondents who perceive service to be poor (and circle a 1 in response to the perceptions item) have a potential range on the difference score of 0 (if their expected level is I) to -6 (if their expected level is 7). Respondents who perceive service to be good (and circle a 6 in response to perceptions item) have a much constrained potential range on the SERVQUAL score for that pair of items $(0$ to 1)."
}

Peter et al.(1993) point out that this violates the assumption of homogeneity of variances in ordinary least squares regression and related statistical techniques. 
Additionally, Carman (1990) contends that the measurement properties of difference scores are not appropriate for (exploratory) factor analysis. As exploratory factor analysis is used to assess the convergent and discriminant validity in the majority of the studies, the results need to be interpreted very carefully when dealing with the original SERVQUAL-instrument, i.e. the difference score. Therefore, Peter et al. (1993) propose two alternatives to the use of difference scores:

(1) Operationalize the difference score using a comprehensive scale, which allows for a direct comparison between the components or

(2) Reformulating the research question, so that the difference score operationalization can be avoided.

Both approaches have been explored in service quality research. Cronin \& Taylor (1992) concluded that on the basis of a conceptual and empirical ground the expectations component and the importance weight might be redundant in defining service quality. Their approach has led to the development of SERVPERF, a measure of service quality solely based on the perceptions component.

Brown et al. (1993) have proposed a non-difference score which allows for a direct comparison between perceptions and expectations, as alternative to traditional SERVQUAL measure. This approach has been advocated in several studies concerned with customer satisfaction (Cadotte et al. 1987; Carman et al. 1990; Churchill \& Surprenant 1982; Oliver 1980; Prakash 1984; Prakash \& Lounsbury 1984; Tse \& Wilson 1988). The non-difference score was operationalized by Brown et al. (1993) in the following way. Each SERVQUAL items was rephrased to reflect a "How" statement (e.g. "How courteous are the service employees of XYZ?). They used a 7-point scale ranging from "Much worse than I expected" (1) to "Much better than I expected" (7); the SERVQUAL-instrument uses a 7-point Likert scale for the both the perceptions and the expectations component. Peter et al. $(1993,661)$ emphasize that:

"In fact, until we have greater knowledge of cognitive algebra that supports the idea that customers use arithmetic differences in forming their thoughts, the direct comparison approach has the advantage of allowing consumers to combine their thoughts as they wish rather than have them in an arbitrary rule forced on them."

In their study they have empirically investigated the effects of four problems associated with difference scores for the SERVQUAL-instrument.

Their findings indicated that the four problems outlined above manifested itself with regard to the SERVQUAL measure. They found that a non-difference score for service quality outperformed the traditional SERVQUAL measure, a difference score, on a number of psychometric criteria. The SERVQUAL measure (0.94) and its components (Perceptions=0.96; Expectation=0.94) exhibited high reliability and only a moderate intercorrelation (0.34). However the non-difference score showed even higher reliability (0.96). This would indicate that reliability might not pose a serious problem in the case of SERVQUAL. Subsequently, the degree of attenuation of correlation might be limited. In fact both measures showed discriminant validity with regard to customer discontent (Lundstrom \& Lamont 1976). However, in their previous studies Parasuraman and his colleagues (Parasuraman et al. 1988, 1991) have not reported the reliabilities of the difference scores, but calculated coefficient alpha on the difference scores. They also failed to report the reliabilities of the perceptions and expectations components and their correlation.

Furthermore, SERVQUAL failed to demonstrate discriminant validity. More in particular, it showed high correlation with the perceptions component (0.79) and a moderate correlation with the expectations components (-0.31). Parasuraman et al. (1993) suggest that may be due 
to common method variance. However, in that same paper they argue that the questionnaire length can be substantially reduced by placing the perceptions and expectations component in two adjacent columns. This alternative, however, might even lead to more severe degree of common method variance.

In addition, they report that the perceptions component showed a stronger relationship with behavioral intentions than the SERVQUAL score $(0.31$ vs. 0.26$)$; this is in line with the findings of a study by Cronin \& Taylor (1992). The non-difference score showed a somewhat higher correlation with behavioral intentions $(0.32)$. Including both the perceptions component and the expectations component, the part correlation between SERVQUAL and behavioral intentions equals 0 (Cohen \& Cohen 1983). This raises the questions whether the difference between perceptions and expectations actually has incremental explanatory value. Apart from the behavioral intentions, the non-difference score also outperformed the SERVQUAL score on predicting the first choice. Both scores produced similar results with regard to recommendations. In general, Brown et al. (1993) conclude that the non-difference score shows a higher degree of nomological validity (cf. Bagozzi 1994).

Brown et al. (1993) also found evidence for the occurrence of variance restriction. They reported that the SERVQUAL scores have smaller variance when the scores are higher than when the scores are low. The non-difference score, on the other hand did not show a restriction of the variance; the variance of the non-difference score was about equal at all levels of the perceptions measure. Parasuraman et al. (1993) emphasize that in most studies up to date the SERVQUAL measure as used as an independent variable and not as an dependent variable measure. However, with further progress in this field the use of service quality as a dependent or endogenous variable will not be far away. Therefore, homogeneity of variance might very well become a serious threat to the use of SERVQUAL.

Additionally, it should be noted that the non-differences score is easier to administer than the traditional SERVQUAL-instrument, be it the original or the modified version, as it only requires half of the items. Parasuraman et al. (1993) suggest that omitting the expectations component in favor for a direct comparison might lead to a reduced diagnostic value; a decrease in service quality may be attributed to a increase of perceptions or a decrease of expectation (ceteris paribus). Moreover, not including expectation explicitly in the measurement instrument will not allow for assessing the impact of expectations on related constructs (cf. Iacobucci et al. 1996). Finally, it should be recommended that difference scores should generally only be used with caution. Peter et al. $(1993,662)$ arrive at an even stronger recommendation:

"In sum, we recommend that difference scores should generally not be used in consumer research, particularly where other methods of measurement can be applied."

\subsubsection{The Distribution of Service Quality}

Service quality shares one important characteristic with customer satisfaction: its distribution Evidence indicates that the majority of the respondents locate their service quality score at the right-hand side of the scale (Brown et al. 1993; Parasuraman et al. 1988; 1991, 1994b; Peterson \& Wilson 1992). This distribution is referred to as negatively skewed (Neter et al. 1988; Tabachnik \& Fidell 1996). According to Peterson \& Wilson $(1992,62)$ this phenomenon is not restricted to customer satisfaction:

"Self-reported measures of "consumer" satisfaction - whether they are domain-specific measures of job satisfaction, marital satisfaction, satisfaction with health, medical, or educational services, or general measures of life satisfaction or subjective well-being - are uniformly negatively skewed with the majority of the survey participants reporting satisfaction." 
Brown et al. (1993) find that SERVQUAL scores are both negatively skewed (skewness=1.19 ) and leptokurtic (kurtosis=1.87), i.e. this distribution is more skewed to the right and more peaked than a normal distribution.

A skewed distribution contains several serious implications for statistical analysis. To begin with, the mean might not be a suitable measure of central tendency. In a negatively skewed distribution the mean is typically to the left of the median and the mode and thus excludes considerable information about the variable under study (Neter et al. 1988; Peterson \& Wilson 1992). Skewness also attenuates the correlation between variables. Consequently, the true relationship between variables in terms of a correlation coefficient may be understated (Peterson \& Wilson 1992). Finally, parametric tests (e.g., t-test, F-test) assume that the population is normally or at least symmetrically distributed (Neter et al. 1988, 1990).

Peterson \& Wilson (1992) provide four explanations for this observed distribution of satisfaction measures. Firstly, the observed distribution actually reflects the satisfaction with the products. Secondly, the shape of the distribution is caused by its antecedents, such as expectations, performance and disconfirmation (Cadotte et al. 1987; Oliver 1980; Oliver 1993a, 1997). Furthermore, customer satisfaction might possess a distribution different from the (normal) distribution of other constructs. Finally, the distribution of customer satisfaction may be caused by research artifacts.

An alternative for measuring service quality, which is less skewed, is the non-difference score for service quality. Brown et al. (1993) report that the non-difference score for service quality is approximately normally distributed. Both skewness $(0.39)$ and kurtosis $(0.29)$ are only slightly positive. Moreover, several authors have brought forward that the number of scale points might have considerably contributed to the skewness of satisfaction measures (Andrews \& Withey 1976; Peterson \& Wilson 1992; Westbrook 1980). Increasing the number of scale points may increase the sensitivity of the scale and consequently reduce skewness.

\section{Conclusion}

This section of chapter 2 concentrated on measurement concerns regarding SERVQUAL. To begin with, replications of SERVQUAL led to mixed results with regard to the dimensionality of SERVQUAL. Several authors have reported relatively large overlap between the dimensions. Furthermore, the importance and number of stages in a service setting might affect the number of dimensions. A different approach to generalizability is to assume that service quality constitutes a second-order construct, which can be operationalized in various service settings by using different first-order factors. The use of importance weights in both SERVQUAL and SERVPERF has not led to improved empirical results. Moreover, the use of difference scores is generally not recommended. Therefore, a non-difference score operationalization of service quality is generally preferred. The distribution of SERVQUAL is negatively skewed. Employing a non-difference score and increasing the number of scale points may considerably alleviate this problem.

\subsection{Conclusion}

Garvin (1984b) distinguishes five major approaches to define quality: (1) the transcendent approach, (2) the product-based approach, (3) the user-based approach, (4) the manufacturingbased approach and the value-based approach. A sixth approach identified by Reeves \& Bednar (1994) is defining quality as meeting and/or exceeding customers' expectations. This approach was initially conceived in the services marketing literature and takes the user-based approach ad extremis. Relying on one definition may hinder the introduction of high-quality products. Therefore, a temporal synthesis of user-based approach, the product-based approach and the manufacturing-based approach may be warranted. Such a synthesis is laid down in the Conceptual Model of Service Quality. In essence, this model posits that perceived service 
quality (or GAP5 in terms of the model) is conceptualized as the comparison between perceptions and expectations. The magnitude and direction of perceived service quality, on its turn, is influenced by four internal or organizational gaps.

On the basis of the Conceptual Model of service Quality a measure instrument, SERVQUAL, was developed by Parasuraman et al. (1988). The instrument consists of two components: (1) perceptions and (2) expectations. The instrument has been modified by the original authors in 1991 (Parasuraman et al. 1991). This modification was concerned with expectations component. Expectations were changed from ideal ("should") expectations to predictive ("would") expectations. Moreover, an importance weight using a constant sum scale on attribute level was added to the original instrument. However, the use of importance weights may be problematic, as the most popular methods, rating and point allocation may not lead to consistent results. Multidimensional scaling and conjoint analysis have been proposed as more valid techniques for obtaining importance weights.

Several conceptual concerns with respect to the SERVQUAL-instrument can be raised. To begin with, the "gap" conceptualization of service quality in the Conceptual Model of Service is based on a relativistic comparison of perceptions versus, while absolute values of perceptions and expectations do not enter the equation. Furthermore, perceptions exceeding expectations at a similar magnitude and direction are assumed to lead to the same amount of service quality. Service quality has been defined as an attitude by some authors to differentiate it from customer satisfaction. Consequently, service quality has been operationalized as perceptions-only score in the SERVPERF-instrument (Cronin \& Taylor 1992). Iacobucci et al. (1994) propose that both service quality and satisfaction can be viewed as an attitude, but that the meaning of each construct should be limited conceptually. Service quality is generally considered to be a multidimensional construct. However, the number and nature of the dimensions remain open to discussion. Recently, Rust and his colleagues (Rust et al. 1993, 1995) have proposed a framework on the different stages in the business process of a service organization. Although both customer satisfaction and service value are related to service quality, they can have been found conceptually different form service quality. The Conceptual Model of service Quality and consequently SERVQUAL are static of nature. Several frameworks have been proposed to incorporate dynamics. The use of perceived dynamics links the static SERVQUAL-instrument to relationship quality and thus to the relationship paradigm (Bitner \& Hubbert 1994; Strandvik \& Liljander 1994). On a different plane of conceptualization service quality has been related to the more short-term concept of behavioral intentions. In general, a positive relationship has been established between service quality and behavioral intentions.

Finally, several measurement concerns regarding SERVQUAL have been addressed. To begin with, replications of SERVQUAL led to mixed results with regard to the dimensionality of SERVQUAL. Several authors have reported relatively large overlap between the dimensions. The importance and number of stages in a service setting might affect the number of dimensions. A different approach to generalizability is to assume that service quality constitutes a second-order construct, which can be operationalized in various service settings by using different first-order factors. The use of importance weights in both SERVQUAL and SERVPERF has not led to improved empirical results. Furthermore, the use of difference scores is generally not recommended. Therefore, a non-difference score operationalization of service quality is generally preferred. The distribution of SERVQUAL is negatively skewed. Employing a non-difference score and increasing the number of scale points may considerably alleviate this problem. 


\section{Chapter 3 \\ Organizational Antecedents to Service Quality}

\section{Outline of the Chapter}

3.1 Introduction

3.2 The Extended Model of Service Quality

3.2.1 Research Design

3.2.2 Model Specification

3.2.3 Measurement Properties

3.3 Testing the Extended Model of Service Quality: A Pre-Study

3.3.1 Research Setting

3.3.2 Sampling Procedure

3.3.3 Measurement Instruments

3.3.4 Results

3.3.5 Discussion

3.4 The Need for an Alternative Model

3.5 Role Stress

3.5.I Role Theory

3.5.2 Defining Role Conflict and Role Ambiguity

3.5.3 The Dynamics of Role Ambiguity and Role Conflict

3.6 Antecedents to Role Stress

3.6.1 Formalization

3.6.2 Empowerment

3.6.3 Leadership Behavior

3.6.4 Group Cohesiveness

3.7 Outcomes of Role Stress

3.7.1 Job Satisfaction

3.7.2 Job Performance

3.8 Conceptual Framework

3.9 Conclusion 


\section{Organizational Antecedents to Service Quality}

\subsection{Introduction}

The service sector has been growing at an high rate during the past four decades. Two disciplines are of the utmost importance for service organizations: (1) marketing and (2) organizational theory (Bowen 1990; Bowen \& Schneider 1988; Mindak \& Folger 1990). However, the growing importance of the service sector has barely led to any attention by organizational theorists; they are still primarily concerned with manufacturing organizations (Bowen \& Scheider 1988; Mills 1986, Schneider 1980). Marketing, on the other hand, has shown a more enthusiastic stance towards the service sector (Rathmell 1966; Regan 1963; Shostack 1977a, b). The 1970s witnessed the dawn of a new stream of research in marketing: services marketing. Since then a considerable body of literature on the marketing of services has been accumulated in this field (Swartz et al. 1992).

Although services have become the single most important economic activity in most advanced, western economies, customers have been become increasingly frustrated with service organizations (Koepp 1987). At the core of their dissatisfaction the service encounter can be found (Bateson 1985; Bitner 1990; Czepiel et al.1985; Shostack 1985). Several authors have acknowledged that the role of customer-contact personal is pivotal to rendering high quality services (Boles \& Babin 1996; Hartline \& Ferrell 1993, 1996; Parasuraman et al. 1985; Zeithaml et al. 1988; Schneider 1980). This is clearly reflected in the SERVQUALinstrument for evaluating perceived service quality (See Chapter 2). Recently, Mohr \& Bitner (1995a,b) reported that employee effort in the service process is generally viewed positively by the customer. As a result of the importance of the service encounter, a lot of "back-stage" employees are dependent on the success of the customer-contact personnel (the "frontstage"). "Therefore, the "back-stage" will attempt to influence "front-stage", the customercontact personnel.

This notion is clearly reflected in the Extended Model of Service Quality. This model links organizational antecedents to the four internal gaps of the Conceptual Model of Service Quality and ultimately to perceived service quality, GAP5. The majority of the antecedents in the Extended Model of Service Quality reflects communication and control processes. In this chapter we will address three main concerns voiced with respect to the Extended model of Service Quality: (1) the research design, (2) the model specification and (3) measurement properties.

Empirical research shows only limited support for the model (Parasuraman et al. 1990; Smidts 1993). This is mainly due to the lack of reliability of the scales developed for the antecedents. Furthermore, the relationship between the organizational gaps and perceived service quality could not confirmed. In this chapter of the thesis the results of an empirical pre-study testing the Extended Model of Service Quality will be presented. The pre-study was conducted with the after-sales service department of a manufacturer of office equipment in the Netherlands. The results of our pre-study find only limited support for the Extended Model of Service Quality. In essence, its findings corroborate the results of previous studies regarding this framework.

This clearly indicates the need for an alternative model. Service employees share three crucial characteristics with salespersons. First, both service employees and salespersons fulfill a "boundary-spanning" role. They constitute the link between the organization and the customer and other external agents. Secondly, they are essential to the success of the (service) organization. Some authors claim that the interaction between service employee and the customer is the core of what a service actually consists of. Thirdly, the service employee is 
often called upon to find innovative solutions to customers' problems. As a result, the customer-contact service employee is extremely susceptible to role stress.

Role stress features prominently both within the field of organizational behavior (Fisher \& Gitelson 1983; House \& Rizzo 1972; Jackson \& Schuler 1985; Kahn et al. 1964; Katz \& Kahn 1978; Rizzo, House \& Lirtzman 1970; Van Sell et al. 1981) and the field of marketing (Behrman \& Perreault 1984; Donnelly \& Ivancevich, 1975; Dubinsky \& Mattson 1979; Ford et al. 1975; Fry et al. 1986; Micheals et al. 1987; Micheals \& Dixon 1994; Oliver \& Brief 1977-1978; Walker et al. 1975; Teas, 1980, 1983). Role stress has been shown to have negative consequences for a number of outcomes, such as job satisfaction and job performance and organizational commitment (Bedeian \& Armenakis 1981; Behrman \& Perreault 1984; Fisher \& Gitelson 1983; Goolsby 1992; House \& Rizzo 1972; Jackson \& Schuler 1985; Johnston et al. 1990; Micheals et al. 1987; Rizzo et al. 1970; Sager 1994; Van Sell et al. 1981).

Role stress can be approached from two ways in a service organization. Levitt $(1972,1976)$ proposes that the "industrialization" of the service organization might lead to more efficient service operations. This would suggest that the use of increased formalization in terms of written rules, procedures and policies. More recently, several authors have proposed that empowerment might show beneficial effects to service organization (Bowen \& Lawler 1992, 1995a,b, Hartline \& Ferrell 1996; Schlesinger \& Heskett 1991). We will include both approaches in our conceptual model and test their effect in the empirical study reported in Chapter 5. These two constructs represent individual variables, the service employee is also affected by his supervisor or manager and his co-workers or colleagues. Therefore both leadership behavior and group cohesiveness were included in our conceptual model as well.

This chapter will be structured as follows. In section 3.2 attention will be focused on the Extended Model of Service Quality. Section 3.3 will be concerned with testing the Extended Model of Service Quality in a pre-study. .In section 3.4 the arising need for an alternative model to the Extended Model of Service Quality will be discussed. Section 3.5 will focus on role stress as focal constructs of this part of the study. Moreover, the conceptual model for the part of the study will be presented. In section 3.6 we will be concerned with the antecedents to role stress and section 3.7 we will be concerned with the outcomes of role stress. Section 3.8 summarizes our conceptual framework. Finally, section 3.9 concludes this chapter of the thesis.

\subsection{The Extended Model of Service Quality}

In this section of Chapter 3 attention will be focused on the Extended Model of Service Quality. This model links the Conceptual Model of Service Quality with organizational antecedents. Thus acknowledging the effect of organizational factors on the dyadic interaction between customer-contact service employee and customer. In the Conceptual Model of Service Quality perceived service quality (GAP5) is determined by four internal or organizational gaps (GAP1 to GAP4). These internal gaps are on their turn determined by sets of organizational factors, or antecedents (Parasuraman et al. 1990; Zeithaml et al. 1988). The majority of these antecedents is concerned with communication and control processes used to manage customercontact service employees and the consequence of these processes. Zeithaml et al. (1988) refer to this model as the Extended Model of Service Quality. The Extended Model of Service Quality is depicted in Figure 3-1. 


\section{Figure 3-1: The Extended Model of Service Quality}

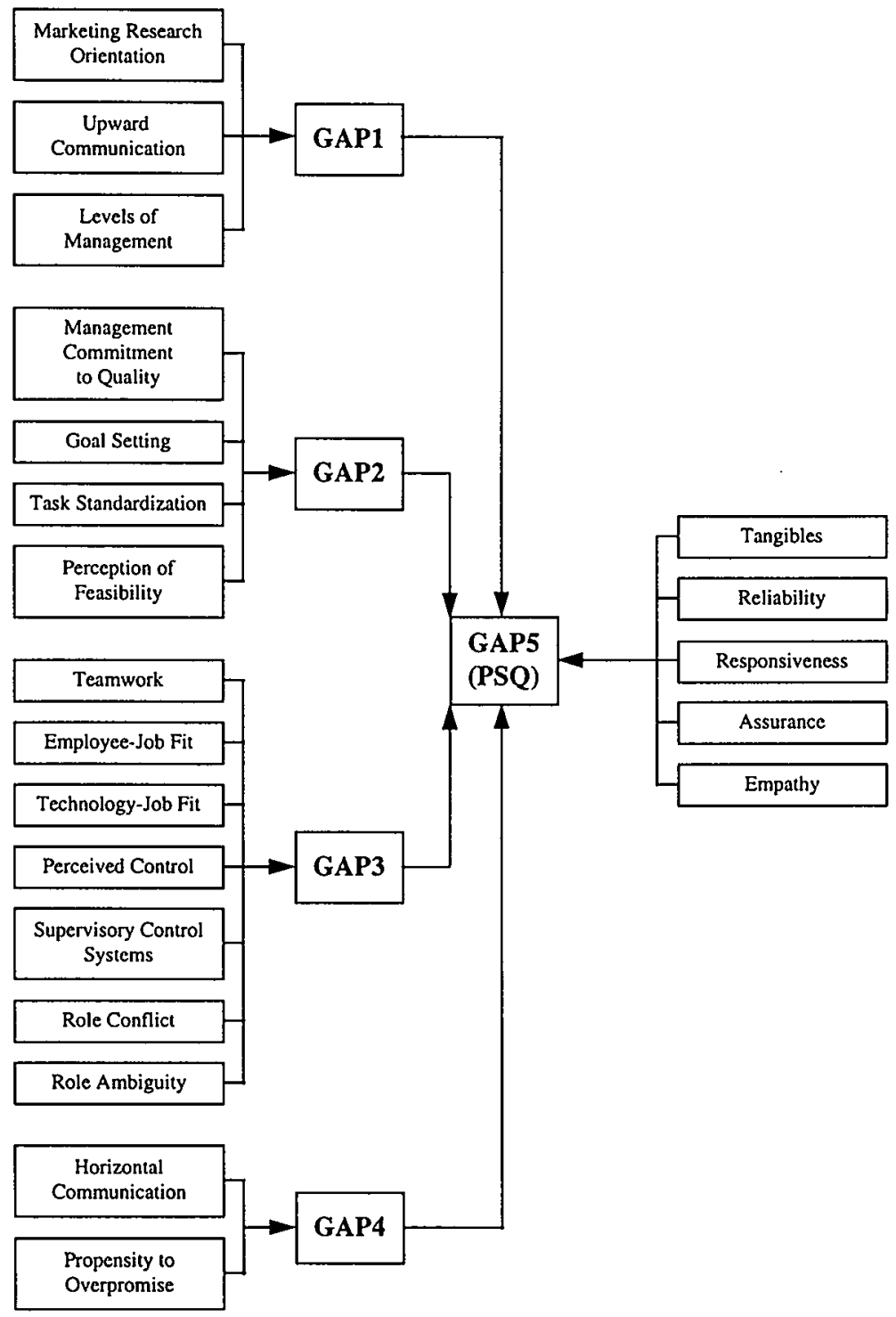

Source: Zeithaml et al. $(1988,46)$

Most of the research in the field of service quality concentrates on the measurement of perceived service quality (GAP5) using the SERVQUAL-instrument (cf. Cronin \& Taylor 1992). Nevertheless, Parasuraman et al. (1990) developed measurement instruments for both the internal gaps and their antecedents. However, only a limited number of studies were carried out with respect to the Extended Model of Service Quality (Kunst \& Lemmink 1993; Parasuraman et al. 1990; Smidts 1993). Both the relationships between the antecedents and the internal gaps (GAP1-GAP4), and the relationship between the internal gaps (GAP1GAP4) and perceived service quality (GAP5) are rather weak. In an empirical study, Parasuraman et al. (1990) were not able to find a significant relationship between the internal gaps and perceived service quality (GAP5). Furthermore, only a limited number of 
antecedents showed to affect their gaps. The review of the Extended Model of Service Quality will focus on the following three issues: (1) the research design; (2) the model specification and the (3) measurement properties.

\subsubsection{Research Design}

To begin with, the nature of the Extended Model of Service Quality requires a relatively complex research design (Parasuraman et al. 1990). The research design demands data to be gathered from several different actors, viz.: (1) customers; (2) customer-contact service employees and (3) service managers. For instance, in order to measure GAP5 (Perceived Service Quality) data has to be collected on customer expectations and perceptions (The SERVQUALinstrument). Next, GAPI requires data from customers, employees and managers (The expectations part of the SERVQUAL-instrument). Finally, the remaining internal gaps (GAP2GAP4) and the antecedents of the internal gaps require data from both managers and employees.

Moreover, the design calls for two different levels of analysis: (1) individual respondents and (2) organizational entities. Assuming that the organizational entities are sub-units and part of a higher-order organization we will even be confronted with a third level of analysis, the organization itself. For example, GAP5 can be measured at the level of individual customers, whereas GAPl has to be aggregated at the level of organizational entities. Furthermore, to examine the relationship between GAP5 (Perceived Service Quality) and the internal gaps (GAP1-GAP4) data needs to be aggregated at the level of organizational entities. Consequently, Parasuraman et al. (1990) had to collapse their sample consisting of 1936 customers, 728 employees and 231 managers into 89 organizational entities, which were used as a unit of analysis. This clearly constitutes a potential bias (Rousseau 1978, 1985). Finally, this entails that the effect of the internal gaps on perceived service quality (GAP5) cannot be tested on the level of one particular organizational (sub)unit, since sample size $(n=1$ !) will not be large enough to carry out the multivariate statistical analyses needed to test these relationships. It should be noted that this might be remedied by linking GAP5 to the internal gaps (GAP1-GAP4) on the level of the individual service provider.

\subsubsection{Model Specification}

The Extended Model of Service Quality differs from the Conceptual Model of Service Quality in that the Extended Model of Service Quality includes antecedents of the internal gaps (GAP1GAP4). To begin with, it should be noted that the model "only" is of diagnostic value (Kunst \& Lemmink 1993). The model as such offers no clear path along which systematic improvements in the organization can be carried out (Lemmink \& Behara 1992).

Furthermore, the underlying assumptions of the internal gaps can be questioned. The Conceptual Service Quality Model essentially assumes a formal, hierarchical, top-down management philosophy with limited employee participation in decision-making. Pivotal to the model is the role of (top) management. Management assesses customer expectations and translates them into service quality specifications. Next, management should provide the means to attain these service quality specifications in order to assure high perceived service quality. This closely resembles a formalized, mechanistic, bureaucratic organization (Burns \& Stalker 1961; March \& Simon 1958). Bureaucracies have been criticized for leading to rigid behavior by organizational members and resistance to change (Bennis 1966; March \& Simon 1958). This rigid behavior might in turn cause difficulties in dealing with customers (March \& Simon 1958; Merton 1940). The interaction with customers is dominated by general policies, procedures and rules, instead of dealing with customers as individuals. This can have severe adverse consequences for services industries in which customers expect that services are tailored to their individual needs, such as most professional services (Lovelock 1983). Finally, Merton (1957) indicates that in bureaucratic organizations, rules can become ends in themselves; this is referred to as goal displacement.

Nonetheless, Burns \& Stalker (1961) indicate that a bureaucracy might be the most effective in a stable environment. Ruekert et al. (1985) elaborated on that suggesting that tasks are more 
amenable to formalization when (1) a task is of a short duration; (2) the task is repetitive; (3) performance outcomes can be easily and accurately assessed and (4) the task environment is stable and not complex. Clearly, these requirements do not hold for the majority of service settings (Bateson 1992; Grönroos 1990a; Normann 1991). Finally, it should be noted that it is not clear which type of quality specification is intended: (1) standardization of work processes; (2) standardization of outputs or (3) standardization of skills and knowledge (Mintzberg 1983).

In the case of the Extended Model of Service Quality one might question the causal relationship between the internal gaps and the antecedents. In other words, on which criteria can the internal gaps be distinguished from their antecedents? For instance, GAP2, essentially, can be represented by the degree of standardization and formalization (e.g., Aiken \& Hage 1966; Kahn et al. 1964; Oldham \& Hackman 1981), which in turn is in fact an antecedent. Furthermore, the causal direction between the internal gaps and the antecedents might be challenged. For example, assuming that GAP2 can be (partly) represented by formalization, it is generally hypothesized that formalization influences role conflict and role ambiguity (Michaels et al. 1987; Organ \& Green 1981).

Moreover, it is assumed in the Extended Model of Service Quality that the antecedents are not interrelated. Empirical research, on the other hand, indicates for example that role conflict and role ambiguity are affected by levels of management (Jackson \& Schuler 1985; Kahn et al. 1964) and teamwork (Michaels \& Dixon 1994). Moreover, several researchers have found that role conflict and role ambiguity play a vital role in boundary spanning positions, such as service employees (Fisher \& Gitelson 1983; Kahn et al. 1964). Thus, role stress as operationalized in role ambiguity and role conflict might be modeled to reflect a more prominent role.

Kunst \& Lemmink (1993) indicate that the antecedents for the internal gaps are ad hoc as well as structural of nature. For instance, reducing the number of management levels is fundamentally different from improving communication between boundary spanning personnel and management. Also, the responsibilities for these actions might be divided among different departments (Kunst \& Lemmink 1993). For example, employee-job fit is a task for the personnel department, while management commitment to quality falls within the domain of top management.

The antecedents in the extended service quality model are presented as a coordinative row of factors. With respect to the control system and the service production system it is clear that there is an interrelationship between the two. Furthermore, it is clear that not always a top down approach is used in improving service quality. A much more interrelated and bottom-up process has to be proposed in order to deal with the dynamics of the quality improvement process. Recent developments of methods of Total Quality Management could be used to guide the service quality improvement process. One of these processes, Service Quality Deployment (SQD), has been developed by Lemmink \& Behara (1992) and Behara \& Chase (1993) based on Quality Function Deployment or QFD (Griffin \& Hauser 1993). SQD is a design process, which translates customer's expectations of service quality into appropriate service requirements. The responsibility for the tasks that comprise a quality service is then assigned to different teams and functional groups throughout the organization. The fundamental issue common to both SQD and the extend service quality model is that the "voice of the customer" (Griffin \& Hauser 1993) must be "heard" and translated into action that is deployed throughout the organization in order to improve service quality. In that way SQD operationalizes the process of narrowing or closing of the organizational gaps, thus increasing perceived service quality.

Relevant antecedents might be omitted from the model. For instance, Parasuraman et al. (1990) suggest that customer behavior might be a likely candidate for inclusion in the model. Furthermore, an extensive review of the relevant marketing and organizational behavior literature might identify additional antecedents, such as organizational commitment (Chonko 1986; Hunt et al. 1985; Mowday et al. 1979, 1982), job satisfaction (Locke 1970; Michaels et al. 1987) and supervisory behavior (House 1971; House et al. 1971; House \& Dessler 1974; Schriesheim et al. 1976). 
Finally, the model essentially is of a static nature. As a result, the sequential order among variables cannot be established unambiguously. Therefore, a longitudinal or (quasi-) experimental research design might be warranted to overcome this shortcoming (e.g. Bolton \& Drew 1991a; Boulding et al. 1993).

\subsubsection{Measurement Properties}

The validity and reliability of GAP5 as operationalized by the SERVQUAL-instrument has been extensively treated by numerous authors (See Chapter 2 for more details). Therefore, we will not be concerned with GAP5 in this chapter, but will focus on the internal gaps, GAP1 To GAP4. Parasuraman et al. (1990) report that the internal consistency of the items pertaining to GAP2GAP4 in terms of coefficient $\alpha$ is well over the threshold level of 0.7 as recommended by Nunnally \& Bernstein (1994). However, internal gaps are not measured at the level of the individual items as GAP5 (e.g., using the SERVQUAL-instrument), which demands a high level of abstraction from the respondents (Smidts 1993). Also, the gap scores might be difficult to interpret, as they are aggregated on the dimension level. Therefore, Smidts (1993) proposes to measure GAP2-GAP4 on the same items as GAP5 (e.g., the SERVQUAL-instrument). This will not only considerably decrease the level of abstraction required, but allow researchers to identify the contribution of the individual items to these gaps. For example, one might determine for which items no standards exist (GAP2). Also, differences between management and employees might be detected and these can be employed to guide the quality improvement process. This means, however, that the questionnaire will increase in length considerably. On the one hand, this could lead to a higher rate of non-response, while, on the other hand, a positive effect on the internal consistency may be assumed. Finally, GAP1 is measured as a difference score, which might introduce additional problems regarding validity and reliability (See Chapter 2 for more details).

Regarding the antecedents to the internal gaps (GAP1-GAP4) it can be concluded that the majority of them are characterized by a relatively low internal consistency as represented by coefficient $\alpha$. Parasuraman et al. (1990) and Smidts (1993) report that respectively 12 and 13 out of the 14 multi-item scales exhibit a value lower than 0.7 (See Table 3-1). Additionally, two antecedents are operationalized as single items. Several reasons can be brought forward for the superiority of multi-item scales as compared to single items (Churchill 1979; Nunnally \& Bernstein 1994). The relatively low values of coefficient $\alpha$ might be explained as follows: (1) the items might not pertain to the same construct; (2) the items might represent different aspects of the construct or (3) the number of items is too small. The internal consistency of the antecedents might be improved by using published scales with favorable psychometric properties or further refinement of the existing scales. For example, the use of published scales regarding the role conflict and role ambiguity constructs could be considered.

\section{Conclusion}

This section of chapter 3 focused on the Extended Model of service Quality. This model links internal or organizational antecedents to the gaps in the Conceptual Model of Service Quality. The research design for the Extended Model of service Quality requires a relatively complex and elaborate design. The model uses data from: (1) customers, (2) service managers and (3) customer-contact service employees. Furthermore, the research design calls for two levels of analysis: (1) individuals and (2) organizational entities. Moreover, the organizational entities may be viewed as sub-units and therefore are part of a larger organizational body. Thus, including a third level of analysis: the organization itself.

The model specification of the Extended Model of Service Quality also raises several concerns. It should be noted that the model is mainly of diagnostic value. There are no clear paths along which service improvements can be carried out. The conceptualization of the internal gaps closely resembles a formalized, mechanistic, bureaucratic organization. Such an organizational configuration might not be appropriate for all service organizations. Moreover, the relationship between the antecedents and the internal gaps is not unambiguous. Furthermore, 
most of the antecedents are of an ad hoc as well as a structural level. The Extended Model of Service Quality proposes a top-down approach, whereas more recently Total Quality Management recommends the use of bottom-up procedures, such as QFD or its services counterpart SQD. Clearly, the model might suffer from omission of relevant variables. Finally, the model essentially is static of nature and therefore the sequential order of variables cannot be determined unambiguously.

Empirical research has identified several shortcomings with regard to measurement properties of the internal gaps and the antecedents. Although the internal gaps (GAP2 to GAP4) show sufficient reliability in terms of coefficient $\alpha$, they are measured on attribute level only. Therefore, Smidts (1993) suggested to measure the internal gaps on item level; thus increasing reliability and specificity (diagnostic value). The antecedents to the internal gaps exhibit unacceptably low levels reliability in terms of coefficient $\alpha$. Either these measures need to be improved or published scales with favorable psychometric properties need to be included in the framework.

\subsection{Testing the Extended Model of Service Quality: A Pre-Study}

In this section of chapter 3 the findings of a pre-study using the Extended Model of Service Quality will be presented. We conducted this research in order to cross-validate the findings of previous research in this area. If our results are similar to the results of previous studies the need for an alternative model should be considered. To begin with, the research setting will be briefly described in section 3.3.1. The sampling procedures and measures will be discussed in section 3.3.2. The measurement instruments will be shown in section 3.3.3. The results of the pre-study will be presented in section 3.3.4. Finally, this section will be concluded by a discussion and conclusion (3.3.5).

\subsection{Research Setting}

This empirical study was conducted with the after-sales service department of a manufacturer of office equipment in The Netherlands. This department consists of fourteen field service units (FSU's) providing after-sales services to customers on a geographical basis. Each FSU includes a manager and approximately fifteen service engineers. Furthermore, there is a central planning department, which receives the service calls from customers and allocates the jobs to the different service engineers in a FSU. More information on the research setting is provided in Chapter 5.

\subsubsection{Sampling Procedure}

The research design, essentially, consists of two parts: (1) measurement of the perceived service quality of customers in all fourteen customer service regions and (2) measurement of the internal gaps and antecedents of these gaps for employees in the fourteen field service units or FSU's.

Written questionnaires were sent out to customers of all fourteen customer service regions. Approximately 5.473 questionnaires were sent out and 1297 were returned (response rate $=24 \%$ ). Of these 1272 were ultimately usable for analysis. Written questionnaires were administered to all 242 customer-contact service employees of the fourteen FSU's. Of these 151 were returned (response rate $=61 \%$ ). Three questionnaires were later omitted for analysis, as more than $25 \%$ of the items were left unanswered.

\subsubsection{Measurement Instruments}

We used an adapted version of the SERVQUAL-instrument for the external part of the study. Previous studies for this organization, interviews with management and service engineers suggested that technical quality and functional quality need to be both included in our model. Technical quality was operationalized using four items. Functional quality was operationalized to reflect the business process in the unit and consisted of four dimensions: (1) quality of the service provided by the planning department ( 4 items); (2) quality of the service provided by 
service engineers ( 7 items); (3) service provided by supplies department ( 2 items) and (4) complaints handling ( 5 items). This structure reflects the business process as suggested by Rust et al. (1995). These dimensions were operationalized on a 9-point Likert-type scale ranging from 1 ("Much worse than expected") to 9 ("Much better than expected"). For the external part the 5 items making up the complaints handling dimension were omitted, as only a limited number of customers filed complaints (19.3\%).

The internal part of the study consists of the instruments proposed by Parasuraman et al. (1990) to measure the internal gaps (GAP1 to GAP4) and their antecedents (See Appendix IV). It should be noted, however, that the number of items for the GAP2 to GAP4 was increased to 22 to equal the number of items in the external part of the study. In other words, each of the internal gaps was evaluated on the 22 items of the SERVQUAL-instrument instead of dimension level as in the original instrument (See Appendix 4). Moreover, GAP1 was not operationalized as the difference between the expected service of the customer and management perceptions of these expectations. Using a direct comparison scale it is impossible to isolate the expectations component. Instead the service quality scores were taken for both customers and service employees.

\subsubsection{Results}

To begin with, we explored the internal consistency of both the internal gaps (GAP1-GAP4) and their antecedents. From Table 3-1 it can be shown that our findings are comparable to both the findings of Parasuraman et al. (1990) and Smidts (1993), as we find relatively high values of coefficient $\alpha$ for the internal gaps (ranging from 0.85 to 0.92 ) and relatively low values of coefficient $\alpha$ for the antecedents. The relatively high scores of coefficient $\alpha$ for the gap scores of GAP2, GAP3 and GAP4 are somewhat higher as compared to Parasuraman et al. (1990). The reliability of perceived service quality, GAP5, was assessed using the reliability coefficient for linear combinations (Nunnally \& Bernstein 1994). This reliability coefficient for linear combination equaled 0.92 . Although only one of the multi-item scales exhibit a coefficient $\alpha$ exceeding 0.7 , the cut-off value suggested by Nunnally \& Bernstein 1994, we carried out OLS regression to examine the effects of the antecedents on the internal gaps (GAP1 to GAP4). The results are exhibited in Table 3-2. For GAP1 the results are similar to Parasuraman et al. (1990). They found none of the antecedents to have a statistically significant effect on GAP1 and actually reported an adjusted $\mathrm{R}^{2}$ of $0.03(!)$. Parasuraman and his colleagues attribute these somewhat disappointing results to low reliabilities of the antecedents for GAP1 (See Table 3-1).

The results for GAP2 shows that management commitment to quality and goal setting have a negative effect on GAP2; thus closing GAP2. Additionally, Parasuraman et al. (1990) find that task standardization negatively affects GAP2. The adjusted $\mathrm{R}^{2}$ equals 0.14 , whereas Parasuraman et al. (1990) report an adjusted $R^{2}$ of 0.27 . Again these effect might be attenuated due to the lack of adequate reliability. 


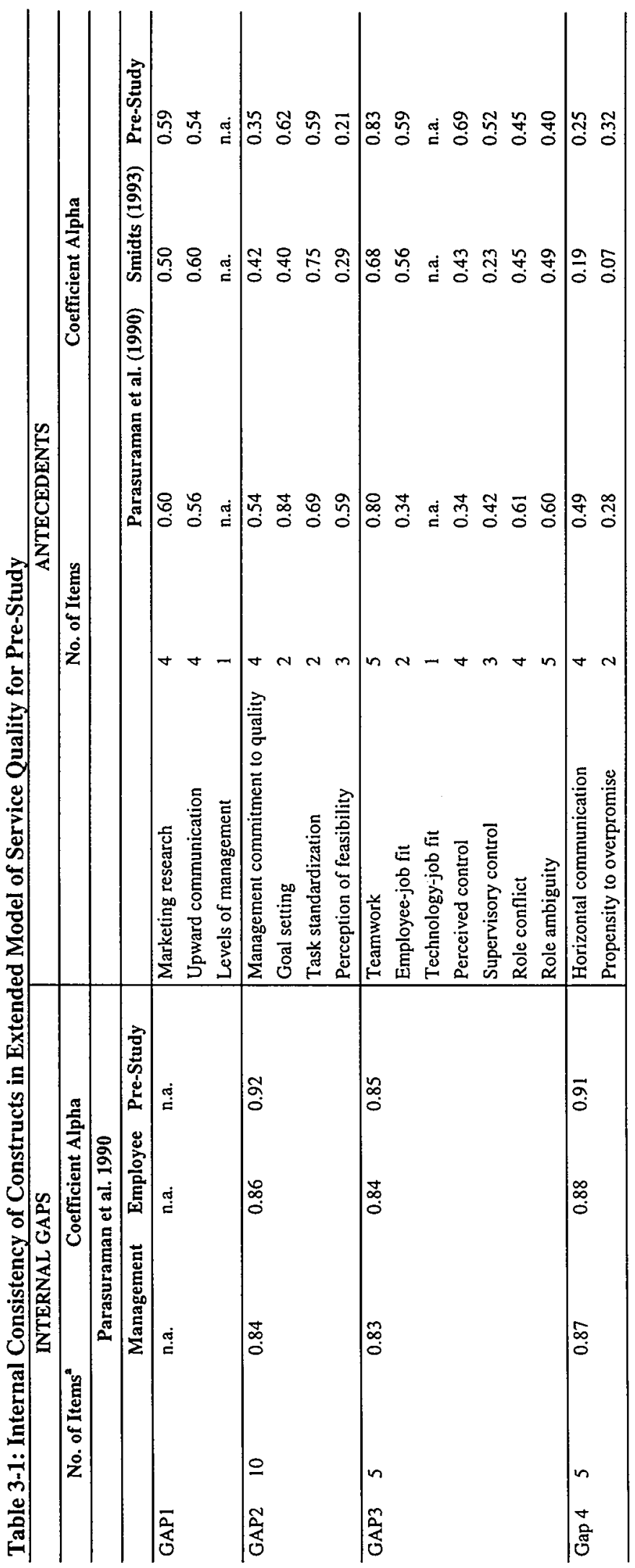


Of the antecedents hypothesize to influence GAP3 we find only technology-job fit to reduce the magnitude of GAP3 (with employee job fit being a borderline case at $t=-1.89$ [p=0.06]). Parasuraman et al. (1990) additionally report significant effects for teamwork, employee-job fit and perceived control. The adjusted $\mathrm{R}^{2}$ for this model equals 0.25 , which is quite remarkable as Parasuraman et al. (1990) report an adjusted $R^{2}$ of 0.27 . Similar to GAP1 and GAP2 the results may be affected by the low reliabilities of the antecedent measures.

With regard to GAP4 the results of the pre-study and Parasuraman et al. (1990) are quite similar again. Their results reveal that solely horizontal communication negatively influences GAP4. They report an adjusted $R^{2}$ of 0.15 (Pre-study: adjusted $R^{2}=0.05$ ). Subsequently, we used logistic regression to investigate the influence of the effects of the internal gaps (GAP1 to GAP4) on perceived service quality (GAP5).

In using logistic regression analysis our approach is slightly divergent from the approach followed by Parasuraman et al. (1990). In this study only fourteen units were available. Thus, by aggregating analyses would be restricted to a sample size of fourteen. Given rules of thumb, like a ratio of 10 to 1 for cases and regressors (Darlington 1990), and the more formal approach in power analysis (Cohen \& Cohen 1983; Green 1991, Tabachnik \& Fidell 1996) this sample size will not be adequate. An alternative avenue for analysis is provided by logistic regression (Darlington 1990; DeMaris 1992; Tabachnik \& Fidell 1996). This approach entails rank ordering the FSU's in correspondence with their score on perceived service quality obtained in the external study. In rank ordering we used three categories: (1) FSU's scoring high on perceived service quality (5 FSU's), FSU's scoring low on perceived service quality (5 FSU's) and (3) FSU's scoring middle of the road for perceived service quality (4 FSU's). We decide to eliminate the middle of the road FSU's in order to increase the contrast in perceived service quality between the FSU's. As a consequence, 92 service employees remained available for the logistic regression analysis. Subsequently, the service employees for the high and low scoring FSU's were coded 1 (FSU high) and 0 (FSU low). GAPl to GAP4 were used as independent variables in the logistic regression equation.

Maximum likelihood estimation was used to estimate the parameters in the logistic regression model (Darlington 1990; DeMaris 1992; Tabachnik \& Fidell 1996). A hierarchical approach was used to assess the fit of the logistic regression model. Our model was tested against a null model consisting only of a constant term or intercept. The difference in log likelihood between these two models follows a $\chi^{2}$ distribution. Our results indicate that the fit of our model is poor: $\chi^{2}(4)=4.36, \mathrm{p}=0.36$ ). Therefore, it can be concluded that our model does not statistically significantly improve the fit of model over a model only including a constant term. These finding are similar to the findings reported by Parasuraman et al. (1990) using OLS regression analysis. They find that none of the internal gaps (GAP1 to GAP4) statistically significantly affect GAP5, perceived service quality. 


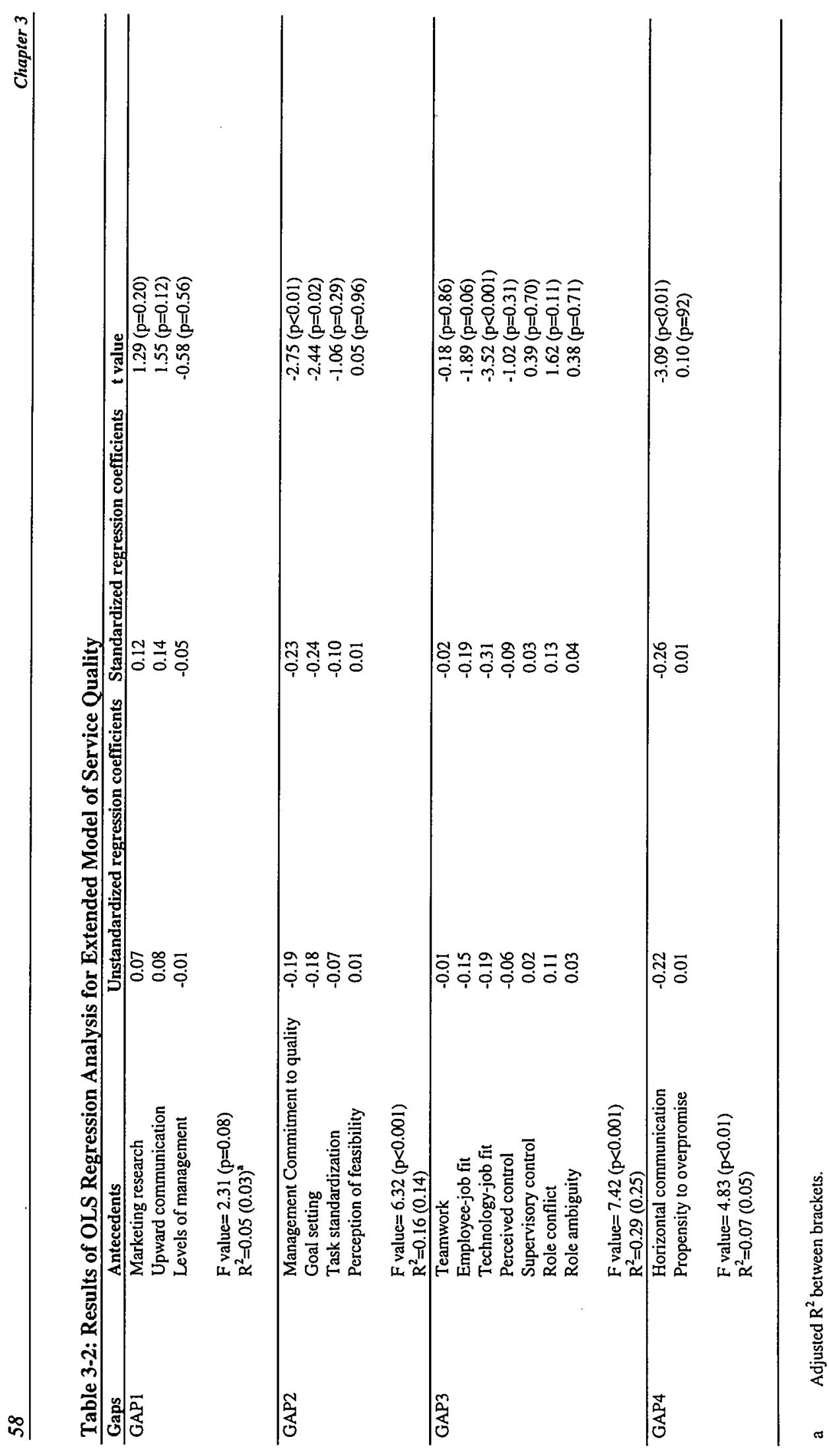




\subsubsection{Discussion}

Our results suggest that the Extended Model of Service needs considerable improvement on the basis of our pre-study. Our findings indicate that only one of the scales for the antecedents shows sufficient reliability. The internal gaps on the other hand exhibit relatively high reliability in terms of coefficient $\alpha$. Thus, it seems that the scales operationalizing the antecedents need considerable improvement. Alternatively, the use of existing scales exhibiting favorable psychometric properties could be considered.

We used OLS regression to assess the influence of the antecedents on their correspondent internal gaps. Our results indicate that only a limited number of antecedents affect the hypothesized gap. For GAPI we even found that none of the antecedents affects this gap. We used logistic regression to test for the proposed effects of the internal gaps on GAP5 and found that none of the internal gaps showed a statistically significant effect on GAP5. Our findings are quite comparable to the results of previous studies (Parasuraman et al. 1990; Smidts 1993). Therefore, we address the need for an alternative model in the next section.

\subsection{The Need for an Alternative Model}

In section 3.2 of this chapter we reviewed and criticized the Extended Model of Service Quality. Subsequently, in section 3.3 we tested the Extended Model of Service Quality in an empirical pre-study. Our findings can be summarized as follows. To begin with, the research design is fairly complex. Therefore, we would advise to restrict the scope of future studies in terms of the number of actors and levels studied. For instance, researchers might want to focus on the effects of contact personnel on perceived service quality, since these employees have shown to be an extremely important factor in rendering high quality services (Bitner et al. 1990, Mohr \& Bitner 1995a,b).

Secondly, the measurement instruments will need considerable improvement. The number of items used to measure the internal gaps (GAP1-GAP4) might need to be increased in order to lower the level of abstraction and to improve the internal consistency of these gaps. Also, the operationalization of GAP1 needs be reconsidered. GAP1 is measured as a difference score. However, GAPl could also be measured instructing internal respondents to complete the external instrument from the perspective of their own customers, as we did in our study. With regard to the antecedents, it can be concluded that the internal consistency of the majority of the constructs is below the 0.7 threshold value proposed by Nunnally \& Bernstein (1994). Hence, we propose that either these scales will need further refinement or that published scales with favorable psychometric properties should be used.

Thirdly, some issues with regard to the model specifications need to be focused on. To begin with, the underlying logic of the internal gaps can be questioned. Essentially, it resembles a formalized, mechanistic, bureaucratic organization. However, the requirements for such an organizational configuration are clearly not satisfied by most service organizations. Next, the causal relationship between internal gaps and antecedents is ambiguous. Further, in the Extended Model of Service Quality it is assumed that the antecedents are not interrelated, whereas empirical research suggests that interrelations might exist. Moreover, the antecedents are of an ad hoc as well as a structural nature. The model is essentially of a static nature. In order to examine causal relationships a longitudinal or (quasi-)experimental research design might be required.

Fourthly, there is only limited empirical support for the model in its current specification. We find only limited support for the relationship between the antecedents and their corresponding gaps. With regard to the effect of the internal gaps on GAP5 we find that the internal gaps show no statistically significant effect on perceived service quality. Omitting the internal gaps from the model might therefore be considered. This will lead to a more parsimonious and conceptually appealing model. 
Consequently, a major revision of the model is needed. Two fields of scientific research are extremely relevant for the revision of the model: (1) marketing and (2) organizational theory (Bowen 1990; Bowen \& Schneider 1988; Mindak \& Folger 1990). Bowen \& Schneider (1988), however, indicate that the perspectives of both fields are rather different. Marketing literature has mainly focused on the customer, whereas organizational theory mainly concentrated on the employee. Solomon et al. (1985), however, suggest that dyadic interaction between service provider and customer is a critical determinant of perceived service quality. Therefore, both fields might provide valuable insights to the study of quality management in service organizations.

In marketing, the unique nature of services vis-à-vis goods has been generally acknowledged. Especially quality management is strongly affected by this unique nature of services (Booms \& Bitner 1981; Czepiel et al. 1985; Shostack 1977a,b; Zeithaml 1981; Zeithaml et al. 1985). Since the beginning of the 1980s service quality has been an increasingly researched topic in marketing (Cronin \& Taylor 1992, 1994; Parasuraman et al. 1985, 1988, 1991; Rust \& Oliver 1994; Zeithaml et al. 1988, 1990). However, in marketing literature internal factors have also been extensively researched, especially in the sales and purchasing literature (e.g., Bagozzi 1978; Behrman \& Perreault 1984; Michaels et al. 1987; Teas 1983). The relevance of this literature for service organizations can be seen, as both the sales and purchasing literature and the services literature focus on boundary spanning roles (Shamir 1992; Singh \& Rhoads 1991).

Organizational theory, on the other hand, is still predominantly concerned with manufacturing organizations (Mills 1986; Schneider 1986). However, frameworks and models developed in manufacturing might be tested for service organizations in order to assess their external validity. For instance, Hartline \& Ferrell (1993) delve deeply into the organizational management literature to develop their model of service quality implementation. Essentially, the field of organizational theory aims to explain organizational effectiveness (Cameron \& Whetten 1983; Goodman \& Pennings 1977; Katz \& Kahn 1978; Steers 1977; Van de Ven \& Ferry 1980). Several approaches can be identified to measure organizational effectiveness. Measures, such as job satisfaction, absenteeism, turnover, motivation, growth, profit, are often employed as measures of organizational effectiveness (Staw 1984; Steers 1977). These measures clearly are a reflection of the internal focus of the organizational behavior field. However, product quality or evaluations by external entities have also been proposed as measure of organizational effectiveness (Campbell 1977).

There are several characteristics which customer-contact personnel in service organizations share with salespeople. Churchill et al. (1974) report the following three "unique" properties of salespeople. To begin with, salespeople fulfill a "boundary" role at the interface between the organization and the market environment. Customer-contact personnel in service organizations in fact constitute the link between the organization and the customer and as such occupy a boundary position (Parkington \& Schneider 1979; Schneider et al. 1980). Second, the salesperson's role is essential to the economic success of an organization. As could already been observed above, in many services the personal interaction between service provider and customer is an important determinant of service quality as perceived by the customer. Perceived service quality will subsequently result in improved economic performance of the service organization. Finally, the salesperson's role often calls for the performance of innovative and creative activities. Although some service may be standardized and even industrialized (Levitt 1972, 1976; Lovelock 1983), the nature of other services may make them less suitable for such operations (Hartline \& Ferrell 1993; Schlesinger \& Heskett 1991; Bowen \& Lawler 1992, 1995a,b). These three characteristics make customer-contact personnel in service organizations extremely susceptible to role stress. As boundary spanners customer-contact personnel has to deal with both demand from the inside the organization, such as co-workers and superiors, and outside the organization, such as customers (Adams 1976, 1980; Lysonski 1985; Kahn et al. 1964; Katz \& Kahn 1978; Keller \& Holland 1975; Walker et al. 1975). 
Furthermore, Hartline \& Ferrell (1993) argue that service organizations often design standards and procedures that limit the flexibility of customer-contact personnel. Originally, such standards and procedures are established in order to ensure the delivery of high service quality (Levitt 1972, 1976; Parasuraman, Zeithaml \& Berry 1985, 1988). However, such a bureaucratic orientation might impede customer-contact personnel from rendering high service quality and satisfying customers (Parkington \& Schneider 1979; Schneider 1980). Empowerment might just add the flexibility to the service delivery system that allows customer-contact personnel to fine-tune standards and procedures to improve service quality and customer satisfaction (Hartline \& Ferrell 1993). Apart from "industrialization" and empowerment service employees are also affected by their managers or supervisors and their co-workers or colleagues.

\section{Conclusion}

Our need for an alternative model is based on four considerations. To begin with, the research design of the Extended Model of service Quality is fairly complex and elaborate. A more limited approach might be advised. Furthermore, the measurement instruments, especially for the antecedents, need considerable improvement. The model specification of the Extended Model of Service Quality makes it closely resemble a formalized, mechanistic, bureaucratic organization. The relationship between the gaps and the antecedents are not unambiguous. Moreover, the antecedents in the model might show considerable interrelations, which is not allowed for in the model in its present form. The antecedents are both ad hoc and structural of nature. Finally, the model is static and needs a more dynamic approach.

Therefore, a major revision should be considered. Two fields of research are particularly relevant for this revision: (1) marketing and (2) organizational theory. Marketing predominantly focuses on the customer as its object of study, while organizational theory focuses predominantly on the employee as its object of study. However, at the interface of the two disciplines valuable contributions can be found.

Customer-contact service employees share several characteristics with salespersons. Both salespersons and customer-contact service employees fulfill a boundary spanning role and form the link between the organization and the customer. Furthermore, both the performance of the salesperson and the performance of customer-contact service employees are essential to the economic success of the organization. Finally, when dealing with customers both the customer-contact service employee and the salesperson are called upon to perform innovative and creative activities to solve customers' problems. As a results of these characteristics service employees are particularly prone to role stress. Recently, two models have been proposed for the management of service employees. The first model suggests that service may be improved by "industrializing" the service; thus limiting the discretionary powers of service employees. The other model, also referred to as the "involvement" model, appeals to the ability of service employees to control their own activities using empowerment as its focal construct. In addition, we also have to take into account the supervisor and co-worker in the service organizations as major determinants of the performance of service employees.

\subsection{Role Stress}

Kahn et al. (1964) provide a theoretical framework for the study of role ambiguity and role conflict in their seminal work titled Organizational Stress: Studies in Role Conflict and Ambiguity. This framework is based on role theory. Therefore, attention will first be focused on role theory. Next, role ambiguity and role conflict will be defined on the basis of the roletheoretic framework developed by Kahn et al. (1964). Finally, the dynamic nature of role ambiguity and role conflict will be discussed. 


\subsubsection{Role Theory}

Role theory is essentially based on a dramaturgical metaphor. Individuals are regarded as social actors and are expected to perform certain "roles" appropriate to the position they occupy in society (Biddle \& Thomas 1966; Kahn et al 1964; Katz \& Kahn 1978; Solomon et al. 1985). Applying role theory to organizations, an organization can be defined as open system of roles (Katz \& Kahn 1978). In other words, the organization is seen as a set of people fulfilling certain roles. Essentially, relationships in an organization exist between roles not necessarily between individuals. Accordingly, Kahn et al. $(1964,11)$ in their seminal work on role stress propose that the life of an individual in a work-related context can be seen as:

"...as an array of roles which he plays in the particular set of organizations and groups to which he belongs."

Furthermore, role theory posits that a role in an organization cannot be seen in isolation. Each role is interrelated to a number of others. The association between roles in an organization is often based on work-flow structure, technology or the hierarchy of authority. Kahn et al. $(1964,13)$ provide the example of a press foreman in a factory producing external trim parts for automobiles:

"The offices most directly related to that of press foreman might include general foreman and superintendent, from which the press foreman's work assignments emanate and to which he turns for approval of work done. Also directly related to the office of press foreman will be the foreman of the sheetmetal shop, which provides stock for the presses, the inspector who must pass or reject the completed stampings, the shipping foreman who receives and packages the stampings, and, of course, the fourteen press operators."

Collectively, these roles are referred to as the role set of that specific focal person ${ }^{2}$. However, the role set is not limited by organizational boundaries, individuals from outside the organization should also be included in the role set. Especially, boundary spanners, such as salespeople and service contact-personnel might be affected by external agents (e.g., Goolsby 1992; Parkington \& Schneider 1979; Schneider 1980; Walker et al. 1975).

Individuals making up the role set (the so-called role senders) hold certain expectations for the role of the focal person. Role expectations include such issues as what focal person should do, what he or she should think or how he or she should interact with others. Role expectations tend to be communicated or "sent" to the focal person in order to produce conformity with the role expectations of his or her role senders. These influence attempts are referred to as role pressures. Role pressures lead to certain perceptions and cognitions of the sent role by the focal person, the so-called received role. This perceptual process arouses certain psychological forces in the focal person. These role forces ultimately cause role behavior and role performance. However, role pressure might not always lead to the desired role behavior and role performance. Finally, role behavior and performance are not only contingent on role pressures from his or her role set. Individuals are confronted by a plethora of psychological forces. Kahn et al. (1964) indicate that an individual might even be a "selfsender". In other words, the focal person himself has certain role expectations about his role.

\subsubsection{Defining Role Conflict and Role Ambiguity}

Role senders can hold different role expectation with regard to the focal person. If these role expectations cause divergent role forces, the individual might experience role conflict. Kahn et al. $(1964,19)$ define role conflict as:

"...the simultaneous occurrence of two (or more) sets of pressures such that compliance with one would make more difficult compliance with the other." 
Furthermore, they contend that role conflict consists of an objective component and a subjective component. The objective component, objective or sent role conflict, is a condition in the environment and can be verified in isolation from the focal person. The subjective component, on the other hand, is the perception of the objective role conflict by the focal person, and as such cannot be studied in isolation from the focal person. Accordingly, Walker et al. $(1975,33)$ define perceived role conflict in a salesforce context as follows:

"Perceived role conflict exists when a salesman believes that the expectations and demands of two role set members are incompatible."

Objective and subjective role conflict need not necessarily be congruent, as the perception of the focal person does not adequately mirror organizational reality. In general, a considerable degree of correlation might be expected between subjective and objective role conflict. However, empirical support is somewhat disappointing and further research needed to explore the relationship between the objective and subjective components of role conflict (King \& King 1990).

Kahn et al. (1964) identify several types of role conflict:

(1) Intra-sender role conflict: the extent to which two or more role expectations from a single role sender are incompatible;

(2) Inter-sender conflict: the extent to which role expectations from one role sender opposes role expectations from other role senders;

(3) Inter-role conflict: the extent to which role expectations are incongruent with the role expectations pertaining to a different role;

(4) Person-role conflict: the extent to which role expectations violate the morale values of the role incumbent and

(5) Other complex forms: combinations of the preceding four types of role conflict. For example, role overload can be seen as a combination of inter-sender conflict and personrole conflict.

A large body of the literature is devoted to inter-sender conflict, while other types of role conflict remained relatively unexplored (Behrman \& Perreault 1984; Teas 1983; Walker et al. 1975).

Role ambiguity was defined by Kahn et al. (1964) as a lack of means-end knowledge. More specifically, Kahn cum suis $(1964,25)$ indicate that:

"...role ambiguity is conceived as the degree to which required information is available to a given organizational position."

This deficiency of information might be related to (1) the expectations pertaining to a role, (2) the activities to be performed for fulfilling role expectations and how these activities best can be accomplished and (3) the consequences of performance or nonperformance of these activities. Role ambiguity can result from a number of causes. Generally however, the lack of information might arise from both the organizational environment and the individual level With regard to the organizational environment, it should be noted that information might just not be available. For instance, who is to predict the next breakthrough innovation in the market, or for that the next downturn in the economy. Consequently, organizational roles in a complex and dynamic organizational environment might be inherently ambiguous. On an individual level it is conceivable that the information is available, but may not be adequately communicated by the role sender (intentionally or unintentionally) to the focal person who needs it. Finally, Kahn et al. (1964) argue that if role senders try to communicate contradictory messages this might lead to uncertainty and confusion for the focal person. This aspect of role 
ambiguity might actually link role ambiguity to role conflict. However, on the other hand, they reason that role conflict and role ambiguity are independent sources of role stress.

As with role conflict, role ambiguity also consists of an objective and a subjective component. The subjective component, or perceived role ambiguity, was defined by Walker et al. $(1975,33)$ in a salesforce context as follows:

"Perceived role ambiguity occurs when the salesman does not feel he has the necessary information to perform his role adequately, when is uncertain about what members of his role set expect of him."

Again, the congruency between the subjective and objective role ambiguity may be less than perfect.

\title{
3.5.3 The Dynamics of Role Ambiguity and Role Conflict
}

From the above, the impression could be gained that the process leading to role ambiguity and role conflict is static of nature. However, Kahn et al. $(1964,29)$ indicate that this process may not be that simple:

\begin{abstract}
"An adequate understanding of processes of adjustment to stresses in organizations must take into account many factors. Organizations are complex, and interdependencies among members are potent and subtle. The personalities of members, especially those whose adjustments are to be investigated, must be considered, as must the pattern of social relations. Processes of communication and social influence are of major concern, as are the intrapsychic process involved in coping with psychological conflict, tension, and anxiety. Moreover, these many variables tend to be related in complex ways."
\end{abstract}

Therefore they propose a dynamic, theoretical model that is based on the concept of the role episode (See Figure 3-2). The role episode consists of the complete cycle of role sending, response by the focal person and the influence of this response on the role sender. Figure 3-2 implies the following causal sequence. As already was explained above, the role sender holds certain role expectations regarding the focal person. These role expectations are, in turn, converted into role pressures. These role pressures aim to bring about conformity with the role sender's expectations. Next, the focal person responds to the pressures exerted by the role sender. This response can reveal itself in several ways. The focal person might comply with pressures or he might persuade the role sender to change incongruent requirements. The focal person might also react by avoiding potentially stressful situations or by using defense mechanisms which distort reality, such as denial and mental disengagement (Goolsby 1992).

The response of the focal person at one point in time $\left(t_{1}\right)$ will feed back on the role sender's role expectations at the next moment $\left(\mathrm{t}_{2}\right)$. However, a role episode is only a link in a chain. The process as whole is cyclic and ongoing. Furthermore, the role episode is affected by organizational factors, such as the size of the organization its structure and number of organizational levels, personality factors, such as anxiety and flexibility, and interpersonal factors, such as organizational status and power. 
Figure 3-2: The Dynamics of Role Ambiguity and Role Conflict

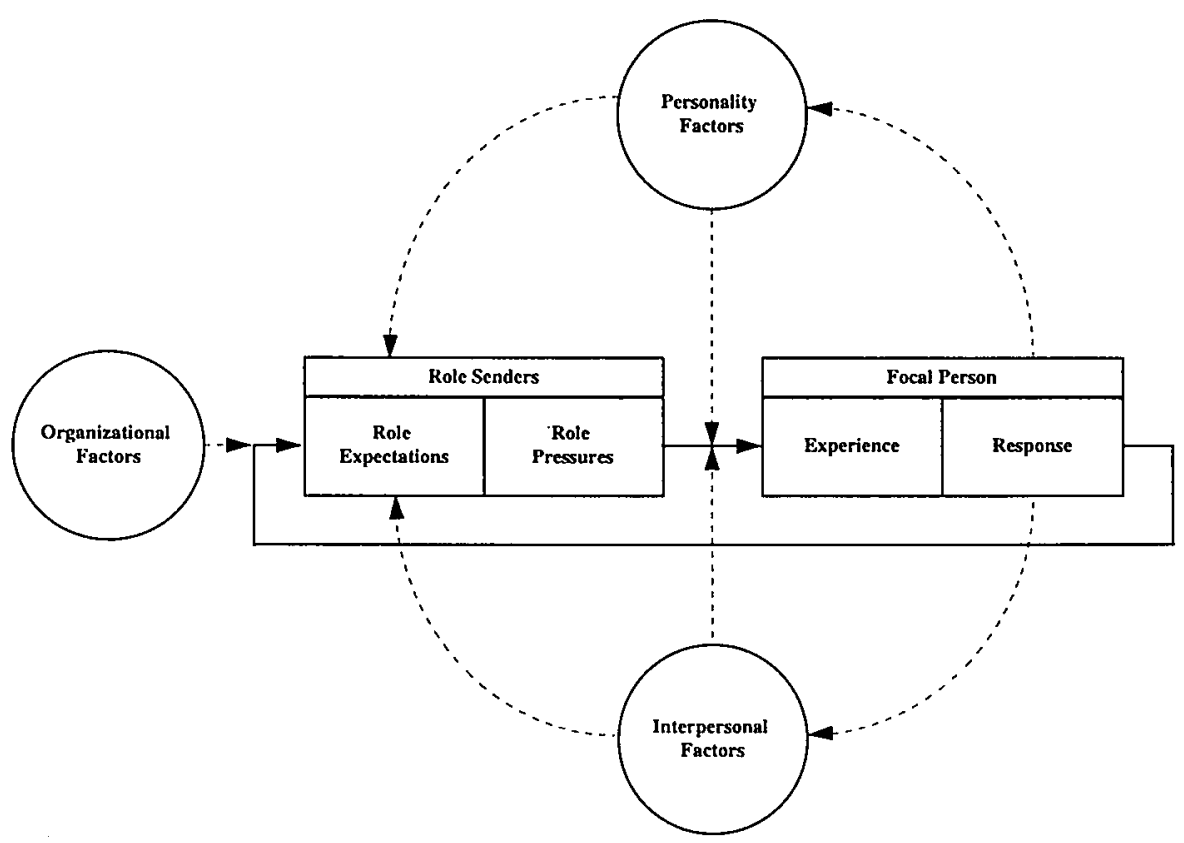

Source: Kahn et al. $(1964,30)$

\section{Conclusion}

Role theory posits that each individual performs a certain role in an organization. This role cannot be seen in isolation, but is related to other roles in the organization. Other individuals in the organization attempt to exert influences on the focal person by communicating role pressures or role expectations. Role conflict and role ambiguity occur when the role expectations differ between role senders and focal person. Role conflict occurs when the focal person is confronted with conflicting role expectations from different external agents, i.e. inter-sender role conflict. Role ambiguity refers to lack of clarity regarding the role to be performed. Role ambiguity and role conflict are the result of a dynamic process affected by personal factors, interpersonal factors and organizational factors.

\subsection{Antecedents to Role Stress}

In this section of Chapter 3 we will be discussing the antecedents of role stress. More in particular, we will identify four antecedents to role stress: (1) formalization, (2) empowerment, (3) leadership behavior and (4) group cohesiveness.

\subsubsection{Formalization}

In order to improve the efficiency and customer satisfaction Levitt $(1972,1976)$ recommended the industrialization of service industries. He argued that efficiency as well as customer satisfaction would be enhanced by:

(1) division of labor;

(2) standardization and formalization of tasks;

(3) substitution of equipment ("hard technology") and service delivery systems ("soft technology" for employees and 
(4) limited decision-making discretion for employees.

In other words, in the "industrialization of services" model the role of customer-contact personnel will be limited to the execution of the service delivery process as designed by management. A similar logic can be found in the Extended Model of Service Quality (See Figure 3-1) as proposed by Parasuraman and his colleagues (Parasuraman et al. 1990; Zeithaml et al 1988).

Central to these conceptions is formalization. Formalization can be defined as (Pugh et al. $1968,75)$ :

"... the extent to which rules, procedures, instructions and communications are written."

Although some authors have directly linked formalization to job outcomes (Aiken \& Hage 1966; Rushing 1966), others argued that intervening constructs, such as task environment (Ruekert et al. 1985) and role stress (Organ \& Greene 1981; Podsakoff et al. 1986) should be introduced. The presence of written rules, standards and policies should clarify role expectations and reduce role ambiguity and role conflict (Kahn et al. 1964; Organ \& Greene 1981; Rizzo et al. 1970; House \& Rizzo 1972; Rogers \& Molnar 1976). Meta-analytic studies, however, only found the hypothesized negative relationship for role ambiguity, while the results for the relationship between formalization and role conflict are mixed (Fisher \& Gitelson 1983; Jackson \& Schuler 1985). Organ \& Greene (1981) and Nicholson \& Goh (1983) found a positive relationship between formalization and role conflict for employees possessing professional norms. Furthermore, formalization might limit the flexibility of boundary role positions, thus leading to increased levels of role conflict (Clopton 1984; Micheals et al. 1987). For instance, Parasuraman et al. (1988) relate role conflict for customercontact personnel to excessive paperwork and internal roadblocks. This relationship is corroborated by the findings of Micheals et al. (1987) in industrial buying context.

In order to explore the relation between formalization and role stress in service organizations the following hypotheses will be formulated:

$\mathbf{H}_{1 \mathbf{a}}$ : There will be a negative relationship between formalization and role ambiguity.

$\mathbf{H}_{1 \mathrm{~b}}$ : There will be a positive relationship between formalization and role conflict.

\subsubsection{Empowerment}

A second approach that may govern the employee/company interface is frequently referred to as the "involvement" model (Bowen \& Lawler 1995a,b). According to this model, which has its roots in participatory management (e.g., Argyris 1964; McGregor 1960), employees are capable of coordination, planning and control of service quality. A central concept to the involvement approach, which has become increasingly popular recently in service organizations, is empowerment (Bowen \& Lawler 1995a,b; Hartline \& Ferrell 1996; Schlesinger \& Heskett 1991). Employees are free to fine-tune service regulations in order to meet or exceed customer expectations. The essence of empowerment is maybe best captured in being (Zemke \& Schaaf 1989, 68):

"...the reverse of doing things by the book"

Despite its popularity there is no accepted and clear-cut definition of empowerment. Essentially, two aspects of empowerment can be distinguished (Chiles \& Zorn 1995; Conger \& Kanungo 1988): (1) competence and (2) autonomy. In other words, the employee must both feel capable of competently performing his or her job and believe that he or she has the authority to make the necessary decisions pertaining to his or her job.

Empowerment has been heralded as a remedy for inefficient operations and dissatisfied customers in service organizations (Bowen \& Lawler 1992, 1995a,b; Hartline \& Ferrell 1993; 
Schlesinger \& Heskett 1991). This development constitutes a stark contrast to the emphasis on the standardization and industrialization of service organizations in 1970s. The "industrialization of service"-model is characterized by a strong emphasis on control; control of the service employee. The empowerment approach can be seen as part of the still evolving "commitment" or "involvement" model. This anti-thetical model is based on the assumption that service employee might hold the keys for quite some problems in service organizations. More in particular, that most service employees can make good decisions if they are properly socialized, trained and informed. Moreover, that service employees can be internally motivated to perform effectively and that they are capable of self-control and self-direction (Bowen \& Lawler 1992).

Bowen \& Lawler (1992) discern a number of costs and benefits of empowerment. According tot them the following benefits may be gained from empowerment:

(1) Quicker on-line response to customer needs during service delivery;

(2) Quicker on-line response to dissatisfied customers during service recovery;

(3) Service employees feel better about their jobs and about themselves;

(4) Employees will interact with customers with more warmth and enthusiasm;

(5) Empowered employees can be a great source of service ideas and

(6) Great word-of-mouth advertising and customer retention.

Apart from benefits there of course also a number of costs associated with empowerment in service organizations:

(1) A considerable investment in selection and training of service employees;

(2) High labor costs;

(3) Slower or inconsistent service delivery;

(4) Violations of "Fair Play" and

(5) Giveaways and bad decisions by service employees.

Bowen \& Lawler (1992) distinguish three stages of empowerment. In each of these stages information, power and rewards are to an increasing degree pushed down to the service employees.

(1) Suggestion involvement is the first stage on the empowerment ladder. It is only small deviation form the traditional control-model as proposed by Levitt $(1972,1976)$. In this first stage service employees are stimulated to provide management with ideas to improve service operations. However, management still retains all decision-making power. Bowen \& Lawler (1992) argue that suggestion involvement can be employed simultaneous to the traditional production-line approach of service management.

(2) Job involvement is the second stage. Job involvement means that jobs are redesigned in such a way that employees can use a variety of skills. As a matter of fact managers surrender decision-making power with respect to operational decisions while upholding their decision-making power regarding tactical and strategic decisions. Thus, in this stage of the empowerment process great deal of discretionary leeway is given to service employee on group or unit level. Teams are often appropriate management tools in this stage.

(3) The ultimate stage of empowerment is high involvement. In high involvement services organizations managers even give up their decision-making power with regard to tactical and strategic decisions. Service employees are not only involved in their own groups or units, their sense of involvement extends beyond the boundaries of their own unit. The organization as a whole is the object of their involvement. Service employees participate in decision-making at the highest level; there might even be profit sharing or employee ownership. 
Empowerment is not the "best" approach to the management of all service organizations. Bowen \& Lawler (1992) suggest a contingency approach to empowerment on the basis of the business strategy of the service organization, its relationship with the customer, its technology, its business environment and the types of managers and employees. According to this contingency approach empowerment will only outweigh its costs in service organizations if a service organization aims to differentiate itself from its competitors through personalization and customization; the service organization wants to establish and maintain a relationship with its customers; the service organization uses non-routine and complex technology, the service organization faces an unpredictable environment with many surprises; managers that believe that their employees can act independently to the benefit of both the service organization and its customers and employees that have a strong need to grow, deepen and test their abilities (See Table 3-3).

Little empirical research on the consequences of empowerment in service organizations has been conducted (cf. Hartline \& Ferrell 1993). Bowen \& Lawler (1992, 35) comment:

"There is still precious little research on the consequences of empowerment. We have used anecdotal evidence, related research (e.g., in job design), and our work on service. More systematic research must assess the whether this array of costs and benefits fully captures the 'whys' (and 'why nots') of empowerment."

It is the purpose of this study to explore the relationship between empowerment and role stress. If empowerment leads both to increased competence and control, role stress might be significantly reduced. Role conflict might be decreased, because of the flexibility given to customer-contact personnel. They need not necessarily obey all the standards and procedures established by their managers; empowered customer-contact service employees might well deviate from these rules and standards in order to really satisfy customers. Role ambiguity might also decrease, since empowered employees have to obtain their own information and take their own decisions. Furthermore, empowered employees know how to perform their jobs competently.

Empirical research on the relationship between empowerment and role stress is both scarce and mixed (Bowen and Lawler 1995a,b). Hartline and Ferrell (1996) report a direct positive relationship between empowerment (operationalized as tolerance of freedom) and role conflict and an indirect positive effect of empowerment on role ambiguity. This is explained by the fact that empowerment may increase uncertainty, as there are less standards or procedures that can be used as guidelines by employees. Alternatively, other empirical work particularly in the areas of autonomy and participation in decision making are indicative of negative relationships of the autonomy dimension of empowerment and role ambiguity and conflict (Jackson and Schuler 1985). An explanation that has been advanced for the nature of these correlates is that the information dissemination associated with freedom of authority in fact reduces role stress. Teas (1983) has demonstrated that allowing employees the autonomy to influence decisions leads to higher levels of role clarity. and consequently less ambiguity and conflict. No empirical evidence of the relationship between work-specific competence and role stress could be traced. However, as Gist and Mitchell (1992) argue, employees that experience a work-specific sense of competence are more likely to assume an active orientation with regard to their work and hence

\section{Table 3-3: Contingency Approach to Empowerment}

Contingency
Basic business strategy
Tie to customer
Technology
Business Environment
Types of people

Contingency

strategy

Technology

Types of people

\section{Product-Line Approach}

Low cost, high volume

Transaction, short time period

Routine, simple

Predictable, few surprises

Theory X managers, employees with low growth needs, low social needs and weak interpersonal skills
Empowerment

Differentiation, customized, personalized

Relationship, long time

Nonroutine, complex

Unpredictable, many surprises

Theory Y managers, employees with high growth needs, high social needs and strong interpersonal skills 
will experience lower levels of role stress. Due to the relatively autonomous position of aftersales departments in organizations, the delegation of authority to after-sales representatives in customer-oriented companies and the often idiosyncratic nature of customer problems associated with after-sales service, we expect negative relationships between the empowerment dimensions, competence and autonomy, and role stressors. Thus, we hypothesize that:

$\mathbf{H}_{2 \mathrm{a}}$ : There will be a negative relationship between autonomy and role ambiguity.

$\mathbf{H}_{2 \mathbf{b}}$ : There will be a negative relationship between autonomy and role conflict.

$\mathbf{H}_{3 \mathbf{a}}$ : There will be a negative relationship between competence and role ambiguity.

$\mathbf{H}_{3 \mathrm{~h}}$ : There will be a negative relationship between competence and role conflict.

\subsubsection{Leadership Behavior}

A second internal interface that has been identified as a determinant of role stress concerns leadership behavior (Hampton et al. 1986; Michaels et al. 1987). As the supervisor is an integral part of a service employee's role performance, for instance, by providing key resources and by motivating personnel it is important to take leadership into account. Furthermore, leadership behavior in services may affect employees' performance, although it has often been shown that the effect may be mediated by role stressors (Babin and Boles 1996). Two dimensions of leadership have constantly emerged from the literature; leader initiating structure and leader consideration. Leader initiating structure relates to the way in which a supervisor guides service employees, provides a psychological framework that clarifies roles, monitors subordinates' activities and stimulates them to display better performance. The initiating structure leadership dimension is thus primarily concerned with task-specific issues. The second dimension, leader consideration is the degree to which a supervisor creates an atmosphere of affective support and socioemotional concern for the well being of subordinates (House 1971; House \& Dessler 1974; House et al. 1971). Leader consideration is primarily oriented towards creating good relationships with workers. Although conceptually different, both dimensions aim at enabling subordinates to perform their roles well. In a services context, managers may schedule meetings devoted to customer expectations of service quality or dealing with customer complaints. Training methods, such as role-playing exercises may elucidate how managers expects aftersales service employees to deal with demanding customers and provide scripts for handling customer complaints.

A number of studies have examined the relationship between leadership dimensions and role stressors. There is substantial empirical evidence indicating a negative association between initiating structure and role ambiguity (Fisher \& Gitelson 1983; Jackson and Schuler 1985). The explanation behind this is that initiating structure is concerned with providing service employees with information that provides them with information about what is expected from them. Similarly, predominant empirical support exists for an inverse relationship between initiating structure and role conflict (Teas 1983; Behrman and Perrault 1984). As clarification and explanation enable service employees to identify the relative importance among conflicting issues role conflict will be decreased. Thus, we hypothesize that

\section{$\mathrm{H}_{4 \mathrm{a}}$ : There will be a negative relationship between initiating structure and role ambiguity. $\mathbf{H}_{\mathbf{4}}$ : There will be a negative relationship between initiating structure and role conflict.}

Empirical evidence in several organizational settings supports the contention that leadership consideration also leads to reduced levels of role ambiguity. Jackson and Schuler (1985) argue that although leader consideration has been conceptualized as socioemotional behavior it also seems to have a task-oriented function. As considerate behavior by supervisors is often shown after an employee has performed well, it indirectly clarifies roles by rewarding what is expected 
(Podsakoff et al. 1984). Furthermore, supportive leadership behavior also clarifies roles by consultations and open communications. Moreover, as Michaels et al. (1987) argue, leadership consideration may also include employee participation to a certain extent allowing the opportunity for discussing and resolving conflicts. Therefore, we hypothesize that:

\section{$\mathbf{H}_{5 \mathbf{a}}$ : There will be a negative relationship between leadership consideration and role ambiguity.}

$\mathbf{H}_{5 \mathrm{~b}}$ : There will be a negative relationship between leadership consideration and role conflict.

\subsubsection{Group Cohesiveness}

A supportive working environment not only depends on the behavior and attitude of supervisors but also on the concern and dedication of coworkers. Therefore, a group-level attribute that has been identified as an antecedent of role stress in organizations in the literature is group cohesiveness (Griffith 1988). Group cohesiveness has been defined as (Lott and Lott 1965, 259):

"...the desire of individuals to maintain their membership in a group."

As Kahn and Quinn (1970) argue, the psychological support of direct colleagues may help to decrease the strain of occupational roles. The underlying assumption here is that groups in which close ties between group members exist are more supportive of individual employees than noncohesive groups. Employees in cohesive groups are more likely to communicate with coworkers about problems they experience with respect to role ambiguity and role conflict. Beehr (1976) reports a negative correlation between group cohesiveness and role ambiguity. In addition, Babin and Boles (1996) demonstrate that employees perceiving considerable variance in performance of duties experience higher levels of role conflict. We hypothesize that:

\section{$\mathrm{H}_{6 \mathrm{a}}$ : There will be a negative relationship between group cohesiveness and role ambiguity. $\mathbf{H}_{6 \mathrm{~b}}$ : There will be a negative relationship between group cohesiveness and role conflict.}

\section{Conclusion}

We included both the "industrialization" approach and the "involvement" approach to service management in our conceptual model. The core of the "industrialization" model essentially is formalization. We assume that formalization will negatively affect role ambiguity, while formalization will positively affect role conflict. Formalization will create clarity regarding what the organization, the service manager and the colleagues expect from the service employee and thus reduce role ambiguity. Role conflict, on the other hand, may be increased by limiting the discretionary powers of the service employee. The service employee is required to work "by the rules" and the rules might not necessarily reflect the customer's point of view. Empowerment is included in the model as a proponent of the involvement model. Empowerment is operationalized in two dimensions: (1) competence and (2) autonomy. We expect that both competence and autonomy will reduce role stress in terms of role ambiguity and role conflict.

In addition to formalization and empowerment we also included leadership behavior and group cohesiveness as antecedents to role stress. Leadership behavior consists of two dimensions: (1) initiating structure and (2) leader consideration. Both dimensions are expected to negatively influence role stress. As far as group cohesiveness is concerned we hypothesize that increased group cohesiveness will reduce both components of role stress.

\subsection{Outcomes of Role Stress}

We distinguish two outcome variables for role stress: (1) jobs satisfaction and (2) performance. Performance is conceptualized in terms of service quality as perceived by the service employees. 


\subsubsection{Job Satisfaction}

Churchill et al. $(1974,255)$ define job satisfaction in a salesforce context as:

"all characteristics of the job itself and the work environmem which industrial salesman find rewarding, fulfilling, and satisfying, or frustrating and unsatisfying."

Role conflict and role ambiguity have been frequently identified as antecedents to job satisfaction (Churchill, Ford \& Walker 1976; Donelly \& Ivancevich 1975; Dubinsky \& Mattson 1979; Fisher \& Gitelson 1983; House \& Rizzo 1972; Jackson \& Schuler 1985; Kahn et al. 1964; Katz \& Kahn 1978; King \& King 1990; Micheals et al. 1988 Rizzo et al. 1970; Teas 1980, 1983). In general, measures of job satisfaction are indicative of an affective reaction, i.e., how employees feel about their work (Dubinsky and Hartley 1986). Included in most measures of job satisfaction are aspects such as pay, career opportunities, and the nature of the work itself (Brown and Peterson 1993; Ironson et al. 1989). Employees who experience role conflict and role ambiguity will experience less job satisfaction (Bagozzi 1978; Teas 1983; Behrman and Perrault 1984; Jackson and Schuler 1985; Michaels et al. 1987; Boles and Babin 1996). The dominant view in the literature is that the negative association that has been found in diverse organizational settings is related to the negative emotional connotations associated with role stressors (Boles and Babin 1996). We hypothesize that

$\mathbf{H}_{7 \mathbf{a}}:$ There will be a negative relationship between role ambiguity and job satisfaction. $\mathbf{H}_{7_{\mathbf{b}}}$ : There will be a negative relationship between role conflict and job satisfaction.

\subsubsection{Job Performance}

Job performance can be defined as the degree to which employees execute their job tasks, responsibilities and assignments adequately. Essentially two categories of performance measures can be distinguished: (1) objective performance measures and (2) subjective or selfreported measures. Self-reported measures are often based an assessment by the person itself or his supervisor. In this study we will use a self-reported measure of service quality as performance measure for the contact personnel or service employees.

It could be expected that role perceptions might have a considerably negative effect on job performance. The negative association between perceived role stress and performance can be explained as follows. Jackson \& Schuler (1985) indicate that there exists both a cognitive and a motivational explanation. The cognitive explanation entails that performance might be impeded by role ambiguity and role conflict, because employees are confronted with a lack of knowledge or with incompatible role expectations. They conclude (Jackson \& Schuler 1985 , 43):

"Therefore, regardless of the amount of effort expended, behaviors are most likely to be inefficient, misdirected, or insufficient."

The motivational explanation, on the other hand, would lead to a negative relationship, because role ambiguity and role conflict are negatively related to effort-to-performance and performance -to-reward expectancies.

Generally, the evidence in marketing settings points in the direction of a positive relationship; the more satisfied an employee is, the better she or he will perform (Behrman and Perrault 1984). Although intuitively appealing, empirical evidence for the relationship between job satisfaction and job performance has remained weak (Bagozzi 1980a; Micheals et al. 1987; Brown and Peterson 1993). For instance, Iaffaldano and Muchinsky (1985) in a meta analytic research report that the correlation between job satisfaction and job performance is .17 . Hartline and Ferrell (1996) argue that the weak association may be the result of the fact that in most studies performance is operationalized in terms of outcomes (e.g., sales volume) instead of 
behaviors (e.g., teamwork, courteousness) and that especially in a services context job satisfaction is more closely related to behavioral performance. There is evidence that satisfied employees deliver better service to customers (Weaterly and Tansik 1993a,b; Hartline and Ferrell 1996). Due to the fact that there is a close connection with the physical product, evaluations of after-sales services are commonly based on customer perceptions of the outcome as well as the process of service delivery, i.e., the encounter with the service provider (Brown and Swartz 1989; Grönroos 1984; Lapierre 1996). Therefore, Grönroos (1984) argues that quality perceptions are essentially based on the technical quality of the outcome and the functional quality of the process. Both outcome and process may be used as criteria or cues to assessing the quality of service (De Ruyter \& Wetzels 1998b). Therefore, we hypothesize positive relationships between job satisfaction and technical and functional service quality:

$\mathbf{H}_{8 \mathbf{a}}$ : There will be a positive relationship between job satisfaction and technical quality.

$\mathbf{H}_{\mathbf{8 b}}$ : There will be a positive relationship between job satisfaction and functional quality.

\section{Conclusion}

We have hypothesized that role ambiguity and role conflict lead to decreased levels of job satisfaction. The negative emotions associated with role stress will reduce job satisfaction. Several authors have suggested that there is a positive relationship between job satisfaction and job performance of service employees in terms of service quality. We have operationalized service quality as consisting of both an outcome (technical quality) and process component (functional quality).

\subsection{Conceptual Framework}

Figure 3-3 depicts the proposed conceptual model for the relationship between antecedents and outcomes of role stress using the Katz et al. (1964) framework. In this study attention will be focused on four antecedents to role stress: (1) formalization, (2) empowerment, (3)

\section{Figure 3-3: Conceptual Framework}

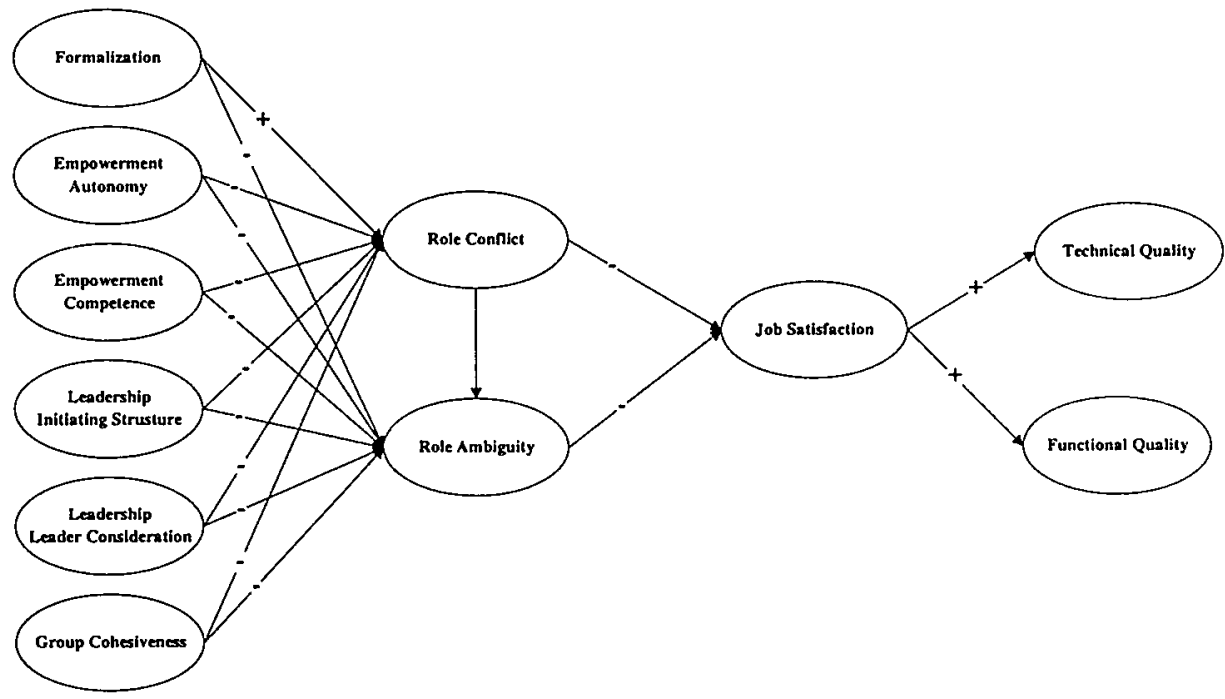


leadership behavior and (4) group cohesiveness. Empowerment is operationalized as consisting of two dimensions: (1) competence and (2) control. Leadership behavior similarly consists of two dimensions: (1) initiating structure and (2) leadership consideration. Role stress is the focal construct in this study and consists of two components: (1) role ambiguity and (2) role conflict. Job satisfaction and job performances are posited as consequences of role ambiguity and role conflict.

\subsection{Conclusion}

The Extended Model of Service Quality links internal or organizational antecedents to the gaps in the Conceptual Model of Service Quality. The research design for the Extended Model of service Quality requires a relatively complex and elaborate design. The model uses data from: (1) customers, (2) service managers and (3) customer-contact service employees. Furthermore, the research design calls for two levels of analysis: (1) individuals and (2) organizational entities. Moreover, the organizational entities may be viewed as sub-units and therefore are part of a larger organizational body. Thus, including a third level of analysis: the organization itself.

The model specification of the Extended Model of Service Quality also raises several concerns. It should be noted that the model is mainly of diagnostic value. There are no clear paths along which service improvements can be carried out. Furthermore, the conceptualization of the internal gaps closely resembles a formalized, mechanistic, bureaucratic organization. Such an organizational configuration might not be appropriate for all service organizations. Moreover, the relationship between the antecedents and the internal gaps is not unambiguous. Most of the antecedents are of an ad hoc as well as a structural level. The Extended Model of Service Quality proposes a top-down approach, whereas, more recently Total Quality Management recommends the use of bottom-up procedures, such as QFD or its services counterpart SQD. Clearly, the model might suffer from omission of relevant variables. Finally, the model essentially is static of nature and therefore the sequential order of variables cannot be determined unambiguously.

Empirical research has identified several shortcomings with regard to measurement properties of the internal gaps and the antecedents. Although the internal gaps (GAP2 to GAP4) show sufficient reliability in terms of coefficient $\alpha$, they are measured on attribute level only. Therefore, Smidts (1993) suggested to measure the internal gaps on item-level; thus increasing reliability and specificity (diagnostic value). The antecedents to the internal gaps exhibit unacceptably low levels of reliability in terms of coefficient $\alpha$. Either these measures need to be improved or published scales with favorable psychometric properties need to be included in the framework. These results have been confirmed in our empirical pre-study.

Our need for an alternative model is based on four considerations. To begin with, the research design of the Extended Model of Service Quality is fairly complex and elaborate. A more limited approach might be advised. Furthermore, the measurement instruments, especially for the antecedents, need considerable improvement. The model specification of the Extended Model of Service Quality makes it closely resemble a formalized, mechanistic, bureaucratic organization. The relationship between the gaps and the antecedents are not unambiguous. Moreover, the antecedents in the model might show considerable interrelations, which is not allowed for in the model in its present form. The antecedents are both ad hoc and structural of nature. Finally, the model is static and needs a more dynamic approach.

Therefore, a major revision should be considered. Two fields of research are particularly relevant for this revision: (1) marketing and (2) organizational theory. Marketing predominantly focuses on the customer as its object of study, while organizational theory focuses predominantly on the employee as its object of study. However, at the interface of the two disciplines valuable contributions can be found. 
Service employees share several characteristics with salespersons. Both service employees and service employees fulfill a boundary spanning role and form the link between the organization and the customer. Furthermore, both the performance of the salesperson and the performance of customer-contact service employees are essential to the economic success of the organization. Finally, when dealing with customers both the customer-contact service employee and the salesperson are called upon to perform innovative and creative activities to solve customers' problems. As a results of these characteristics service employees are particularly prone to role stress. Recently, two models have been proposed for the management of service employees. The first model suggests that service may be improved by "industrializing" the service; thus limiting the discretionary powers of service employees. The other model, also referred to as the "involvement" model, appeals to the ability of service employees to control their own activities using empowerment as its focal construct. In addition, we also have to take into account the supervisor and co-worker in the service organizations as major determinants of the performance of service employees.

Role theory posits that each individual performs a certain role in an organization. This role cannot be seen in isolation, but is related to other roles in the organization. Other individuals in the organization attempt to exert influences on the focal person by communicating role pressures or role expectations. Role conflict and role ambiguity occur, when the role expectations differ between role senders and focal person. Role conflict occurs when the focal person is confronted with conflicting role expectations from different external agents, i.e. inter-sender role conflict. Role ambiguity refers to lack of clarity regarding the role to be performed. Role ambiguity and role conflict are the result of a dynamic process affected by personal factors, interpersonal factors and organizational factors.

We included both the "industrialization" approach and the "involvement" approach to service management in our conceptual model. The core of the "industrialization" model essentially is formalization. We assume that formalization will negatively affect role ambiguity, while formalization will positively affect role conflict. Formalization will create clarity regarding what the organization, the service manager and the colleagues expect from the service employee and thus reduce role ambiguity. Role conflict, on the other hand, may be increased by limiting the discretionary powers of the service employee. The service employee is required to work "by the rules" and the rules might not necessarily reflect the customer's point of view. Empowerment is included in the model as a proponent of the involvement model. Empowerment is operationalized in two dimensions: (1) competence and (2) autonomy. We expect that both authority and control will reduce role stress in terms of role ambiguity and role conflict.

In addition to formalization and empowerment we also included leadership behavior and group cohesiveness as antecedents to role stress. Leadership behavior consists of two dimensions: (1) initiating structure and (2) leader consideration. Both dimensions are expected to negatively influence role stress. As far as group cohesiveness is concerned we hypothesize that increased group cohesiveness will reduce both components of role stress. We have hypothesized that role ambiguity and role conflict lead to decreased levels of job satisfaction. The negative emotions associated with role stress will reduce job satisfaction. Several authors have suggested that there is a positive relationship between job satisfaction in job performance of service employees in terms of service quality. We have operationalized service quality as consisting of both an outcome (technical quality) and process component (functional quality). 


\section{Chapter 4 \\ Service Quality and the Relationship Paradigm}

\section{Outline of the Chapter}

4.1 Introduction

4.2 Quality and Business Performance

4.3 Relationship Marketing in Services

4.4 Conceptualization of Commitment

4.5 Antecedents of Commitment

4.5.1 Service Quality and Customer Satisfaction

4.5.2 Trust

4.5.3 Dependence

4.6 Consequences of Commitment

4.7 Conceptual Model

4.8 Conclusion 


\section{Service Quality and the Relationship Paradigm}

\subsection{Introduction}

As competition intensifies, products and services become more homogeneous, and markets satiate, it is increasingly becoming harder for companies in both manufacturing and service industries to differentiate themselves from other organizations. Merely providing customers with technical solutions to problems does not suffice anymore to be competitive and gain and retain market share. Various additional services, which start before the actual transaction and go far beyond it, have to be delivered in order to stay competitive and create customer loyalty. Research and business practices have shown that in services the keeping of customers costs less than acquiring new ones (Reichheld \& Sasser 1990, 1996). Besides this, loyal customers will generate more revenues in the long run. These notions led to the introduction of relationship marketing in the (service) marketing literature and to the incorporation of relationships in models of service delivery processes. As Anderson \& Fornell $(1994,13)$ state:

"whether or not the customer remains loyal depends critically on the overall level of satisfaction with the current supplier. Hence to a large extent, customer satisfaction drives future profitability."

This emphasizes the importance of keeping customers satisfied and creating good relationships with them. By doing so, companies are able to secure their continuity throughout the years.

The seminal PIMS studies have attempted to link quality to business performance in terms of return on investment (ROI). This link is established via increased market share, reduced costs and premium prices. More recently, Fornell and his colleagues attempted to unravel the intricate relationship between quality and business performance using a different perspective (Anderson et al. 1994; Fornell 1992, 1995; Fornell et al. 1996). They propose customer satisfaction affected by product quality might lead to increased loyalty and profitability. This approach takes a more relationship-based approach to quality and customer satisfaction.

In the relationship marketing literature the concept of commitment plays a central role, as it is a major characteristic of relationship marketing models (Scanzoni 1979). Commitment refers to an implicit or explicit pledge of the continuity of a relationship between exchange partners. This chapter should be viewed as a preliminary attempt to integrate concepts from the service quality/customer satisfaction area with concepts from the relationship marketing area. Service quality and customer satisfaction will be treated as antecedents of commitment in addition to the concepts of trust and dependence. Moreover, the consequences of commitment will also be examined. A model which incorporates antecedents and consequences of commitment in a comprehensive framework will be tested.

This chapter is structured as follows. In section 4.2 we will explore the relationship between quality and business performance. In section 4.3 the concept of relationship marketing will be discussed. In addition, the relationship life cycle, a process through which relationships develop, will be elaborated on. Subsequently, in section 4.4 the concept of commitment in business relationships will be discussed in more detail, because of its importance in relationship marketing. In sections 4.5 and 4.6 several antecedents and consequences of commitment will be identified and discussed and hypotheses regarding these constructs will be formulated. These hypotheses will be graphically summarized in section 4.7 in a conceptual model in which service quality, customer satisfaction, commitment and other related concepts will be incorporated. Finally, this chapter will be concluded in section 4.8 . 
performance has featured prominently in the PIMS (Profit Impact of Marketing Strategies) program sponsored by the Strategic Planning Institute (IPS) (Buzzell \& Gale 1987; Buzzell \& Wiersema 1981a,b; Phillips et al. 1983). From this program it can be concluded that market share is positively associated wit Return on Investment (ROI). The most important determinant of market share is product quality. Buzzell \& Gale $(1987,103)$ put it as follows:

\section{"The 1980s have shown just as clearly that one factor above all others - quality - drives market share."}

The measure of product quality used in the PIMS program is quality as perceived by management relative to the quality of the competitors' product offerings (Buzzell \& Gale 1987; Buzzel \& Wiersema 1981 a; Phillips et al. 1983).

Although Phillips et al. (1983) did not find a consistent direct positive effect of product quality on ROI, earlier work did find a direct positive relationship between product quality and ROI (Buzzel et al. 1975; Schoeffler et al. 1974). Jacobson \& Aaker (1987) similarly report a direct effect of product quality on ROI as well as an indirect via market share. The positive effect of market share on ROI is also reported in meta-analytic studies on the relation between market share and profitability. Capon et al. (1990) report a mean unweighted market share elasticity of 0.2 , while Szymanski et al. (1993) find mean unweighted market share elasticity of 0.26 . The positive effect of product quality on market share is somewhat contradictory to the view product differentiation via superior quality is typically a niche strategy (Porter 1980). The effect of product quality on business performance is typically two-pronged (Buzzell \& Gale 1987):

(1) Superior perceived quality. Superior perceived quality can be achieve by offering a product that more closely meets customer needs than does the competitor's product (Parasuraman et al. 1985; Steenkamp 1989). This will ultimately allow the firm to reap premium prices or offer superior value to customers by charging the same price for a superior product. The latter will lead to market share gains and subsequently cost reductions. These cost reductions result from experience curve effects (cf. Day \& Montgomery 1983).

(2) Superior conformance quality. Superior conformance quality is the result of more strictly adhering to product specifications. Superior conformance quality will lead to lower costs and finally to increased perceived quality (Crosby 1979; Garvin 1987). Of course, given that the product specifications were derived from customer needs. Otherwise customers would be left with high quality product in terms of conformance quality, but which would not suit their needs in terms of perceived quality (Parasuraman et al. 1985; Steenkamp 1989).

Empirical research using the PIMS database further supports the positive effect between product quality and price, but failed to find a relationship between product quality and costs (Jacobson \& Aaker 1987; Phillips et al. 1983). In addition, Phillips et al. (1983) report that quality indirectly reduces cost by increasing market share. This finding is, however not supported by Jacobson and Aaker (1987). The study by Jacobson \& Aaker by far and large represents a re-analysis of the PIMS database used in the study by Phillips et al. (1983). More in particular, the study by Jacobson \& Aaker (1987) makes use of pooled time series cross-sectional data instead of using purely cross-sectional data. Furthermore, product quality is modeled as an endogenous variable in their framework as opposed to Phillips et al. (1983), who modeled product quality as an exogenous variable. The latter permitted Jacobson \& Aaker (1987) to model the remaining four variables (ROI, market share, relative price and relative direct cost) as influencing relative product quality. Their results reveal that price positively affects product quality. This may be consistent with the signaling function of price as a indicator of quality (Monroe \& Dodds 1988; Peterson \& Wilson 1985; Rao \& Monroe 1989; Steenkamp 1989; Zeithaml 1988).

Although the PIMS program was the first attempt to systematically unravel the relationship between product quality and business performance, it left much to be desired (Jacobson \& Aaker 1987; Ramanujam \& Venkatraman 1984; Szymanski et al. 1993; Zahorik \& Rust 1992). To 
begin with, the PIMS database suffers from sample bias. The database is dominated by Fortune 1000 firms, which are characterized by higher market shares and higher profits than non-PIMS firms (Ramanujam \& Venatraman 1984; Szymanski et al. 1993) Service firms are relatively underrepresented (Zahorik \& Rust 1992). Results may therefore not be extended to service firms. Moreover, the validity of the measures used in the studies has been severely criticized. As we have already seen, product quality is operationalized as quality as perceived by management of the business unit involved in the program (Jacobson \& Aaker 1987; Zahorik \& Rust 1992). The same applies for the definition of the business unit itself. Participants may define the market of the business unit too narrowly and thus may inflate the magnitude of the market share (Jacobson \& Aaker 1987; Szymanski et al. 1993). The use of ROI as a measure is financial performance might not be appropriate. Jacobson \& Aaker (1987) argue that ROI is flawed, because it does not accurately represent the underlying concept of the internal rate of return. Finally, the PIMS data are essentially aggragated on business unit level. In other words, brand and product lines are aggregated and effects present on the product level may be concealed (Jacobson \& Aaker 1987).

However, not only the measures seem flawed, also the mechanism which links product quality and profitability seems not fully developed. Recently, Claes Fornell and his colleagues attempted to shed more light on the relationship between product quality and business performance (Anderson et al. 1994; Fornell 1992, 1995; Fornell et al. 1996). They introduce a framework which links perceived quality through customer satisfaction and customer loyalty to business performance, i.e. profitability. Although this framework seems similar to the PIMS framework the starting point of either framework is quite different.

The PIMS approach emphasizes that market share maximization is essential for maximization of profits (Buzzell \& Gale 1987). This notion essentially reflects an offensive strategy given the low growth rates and highly competitive markets in most developed countries (Fornell 1992). The success (or failure) of such a strategy is reflected in gains (or losses) of market share relative to competitors. Fornell and his colleagues, on the other hand, suggest that a more defensive strategy may be more effective in creating and maintaining a healthy customer base (Anderson et al. 1994; Fornell 1992; Fornell \& Wernerfelt 1987, 1988; Fornell et al. 1996). Although it should be recognized that all firms use a mix of offensive and defensive strategies, most firms have devoted a large proportion of their resources to their offensive capabilities (Fornell 1992; Rust \& Zahorik 1993). For instance, Fornell $(1992,7)$ reports that:

"The annual expenditure on advertising and sales promotion in the U.S. alone is well over one trillion dollars."

Essentially, the objective of a defensive strategy is it to maximize customer retention. Or as Fornell $(1992,8)$ formulates it:

"...to minimize customer turnover (maximize customer retention), given certain cost constraints [...], by protecting product and markets from competitive inroads."

According to Fornell (1992) this objective can be achieved by means of erecting switching barriers or by high levels of customer satisfaction. Fornell advances two reasons why barriers might be less effective than customer satisfaction in achieving the objectives of a defensive strategy. First and foremost, switching barriers constitute a liability to attracting potential customers, as these may be aware of the existence of switching barriers. As a consequence, these may have an adverse effect on the willingness of potential customers to purchase the product. Secondly, switching barriers may be negated by external forces, such as imitation by competitors, deregulation, etc. Therefore, customer satisfaction may be a more effective tool to achieve the objective of customer retention. Increased customer loyalty will, on its turn, lead to increased business performance, i.e. profitability (Reicheld \& Sasser 1990). Apart from positively affecting customer loyalty, customer satisfaction also shows beneficial effects for other variables (Anderson et al. 1994; Fornell 1992): 
(1) reduced price elasticities;

(2) reduced marketing costs;

(3) increased marketing costs for competitors;

(4) lower transaction costs;

(5) increased cross-selling;

(6) lower employee turnover;

(7) enhanced reputation and

(8) reduced failure costs.

Although the defensive capabilities of customer satisfaction are generally acknowledged, customer satisfaction may also exhibit offensive capabilities (Rust \& Zahorik 1993; Rust et al. 1995; Zahorik \& Rust 1992). Rust et al. (1995) argue that the offensive capabilities of a firm are mainly enhanced by positive word of mouth and the ability to use improved quality as a theme in advertising.

The above does not mean that there is monotonically increasing relationship between customer satisfaction and market share. It is rather likely that at some point diminishing returns may occur (Anderson et al. 1994). If we assume a positive relationship between customer satisfaction and profitability, how does such a notion relate to the positive relationship between market share and profitability. Fornell (1992) argues that this does not necessarily mean that there is a positive relationship between customer satisfaction and market share. He proposes that in the case of heterogeneous market demand and homogeneous market supply the relationship might actually be negative. This may be caused by the relatively large differences between the customer's ideal point (or ideal product) and the actual product offering for firms operating on a market with diverse customer needs (cf. Green \& Srinivasan 1978). A firm holding a large market share of heterogeneous customers may consequently be faced with less satisfied customers than a firm holding a small market share of homogeneous customers (Anderson et al. 1994; Fornell 1992, 1995; Griffin \& Hauser 1993). Empirical work by Anderson et al. (1994) supports this view. They find a Pearson correlation coefficient of $-0.25(\mathrm{p}=0.03 ; \mathrm{n}=77)$ between market share and customer satisfaction. Moreover, empirical work by Griffin \& Hauser (1993) indicate that the relationship between a monadic satisfaction measure - customers rate a brand they have chosen - and brand share is not significant (rank correlation $=0.20$; $\mathrm{t}$-statistic $=0.58$ $[\mathrm{p}=0.15])$.

More recently, Fornell cum suis (Anderson et al. 1994; Fornell et al. 1996) proposed a framework, in which customer satisfaction is determined by perceived quality, perceived value and customer expectations. Customer satisfaction, on its turn, affects both customer complaints and customer loyalty (Fornell \& Wernerfelt 1987, 1988; Hirschman 1970). This framework has been empirically tested on the basis of firm-level data derived from the Swedish Cüstomer Satisfaction Barometer (Anderson \& Sullivan 1993; Anderson et al. 1994) and the American Customer Satisfaction Index (Fornell et al. 1996).

On the basis of the data of the Swedish Customer Satisfaction Barometer Anderson et al. (1994) found that ROI is strongly affected by customer satisfaction. Ittner \& Larcker (1996) found similar results for the ACSI. Anderson et al. (1994) show that an increase of customer satisfaction with five percentage points results in cumulative discounted returns amounting to $\$ 7.48$ million for a typical Swedish firm with an asset base of $\$ 600$ million. Given an initial ROI of $10.83 \%$ this will result in increase of $11.5 \%$ in five year period. Fornell et al. (1996) contend that measures such as the Swedish Customer Satisfaction Barometer and the American Customer Satisfaction Index provide a leading indicator to a firm's future financial position. Empirical evidence relates that investment strategies based on either of the above indices have resulted in returns well above the market rate of return (Fornell et al.1996).

Both Anderson \& Sullivan (1993) and Anderson et al. (1994) provide empirical support for (current) perceived quality as being the single most important determinant of satisfaction. However, the quality measure used is operationalized relative to price; as such this operationalization show a high degree of resemblance with perceived value (Zeithaml 1988). 
Although perceived quality shows the strongest impact on customer satisfaction, lagged customer satisfaction (customer satisfaction in period $\mathrm{t}-1$ ) also influences customer satisfaction (i.e., in period t-1). This carry-over effect indicates that high customer satisfaction may insulate a firm from short-term fluctuations in perceived quality. Fornell et al. (1996) have respecified their measure of quality for the American Customer Satisfaction Index in order to avoid the overlap between perceived quality and perceived value. Their results reveal that quality appears to have the largest impact on customer satisfaction. More in particular, they find that the customization aspect is substantially more important than the reliabilty aspect.

The effect of perceived quality can be expressed in terms of an average elasticity of ROI with respect to quality. Anderson et al. (1994) report an average elasticity of ROI with respect to quality of 0.20 . This is slightly less than the average elasticity on the basis of the PIMS studies, which equals 0.25 . The positive effect of quality on the financial performance of a firm is also reflect in meta-analytic studies (Capon et al. 1990; Szymanski et al. 1993). Capon et al. (1990) report that on the basis of a counting method the relationship between product quality and financial performance of the firm is positive; of the 112 reported relationships 104 are positive (using a sign test this is statistically significant a $\alpha=0.05$ ). Szymanski et al (1993) find that the relationship between market share and profitability is significantly moderated by product quality. More specifically, they find that the market share elasticity is $0.116 \%$ higher when product quality is omitted from the profit model.

Although in general the positive effect of quality on business performance is recognized both by practitioners and academics, Rust et al $(1995,58)$ contend that:

"...the quality revolution is not without its casualties."

They provide several examples of firms which spend large amounts of resources on quality improvements that could not be sustained by the firms resulting either in bankruptcy or in dismantling the quality program. These examples illustrate that quality improvements may be subject to diminishing returns. This notion has also been uncovered by Fornell and his colleagues on the basis of the above mentioned national studies (Anderson et al. 1994; Fornell et al. 1996). Especially, with regard to service organizations the effect of quality improvements may rather be modest, as customization limits the potential impact of economies of scale (Rust et al. 1995). Rust cum suis therefore propose a framework that makes quality expenditures financially accountable on the level of an individual firm (Rust \& Zahorik 1993; Rust et al.1995): the Return On Quality approach. This approach hinges on four assumptions:

(1) Quality is an investment;

(2) Quality efforts must be financially accountable;

(3) It is possible to spent too much on quality and

(4) Not all quality expenditures are equally valid.

The chain between quality improvements and ultimately profitability is based on the following links (Rust \& Zahorik 1993; Rust et al. 1995). Improvement of service quality results in increased perceived service quality and subsequently leads to an increased level of customer satisfaction. Moreover, quality improvements might negatively affect costs. Customer satisfaction, on its turn, positively affects customer retention and positive word-of-mouth. Customer retention and the attraction of new customer via positive word-of-mouth will lead to market share growth. The combined effect of increased market share and cost reductions will ultimately exhibit a positive effect on profitability. At the heart of this approach is the concept of Return On Quality (ROQ):

$$
R O Q=\left(N P V-N P V_{0}\right) / N P V A S
$$


NPV and $N P V_{0}$ in equation (4.1) represent the net present value for the quality improvement and the net present value for no quality improvement - status quo. NPVAS is the net present value of additional spending and represents the extra expenditures for the quality improvement. Rust et al (1995, 66-67) provide an insightful illustration of this approach for a hotel chain. They indicate that additional spending of $\$ 1.4$ million annually for three years used for increasing the cleanliness of the bathroom results in an increase of net present value with $\$ 1.641$ million. This amounts to an ROQ of:

\section{$\mathrm{ROQ}=\$ 1.641 / \$ 3.676=44.6 \%$}

This approach allows managers to quantify their quality improvements. Alternative quality improvements can be compared on the basis of ROQ and the projects with the highest yield in terms of ROQ can then be implemented. Furthermore, quality improvements can now compete with other investment projects, such as new products. Clearly, trade-offs can be made which was deemed not conceivable before the introduction of this approach.

\section{Conclusion}

The PIMS program has established a positive relationship between quality and profitability in terms of ROI. This can be explained by using a two-pronged approach. In the first place superior quality allows the firm to reap premium prices. In the second place superior conformance quality leads to cost reductions. Empirical research supports the positive relationship between quality and price, but failed to find a relationship between quality and costs. Furthermore, quality positively affects market share and market share subsequently increases the profitability of the firm. A direct relationship between quality and profitability has also been reported by a number of studies. More recently, Fornell and his colleagues have proposed an alternative approach to the relationship between quality and profitability. They proposed that quality is positively related to customer satisfaction. Customer satisfaction leads to increased customer retention and customer loyalty. Rust cum suis propose that quality needs to be financially accountable and that it is possible to spent to much on quality. They suggest that quality improvements need to be evaluated using their Return on Quality concept.

\subsection{Relationship Marketing in Services}

The service business originally evolved around keeping close relationships with customers. However, because of the increasing number of customers and the stressing of the marketing mix paradigm, the relationship with customers moved to the background during the sixties and the seventies (Grönroos 1995). It was not until the early eighties that relationship marketing reemerged again in service practices (Berry 1983, 1995). This was due to the maturing of service marketing with an emphasis on quality, increased recognition of potential benefits for companies and the customer, and technological advances. Another factor was that the marketing mix paradigm did not fit service company's customer relations very well, which led to the development of service marketing as a discipline in its own right (Grönroos 1990a).

How can relationships in services marketing be conceptualized? Berry $(1983,25)$ defined relationship marketing as:

“...attracting, maintaining and - in multi-service organizations - enhancing customer relationships."

Morgan \& Hunt (1994) propose that relationship marketing refers to all marketing activities directed towards establishing, developing and maintaining successful relational exchanges. They argue that in fact there are no buyers and sellers or providers and customers in relational exchanges but partners exchanging resources. Relational exchange differs from discrete transaction on several dimensions (Dwyer et al. 1987). First of all, relational exchanges may 
decrease over time as this may be beneficial to one or both partners. Secondly, relational exchange partners can be expected to derive complex, personal, non-economic satisfactions and engage in social exchange. Thirdly, because obligations and activities may be relatively complex and take place during an extended time period, partners may engage in carefully planning and controlling items of exchange. Finally, third parties may be called in to arbitrate and additional mechanisms for collaboration and resolving conflict may have to be designed. Relational exchange can provide a competitive advantage to the extent that it contributes to product and/or service differentiation and creates barriers to switching (Dwyer et al. 1987).

Relationships between partners do not just emerge or exist, they evolve through a process over time. This process is characterized by five general phases (Scanzoni 1979). The first phase in this relationship life-cycle is called awareness and refers to the recognition that some second partner is a feasible exchange partner. There is no interaction between the parties, they only try to position themselves in the best possible way the increase the attraction towards other companies. After awareness comes exploration, which is the search and trial phase in relational exchange. In this phase potential exchange partners first consider obligations, benefits and burdens and, the possibility of exchange. The third phase is called expansion, which refers to the continual increase in benefits obtained by exchange partners and their increasing interdependence. The main distinction between this phase and the previous phase of exploration is that now the partners trust each other to a greater extent and are satisfied with the relationship which leads to increased risk taking in the dyad. If relationships develop then commitment is formed between the two business partners. Commitment is the most desirable aspect of relationships and refers to an implicit or explicit pledge of relational continuity between exchange partners (Dwyer et al. 1987). Now the exchange partners have achieved a level of satisfaction from the exchange process that virtually precludes other primary exchange partners who could provide similar benefits. Commitment is established on the basis of two important assumptions. The first is that partners provide relatively high levels of inputs to the association. The second assumption pertains to durability, i.e., the common belief of effectiveness of future exchange, also referred to as continuation.

The final phase of the relationship development process is dissolution. This phase begins with an intrapsychic stage in which one partner privately evaluates his or her dissatisfaction with the other party, concluding that the costs of modification or continuation outweigh the disadvantages of the relationship. Afterwards, the relationship enters an interactive phase in which the parties negotiate their unbonding. Dissolution is then presented publicly.

It should be clear that of these five phases, the fourth phase of commitment, is the most desirable one in the development of an ongoing relationship between a buyer and a sell er. If the parties are not committed to their relationship, it will end at a rapid pace. Therefore, the concept of commitment should play a central role in the development of a model that introduces relational exchanges to the marketing of services. However, as a result of the paradigm shift towards relationships, researchers are facing the challenge of conceptualizing and operationalizing heterogeneous, overlapping and equivocal constructs. With respect to the central concept of commitment, Morrow $(1983,486)$ accentuates this challenge by stating that:

"...the growth of commitment-related concepts has not been accompanied by a careful segmentation of commitment's theoretical domain."

Therefore, we shall direct our attention to the conceptualization of commitment in the next section.

\section{Conclusion}

The relationship paradigm suggests that it is beneficial for both the service provider and the customer to maintain a long term relationship. The relationship can be viewed as consisting of five phases: (1) awareness, (2) exploration, (3) expansion, (4) commitment and (5) dissolution. 
The fourth phase, commitment is the most desirable one in the relationship between a service provider and customer.

\subsection{Conceptualization of Commitment}

As mentioned before, commitment plays a central role in relationships. As Scanzoni $(1979,87)$ stated:

"...commitment is the most advanced phase of partners' interdependence."

In marketing-practice and -research it is agreed upon that mutual commitment among partners in business relationships produces significant benefits for companies. Manufacturers can obtain improved product developments, increased margins and market shares. Distributors gain deeper market penetration and higher customer satisfaction. The conceptualization of commitment stems from industrial/organizational psychology and has been viewed as an intention to continue a course of action or activity, such as maintaining a relationship with a business partner (Fehr 1988). As mentioned in the introduction, commitment in the buyer-seller relationship literature is defined as an implicit or explicit pledge of relational continuity between exchange partners (Anderson \& Weitz 1989, 1992; Blau 1964; Cook \& Emerson 1978; Dwyer et al. 1987; Thibaut \& Kelley 1959). Parties identify commitment among exchange partners as key to achieving valuable outcomes for themselves, and they endeavor to develop and maintain this precious attribute in their relationship (Morgan \& Hunt, 1994). Commitment is seen as a sentiment that is critically important in the development of long-term channel relationships or as a favorable affective reaction (Kumar et al. 1995). Therefore, commitment is a psychological sentiment of the mind through which an attitude concerning continuation of a relationship with a business partner is formed.

In the literature two views of organizational commitment have dominated. According to one view, commitment is an affective state of mind an individual or partner has towards a relationship with another individual or partner. This kind of commitment is called affective commitment. Affective commitment is brought about by a person sharing, identifying with, or internalizing the values of the organization (Allen \& Meyer 1990; Kumar et al. 1994,1995; Morgan \& Hunt 1994; Mowday et al. 1982). The other view sees commitment as being more behavioral than affective. This form is referred to as calculative commitment and stems from a cognitive evaluation of the instrumental worth of a continued relationship with the organization. All gains and losses, plusses and minuses or rewards and punishments are added up (Morgan \& Hunt 1994). This view stems from the Side-Bet theory of Becker (1960), which links extraneous interests with a consistent line of activity. From research it can be concluded that of these two forms of commitment affective commitment is the most effective for developing and maintaining mutually beneficial relationships between partners (Kumar et al. 1994). Affective commitment has strong positive influences on (1) intention to stay in a relationship, (2) desire to stay in a relationship, (3) performance, and (4) willingness to invest in a relationship. Furthermore, it was found that it has strong negative influences on (5) development of alternatives for a relationship and (6) opportunistic behavior. Calculative commitment in contrast has positive influences on (5) development of alternatives and (6) opportunism. Therefore, this latter form of commitment ultimately has a negative impact on relationships.

\section{Conclusion}

Commitment is essential in developing long term relationship between service providers and customers. Two approaches to commitment dominate the relationship field. The first approach views commitment as largely affective of content. The second approach considers commitment to be more calculative of nature. Both affective and calculative commitment positively affect intention to maintain an existing relationship. 


\subsection{Antecedents of Commitment}

Because of the importance of commitment in the development of relationships, information on the factors that influence commitment is essential. Firstly, service quality and customer satisfaction, the two key constructs in the services marketing area, will be related to commitment. Subsequently, two additional factors will be related to commitment: trust and dependence. Various studies in the relationship marketing area have shown that these two factors seem to be crucial in influencing commitment (Anderson \& Weitz 1989, 1992; Anderson \& Narus 1990; Geyskens \& Steenkamp 1995; Geyskens et al. 1996; Ganesan 1994; Kumar et al. 1994, 1995; Morgan \& Hunt 1994). As we discuss these constructs, hypotheses for our study will be formulated.

\subsubsection{Service Quality and Customer Satisfaction}

During the past decade substantial research has been devoted to the quality of services and the measurement of service quality. Also in marketing practice service quality has been recognized as being of crucial importance. Especially in recent years, the relationship between service quality and customer satisfaction has received a lot of attention (See Chapter 2). A focal point of discussion is the causal ordering between service quality and customer satisfaction. Also there is considerable debate about the conceptual distinctness of these two concepts. The predominant view is that quality influences customer satisfaction (lacobucci et al. 1996). Cronin \& Taylor (1992) find empirical support that service quality is an antecedent of customer satisfaction. According to Grönroos (1984, 1990a) quality can be classified into two categories. First of all, there is technical quality which relates to the quality of the result or outcome of the service, i.e., what the customer is actually receiving from the service. Secondly, functional quality relates to the manner in or process by which a service is provided, i.e., how the service is delivered.

In literature, there is limited conceptual and empirical evidence for the relationship between service quality, customer satisfaction and commitment. However, as commitment can be viewed and indeed has been operationalized as a proxy for loyalty (Assael 1987; Liljander \& Strandvik 1995a,b; Storbacka et al. 1994) and because strong positive associations between service quality, customer satisfaction and loyalty (Liljander \& Strandvik 1995a,b; De Ruyter et al. 1997c; Venetis 1997; Zeithaml et al 1996) have been reported extensively in the services marketing area, we posit that there will be positive relationships between technical and functional service quality, customer satisfaction and affective and calculative commitment.

$\mathbf{H}_{1 \mathrm{a}}$ : There will be a positive relation between customer satisfaction and affective commitment.

$\mathrm{H}_{1 \mathrm{~b}}$ : There will be a positive relation between customer satisfaction and calculative commitment.

$\mathbf{H}_{2 \mathrm{a}}$ : There will be a positive relation between technical quality and affective commitment.

$\mathbf{H}_{2 \mathrm{~b}}$ : There will be a positive relation between functional quality and affective commitment.

$\mathbf{H}_{3 \mathrm{a}}$ : There will be a positive relation between technical quality and calculative commitment.

$\mathbf{H}_{3 \mathrm{~b}}$ : There will be a positive relation between functional quality and calculative commitment.

$\mathrm{H}_{\mathbf{4}_{\mathrm{a}}}$ : There will be a positive relation between technical quality and customer satisfaction.

$\mathbf{H}_{4 \mathrm{~b}}$ : There will be a positive relation between functional quality and customer satisfaction.

\subsubsection{Trust}

Trust is defined as one party's belief that its needs will be fulfilled in the future by actions undertaken by the other party (Anderson \& Weitz 1989). Trust exists when one party has confidence in the reliability and integrity of the exchange partner (Morgan \& Hunt 1994). In social psychology a consensus emerges that trust consists of two essential elements, trust in the partner's honesty and trust in the partners benevolence. Honesty is the belief that one's partner 
stands by its word. Benevolence is the belief that one's partner is interested in the company's welfare and will not take unexpected actions which will negatively impact the company (Geyskens \& Steenkamp 1995). When a distinction is made between affective and calculative commitment, it was found that trust, comprising of honesty as well as benevolence, has a positive influence on affective commitment (Anderson \& Weitz 1989; Anderson \& Narus 1990; Geyskens \& Steenkamp 1995; Geyskens et al. 1996; Morgan \& Hunt 1994; De Ruyter \& Wetzels 1998c; De Ruyter et al.1997c; Venetis 1997). Calculative commitment was negatively influenced by trust (Geyskens \& Steenkamp 1995; Geyskens et al. 1996). It seems that if partners in a relationship trust each other more they are more emotionally involved and less consciously weighing the benefits against the costs of that relationship. Therefore, we expect that both types of trust will be positively related to affective commitment and negatively to calculative commitment.

$\mathbf{H}_{5 \mathrm{a}}$ : There will be a positive relation between trust (benevolence) and affective commitment.

$\mathbf{H}_{5 \mathrm{~b}}$ : There will be a negative relation between trust (benevolence) and calculative commitment.

\section{$\mathbf{H}_{6 \mathrm{a}}:$ There will be a positive relation between trust (honesty) and affective commitment.}

$\mathrm{H}_{6 \mathbf{b}}$ : There will be a negative relation between trust (honesty) and calculative commitment.

\subsubsection{Dependence}

Dependence is referred to as asymmetry in a relationship between two partners. A company's dependence on a partner traditionally has been defined in channels as the company's need to maintain a relationship with the partner to achieve its goals (Geyskens et al. 1996; Kumar et al. 1995). In other words, the higher the dependence between two parties, the more one party needs the other party to benefit from the relationship. It was found that dependence in relationships has a negative impact on affective commitment (Anderson \& Weitz 1989; Kumar et al. 1995) and a positive influence on calculative commitment (Ganasan 1994; Geyskens \& Steenkamp 1995; Geyskens et al. 1996). If parties feel that they are more dependent on some other party they are less emotionally involved in the relationship and more comparing the costs with the benefits. If a potential relationship with another party seems more favorable in terms of more equality between the partners, then the current relationship is easily terminated. Therefore, we expect that higher dependence between partners will lead to less affective commitment and more calculative commitment.

\section{$\mathrm{H}_{7_{\mathrm{a}}}$ : There will be a negative relation between dependence and affective commitment. \\ $\mathbf{H}_{7 \mathrm{~b}}$ : There will be a positive relation between dependence and calculative commitment.}

\section{Conclusion}

We have identified five antecedents to commitment. To begin with, we assume that technical and functional quality positively affect customer satisfaction. Subsequently, we hypothesized that customer satisfaction increases both calculative and affective commitment. Trust, operationalized as honesty and benevolence, positively influences affective commitment, but negatively affects calculative commitment. Finally, dependence is assumed to have a negative effect on affective commitment and a positive effect on calculative commitment.

\subsection{Consequences of Commitment}

Ultimately, any firm interested in exchange relationships with its customers would have an interest in the continuance of commitment. This has been called the temporal dimension of commitment (Gundlach et al. 1995). The manifestation of this temporal dimension can be found in partners' intentions to continue the relationship in the future. In modeling terms, intention to stay would be the variable that one would like to be able to explain. We expect positive relationships between the two types of commitment and the intention to stay in the relationship. 
Furthermore, we expect that customer satisfaction is positively related to the intention to stay in the relationship.

$\mathbf{H}_{\mathbf{8}}$ : There will be a positive relation between customer satisfaction and intention to stay in the relationship.

$\mathbf{H}_{9}$ : There will be a positive relation between affective commitment and intention to stay in the relationship.

$\mathbf{H}_{10}$ : There will be a positive relation between calculative commitment and intention to stay in the relationship.

\section{Conclusion}

Intention to stay is modeled as outcome to commitment. We posit that both calculative commitment and affective commitment positively affects the intention to stay. Moreover, we also assume a direct positive relationship between customer satisfaction and intention to stay.

\subsection{Conceptual Model}

The hypotheses we formulated can be summarized graphically by the following conceptual framework, rendered in Figure 4-1. To study relational commitment and its relationship with various antecedents and consequences, it is necessary to develop a conceptual framework. The theoretical as well as managerial relevance of an investigation of relationship marketing, in which commitment plays a central role, is based on the identification of a number of antecedents of this type of marketing. These antecedents were discussed in the previous sections of this paper. With affective commitment as primary focal construct and calculative commitment as secondary focal construct five independent antecedents are identified: technical quality, functional quality, trust (benevolence), trust (honesty) and dependence. Customer satisfaction is dependent on service quality, but also influences affective and calculative commitment. Therefore, this concept also will be a direct antecedent of commitment. Finally, we expect that a

\section{Figure 4-1: Conceptual Model}

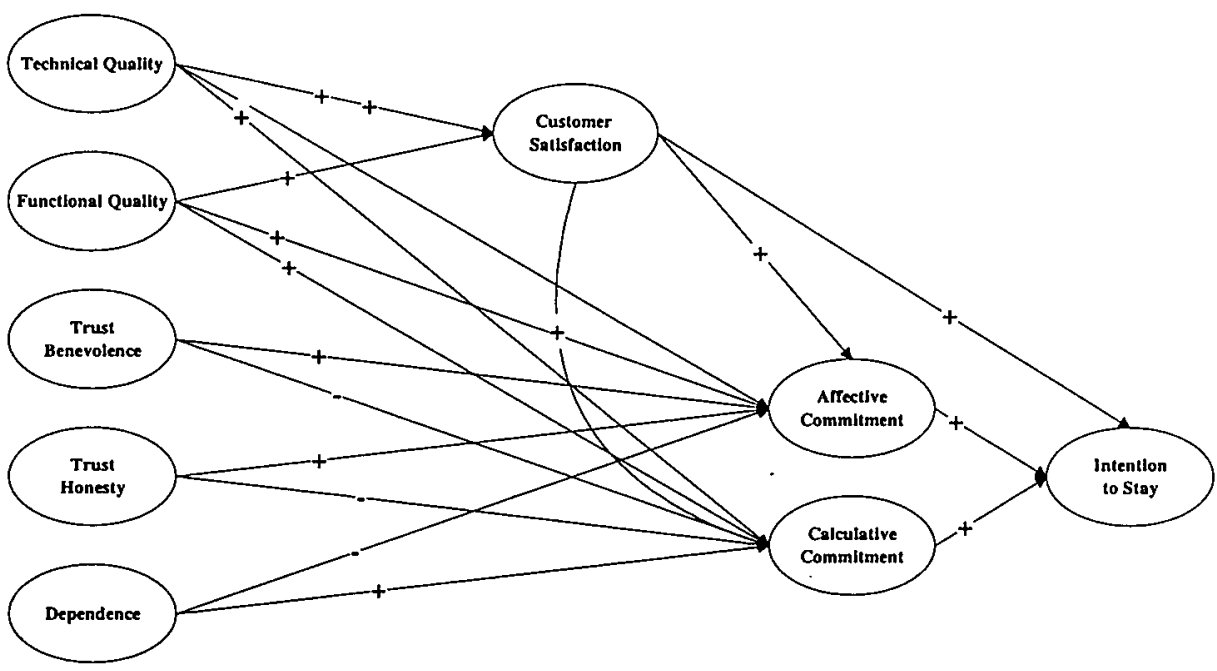


relationship with high levels of customer satisfaction and commitment will lead to a high level of loyalty of the customer towards the selling organization. This behavioral consequence, an intention to stay in the relationship, will therefore be the outcome of our framework of relationship marketing.

\subsection{Conclusion}

The PIMS program has established a positive relationship between quality and profitability in terms of ROI. This can be explained by using a two-pronged approach. In the first place superior quality allows the firm to reap premium prices. In the second place superior conformance quality leads to cost reductions. Empirical research supports the positive relationship between quality and price, but failed to find a relationship between quality and costs. Furthermore, quality positively affects market share and market share subsequently increases the profitability of the firm. A direct relationship between quality and profitability has also been reported by a number of studies. More recently, Fornell and his colleagues have proposed an alternative approach to the relationship between quality and profitability. They proposed that quality is positively related to customer satisfaction. Customer satisfaction leads to increased customer retention and customer loyalty. Rust cum suis propose that quality needs to be financially accountable and that it is possible to spent to much on quality. They suggest that quality improvements need to be evaluated using their return on quality concept.

The relationship paradigm suggests that it is beneficial for both the service provider and the customer to maintain a long term relationship. The relationship can be viewed as consisting of five phases: (1) awareness, (2) exploration, (3) expansion, (4) commitment and (5) dissolution. The fourth phase, commitment is the most desirable one in the relationship between a service provider and customer. Commitment is essential in developing long term relationship between service providers and customers. Two approaches to commitment dominate the relationship field. The fist approach views commitment as largely affective of content. The second approach considers commitment to be more calculative of nature. Both affective and calculative commitment positively affect intention to maintain an existing relationship.

We have identified five antecedents to commitment. To begin with, we assume that technical and functional quality positively affect customer satisfaction. Subsequently, we hypothesized that customer satisfaction increases both calculative and affective commitment. Trust, operationalized as honesty and benevolence, positively influences affective commitment, but negatively affects calculative commitment. Finally, dependence is assumed to have a negative effect on affective commitment and a positive effect on calculative commitment. Intention to stay is modeled as outcome to commitment. We posit that both calculative commitment and affective commitment positively affects the intention to stay. Moreover, we also assume a direct positive relationship between customer satisfaction and intention to stay. 


\section{Chapter 5 \\ Empirical Research}

Role Stress in After-Sales Service Management: its antecedents and consequences

\section{Outline of the Chapter}

5.1 Introduction

5.2 Conceptual Framework

5.3 Methodology

5.3.1 Research Setting

5.3.2 Sampling Design and Data Collection

5.3.3 Questionnaire Design

5.3.4 Data Analysis

5.4 Results

5.4.1 Sample Characteristics

5.4.2 Construct Validation

5.4.3 Testing Substantive Hypotheses

5.4.4 A Longitudinal Approach

5.5 Discussion

5.6 Implications of this Study

5.6.1 Theoretical Implications

5.6.2 Managerial Implications

5.7 Conclusion 


\section{Role Stress in After-Sales Service Management: Its Antecedents and Consequences ${ }^{1}$}

\subsection{Introduction}

In this chapter we will be focusing on the testing of the conceptual model developed in Chapter 3. The conceptual model in Chapter 3 relates organizational antecedents to service quality as a performance measure for customer-contact service personnel. Our conceptual model heavily borrows from role theory; role stress, conceptualized as role ambiguity and role conflict, constitutes the focal constructs of the conceptual model. We have identified four antecedents to role stress: (1) formalization, (2) empowerment, (3) leadership behavior and (4) group cohesiveness. Subsequently, we have posited job satisfaction as a mediator between role stress and service quality as a performance measure.

We conducted an empirical study with the after-sales service unit of a large, Dutch manufacturer of office equipment. It should be emphasized that by far and large this study is exploratory of nature (Babbie 1995; Kerlinger 1986). Babbie (1995) indicates that exploratory studies are typically conducted for three reasons: (1) to satisfy the researcher's curiosity and desire for better understanding, (2) to test the feasibility of undertaking a more careful study and (3) to develop the methods to be employed in a more careful study. In essence, these three reasons apply to our study. First, of all we are applying this framework in an after-sales services setting. Although a boundary spanning position, it is different from the traditional sales position frequently researched in the field of marketing. Furthermore, we introduced empowerment as antecedent to role stress. Empowerment has only recently emerged as an explanatory variable in this respect and only a limited amount of research has been conducted since. Moreover, performance of the service employees is measured in terms of service quality and can therefore be considered a subjective, self-evaluation of performance of customercontact of service employees. Finally, we used measures that were originally developed in other settings and which need to be cross-validated in this particular setting.

This chapter is structured as follows. In section 5.2 we will briefly summarize the conceptual model developed in Chapter 3. In section 5.3 the methodological issues with respect to this study will be addressed. We will focus on the research setting (5.3.1), sampling design and data collection (5.3.2), questionnaire design (5.3.3) and the method of data analysis (5.3.4). In section 5.4 the results of this study will be presented. To begin with, the sample characteristics of our study will be provided (5.4.1). We will then concentrate on construct validation using structural equation modeling (5.4.2). Structural equation modeling will be used in section 5.4 .3 to estimate the substantive relationships in the conceptual model. Moreover, a longitudinal approach will be presented in section 5.4.4. In section 5.5 the results of our study will be discussed. In section 5.6 we will discuss the managerial and theoretical implications of our study. Finally, this chapter concludes with section 5.7.

\subsection{Conceptual Framework}

The objective of this section is it to briefly summarize the conceptual framework developed in Chapter 3 of this thesis. The conceptual model in Chapter 3 provides an alternative to the Extended Model of Service Quality presented in Chapter 3 (See Figure 5-1). It includes role stress, conceptualized as role ambiguity and role conflict, as its focal constructs. The model is aimed at service organizations and in most services the encounter between customer-contact service employee and customers is still at the heart of the business. Service quality is "created"

An adapted version of this chapter is submitted to the Journal of Service Research. 


\section{Figure 5-1: Relationships in the Conceptual Framework ${ }^{\mathrm{a}}$}

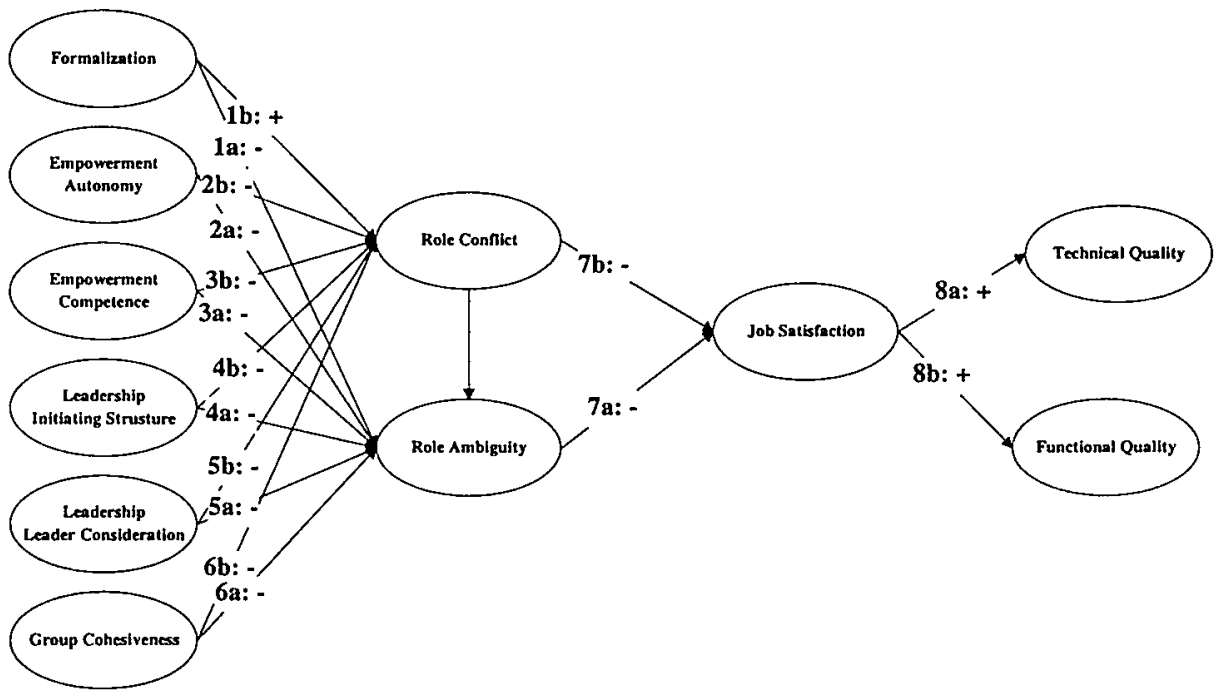

a The direction and the number of the hypothesis are attached to the corresponding relationships.

in this service encounter. We have identified a number of organizational antecedents to service quality, which are included in the model as a measure of service employee performance.

We have identified four antecedents regarding role stress: (1) formalization, (2) empowerment, (3) leadership behavior and (4) group cohesiveness. Empowerment consists of two dimensions: (1) autonomy and (2) competence. Role stress, role ambiguity and role conflict, on its turn influences job satisfaction. Finally, we posit that job satisfaction affects service employee performance in terms of technical and functional quality. In other words, service quality is the final outcome variable in our conceptual framework.

\subsection{Methodology}

In this section we will focus on the methodological issues concerned with this study. In section 5.3.1 the research setting will be described. Subsequently, we will concentrate on sampling design and data collection (5.3.2). In the next section (5.3.3) the questionnaire design will be discussed. Finally, section 5.3 .4 on data analysis concludes this section.

\subsubsection{Research Setting}

Our empirical study was conducted among customers of one of the leading office equipment firms in the Netherlands. The firm employs approximately 20,000 people and achieved an annual turnover of approximately $\$ 3$ billion. It operates internationally in about 80 countries. Its customer base is mainly located in Western Europe (more than $50 \%$ of turnover), the United States (approximately one third of turnover) however more recently the firm has also engaged activities in Eastern Europe and Asia. The company aims at being a technology and quality leader ( $7 \%$ of annual turnover are invested in $R \& D$ ). Recently, it introduced new and innovative products in almost all its markets. Its products combine reliability and ease-of-use. The company's range of products includes materials and machines for printing, plotting and copying. The company focuses on the medium and high volume segments and as such has relatively long 
relationships with its customers. One quarter of the employees is employed in services (i.e., more than 5,000 people).

The service department of the firm in the Netherlands employs approximately 250 service engineers, which are organized in 12 units with their own manager and customer base. The total number of customers is approximately 10,000 . If customers are confronted with a failure of the machine, they report this failure to central planning department. The planning department plans the jobs for the service engineers. The service engineers then take care of the problem. However, if parts are not available service engineers make an appointment and fix the problem as soon as possible.

\subsubsection{Sampling Design and Data Collection}

The relationships in the conceptual framework developed in Chapter 3 and briefly summarized in section 5.2 were tested with the after-sales service department of a major Dutch manufacturer of office equipment. Given the number of employees we decided to conduct a census, i.e. all employees were approached to participate in our study. This study consists both of a crosssectional and a longitudinal part. The use of a panel design allowed us to determine the effect of time lags. Our sampling design consisted of two waves, or time points. The interval between the two studies was approximately nine months.

A mail questionnaire was designed containing both open-ended and closed questions. All constructs included in our study were measured using multiple item measures. A package containing the questionnaire, a pre-paid return envelope and a personalized cover letter signed by the service manager was mailed. The questionnaires were returned directly to researcher by mail. In the first wave the population consisted of 256 service employees and in the second wave the population consisted of 259 service employees. In the first wave 148 questionnaires were returned and in the second wave 181 questionnaires were returned. The response rate was well above 50\% (wave 1: $57.8 \%$; wave 2: 69.9\%). In total 123 service employees completed both waves.

\section{Questionnaire Design}

Formalization was operationalized using a 6-item scale as proposed by Ferrell \& Skinner (1988). This instrument is an adaptation of the scale developed by John (1984). Empowerment was operationalized using the 9-item empowerment instrument suggested by Hartline \& Ferrell (1993). This empowerment instrument consists of two dimensions: competence (4 items) and autonomy ( 5 items). Leadership behavior was conceptualized in two dimensions: (1) initiating structure and (2) leader consideration. Initiating structure was measured using a 7-item scale suggested by House \& Dessler (1974) and leader consideration was operationalized by a 10-item scale developed by the same authors. Group cohesiveness was measured by scale originally developed by Seashore (1954) and further developed by Beehr (1976). The scale consists of 6 items. Role conflict and role ambiguity were measured by using the 14-item instrument developed by Rizzo et al. (1970). In this instrument role ambiguity is represented by 6 items and role conflict is measured by 8 items. Job satisfaction was operationalized on 8 items and is an adaptation of a scale originally devised by Churchill et al. (1974). Finally, customer-contact service employee performance was operationalized using 13 items for functional quality and 4 items for technical quality. We used the direct comparison scale introduced in chapter 2 . All the items on the different scales were measured with a 9-point Likert-type format. Apart from these measures four demographic variables were included in the study: (1) age, (2) education, (3) company experience and (4) personal experience. An overview of the measurement instruments employed in this study is provided in Table 5-1. The instruments are included in Appendix V. 
Table 5-1: Measurement Instruments

\begin{tabular}{lll}
\hline Construct & Items & Source \\
\hline Formalization & 6 & Ferrell \& Skinner (1988) \\
Empowerment - autonomy & 5 & Hartline \& Ferrell (1993) \\
Empowerment - competence & 4 & Hartine \& Ferrell (1993) \\
Leadership - initiating structure & 7 & House \& Dessler (1974) \\
Leadership - leader consideration & 10 & House \& Dessler (1974) \\
Group cohesiveness & 6 & Seashore (1954)/Beehr 1976 \\
Role conflict & 8 & Rizzo et al. (1970) \\
Role ambiguity & 6 & Rizzo et al. (1970) \\
Job satisfaction & 8 & Churchill et al. (1974) \\
Technical quality & 4 & Instrument developed for this study \\
Functional quality & 13 & Instrument developed for this study \\
\hline
\end{tabular}

\subsubsection{Data Analysis}

In designing our study we were confronted with one major procedural decision. After a thorough review of the literature we felt it compelling to include a relatively large number of constructs (11). These constructs were measured by multi-item scales following generally accepted procedures (cf. Churchill 1979). Consequently, a large number of indicators had to be dealt with (77). For the longitudinal design the number of constructs and items will even be doubled. Consequently, a latent variable model with multiple indicators might not be very helpful, since model complexity in terms of the number of constructs and/or indicators might prevent the researcher from finding a model fitting to the data (Bagozzi \& Heatherton 1994; Baumgartner \& Homburg 1996; Bentler \& Chou 1987; Fry et al. 1986).

Therefore, we opted for a partial aggregation model as proposed by Bagozzi \& Heatherton (1994), who argue that such a model is useful when one wishes to account for measurement error and/or the number of items is relatively large. This approach is based on the work of Kenny (1979) and James et al. (1982) and has received ample support in empirical work in a large variety of academic disciplines (Netemeyer et al. 1990; Osterhus 1997; Settoon et al. 1996; Williams \& Hazer 1986). Moreover, Netemeyer et al. (1990) report that this approach basically yields the same results as a latent variable model with multiple indicators. In brief, this approach entails the summing of items that compose a construct to form a single, aggregate scale for the whole construct, whereby the error variance is fixed at 1-reliability coefficient, and the path from the construct to the aggregate scale is fixed at the square root of the reliability (James et al. 1982; Kenny 1979; Loehlin 1987).

One mayor weak point of this approach is that quality of construct measurement can not be explicitly assessed (Baumgartner \& Homburg 1996). A remedy for this problem is to use confirmatory factor analysis (measurement model) in the first stage of the analysis (Anderson \& Gerbing 1988; Anderson \& Narus 1990; Heide \& John 1992; Kumar et al. 1994). This also takes care of the potential problem of interpretational confounding (Anderson \& Gerbing 1988; Williams \& Hazer 1986). Interpretational confounding refers to the occurrence of distorted structural parameters by simultaneously estimating measurement and structural models. Anderson \& Gerbing $(1988,418)$ indicate that:

"With a one-step approach, the presence of interpretational confounding may not be detected, resulting in fit being maximized at the expense of meaningful interpretability of the constructs."

Confirmatory factor analysis further yields insight into the unidimensionality, reliability and construct validity of the measures used in our study. In the first stage the measurement models were estimated. In the second stage the structural model will be estimated. In Table 52 this approach is represented in matrix notation for the conceptual model depicted in Figure 5-1. As we can observe from Table 5-2 the diagonal elements of both $\Lambda^{X}$ and $\Lambda^{Y}$ are fixed. These elements are fixed at the square root of the reliability coefficient derived from the 
Table 5-2: Matrix Representation of Conceptual Framework Using Partial Aggregation Approach $^{\text {a }}$

\section{Structural Model \\ $\left[\begin{array}{c}\mathbf{R C} \\ \mathrm{RA} \\ \mathrm{JS} \\ \mathrm{TQ} \\ \mathrm{FQ}\end{array}\right]=\left[\begin{array}{lllll}0 & 0 & 0 & 0 & 0 \\ 1 & 0 & 0 & 0 & 0 \\ 0 & 1 & 1 & 0 & 0 \\ 0 & 0 & 0 & 1 & 0 \\ 0 & 0 & 0 & 1 & 0\end{array}\right]\left[\begin{array}{c}\mathrm{RC} \\ \mathrm{RA} \\ \mathrm{JS} \\ \mathrm{TQ} \\ \mathrm{FQ}\end{array}\right]+\left[\begin{array}{cccccc}1 & 1 & 1 & 1 & 1 & 1 \\ 1 & 1 & 1 & 1 & 1 & 1 \\ 0 & 0 & 0 & 0 & 0 & 0 \\ 0 & 0 & 0 & 0 & 0 & 0 \\ 0 & 0 & 0 & 0 & 0 & 0\end{array}\right]\left[\begin{array}{c}\mathrm{FORM} \\ \mathrm{EMA} \\ \mathrm{EMC} \\ \mathrm{LIS} \\ \mathrm{LLC} \\ \mathrm{GC}\end{array}\right]+\left[\begin{array}{c}\zeta_{1} \\ \zeta_{2} \\ \zeta_{3} \\ \zeta_{4} \\ \zeta_{5} \\ \zeta_{6}\end{array}\right]$}

Measurement Models

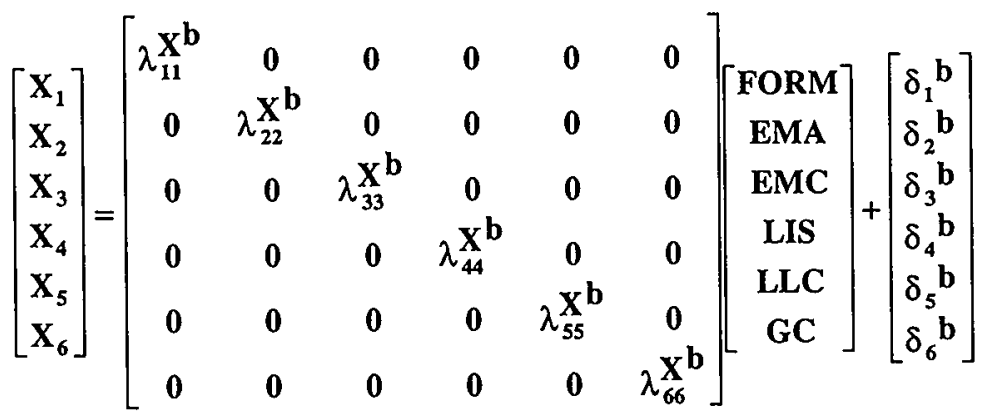

$\left[\begin{array}{c}\mathbf{Y}_{1} \\ \mathbf{Y}_{2} \\ \mathbf{Y}_{3} \\ \mathbf{Y}_{4} \\ \mathbf{Y}_{5}\end{array}\right]=\left[\begin{array}{ccccc}\lambda_{11}^{\mathbf{Y}^{\mathbf{b}}} & \mathbf{0} & 0 & 0 & 0 \\ 0 & \lambda_{22}^{\mathbf{Y}} & 0 & 0 & 0 \\ 0 & 0 & \lambda_{33}^{\mathbf{Y}} & 0 & 0 \\ 0 & 0 & 0 & \lambda_{44}^{\mathbf{Y}} & 0 \\ 0 & 0 & 0 & 0 & \lambda_{55}^{\mathbf{Y}^{b}}\end{array}\right]\left[\begin{array}{c}\mathrm{RC} \\ \mathrm{RA} \\ \mathrm{JS} \\ \mathrm{TQ} \\ \mathrm{FQ}\end{array}\right]+\left[\begin{array}{c}\varepsilon_{1} \mathbf{b} \\ \varepsilon_{2}{ }^{b} \\ \varepsilon_{3}{ }^{b} \\ \varepsilon_{4}{ }^{b} \\ \varepsilon_{5}{ }^{b}\end{array}\right]$

a FORM=Formalization; EMA=Empowerment Autonomy; EMC=Empowerment Competence; LIS=Leadership Iniating Structure; LLC=Leadership Leader Consideration: $G C=$ Group Cohesiveness; RC=Role Conflict; RA=Role Ambiguity; JS=Job Satisfaction; TQ=Technical Quality; Functional Quality.

b Fixed parameter

confirmatory factor analysis in the first stage of this approach. The elements of the vectors $\Theta^{\delta}$ and $\Theta^{\varepsilon}$ are also fixed. They are fixed at 1 minus the reliability coefficient derived from the first stage of the approach.

\subsection{Results}

In this section the results of our empirical research will be focused on. To begin with, in section 5.4.1 we will first present the characteristics of the sample in terms of the demographics included in the questionnaire. Subsequently, the results of the construct validation of the constructs contained in our study will be presented (5.4.2). In section 5.4.3 the results of testing the hypotheses underlying our conceptual framework using a cross-sectional approach will be rendered. Finally, in section 5.4 .4 we will discuss the results of testing our hypotheses using a longitudinal research design. 


\subsubsection{Sample Characteristics}

A number of demographic variables have been included in the questionnaire in order to describe the sample characteristics for the two waves (See Table 5-3). Regarding age we can see that the sample is almost divided in equal parts if we split age at 40 years (wave 1: $52.7 \%$ vs. $43.3 \%$; wave 2: $58.9 \%$ vs. $41.1 \%$ ). In the second wave the percentage of younger people is slightly larger. As far as education is concerned it becomes apparent that more of the younger (see above) and recently recruited employees participated in the second wave, as the percentage of employees having only a secondary school education increased in the second wave (wave 1: 19.2\%; wave 2: $32.4 \%$ ). The number of employees having a secondary school + education (+ means plus internal training courses) has correspondingly decreased (Wave 1: $80.8 \%$; wave 2: $67.6 \%$ ). With respect to company experience and personal experience we can see that a large majority of the service employees has extensive company and personal experience in this job. The percentage of highly experienced employees remains almost unchanged over the waves.

Table 5-3: Sample Characteristics for the Two Waves

\begin{tabular}{|c|c|c|c|}
\hline Demographics & Category & Frequency & Percentage \\
\hline \multicolumn{4}{|c|}{ Wave 1} \\
\hline \multirow[t]{4}{*}{ Age } & $<31$ years & 36 & $24.3 \%$ \\
\hline & 31.40 years & 42 & $28.4 \%$ \\
\hline & $41-50$ years & 53 & $35.8 \%$ \\
\hline & $>50$ years & 13 & $8.8 \%$ \\
\hline \multirow[t]{2}{*}{ Education } & secondary school & 28 & $19.2 \%$ \\
\hline & secondary school + & 118 & $80.8 \%$ \\
\hline \multirow[t]{6}{*}{ Company Experience } & $<1$ year & 9 & $6.2 \%$ \\
\hline & $1-4$ years & 21 & $14.4 \%$ \\
\hline & 5.8 years & 18 & $12.3 \%$ \\
\hline & $9-12$ years & 14 & $9.6 \%$ \\
\hline & $12-15$ years & 17 & $11.6 \%$ \\
\hline & $>15$ years & 67 & $45.9 \%$ \\
\hline \multirow[t]{6}{*}{ Personal Experience } & $<1$ year & 13 & $9.1 \%$ \\
\hline & $1-4$ years & 29 & $20.3 \%$ \\
\hline & $5-8$ years & 24 & $16.8 \%$ \\
\hline & $9-12$ years & 9 & $6.3 \%$ \\
\hline & $12-15$ years & 15 & $10.5 \%$ \\
\hline & $>15$ years & 53 & $37.1 \%$ \\
\hline \multicolumn{4}{|c|}{ Wave 2} \\
\hline \multirow{4}{*}{ Age } & $<31$ years & 63 & $36.0 \%$ \\
\hline & $31-40$ years & 40 & $22.9 \%$ \\
\hline & $41-50$ years & 61 & $34.9 \%$ \\
\hline & $>50$ years & 11 & $6.3 \%$ \\
\hline \multirow[t]{2}{*}{ Education } & secondary school & 57 & $32.4 \%$ \\
\hline & secondary school + & 119 & $67.6 \%$ \\
\hline \multirow[t]{6}{*}{ Company Experience } & $<1$ year & 20 & $11.4 \%$ \\
\hline & $1-4$ years & 27 & $15.3 \%$ \\
\hline & 5-8 years & 28 & $15.9 \%$ \\
\hline & $9-12$ years & 14 & $8.0 \%$ \\
\hline & $12-15$ years & 11 & $6.3 \%$ \\
\hline & $>15$ years & 76 & $43.2 \%$ \\
\hline \multirow[t]{6}{*}{ Personal Experience } & $<1$ year & 15 & $8.5 \%$ \\
\hline & $1-4$ years & 42 & $23.9 \%$ \\
\hline & 5-8 years & 30 & $17.0 \%$ \\
\hline & 9.12 years & 14 & $8.0 \%$ \\
\hline & $12-15$ years & 13 & $7.4 \%$ \\
\hline & $>15$ years & 62 & $35.2 \%$ \\
\hline
\end{tabular}




\subsubsection{Construct Validation}

The first stage of the partial aggregation approach is to assess the construct validity of the constructs used in our empirical research. We used structural equation modeling, more in particular, confirmatory factor analysis to evaluate unidimensionality, reliability, convergent validity and discriminant validity (Anderson \& Gerbing 1988; Bagozzi 1980a; Bollen 1989; Gerbing \& Anderson 1988; Kumar \& Dillon 1987; Steenkamp \& van Trijp 1991). As the number of items adversely affects the acceptance of structural equation models (Bentler \& Chou 1987), we split the constructs in our study into three subsets (cf. Heide \& John 1990; Kumar et al. 1992). The first model includes: (1) group cohesiveness, (2) leadership initiating structure and (3) leadership - leader consideration (23 items). The second model is concerned with: (1) formalization, (2) empowerment - competence (3) empowerment autonomy, (4) role ambiguity and (5) role conflict (29 items). Model three includes: (1) job satisfaction, (2) technical quality and (3) functional quality (25 items).

With regard to the first stage of the approach we are confronted with items which "misbehave". Anderson \& Gerbing (1988) propose four approaches to re-specifying measurement models in the case of "misbehaving" indicators: (1) relate the indicator to a different factor, (2) delete the indicator from the model, (3) relate the indicator to multiple factors or (4) use correlated measurement errors. The last two options are not preferable as they violate unidimensionality assumption (Hattie 1985; Kumar \& Dillon 1987; Steenkamp \& van Trijp 1991). Furthermore, relating indicators to a different factor would seriously compromise validity, as this would lead to a post-hoc justification for the composition of a measurement scale. This clearly is not acceptable. Therefore, we decided to delete misbehaving indicators in order to preserve scale purity. The results of the first stage of the partial aggregation approach are shown in Table 5-4.

In model 1 we initially obtained an unacceptable fit. However, after an iterative process, in which we inspected t-values, the pattern of standardized residuals and the modification indices (Anderson \& Gerbing 1988; Steenkamp \& van Trijp 1991), one item for group cohesiveness, two items for initiating structure and three items for leader consideration were deleted. Subsequently, we obtained a good fit: $\chi^{2}(116)=148.26(p=0.023) ; \mathrm{GFI}=0.92 ; \mathrm{AGFI}=0.89$; RMSR=0.053; TLI=0.96; CFI=0.97 (Bagozzi \& Yi, 1988; Bentler 1990; Bollen 1989; Hoelter 1983; Marsh \& Hocevar 1985; Steenkamp \& van Trijp 1991). Although the significant $\chi^{2}$ $\left(\chi^{2}(116)=148.26, p=0.023\right)$ indicates that the model does not fit the data adequately, we have to realize that that the sample characteristics, such as sample size, affect the $\chi^{2}$-test (Bearden et al. 1982; Bentler 1990; Bentler \& Bonnett 1980; Hoelter 1983; Marsh et al. 1988, 1996).

Consequently, a wide variety of fit indexes have been developed that are supposedly independent of sample size ( $\mathrm{Hu} \&$ Bentler 1995; Marsh et al. 1988, 1996). Among these the Tucker-Lewis Index (TLD) (Bentler \& Bonnett 1980; Tucker \& Lewis 1973) and the Comparative Fit Index (Bentler 1990) seem to be relatively unaffected by sample size (Marsh et al. 1988, 1996). Given the large sample size the Root Mean Square Error of Approximation (RMSEA) might provide even a better indication of goodness-of-fit (Steiger 1990). The value of the RMSEA equals 0.039 and is below the recommended cut-off value of 0.08 . The results for model 1 are summarized in Table 5-4. 
Table 5-4: Results of Confirmatory Factor Analysis

\begin{tabular}{|c|c|c|c|c|c|c|c|c|}
\hline \multicolumn{9}{|c|}{ Model Fit } \\
\hline & $x^{2}$ & df & GFI & AGFI & RMSR & TLI & CFI & RMSEA \\
\hline Model 1 & $148.26(\mathrm{p}=0.023)$ & 116 & 0.92 & 0.89 & 0.053 & 0.96 & 0.97 & 0.039 \\
\hline Model 2 & $209.05(\mathrm{p}=0.062)$ & 179 & 0.90 & 0.87 & 0.054 & 0.97 & 0.97 & 0.031 \\
\hline Model 3 & $166.62(p=0.001)$ & 116 & 0.89 & 0.86 & 0.062 & 0.92 & 0.94 & 0.049 \\
\hline \multicolumn{9}{|c|}{ Reliability of Measures } \\
\hline & \multicolumn{2}{|l|}{ Construct } & \multicolumn{3}{|c|}{ Number of Items } & \multicolumn{3}{|c|}{ Reliability } \\
\hline \multirow[t]{3}{*}{ Model 1} & \multirow{2}{*}{\multicolumn{2}{|c|}{$\begin{array}{l}\text { Group Cohesiveness } \\
\text { Initiating Structure }\end{array}$}} & \multicolumn{2}{|c|}{5} & \multicolumn{2}{|c|}{0.67} & & \\
\hline & & & 5 & & \multirow{2}{*}{\multicolumn{2}{|c|}{$\begin{array}{l}0.73 \\
0.87\end{array}$}} & & \\
\hline & \multicolumn{2}{|l|}{ Leader Consideration } & \multicolumn{2}{|l|}{7} & & & & \\
\hline \multirow[t]{5}{*}{ Model 2} & \multicolumn{2}{|l|}{ Formalization } & \multicolumn{2}{|l|}{4} & \multicolumn{2}{|c|}{0.07} & & \\
\hline & \multicolumn{2}{|l|}{ Competence } & \multicolumn{2}{|l|}{4} & \multicolumn{2}{|c|}{0.81} & & \\
\hline & \multicolumn{2}{|l|}{ Autonomy } & 4 & & \multicolumn{2}{|c|}{0.80} & & \\
\hline & \multicolumn{2}{|l|}{ Role Ambiguity } & \multicolumn{2}{|l|}{4} & \multicolumn{2}{|c|}{0.75} & & \\
\hline & \multicolumn{2}{|l|}{ Role Conflict } & \multicolumn{2}{|l|}{5} & \multicolumn{2}{|c|}{0.74} & & \\
\hline \multirow[t]{3}{*}{ Model 3} & \multicolumn{2}{|l|}{ Job Satisfaction } & \multicolumn{2}{|l|}{6} & \multicolumn{2}{|c|}{0.78} & & \\
\hline & \multirow{2}{*}{\multicolumn{2}{|c|}{$\begin{array}{l}\text { Technical Quality } \\
\text { Functional Ouality }\end{array}$}} & \multirow{2}{*}{\multicolumn{2}{|c|}{3}} & & & \\
\hline & & & & & \multicolumn{2}{|c|}{$\begin{array}{l}0.73 \\
0.78\end{array}$} & & \\
\hline
\end{tabular}

For the second model we also initially obtained a fit which could not be considered adequate. After an iterative process, in which we inspected t-values, the pattern of standardized residuals and the modification indices, eight items were deleted (two items for formalization, one item for autonomy, two items for role ambiguity and three items for role conflict). This model resulted in a good fit: $\chi^{2}(179)=209.05 \quad(p=0.062)$; GFI $=0.90$; $\mathrm{AGFI}=0.87 ; \mathrm{RMSR}=0.054 ; \mathrm{TLI}=0.97 ; \mathrm{CFI}=0.97 ; \mathrm{RMSEA}=0.031$ ). The results for model 2 are summarized in Table 5-4.

Finally, for the third model the same procedure was followed as for the previous two models. After deleting two items job satisfaction, one item for technical quality and five items for functional quality we obtained a good fit to the data: $\chi^{2}(116)=166.62(\mathrm{p}=0.001)$; $\mathrm{GFI}=0.89 ; \mathrm{AGFI}=0.86 ; \mathrm{RMSR}=0.062 ; \mathrm{TLI}=0.92 ; \mathrm{CFI}=0.94 ; \mathrm{RMSEA}=0.031$ ). The results for model 3 are summarized in Table 5-4.

Within-method convergent validity was assessed testing the significance and magnitude of the elements of the matrix $\Lambda^{x}$. We found that 47 out of 55 items loaded higher than 0.5 on their respective constructs with a minimum t-value of 3.27 (See Appendix VI). Discriminant validity was evaluated by testing whether pairs of constructs were correlated less than unity. We used a $\Delta \chi^{2}$ with one degree of freedom to test for unity between the constructs. All tests were significant at $\alpha=0.05$. Moreover, the reliability of the constructs in both models was evaluated using composite reliability and variance extracted measures (Fornell and Larcker 1981; Jöreskog 1971). From Table 5-4 it can be concluded that the constructs exhibited a high degree of reliability in terms of composite reliability, all reliability coefficients except the reliability coefficient for group cohesiveness (reliability coefficient $=0.67$ ) exceeded the recommended value of 0.7 (Variance extracted is reported in Appendix VI). These reliability coefficients will be used to correct the constructs for measurement error in the second stage for our approach (See 5.3.4).

\subsubsection{Testing Substantive Hypotheses}

As was already indicated we used the partial aggregation approach to test the relationships in our conceptual model. The reliability coefficients determined in the first stage of this approach were subsequently used to correct the constructs for measurement error. LISREL8 and PRELIS2 were used to the free elements in our conceptual framework using maximum likelihood estimation (Jöreskog \& Sörbom 1993). It can be concluded that the conceptual model initially did not show 
a good fit: $\chi^{2}(22)=73.85$ ( $\left.<<0.001\right) ; \mathrm{GFI}=0.93 ; \mathrm{AGFI}=0.80 ; \mathrm{RMSR}=0.068 ; \mathrm{TLI}=0.74$; $\mathrm{CFI}=0.90$; RMSEA=0.11. As our study is largely exploratory we followed the suggestions by Silvia \& MacCallum (1988). We estimated all parameters in the structural model and proceeded by fixing non-significant parameters one at a time. We found that nine of the paths hypothesized in the conceptual model were not significantly different from zero. More in particular, we found that formalization, competence and leader consideration did not affect the role stressors. Moreover, group cohesiveness did not directly influence role ambiguity and initiating structure did not directly affect role conflict. Finally, role conflict showed no effect on job satisfaction. Deleting these paths did not significantly affect the fit $\left(\Delta \chi^{2}(9)=11.28\right.$, $\mathrm{p}=0.26)$ and resulted in a more parsimonious model $\left(\chi^{2}(31)=85.13(\mathrm{p}<0.001)\right.$; GFI $=0.93$; $\mathrm{AGFI}=0.85 ; \mathrm{TLI}=0.81 ; \mathrm{CFI}=0.90 ; \mathrm{RMSEA}=0.098$ ). Furthermore, inspection of the univariate Lagrangian Multiplier (LM) test (in LISREL terminology this test is referred to as modification index) suggested an additional relationship in our model (Bollen 1989; Jöreskog \& Sörbom, 1989, 1993). We found that autonomy and group cohesiveness directly affect job satisfaction. Autonomy directly influences functional quality as well. This final model showed a good fit to the data: $\chi^{2}(28)=48.75,(p=0.01)$; $G F I=0.96 ; A G F I=0.89 ; T L I=0.92 ; C F I=0.96$; RMSEA $=0.064$. All measures well exceed the recommended cut-off values (Bagozzi \& Yi 1988; Jöreskog \& Sörbom 1989, 1993). The value of the $\chi^{2} / \mathrm{df}$ ratio also indicates a good fit of the data to the hypothesized model (Bagozzi \& Yi 1988; Hoelter 1983). Finally the Q-plot clearly showed a linear trend through the plotted values indicating a good fit (Bagozzi \& Yi 1988; Jöreskog \& Sörbom 1989). Finally, it should be noted that given the exploratory nature of our study further research will be needed to assess the cross-validity of our model (Cudeck \& Browne 1983; MacCallum et al. 1992; Silvia \& MacCallum 1988).

Inspection of the path coefficients allows us to test the relationships in the conceptual framework (See Table 5-5). Starting with the antecedents to the role stressors we can observe that formalization does not exhibit a significant relationship with role ambiguity and role conflict. Therefore, we may reject hypothesis $1 \mathrm{a}$ and hypothesis $1 \mathrm{~b}$. Moreover, with regard to empowerment it is shown in Table 5-5 that only the autonomy component negatively affects role ambiguity (standardized path coefficient $=-0.21$; t-value $=-2.15$ ) and role conflict (standardized path coefficient $=-0.44$; $t$-value $=-5.01$ ). As a result, we fail to reject hypothesis $2 \mathrm{a}$ and hypothesis $2 \mathrm{~b}$. For the competence component our data fail to support the hypothesized relationship with the role stressors. Consequently, we can reject hypothesis $3 a$ and hypothesis 3b. As far as leadership behavior is concerned it can be seen that only initiating structure negatively influences role ambiguity (standardized path coefficient $=-0.36$; $t$-value $=-4.42$ ). Thus, we fail to reject hypothesis $4 \mathrm{a}$ and we have to reject hypothesis $4 \mathrm{~b}$, hypothesis $5 \mathrm{a}$ and hypothesis $5 \mathrm{~b}$. The effect of group cohesiveness, on the other hand, seems to be limited to role conflict (standardized path coefficient $=-0.32$; $t$-value $=-3.38$ ). As a result, we need to reject hypothesis $6 \mathrm{a}$, but we fail to reject hypothesis $6 \mathrm{~b}$. The effect of the role stressors on job satisfaction seems to be limited to role ambiguity (standardized path coefficient=-0.23; $t$ value $=-2.38$ ). We fail to reject hypothesis $7 \mathrm{a}$, but we have to reject hypothesis $7 \mathrm{~b}$. Finally, we fail to reject hypothesis $8 \mathrm{a}$ and $8 \mathrm{~b}$. Job satisfaction positively affects both technical quality (standardized path coefficient $=0.44 ; \mathrm{t}$-value $=4.90$ ) and functional quality (standardized path coefficient $=0.38$; $t$-value $=3.73$ ). Finally, it should be noted that role conflict significantly increases role ambiguity (standardized path coefficient $=0.40 ; \mathrm{t}$-value $=3.86$ ). 
Table 5-5: Estimated Path Coefficients ${ }^{\mathrm{a}}$

\begin{tabular}{|c|c|c|c|}
\hline Relationships & Hypothesis & Standardized Path Coefficient ${ }^{b}$ & Hypothesis Testing \\
\hline FORM $\rightarrow$ RA & $\mathrm{H}_{1 \mathrm{a}}$ & n.s. & Rejected \\
\hline FORM $\rightarrow \mathrm{RC}$ & $\mathrm{H}_{1 b}$ & n.s. & Rejected \\
\hline $\mathrm{EMA} \rightarrow \mathrm{RA}$ & $\mathrm{H}_{2 \mathrm{a}}$ & $-0.21(-2.15)$ & Failed to Reject \\
\hline $\mathrm{EMA} \rightarrow \mathrm{RC}$ & $\mathrm{H}_{2 \mathrm{~b}}$ & $-0.44(-5.01)$ & Failed to Reject \\
\hline $\mathrm{EMC} \rightarrow \mathrm{RA}$ & $\mathrm{H}_{3 \mathbf{a}}$ & n.s. & Rejected \\
\hline $\mathrm{EMC} \rightarrow \mathrm{RC}$ & $\mathrm{H}_{3 \mathrm{~b}}$ & n.s. & Rejected \\
\hline $\mathrm{LIS} \rightarrow \mathrm{RA}$ & $\mathrm{H}_{4 \mathrm{a}}$ & $-0.36(-4.42)$ & Failed to Reject \\
\hline LIS $\rightarrow$ RC & $\mathrm{H}_{4 b}$ & n.s. & Rejected \\
\hline $\mathrm{LLC} \rightarrow \mathrm{RA}$ & $\mathrm{H}_{5 \mathrm{a}}$ & n.s. & Rejected \\
\hline $\mathrm{LLC} \rightarrow \mathrm{RC}$ & $\mathrm{H}_{5 \mathrm{~b}}$ & n.s. & Rejected \\
\hline $\mathrm{GC} \rightarrow \mathrm{RA}$ & $\mathrm{H}_{6 \mathrm{a}}$ & n.s. & Rejected \\
\hline $\mathrm{GC} \rightarrow \mathrm{RC}$ & $\mathrm{H}_{6 \mathrm{~b}}$ & $-0.32(-3.38)$ & Failed to Reject \\
\hline $\mathrm{RA} \rightarrow \mathrm{JS}$ & $\mathrm{H}_{7 \mathrm{a}}$ & $-0.23(-2.38)$ & Failed to Reject \\
\hline $\mathrm{RC} \rightarrow \mathrm{JS}$ & $\mathrm{H}_{7 \mathrm{~b}}$ & n.s. & Rejected \\
\hline $\mathrm{JS} \rightarrow \mathrm{TQ}$ & $\mathrm{H}_{8 \mathrm{a}}$ & $0.44(4.90)$ & Failed to Reject \\
\hline $\mathrm{IS} \rightarrow \mathrm{FQ}$ & $\mathrm{H}_{8 \mathrm{~b}}$ & $0.38(3.73)$ & Failed to Reject \\
\hline
\end{tabular}

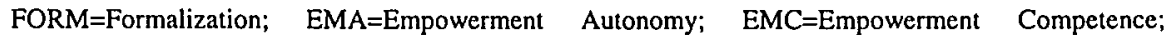
LIS=Leadership Iniating Structure; LLC=Leadership Leader Consideration; GC=Group Cohesiveness; $\mathrm{RC}=$ Role Conflict; $\mathrm{RA}=$ Role Ambiguity; JS=Job Satisfaction; $\mathrm{TQ}=$ Technical Quality; Functional Quality.

b Corresponding t-value in parentheses.

As we already indicated we also found three relationship not posited in our conceptual framework (See Figure 5-2). We found that both autonomy (standardized path coefficient $=0.32 ; \mathrm{t}$-value $=3.47$ ) and group cohesiveness (standardized path coefficient $=0.37$; $\mathrm{t}$ value $=4.09$ ) positively affect job satisfaction. Finally, autonomy also exhibits a direct positive

\section{Figure 5-2: Relationships in Final Cross-Sectional Model}

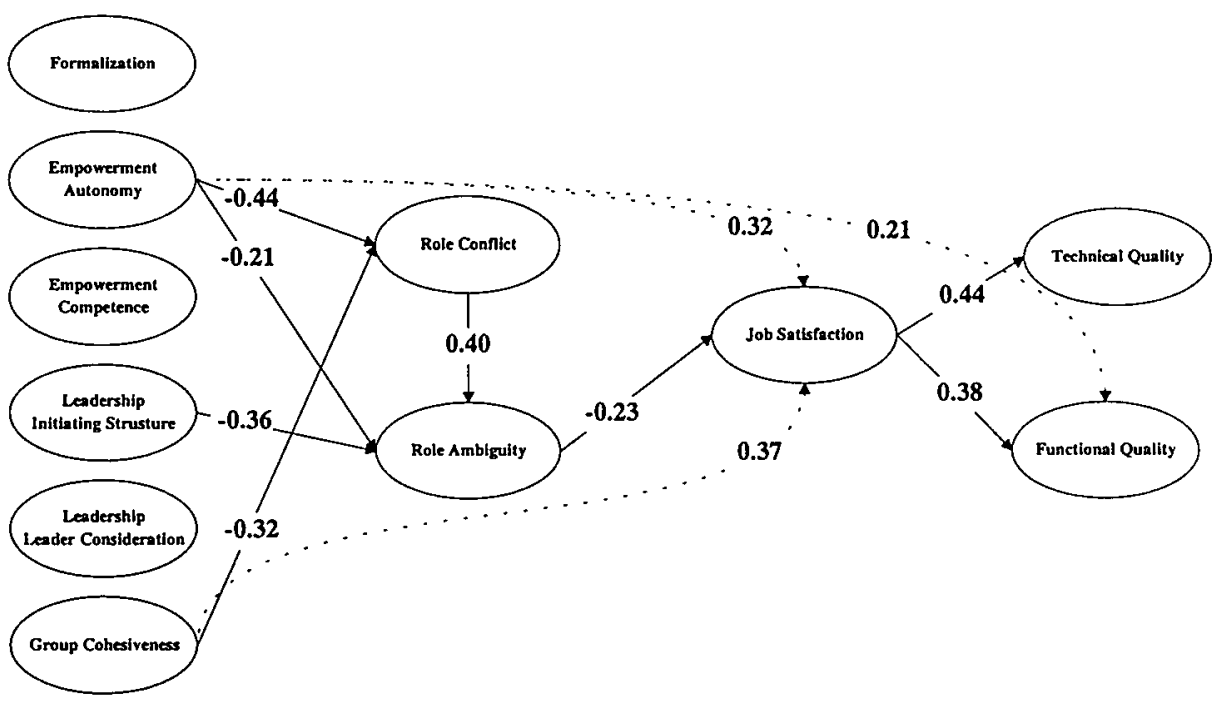


effect on functional quality (standardized path coefficient $=0.21 ; t-v a l u e=2.25$ ). However, as these effects are more or less empirically determined these will need to cross-validated using additional samples. The relationships in the final model are depicted in Figure 5-2.

\subsubsection{A Longitudinal Approach}

Although structural equation modeling is occasionally referred to as "causal analysis", it cannot be used to as evidence for causation in a cross-sectional research (Bollen 1989; James et al. 1982). This would require an experimental design or a longitudinal design, such as a panel design (Menard 1991; Markus 1979; Williams \& Podsakoff 1989). In this section of chapter 5 we will present the findings of a longitudinal study using a panel design. We will use structural equation modeling to analyze the data obtained from this study.

Although longitudinal research shows a vast potential for the study of organizational phenomena, this potential has still remained largely idle (Kessler \& Greenberg 1981; Williams \& Podsakoff 1989). Several reasons have been unearthed for this lack of longitudinal studies in this field of research (Williams \& Podsakoff 1989; Menard 1991). Chief among which is the relationship between the research and the organization involved in the study. Both researcher and organization have to invest a considerable amount of time, effort and resources in order to complete a longitudinal study. Williams \& Podsakoff (1989, 249) relate the following account of their own experience:

"Both of the present authors have been involved in studies with organizations that were originally designed to gather longitudinal data but fell apart after the first wave of data gathering because the organization felt that the data obtained from the initial wave answered their questions adequately or because they felt the time required to gather additional data was too costly, too time-consuming, or both."

The researchers involved in the present study were extremely lucky to find an organization, which was willing to participate in study, which took two years to be completed. The researchers have experience nothing less but complete cooperation and stimulating discussions with regard to this study. We feel therefore that we should be very grateful to all people participating in the study. Both managers and service employee were always willing to put in that extra effort that made this study a success. However, even if the organization remains participating in the study, the mortality from wave to wave may considerably reduce the sample size (Menard 1991; Williams \& Podsakoff 1989). In our study, we finally succeeded in capturing 123 respondents, while there were 147 respondents in the first wave and 181 in the second wave.

Although these reasons may be detrimental to the application of longitudinal research designs, the most important reason according to Williams \& Podsakoff (1989) is the lack of standard analytical techniques for longitudinal designs. Williams \& Podsakoff (1989) distinguish five statistical techniques for analyzing panel designs: (1) cross-lagged correlation analysis, (2) dynamic correlation analysis, (3) frequency-of-change-in-product-momenttechnique, (4) path analysis and (5) structural equation modeling. Given the shortcomings of the other techniques Williams \& Podsakoff (1989) strongly advise the use of structural equation modeling. As the number of indicators and construct are relatively large we again used the partial aggregation approach (cf. Williams \& Podsakoff 1989). Furthermore, we would like to emphasize that our work is largely exploratory, since the number of longitudinal studies is limited in this field (Williams \& Podsakoff 1989). Although we have assumed the presence of autoregressive and lagged effects the extant literature is at the most sketchy regarding the direction and magnitude of these relationships.

Following Hom \& Griffeth (1991) we tested a sequence of nested, longitudinal models. ${ }^{2}$ The results are reported in Table 5-6. We started with the structural null model in which we 
Table 5-6: Fit Indices for Sequence of Nested Longitudinal Models

\begin{tabular}{|c|c|c|c|c|c|c|c|}
\hline \multicolumn{8}{|c|}{ Model Fit } \\
\hline Model & $x^{2}$ & df & GFI & AGFI & TLI & CFI & RMSEA \\
\hline Structural Null Model & $\begin{array}{l}862.43 \\
(p<0.001)\end{array}$ & 216 & 0.51 & 0.42 & 0.17 & 0.23 & 0.16 \\
\hline Autoregressive Effects Model & $\begin{array}{l}657.31 \\
(\mathrm{p}<0.001)\end{array}$ & 205 & 0.62 & 0.53 & 0.39 & 0.46 & 0.13 \\
\hline $\begin{array}{l}\text { Contemporaneous and } \\
\text { Autoregressive Effects Model }\end{array}$ & $\begin{array}{l}394.64 \\
(p<0.001)\end{array}$ & 171 & 0.76 & 0.65 & 0.64 & 0.73 & 0.10 \\
\hline $\begin{array}{l}\text { Contemporaneous, Autoregressive } \\
\text { and Lagged Effects Model }\end{array}$ & $\begin{array}{l}355.17 \\
(p<0.001)\end{array}$ & 155 & 0.79 & 0.66 & 0.64 & 0.76 & 0.10 \\
\hline $\begin{array}{l}\text { Final Longitudinal Model } \\
(\mathrm{JS} \rightarrow \mathrm{Q})\end{array}$ & $\begin{array}{l}231.66 \\
(p<0.001)\end{array}$ & 179 & 0.85 & 0.79 & 0.92 & 0.94 & 0.049 \\
\hline $\begin{array}{l}\text { Final Longitudinal Model } \\
(\mathrm{Q} \rightarrow \mathrm{JS})\end{array}$ & $\begin{array}{l}266.24 \\
(p<0.001)\end{array}$ & 179 & 0.84 & 0.77 & 0.87 & 0.90 & 0.063 \\
\hline
\end{tabular}

assumed no substantive relationship at all. The model fit of this model is clearly poor: $\chi^{2}(216)=862.43(\mathrm{p}<0.001) ; \mathrm{GFI}=0.51 ; \mathrm{AGFI}=0.42 ; \mathrm{TLI}=0.17 ; \mathrm{CFI}=0.23 ; \mathrm{RMSEA}=0.16$. By adding the autoregressive effects or stability parameters the fit of the model significantly improves: $\Delta \chi^{2}(11)=205.12 \quad(p<0.001)$. Subsequently, we included the contemporaneous effects and this still further improved the model fit over the model including only autoregressive effects: $\Delta \chi^{2}(34)=262.12(p<0.001)$. Finally, we included also the lagged effects and arrived at a still significantly better fitting model: $\Delta \chi^{2}(16)=39.47(\mathrm{p}<0.001)$. However, the model fit was still not adequate: $\chi^{2}(155)=355.17$ ( $\left.<<0.001\right)$; GFI=0.79; AGFI=0.66; TLI=0.64; CFI=0.76; RMSEA=0.10. A graphical overview of the effects included in our longitudinal approach is provided in Figure 5-3 and Figure 5-4. We again followed the procedure suggested by Silvia \& MacCallum (1988). We estimated all parameters in the structural model and proceeded by fixing non-significant parameters one at a time. Using the univariate Lagrangian Multiplier test (modification index in LISREL terminology) and the pattern of standardized residuals we arrived at the model depicted in Figure 5-5.

This model shows a good fit to the data: $\chi^{2}(179)=231.66,(\mathrm{p}<0.001)$; GFI $=0.85$; $\mathrm{AGFI}=0.79 ; \mathrm{TLI}=0.92 ; \mathrm{CFI}=0.94 ; \mathrm{RMSEA}=0.049$ (See Table 5-6). In this model all the autoregressive effects or stability coefficients are significant and substantial of magnitude (ranging from a standardized coefficient of 0.25 to 0.58 ). Including these effects substantially improved the explanatory power of our model. As far as the lagged effects are concerned we found only three significant effects. If we compare the squared multiple correlations we find that for role ambiguity, role conflict, technical quality and functional quality in the crosssectional design (including no autoregressive and lagged effects) that these have substantially improved in the longitudinal design (RA: $69 \%$ vs. $50 \%$; RC: $40 \%$ vs. $38 \%$; TQ $40 \%$ vs. $19 \%$; FQ: $36 \%$ vs. $21 \%$ ). 


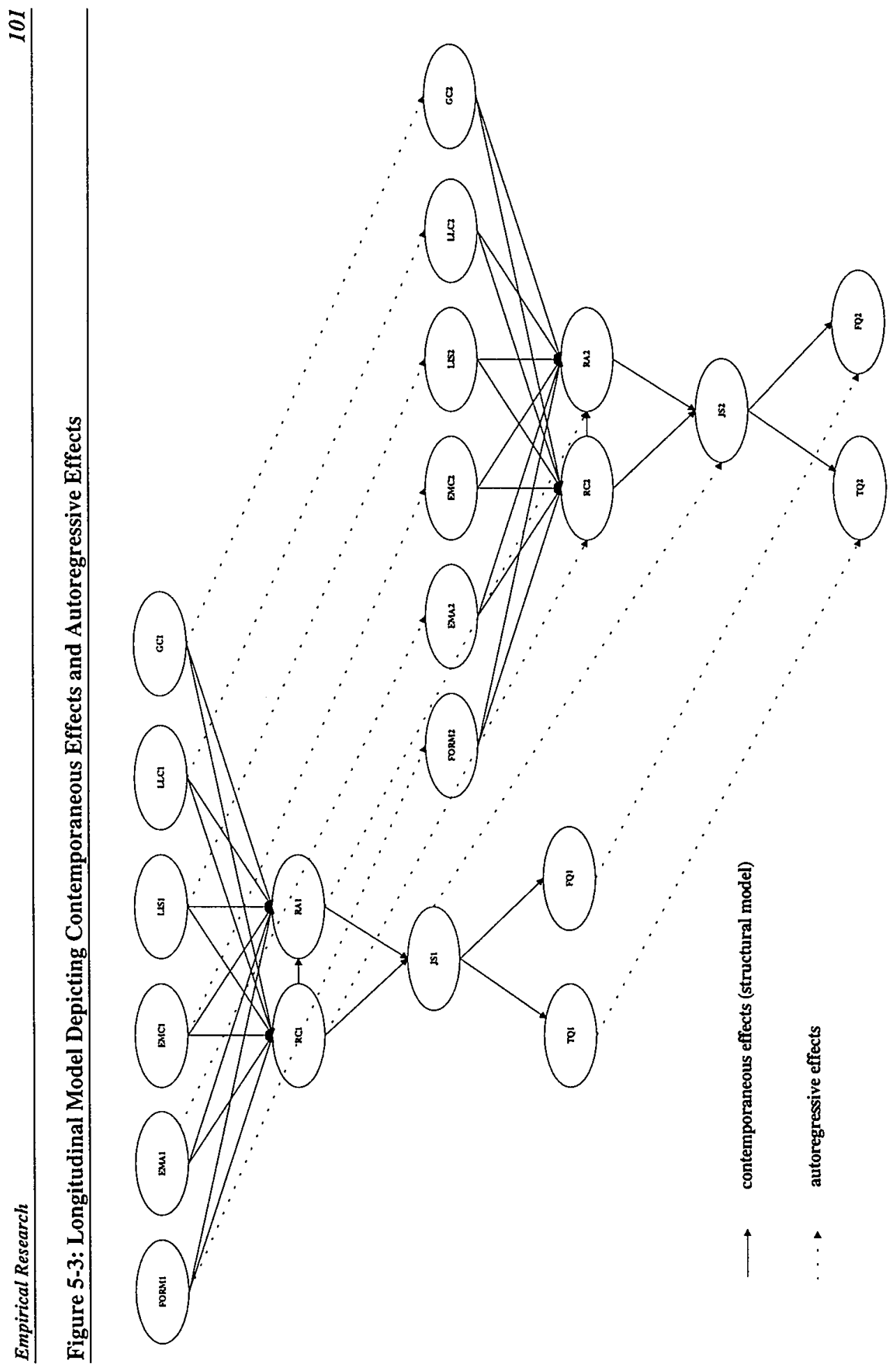




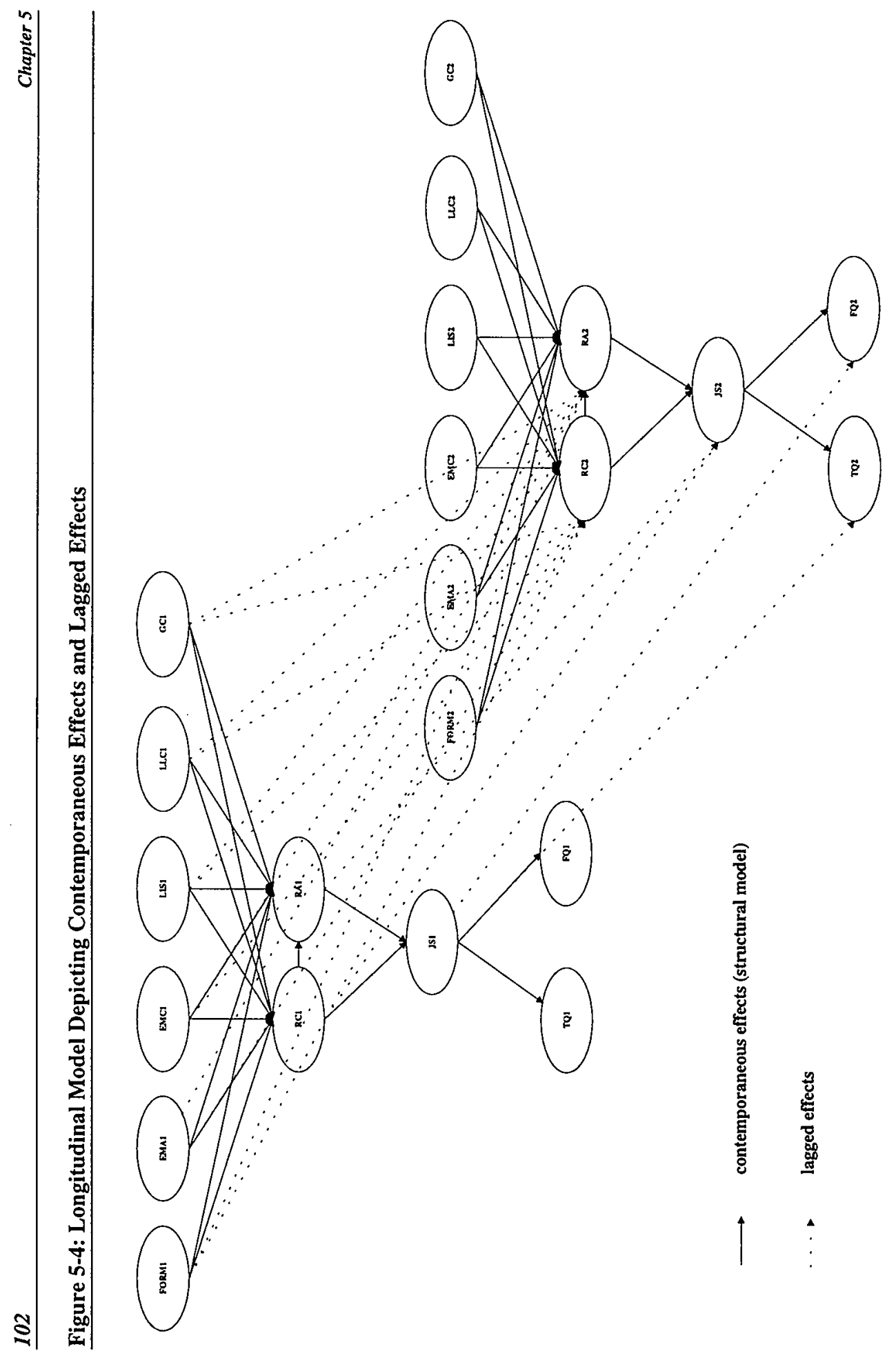


We can now use the standardized path coefficients to test for the hypothesized substantive effects in our conceptual framework. The results of the final model for the longitudinal design are presented in Figure 5-5. In essence, the findings of the longitudinal design are quite similar to the findings of the cross-sectional design. The pervasive effect of the autonomy component of empowerment is also found in the longitudinal design. Autonomy negatively affects both role conflict (standardized path coefficient $=-0.32 ; \mathrm{t}=-3.18$ ) and role ambiguity (standardized path coefficient $=-0.38 ; \mathrm{t}=-3.45)$. Furthermore, we found that autonomy also positively influences jobs satisfaction (standardized path coefficient $=0.25 ; \mathrm{t}=2.27$ ). Moreover, we found that initiating structure exhibits a negative effect on role ambiguity (standardized path coefficient=-0.35; $\mathrm{t}=-3.70$ ). We did not find an effect of group cohesiveness on the role stressors. However, we found a positive effect of formalization on role conflict (standardized path coefficient $=0.25 ; t=2.39$ ). The relationship between the role stressors, job satisfaction and service quality is essentially similar to the cross-sectional design. We can observe that role conflict positively affects role ambiguity (standardized path coefficient $=0.33 ; t=2.96$ ) and that role ambiguity, on its turn, shows a negative relationship with job satisfaction (standardized path coefficient $=-0.33 ; \mathrm{t}=-2.04$ ). Finally, job satisfaction positively influences both technical quality (standardized path coefficient $=0.49 ; \mathrm{t}=4.46$ ) and functional quality (standardized path coefficient $=0.50 ; \mathrm{t}=4.90$ ).

We found the autoregressive effects or stability parameters and to a lesser extent the lagged effects to have a positive effect on the explanatory power of our model. As far as the autoregressive effects are concerned we found that all effects are significant and quite substantial in terms of magnitude. All the effects are positive, i.e. the first wave constructs exert a positive effect on the corresponding second wave constructs. We found the largest effects for empowerment (competence $=0.50$; autonomy $=0.53$ ), formalization $(0.46)$, group cohesiveness $(0.58)$, role ambiguity $(0.51)$ and job satisfaction $(0.48)$. Therefore, it is quite

\section{Figure 5-5: Relationships in Final Longitudinal Model}

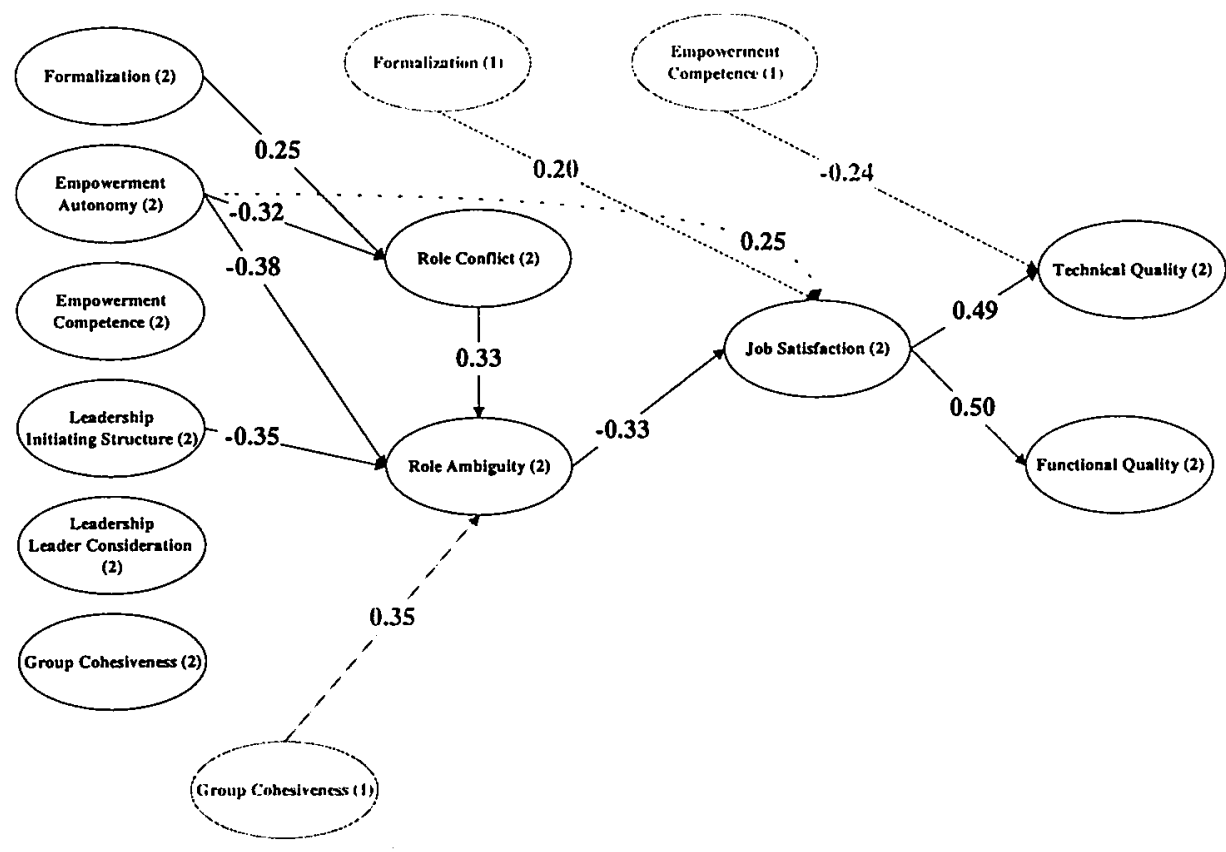


interesting to note that these variables are part of the significant lagged effects in our final model. We found three lagged effects. To begin with, we found that formalization in the first wave positively affects job satisfaction in the second wave (standardized path coefficient $=0.19 ; t=2.01$ ). Secondly, we found a negative effect of the competence effect of autonomy on technical quality (standardized path coefficient=-0.24; $t=-2.57$ ). Finally, we found a positive effect of group cohesiveness on role ambiguity (standardized path coefficient $=0.35 ; t=2.69$ ).

Finally, we tested one additional model for the causal relationship between job satisfaction and service quality as measure of job performance. There is no equivocal perspective on the relationship between job satisfaction and job performance (Bagozzi 1978, 1980a; Fry et al. 1986; Iaffaldano \& Muchinsky 1985; Schwab \& Cummings 1970; Sheridan \& Slocum 1975; Wanous 1974). However, reversing the relationship between job satisfaction and service quality led to a worse fit: $\chi^{2}(179)=266.24$, ( $\left.<<0.001\right) ;$ GFI=0.84; AGFI=0.77; TLI=0.87; $\mathrm{CFI}=0.90$; RMSEA $=0.063$. Moreover, the paths leading from service quality to job satisfaction were not significant. Finally, we found no reciprocal relationships, however this may be due to lag time between the two waves (Williams \& Podsakoff 1989).

\subsection{Discussion}

We used both a cross-sectional and a longitudinal approach to test the substantive relationships in our conceptual framework. Since there were only minor differences between the two approaches we will not discuss the results separately. We found that the autonomy component of empowerment exerted quite a pervasive effect in our model. The competence component of empowerment, on the other hand, showed no contemporaneous effect. However, the findings with regards to the relationship between autonomy and role ambiguity are contrary to the results obtained by Hartline \& Ferrell (1993). They report a positive effect of empowerment on role ambiguity for hotel employees and no relationship between empowerment and role conflict. There may be four factors, which account for this result. To begin with, their empowerment construct is based on the perception of the hotel manager and not the perception of the hotel employee. Moreover, they estimated their model using (classical) path analysis with ordinary least squares regression, while we applied structural equation modeling using maximum likelihood estimation. Thirdly, they used an aggregated research design in which all individual level and group level variables were aggregated into unit level (hotel). This will necessarily confound the results at these lower levels (Rousseau 1985). In their 1996 article (Hartline \& Ferrell 1996) they even report a positive relationship between empowerment and role conflict. Finally, because of this aggregation approach the sample size was reduced to 97. The sample size can affect the parameter estimates and the standard error of the estimate (Bollen 1989). In general, we would expect that empowerment shows a negative effect on both role stressors (Bowen Lawler 1992, 1995a,b; Conger \& Kanungo 1988; Hartline \& Ferrell 1993, 1996; Schlesinger \& Heskett 1991; Spreitzer 1995; Thomas \& Velthouse 1990). It is argued within organizational theory that customer-contact service employees need a less mechanistic control system than manufacturing employees (Bowen et al. 1989; Mills 1983, 1985, 1986; Mills et al. 1983). More recently, this has resulted in the emergence of empowerment as a control mechanism in service organization. As a result, it is hardly surprising that we find that empowerment (autonomy) reduces role stress and increases job satisfaction.

In our cross-sectional approach we found no effect of formalization on the role stressors. However, in the longitudinal design we found a positive effect of formalization on role conflict. Although the negative relationship between formalization and role ambiguity is confirmed by meta-analytical studies (Fisher \& Gitelson 1983; Jackson \& Schuler 1985), the relationship between formalization and role conflict is less clear (Jackson \& Schuler 1985; Nicholson \& Goh 1983; Organ \& Greene 1981; Rogers \& Molnar 1976). In boundary spanning positions the relationship between formalization and role conflict is often positive (Clopton 1984; Michaels et 
al. 1987, 1988). Formal rules, procedures and policies may conflict with customer needs and therefore increase role conflict. If customer-contact service employees are forced to adhere to the "rule book", they will suffer from role conflict with respect to the customer. If they deviate from the "rule book" they might experience role conflict with regard to their manager. Finally, formalization showed a positive lagged effect on job satisfaction. This can be interpreted as a long-term effect of formalization. Although the short-term effect might be experienced as increasing role conflict, in the longer term it provides clarity and thereby job satisfaction. The negative effect of group cohesiveness on role stress is only supported in our cross-sectional design. We find that group cohesiveness may reduce role conflict, as their co-workers are able to support their colleagues. In the longitudinal model, group cohesiveness showed a positive effect on role ambiguity. It could be that group norms could actually be in conflict with organizational norms and procedures.

The two supervisory behavior dimensions generally exhibit a negative effect on both role stressors (Fisher \& Gitelson 1983; Fry et al. 1986; Jackson \& Schuler 1985; Micheals et al. 1987). However, initiating structure seems to be stronger related to role ambiguity than to role conflict (Jackson \& Schuler 1985). Initiating structure tends to clarify roles and thus reduces role ambiguity in boundary spanning positions (Hampton et al. 1986; Micheals et al. 1987; Walker et al. 1975). Our results confirm the negative relationship between initiating structure and role ambiguity, but fail to find a negative relationship between initiating structure and role conflict. Our research indicates that leadership consideration may be relatively independent of role stress (Jackson \& Schuler 1985), since we found no relationship between leadership consideration and the role stressors. Mills $(1983,1985)$ further argues that because of the task uncertainty and information equivocality in boundary spanning positions, the supervisor should use a more consultive style of management. Therefore, traditional management styles such as initiating structure and leader consideration might be less effective. However, instrumental leadership or initiating structure may be used to define the boundaries of the service employee.

In general, it is hypothesized that role ambiguity and role conflict negatively affect job satisfaction (Brown \& Peterson 1993; Churchill et al. 1985; Fisher \& Gitelson 1983; Fry et al. 1986; Jackson \& Schuler 1985; Kahn et al. 1964; Katz \& Kahn 1978; King \& King 1990). However, more recently, empirical research reported that role ambiguity might show a more dysfunctional effect on job satisfaction than role conflict (Singh 1993; Singh et al. 1996). This finding is corroborated by Hartline \& Ferrell (1996) who reported a negative relationship between role ambiguity and job satisfaction in a hotel context, but fail to find a negative relationship between role conflict and job satisfaction.

Behrman \& Perrault (1984) argue that aspects of conflict are inherent to sales positions and therefore independent of organizational antecedents. Singh \& Rhoads (1991) have pointed out that role conflict cannot easily be controlled by management actions. Indeed, it has been demonstrated that personal characteristics of sales persons (e.g., innovativeness, locus of control) offer a better explanation of role conflict (Behrman \& Perrault 1984). Finally, it has been argued that only those employees who can cope with role conflict will eventually stay in their boundary spanning positions (Goolsby 1992; Weatherly \& Tansik 1993a,b).

Although the intuitive appeal of a strong, positive relationship between job satisfaction and job performance is high (Grönroos 1990a; Heskett 1987, 1995), empirical research using metaanalytical procedures have produced only moderate correlations between the two constructs (Brown \& Peterson 1993; Iaffaldano \& Muchinsky 1985). However, this is based mainly on objective, outcome-related measures of performance (Hartline \& Ferrell 1996). It can be argued that job satisfaction is more closely related to behavioral-based performance than to outcomebased performance (Churchill et al. 1985; Schneider 1980). In our study we find a strong, positive relationship between job satisfaction and job performance in terms of technical quality and functional quality. 


\subsection{Implications of this Study}

In this section of chapter 5 we will discus the theoretical implications of this study (5.6.1) and the managerial implications of this study (5.6.2).

\subsubsection{Theoretical Implications}

Part of the strength of a research project lies in the recognition of its limitations. These limitations may serve as points for a future research agenda. To begin with, our results are based on the results of a sample of customer-contact service employees of the after-sales service department of a large, Dutch manufacturer of office equipment. This approach is quite likely to have contributed to the internal validity of our study, however it questions the external validity of our findings (Cook \& Campbell 1979; Keppel 1991; Kerlinger 1986). As a result, this study needs to be replicated in other after-sales service settings in order to generalize our findings.

All our measurement instruments are based on paper-and-pencil self-reports, so that the strength of the relationships between the constructs may be somewhat inflated by common method variance. However, we extensively pre-tested and cross-validated our measures and considering the results of the construct validation, it is unlikely that the results of our model are solely due to common method variance. Moreover, we attempted to minimize the biased responses to our measurement instruments. We assured the confidentiality of the respondents and had the questionnaires sent directly to the researchers.

We identified only four organizational influences to role stress (1) formalization, (2) empowerment, (3) supervisory behavior and (4) group cohesiveness. While these factors in the longitudinal design account for $69 \%$ of the variance in role ambiguity, $40 \%$ of the variance in role conflict, $45 \%$ of the variance of job satisfaction, $40 \%$ of the variance of technical quality and $36 \%$ of the variance in functional quality, our study might still be suffering from omitted variables. Therefore, it would also be worthwhile to examine the influence of personal variables, such as innovativeness, creativity, self-esteem and locus of control, as antecedents to role stress, as these characteristics are often required in boundary positions (Michaels et al. 1988). This may increase the conceptual as well as the explanatory power of a model of role stressors.

As our research is mainly exploratory we use a fairly simple and straightforward role stress model (cf. Singh et al. 1996). This model can be extended by adding several constructs, chief among which is organizational commitment (Brown \& Peterson 1993; Mathieu \& Zajac 1990). Organizational commitment, on its turn, is closely (and negatively) related to turnover intentions and actual turnover (Bluedorn 1982; Brown \& Peterson 1993; Hom \& Griffeth 1991; Mathieu \& Zajac 1990; Tett \& Meyer 1993). The relationship between job satisfaction and turnover (intention) has been hypothesized to be mediated by commitment (Brown \& Peterson 1993; Johnston et al. 1990; Mathieu \& Zajac 1990; Tett \& Meyer 1993). The same mediating relationship is assumed for performance (Brown \& Peterson 1993; Johnston et al. 1988; Mathieu \& Zajac 1990). Alternatively, it has been posited that turnover (intention) is directly affected by job satisfaction and job performance (Lucas et al. 1990; Tett \& Meyer 1993; Sager 1991). Finally, high (voluntary) turnover rates might potentially have negative effect on performance especially in service organizations, as experienced customer-contact employees are replaced by inexperienced customer-contact employees (Weatherly \& Tansik 1993a, 1993b). This hypothesis, however, needs additional conceptual and empirical grounding.

We mainly used global measures for our study (Ironson et al. 1989). However, several authors have proposed multifaceted or multidimensional scales for some important constructs in our conceptual framework. Singh \& Rhoads (1991) propose that role ambiguity is not a global measure, but rather consists of several facets. They developed a measurement instrument, MULTIRAM, which consists of seven facets (boss, company, customers, ethical, coworkers, other managers and family). Singh (1993) used this instrument in an empirical study and reported differential effects of organizational antecedents on the different role ambiguity facets and also differential relationships between the role ambiguity facets and several outcome variables. These differential effects could be further explored. Job satisfaction is also considered 
to be a multifaceted construct (Ironson et al. 1989; Lucas et al. 1987; Smith et al. 1969). Lucas et al. (1987), for instance, distinguish between two components of job satisfaction: (1) intrinsic job satisfaction and (2) extrinsic job satisfaction. They also report differential effects for these two components on turnover. Finally, recently Meyer \& Allen conceptualized a three dimensional commitment measure (Allen \& Meyer 1990; Meyer \& Allen 1991). Although developed in organization theory, this conceptualization has been very popular in relationship marketing research (See Chapter 6). In sum, differential effect could be researched for all facets and dimensions mentioned above.

From previous studies we have learned that results pertaining to the relationship between role conflict and the antecedents incorporated in our model are mixed. However, with regard to the modest explanatory capacity of role conflict in our model as compared to role ambiguity, it should be noted that conflict can take on many forms (intersender, intrasender, person-role, interrole) as pointed out by Kahn et al. (1964). Since our operationalization of role conflict reflected measurement of overall role conflict only, it might well be that the effects of specific types of conflict were not observable at the aggregate level. Additional research is needed to examine the antecedents and consequences of multiple types of role conflict in a services setting. Apart from including additional mediating effects, several authors have proposed that moderating effects may be insightful with regard to role stress (Jackson \& Schuler 1985; King \& King 1990; Micheals \& Dixon 1994; Singh et al. 1996). The identification of moderator variables could further enhance our knowledge of service employee management.

Furthermore, we used an individual level of analysis. However, some variables can be operationalized at higher level, unit or organizational level (Klein et al. 1994; Rousseau 1985; Singh et al. 1996). However, as aggregation potentially biases results when data is not analyzed at the lowest level of analysis, a multiple-level design may be more appropriate (Klein et al. 1994; Rousseau 1985).

Our research showed that the autoregressive effects have quite a substantial effect on our longitudinal model. The lagged effects are less substantial, as we found only three lagged effects to be significant. However, this may be related to the length of the time lag in our model. For future research we need to include more waves and shorter lags. The shorter lags may now be reflected by contemporaneous effects in our model (Williams \& Podsakoff 1989).

Finally, limitations lie also in the compatibility of the procedure of structural equation modeling that was followed. Although the formulated model captures the observed relationships satisfactorily and allows us to test the hypotheses on the antecedents and consequences of role stressors, it should be noted that a statistical fit might also be achieved with models other than the ones we tested in our study (Bollen 1989).

\subsubsection{Managerial Implications}

As job satisfaction positively affect job performance in terms of service quality, a behaviorbased measure, it is essential to increase job satisfaction for customer-contact service employees by reducing role conflict and role ambiguity. Empowerment can serve to decrease both role ambiguity and role conflict and increasing job satisfaction. However, the competence component in the first wave seems to have a negative effect on technical quality in the second wave. Therefore, further longitudinal research is needed to evaluate the longerterm effects of empowerment. Moreover, initiating structure seems to be able to clarify role requirement and expectations. Service managers need to clarify their goals and expectations with regard to their customer-contact service employees. This might be even more important if empowerment is introduced, using self-directed work teams (Fisher 1993). Group cohesiveness may be used to reduce role conflict. Although group cohesiveness showed a positive lagged effect on role ambiguity. This indicates that creating "tight-knit" workgroups may actually prove detrimental, as the norms they develop may be hard to change. Formalization seems to have a positive effect on role conflict, however formalization also 
showed a positive lagged effect on job satisfaction. In sum, additional longitudinal research is needed, before unequivocal "do's and don'ts" can be formulated.

It has been suggested that performance assessment shift from objective to subjective measures, as the perceived uncertainty concerning the characteristics of successful performance increases (Bommer et al. 1995; Keeley 1977; Mills 1983; Thompson 1967). The use of self-reported performance measures has recently emerged as a viable option of performance measurement, as they are more closely related to actual performance than management evaluations (Levy \& Sharma 1995). Furthermore, research indicates that for service settings service quality assessments by customer-contact service employees may be highly correlated with customer assessments (Parkington \& Schneider 1979; Schneider 1980). The use of subjective, self-reported measures may actually provide more control to service employees with regard to their evaluation and thus reduce the role stress experienced by them (Hartline \& Ferrell 1996). Further research is needed on the use of subjective, self-reported performance measures in service settings.

Job satisfaction is a significant determinant of job performance in terms of service quality. Job satisfaction is positively related to organizational commitment (Brown \& Peterson 1993; Mathieu \& Zajac 1990). Management in service organizations should undertake steps to increase organizational commitment among their employees. Especially, as organizational commitment negatively affects turnover intentions and turnover poses a serious threat to continuity in service industries (Weatherly \& Tansik 1993a,b). Mowday et al. (1982) distinguish three distinct stages in the commitment process: (1) pre-entry, (2) early employment and (3) entrenchment, in which different factors might influence organizational commitment. As a result, management might have to develop individual approaches for service employees in different stages of the commitment process. Hartline \& Ferrell (1993, 1996) also point out the essential role of organizational socialization in this respect.

\subsection{Conclusion}

In this chapter we tested the conceptual framework laid down in Chapter 3. This framework introduces role stress as focal construct with regard to management of customer-contact service employees. The framework conceptualizes role stress as role ambiguity and role conflict. We identified four antecedent to the role stressors: (1) formalization, (2) empowerment, (3) supervisory behavior and (4) group cohesiveness. Subsequently, the relationship between the role stressors and job performance in terms of service quality was mediated by job satisfaction. Our research employed both a cross-sectional and a longitudinal approach. Finally, it should be emphasized that our research is mainly exploratory of nature.

To test the substantive relationships in our conceptual framework we used structural equation modeling, more in particular the partial aggregation approach, as we used a large number of indicators and constructs in our empirical research. This approach entails specifying a measurement model or confirmatory factor analysis model first. Subsequently, the reliability coefficient derived from this stage is used to correct for measurement error in the structural model, the second stage of this approach. In the structural model the error variance of the construct is fixed at 1-reliability coefficient, and the path from the construct to the aggregate scale is fixed at the square root of the reliability.

Using confirmatory factor analysis we assessed the construct validity both in the crosssectional and the longitudinal approach. All constructs exhibited sufficient construct validity in terms of unidimensionality, discriminant validity and convergent validity, and reliability. In the structural model we found that the autonomy component of empowerment showed a pervasive effect in the model. As the results differed only slightly between the cross-sectional approach and the longitudinal approach we will not address them separately. The autonomy component of empowerment affects the role stressors negatively and job satisfaction positively. We also found a negative effect of initiating structure on role ambiguity. Finally, for the longitudinal model we reported a positive effect of formalization on role conflict. 
As far as the role stressors, job satisfaction and job performance are concerned, we found that it is role ambiguity that exerts a negative effect on job satisfaction. The relation between role conflict and job satisfaction is mediated by role ambiguity. Finally, job satisfaction shows a considerable effect on job performance in terms of service quality. We also found that the inclusion of autoregressive and lagged effects considerable improved the explanatory power of our model. The autoregressive effects are all significant and of considerable magnitude, indicating the effect of the corresponding construct in the first wave. We found three lagged effects. Firstly, formalization in the first wave positively affects job satisfaction in the second wave. Secondly, group cohesiveness in the first wave positively affects role ambiguity in the second wave. Thirdly, the competence component of empowerment shows negative effect on job performance in terms of technical quality. 


\section{Chapter 6 \\ Empirical Research}

Commitment in Service Relationships: An Empirical Test of Its Antecedents and Consequences

\section{Outline of the Chapter}

6.1 Introduction

6.2 Conceptual Framework

6.3 Methodology

6.3.I Research Setting

6.3.2 Sampling Design and Data Collection

6.3.3 Questionnaire Design

6.3.4 Data Analysis

6.4 Results of Empirical Research

6.4.1 Sample Characteristics

6.4.2 Construct Validation

6.4.3 Testing Substantive Hypotheses

6.5 Discussion

6.6 Implications of this Study

6.6.1 Theoretical Implications

6.6.2 Managerial implications

6.7 Conclusion 


\section{Commitment in Service Relationships: An Empirical Test of Its Antecedents and Consequences ${ }^{1}$}

\subsection{Introduction}

It is the purpose of the empirical study presented in this chapter to test the conceptual model laid down in Chapter 4 of this thesis. The conceptual model developed in Chapter 4 attempts to bridge the gap between the service quality/customer satisfaction research tradition and the relationship marketing research tradition, also referred to as the relationship paradigm. We developed a conceptual model, in which we assumed that quality, conceptualized in two dimensions as technical quality and functional quality, primarily affects customer satisfaction and both affective and calculative commitment. Customer satisfaction, on its turn, affects the two commitment components and intention to stay with the same service provider.

We carried out a large scale study using a survey with the after-sales service unit of large, Dutch manufacturer of office equipment to test the hypothesized effects in our conceptual framework. It should be emphasized that by far and large this study is exploratory of nature (Babbie 1995; Kerlinger 1986). Its main purpose is it to assess the applicability of the relationship-based constructs in an after-sales context. Our results are very encouraging in that respect.

This chapter will proceed as follows. In section 6.2 we will first briefly summarize the conceptual model developed in chapter 4. Section 6.3 contains a description of the methodology concerning the empirical study. We will provide an overview of the research setting (6.3.1), sampling design and data collection (6.3.2), questionnaire design (6.3.3) and the method of data analysis (6.3.4). Section 6.4 will be concerned with the results of our empirical study. In section 6.5 our findings will be discussed in more detail. Subsequently, section 6.6 contains the implications of our study. Finally, we conclude this chapter in section 6.7 .

\section{2}

\section{Conceptual Framework}

It is the objective of this section to briefly summarize the conceptual framework developed in Chapter 4 of this thesis. The conceptual framework formulated in Chapter 4 attempts to link up the service quality/customer satisfaction research tradition with the more recent research on relationship marketing (See Figure 6-1). Both service quality and customer satisfaction have been included as antecedents to commitment. Customer satisfaction is modeled as a mediator between service quality and commitment. However, we also included the direct paths between service quality and commitment in the framework. Furthermore, we assume that customer satisfaction affects commitment and intention to stay, as a terminal construct. As can be observed from the conceptual framework, both service quality and commitment consist of two componehts. Service quality consists of technical quality and functional quality and commitment consists of affective commitment and calculative commitment. Apart from service quality and customer satisfaction two additional antecedents of commitment have been identified: (1) trust and (2) dependence. Trust is conceptualized as consisting of trust in a partner's benevolence and trust in a partner's honesty. Finally, we hypothesize that commitment and customer satisfaction influence intention to stay, as the terminal consequence of our conceptual framework. 


\section{Figure 6-1: Relationships in Conceptual Framework}

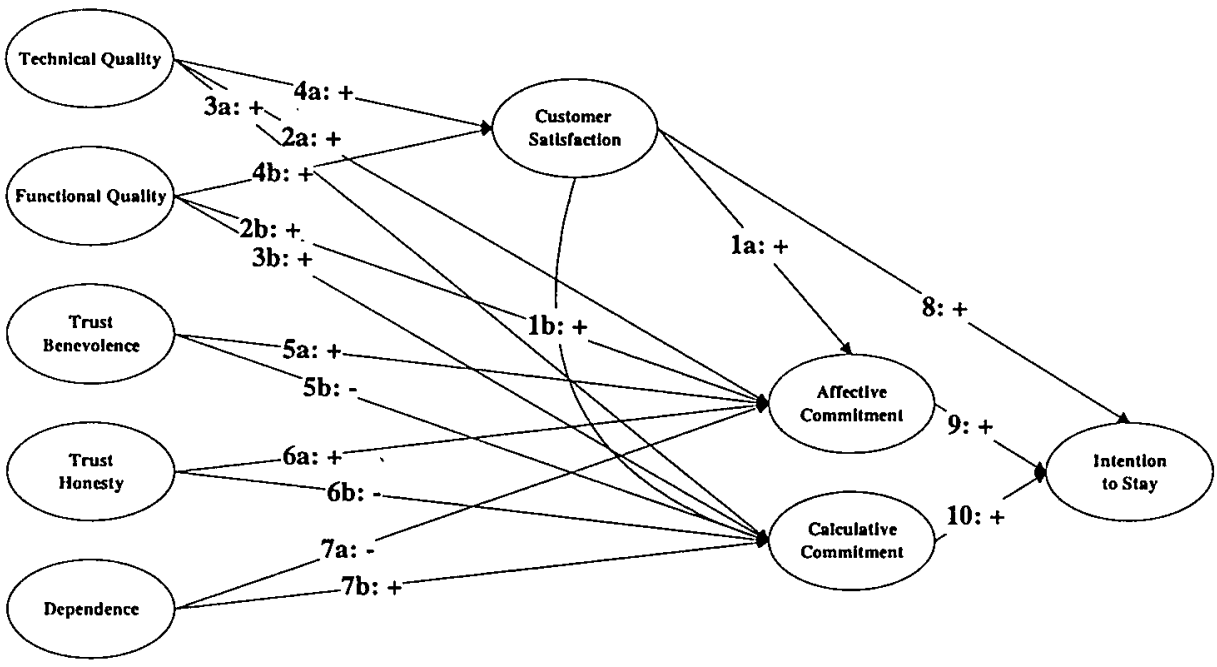

a The direction and the number of the hypothesis are attached to the corresponding relationships.

\subsection{Methodology}

This section on methodology will focus on the following issues. To begin with, we will describe the research setting (6.3.1). Furthermore, the sampling design and data collection will be addressed in section 6.3.2. Questionnaire design features in section 6.3.3. Finally, we conclude this section with a review of our data analysis approach in 6.3.4.

\subsubsection{Research Setting}

Our empirical study was conducted among customers of one of the leading office equipment firms in the Netherlands. This is the same firm, which cooperated in the empirical study in Chapter 5. Further details can be found in section 5.3.1.

\subsubsection{Sampling Design and Data Collection}

The relationships that were at central focus in this study, were the relationships between a major Dutch office equipment manufacturer and its customers. The hypotheses were tested empirically using a disproportionate stratified random sample of customers of this office equipment manufacturer. Stratified sampling involves dividing the population into a number of mutually exclusive subpopulations or strata and subsequently simple random samples are (disproportionally) drawn from the strata (Cochran 1963; Tryfos 1996). We used volume segments as a criterion to obtain the strata. Prior information provided to the researchers indicated that customers within volume segments are rather homogenous. Three volume segments were distinguished: (1) low volume $(50 \%)$, (2) medium volume (35\%) and (3) high volume (15\%). Total sample size equaled 2000 , of which $20 \%$ were accounted for by high volume customers, $35 \%$ by medium volume customer and $45 \%$ by low volume customers. The larger than proportionate share of the high and medium volume is related to the focus of the company on this particular segment.

A mail questionnaire was designed containing both closed and open-ended questions. Most of the constructs included in our conceptual framework consisted of multiple items. A package containing the questionnaire, a personalized cover letter signed by the service manager and a pre-paid return envelope was mailed. The bulk of the questionnaires $(50 \%)$ was received within two weeks after mailing them. Twelve packages were undeliverable, thus 
reducing the effective sample size to 1988. In total 588 usable questionnaires were received from customers, which is a response rate of $29.6 \%$. Sixteen of the questionnaires showed either large proportion of missing data or a tendency for yea- and nay saying. Consequently, 572 questionnaires $(28.7 \%$ ) could be used for further analyses.

\subsubsection{Questionnaire Design}

To measure the various constructs in the conceptual model of the service delivery process established scales were used. All items were measured on 9-point Likert type scales, except for the measurement of customer satisfaction with the manufacturer's service, for which we used a 10-point scale. All items were 'double-back' translated (Brislin 1980) into Dutch by a qualified translator. Affective and calculative commitment were each measured by four items based on the construct definitions and scales of Kumar et al. (1994). As mentioned before, trust in a partner consists of honesty and benevolence of that partner. Trust in the honesty of the manufacturer was measured by five items based on the construct definitions and scales of Kumar et al. (1995). Trust in benevolence of the partner was also measured by five items based on construct definitions and scales of Kumar et al. (1995). The dependence on the manufacturer was measured by three items based on the definitions by Kumar et al. (1995). Overall perceived service quality, divided into technical and functional quality, was measured using the direct comparison method as introduced in Chapter 2. In other words, customers were asked to give a direct comparison of their perceptions to their expectations. The reference point for their expectations was the service an excellent company should offer. The items were customized in wording and subject to the specific service setting of this study, as Carman (1990) proposes. The scale for technical quality consists of four items and the scale for functional quality consists of thirteen items. For measuring the overall customer satisfaction with the manufacturer's service a single item was used. As already mentioned, customers were asked to grade the service of the partner on a 10-point scale. Finally, the behavioral consequence, the intention to stay in the relationship was measured by three items. These items are based on the "expectation of continuity" construct provided by Kumar et al. (1995). Apart from the measures used in the study we also asked the respondents to report on some demographic variables. These included function in the decision making unit (DMU), number of employees, number of machines, relationship length and industry.

The questionnaire consisted of the items mentioned above and was pre-tested in three consecutive stages (Bagozzi 1994; Hunt et al. 1982). We used the debriefing method as suggested by Hunt et al. (1982). In the first round we used ten marketing students, which were interviewed after they had completed the questionnaire. Next, eight employees (three managers and five service engineers) of the office equipment manufacturer were asked to do the same. Finally, eighteen customers of the firm were approached to carry out the same task. After each stage the questionnaire was modified and refined in a minor way. An overview of the measurement instruments is provided in Table 6-1. The instruments are included in Appendix VII.

\section{Table 6-1: Measurement Instruments}

\begin{tabular}{lll}
\hline Construct & Items & Source \\
\hline Technical quality & 4 & Developed for this study \\
Functional quality & 13 & Developed for this study \\
Customer satisfaction & 1 & Single item measure \\
Trust benevolence & 5 & Kumar et al. (1995) \\
Trust honesty & 5 & Kumar et al. (1995) \\
Dependence & 3 & Kumar et al. (1995) \\
Affective commitment & 4 & Kumar et al. (1994) \\
Calculative commitment & 4 & Kumar et al. (1994) \\
Intention to stay & 3 & Kumar et al. (1995) \\
\hline
\end{tabular}




\subsubsection{Data Analysis}

Our approach to data analysis was governed by similar considerations as in Chapter 5 . Our literature review (See Chapter 4) yielded a relatively large number of constructs (9) and as all except one were measured as multi-item measures also a relatively large number of indicators (42). As was already indicated in Chapter 5 model complexity in terms of the number of indicators and/or construct might adversely affect the capability of structural equation modeling to find a model fitting to the data. Therefore, we opted again for the partial aggregation model as proposed by Bagozzi \& Heatherton (1994). The partial aggregation model is particularly useful if the researcher is confronted with a large number of indicators and the researcher still wishes to adjust for measurement error.

In summary, this approach consists of two stages. In the first stage the measurement models are employed for construct validation. On the basis of the results of the measurement model or the confirmatory factor analysis a reliability coefficient can be derived which on its turn can be used in the second stage, estimating the structural model. In the second stage the items left in the analysis after conducting the confirmatory factor analysis are summed for each construct and constitute a single indicator for the construct. As there is only one indicator per construct we need to fix both the error variance and the path from the construct to the indicator. As we have already seen the error variance is fixed at 1-reliability coefficient, and the path from the construct to the aggregate scale is fixed at the square root of the reliability.

\subsection{Results of Empirical Research}

In this section the results of our empirical research will be presented. To begin with, in section 6.4.1 we will first present the characteristics of the sample in terms of the demographics included in the questionnaire. Subsequently, the results of construct validation of the constructs contained in our study will be addressed in section 6.4.2. Finally, in section 6.4 .3 the results of testing the hypotheses underlying our conceptual framework will be discussed.

\subsubsection{Sample Characteristics}

A number of demographic variables were included in the questionnaire. These can be used to describe the sample characteristics (See Table 6-2). In terms of function in the decision making unit (DMU) we see the distinction between decider/influencer and user accounts almost for the same proportion. Concerning the number of the employees, about $67 \%$ of the customers employ between 11 and 200 people. Furthermore, the majority of customers uses one or two machines (59.3\%). This could account for the fact that only one quarter of the customers reports to use a machine from a competitor. The mean number of failures is almost 30 on an annual basis. However, customers indicated that about 18 could be solved by themselves $(56.7 \%)$. With respect to the industry we can see that about $75 \%$ of the customers operate in the services sector (service companies, governmental agencies, health and educational authorities). The remainder of the customers is mainly located in the industrial sector. The average length of the relationship reported is 4.8 years ( $S D=1.9$ years). Finally, a time trend extrapolation test was carried out. The assumption of such a test is that respondents who respond less readily, are more like nonrespondents (Armstrong \& Overton 1977). No significant difference between early and late respondents was found. 
Table 6-2: Sample Characteristics

\begin{tabular}{llll}
\hline Demographics & Category & Frequency & Percentage \\
\hline Function in DMU & Decider & 95 & $16.9 \%$ \\
& Influencer & 175 & $31.1 \%$ \\
& User & 292 & $52.0 \%$ \\
\hline Number of Employees & $1-10$ & 78 & $13.9 \%$ \\
& $11-50$ & 197 & $35.1 \%$ \\
& $51-200$ & 179 & $31.9 \%$ \\
& more than 200 & 107 & $19.1 \%$ \\
\hline Number of Machines & $I$ & 193 & $34.3 \%$ \\
& 2 & 141 & $25.0 \%$ \\
& 3 & 54 & $9.6 \%$ \\
& $4-10$ & 126 & $22.4 \%$ \\
& more than 10 & 49 & $8.7 \%$ \\
\hline
\end{tabular}

\subsubsection{Construct Validation}

Before we will proceed with testing the substantive relationships in the structural model we have to assess construct validity of our measures (Steenkamp \& van Trijp 1991). To validate the constructs in our study we used structural equation modeling (Anderson \& Gerbing 1988; Bagozzi 1980a; Bagozzi \& Philips 1991; Bollen 1989; Gerbing \& Anderson 1988; Steenkamp \& van Trijp 1991). As the number of items adversely affects the acceptance of structural equation models (Bentler \& Chou 1987), we split the constructs in our study into two subsets (cf. Heide \& John 1990; Kumar et al. 1992). The first model contains technical quality and functional quality. The second model is concerned with trust in a partner's benevolence, trust in a partner's honesty, dependence, affective commitment, calculative commitment, and intention to stay. This method has recently been recommended for construct validation (See Chapter 5). LISREL8 and its preprocessor program PRELIS2 were used to obtain maximum likelihood estimates for the free parameters in the confirmatory factor analysis (Jöreskog \& Sörbom 1993). ${ }^{2}$ The results are presented in Table 6-3.

In model 1 we initially obtained an unacceptable fit. However, after an iterative process, in which we inspected $t$-values, the pattern of standardized residuals and the modification indices (Anderson \& Gerbing 1988; Steenkamp \& van Trijp 1991), five quality items were deleted (one item for technical quality and four items for functional quality) and we obtained a good fit: $\chi^{2}(53)=234.31$ (p<0.001); GFI=0.93; $\mathrm{AGFI}=0.90 ; \mathrm{RMSR}=0.04 ; \mathrm{TLI}=0.94 ; \mathrm{CFI}=0.95$ (Bagozzi \& Yi 1988; Bentler 1990; Bollen 1989; Hoelter 1983; Marsh \& Hocevar 1985; Steenkamp \& van Trijp 1991). Although the significant $\chi^{2}$ indicates that the model does not fit the data adequately, we have to realize that that the large sample size affects the $\chi^{2}$-test (Bearden et al. 1982; Bentler 1990; Bentler \& Bonnett 1980; Hoelter 1983; Marsh et al. 1988). Consequently, a wide variety of fit indexes have been developed that are supposedly independent of sample size (Hu \& Bentler, 1995; Marsh et al. 1988, 1996). Among these the Tucker-Lewis Index (TLI) (Bentler \& Bonnett 1980; Tucker \& Lewis 1973) and the Comparative Fit Index (Bentler 1990) seem to be relatively unaffected by sample size (Marsh et al. 1988, 1996). Given the large sample size the Root Mean Square Error of Approximation (RMSEA) might provide even a better indication of goodness-of-fit (Steiger 1990). The value of the RMSEA equals 0.077 and is below the recommended cut-off value of 0.08 . For further analyses there remained three items for technical quality and nine items for functional quality. The results for model 1 are summarized in Table 6-3.

Within-method convergent validity was assessed testing the significance and magnitude of the elements of the matrix $\Lambda^{x}$. We found that all items loaded higher than 0.5 on their 
Table 6-3: Results of Confirmatory Factor Analysis

Model Fit

\begin{tabular}{|c|c|c|c|c|c|c|c|c|}
\hline & $x^{2}$ & df & GFI & AGFI & RMSR & TLI & CFI & RMSEA \\
\hline Model 1 & $234.31(p<0.001)$ & 53 & 0.93 & 0.90 & 0.04 & 0.94 & 0.95 & 0.077 \\
\hline Model 2 & $503.05(\mathrm{p}<0.001)$ & 194 & 0.92 & 0.90 & 0.04 & 0.95 & 0.96 & 0.053 \\
\hline \multicolumn{9}{|c|}{ Reliability of Measures } \\
\hline & \multicolumn{2}{|l|}{ Construct } & \multicolumn{3}{|c|}{ Number of Items } & Reliability & & \\
\hline \multirow[t]{2}{*}{ Model 1} & \multirow{2}{*}{\multicolumn{2}{|c|}{$\begin{array}{l}\text { Technical Quality } \\
\text { Functional Quality }\end{array}$}} & \multicolumn{2}{|c|}{3} & \multicolumn{2}{|c|}{0.84} & & \\
\hline & & & 9 & & \multicolumn{2}{|c|}{0.90} & & \\
\hline \multirow[t]{6}{*}{ Model 2} & \multicolumn{2}{|l|}{ Trust Benevolence } & 5 & & \multicolumn{2}{|c|}{0.92} & & \\
\hline & \multicolumn{2}{|l|}{ Trust Honesty } & 4 & & \multicolumn{2}{|c|}{0.80} & & \\
\hline & \multicolumn{2}{|c|}{ Dependence } & 2 & & \multicolumn{2}{|c|}{0.80} & & \\
\hline & \multicolumn{2}{|c|}{ Affective Commitment } & 4 & & \multicolumn{2}{|c|}{0.95} & & \\
\hline & \multicolumn{2}{|c|}{ Calculative commitment } & 4 & & \multicolumn{2}{|c|}{0.87} & & \\
\hline & \multicolumn{2}{|c|}{ Intention to Stay } & 3 & & \multicolumn{2}{|c|}{0.77} & & \\
\hline
\end{tabular}

respective constructs with a minimum t-value of 15.36 (See Appendix VIII). Discriminant validity was evaluated by testing whether pairs of constructs were correlated less than unity. We used a $\Delta \chi^{2}$ with one degree of freedom to test for unity between technical quality and functional quality. The test was significant at $\alpha=0.05$.

Initially, model 2 showed an inadequate model fit as well. Therefore we omitted two items from the model using $t$ values, the pattern of standardized residuals and the modification indices in an iterative fashion. The items that did not fit the structure were the third item of the dependence construct and the first of trust in the partner's honesty. These two items were subsequently left out in further analyses. Consequently model fit proved to be good: $\chi^{2}=503.05 \quad(\mathrm{p}<0.001) ; \quad \mathrm{GFI}=0.92 ; \quad$ AGFI $=0.90 ; \quad$ RMSR $=0.04 ; \quad$ TLI $=0.95 ; \quad$ CFI $=0.96$; RMSEA $=0.053$ (See Table 6-3).

Within-method convergent validity was assessed testing the significance and magnitude of the elements of the matrix $\Lambda^{\mathrm{x}}$. We found that all items loaded higher than 0.5 on their respective constructs except one (standardized loading $=0.37$ ). The minimum t-value reported is 8.54. See Appendix VIII for more details. Discriminant validity was evaluated by testing whether pairs of constructs were correlated less than unity. We used a $\Delta \chi^{2}$ with one degree of freedom to test for unity between the ten pairs of constructs. All tests were significant at $\alpha=0.05$.

Additionally, the reliability of the constructs in both models was evaluated using composite reliability and variance extracted measures (Fornell \& Larcker 1981; Jöreskog 1971). From Table 6-3 it can be concluded that the constructs exhibited a high degree of reliability in terms of composite reliability, all values exceeded the recommended value of 0.7 . Variance extracted is reported in Appendix VIII and we can observe that all values exceeded 0.5 , as recommended by Fornell \& Larcker (1981). These reliability coefficients will be used to correct the constructs for measurement error in the second stage for our approach (See 6.4.3) ${ }^{3}$.

\subsubsection{Testing Substantive Hypotheses}

In order to test the hypotheses we formulated we used the partial aggregation approach as outlined in section 6.3.4. After correcting the constructs for measurement error the free elements were estimated using PRELIS2 and LISREL 8 (Jöreskog \& Sörbom 1993). We used LISREL8 to obtain maximum likelihood estimates of the path coefficients. It can be concluded that the fit of this model is not adequate: $\chi^{2}(9)=130.36(p<0.001) ; \mathrm{GFI}=0.95$, 
$\mathrm{AGFI}=0.77, \mathrm{RMSR}=0.07 ; \mathrm{TLI}=0.75 ; \mathrm{CFI}=0.94 ; \mathrm{RMSEA}=0.15$. As our study is largely exploratory we followed the suggestions by Silvia \& MacCallum (1988). We estimated all parameters in the structural model and proceeded by fixing non-significant parameters one at a time. We found that five of the paths hypothesized in the conceptual model were not significantly different from zero. More in particular, we found that the relationship between customer satisfaction and intention to stay was not significant. Furthermore, the direct relationship between functional quality and affective commitment and calculative commitment could not be found. The same holds for the relationship between technical quality and calculative commitment. Finally, we were not able to find a relation between dependence and affective commitment. Deleting these paths did not significantly affect the fit $\left(\Delta \chi^{2}(5)=2.26, \mathrm{p}=0.32\right)$ and resulted in a more parsimonious model $\left(\chi^{2}(13)=132.62(\mathrm{p}<0.001)\right.$; $\mathrm{GFI}=0.95 ; \mathrm{AGFI}=0.84 ; \mathrm{TLI}=0.83 ; \mathrm{CFI}=0.94 ; \mathrm{RMSEA}=0.13$ ). Interestingly, inspection of the univariate Lagrangian Multiplier (LM) test (in LISREL terminology this test is referred to as modification index) suggested an additional relationship in our model (Bollen 1989; Jöreskog \& Sörbom 1989, 1993). In addition to the relations hypothesized à priori on the basis of our review of the literature, it was found that trust in a partner's honesty directly affected customer satisfaction and that trust in a partner's benevolence directly related to intention to stay. The model shows a good fit to the data: $\chi^{2}(11)=19.59(\mathrm{p}=0.051) ; \mathrm{GFI}=0.99 ; \mathrm{AGFI}=0.97$; TLI=0.99; CFI=0.99; RMSEA $=0.037$. All measures well exceed the recommended cut-off values (Bagozzi \& Yi 1988; Jöreskog \& Sörbom, 1989). Furthermore, the value of the $\chi^{2} / \mathrm{df}$ ratio also indicates a good fit of the data to the hypothesized model (Bagozzi \& Yi 1988; Hoelter 1983). Finally the Q-plot clearly showed a linear trend through the plotted values indicating a good fit (Bagozzi \& Yi 1988; Jöreskog \& Sörbom 1989). Finally, it should be noted that given the exploratory nature of our study further research will be needed to assess the cross-validity of our model (Cudeck \& Browne 1983; MacCallum et al. 1992; Silvia \& MacCallum 1988).

Inspection of the path coefficients allows us to test our hypothesis (See Table 6-4). To begin with, the relationships between service quality, customer satisfaction, and affective and calculative commitment were tested. Hypothesis $1 \mathrm{a}$ is supported by a significant positive relationship between customer satisfaction and affective commitment (standardized path coefficient $=0.17 ; \mathrm{t}$-value $=3.85$ ). More satisfied customers will be more affectively committed to the supplier. Furthermore, we also found a significant relationship between customer satisfaction and calculative commitment, which supports hypothesis $1 \mathrm{~b}$ (standardized path coefficient $=0.14 ; \mathrm{t}$-value $=2.56$ ). More satisfied customers will be more calculatively committed to the supplier. A significant positive relationship between technical quality and affective commitment supports hypothesis $2 \mathrm{a}$ (standardized path coefficient $=0.13$; $\mathrm{t}$ value=3.27). Higher quality of the service outcome will result in more affective commitment of customers to the supplier. In our study we found no support for hypothesis $2 b$; there is no significant relationship between the functional quality of a service, that is the quality of the service process, and affective commitment of customers. Also hypothesis $3 \mathrm{a}$ and $3 \mathrm{~b}$ are not supported by our study: both technical and functional quality are not significantly related to calculative commitment. Hypothesis $4 \mathrm{a}$, however, a positive relation between technical quality and customer satisfaction, is supported by our findings (standardized path coefficient $=0.24$; tvalue $=3.65$ ). In other words, higher levels of outcome quality will lead to higher levels of customer satisfaction. The same applies to functional quality; higher quality of the service process will result in more satisfaction (standardized path coefficient $=0.21 ; t$-value $=3.32$ ). This is in support of hypothesis $4 \mathrm{~b}$.

Furthermore, the relationships between commitment, trust and dependence were studied. Hypothesis $5 \mathrm{a}$ is supported by a significant positive relationship between trust in a partner's benevolence and affective commitment (standardized path coefficient $=0.21 ; t$-value $=4.27$ ). The more a customer beliefs that its supplier is interested in its welfare and that the supplier will not take any unexpected actions which negatively impacts the customer, the higher the level of affective commitment of the customer in the relationship. The negative relation 
between trust in the supplier's benevolence and calculative commitment, as stated by hypothesis $5 \mathrm{~b}$, is not supported. A significant positive relationship between these two constructs is found (standardized path coefficient $=0.55$; $t$-value=7.94). Apparently, more trust in the partner's benevolence leads to increased calculative commitment of a customer. Both hypotheses $6 \mathrm{a}$ and $6 \mathrm{~b}$ on trust in the partner's honesty are supported. The higher the belief of the customer that the supplier will stand by its word, the higher the affective commitment of the customer in the relationship (standardized path coefficient $=0.44 ; t$-value $=7.58$ ) and the lower the calculative commitment (standardized path coefficient $=-0.40$; $t$-value $=-5.02$ ). Dependence on the supplier was not found to be significantly related to affective commitment, which is in conflict with hypothesis $7 \mathrm{a}$. However, it is positively related to calculative commitment (standardized path coefficient $=0.35, t$-value $=7.75$ ). The more a customer depends on its supplier, the higher his/her calculative commitment in the relationship with that partner and therefore, the more he/she will be balancing gains and losses of that relationship. This is in accordance with hypothesis $7 \mathrm{~b}$.

Finally, it was tested what the consequences of customer satisfaction and commitment in a relationship marketing context were. Firstly, no significant relation between customer satisfaction and the intention to stay in the relationship was found. This leads to rejection of hypothesis 8 . However, it can be concluded that both types of commitment do influence the intention to stay. More affectively committed customers, intend to stay longer in the relationship with the supplier (standardized path coefficient $=0.44 ; t$-value $=8.26$ ) and also more calculatively committed customers have a higher intention to continue that relationship (standardized path coefficient $=0.16 ; t$-value $=3.80$ ). Therefore, hypotheses 9 and 10 are supported by our study.

Inspection of the modification indices suggested two additional relationships in our model (Jöreskog \& Sörbom 1989). In addition to the relations mentioned above, it could be concluded that trust in the partner's honesty also has a direct positive effect on customer satisfaction with the service (standardized path coefficient $=0.41$; $t$-value $=9.59$ ). Moreover, trust in a partner's benevolence was also found to be directly influencing the intention to stay in a positive way (standardized path coefficient=0.29; $t$-value=5.19). Since we left the realm

Table 6-4: Estimated Path Coefficients ${ }^{\mathrm{a}}$

\begin{tabular}{llll}
\hline Relationships & Hypothesis & Standardized Path Coefficient & Hypothesis Testing \\
\hline CSAT $\rightarrow$ AC & $\mathrm{H}_{1 \mathbf{a}}$ & $0.17(3.85)$ & Failed to Reject \\
$\mathrm{CSAT} \rightarrow \mathrm{CC}$ & $\mathrm{H}_{1 \mathrm{~b}}$ & $0.14(2.56)$ & Failed to Reject \\
$\mathrm{TQ} \rightarrow \mathrm{AC}$ & $\mathrm{H}_{2 \mathrm{a}}$ & $0.13(3.27)$ & Failed to Reject \\
$\mathrm{FQ} \rightarrow \mathrm{AC}$ & $\mathrm{H}_{2 \mathrm{~b}}$ & n.s. & Rejected \\
$\mathrm{TQ} \rightarrow \mathrm{CC}$ & $\mathrm{H}_{3 \mathbf{a}}$ & n.s. & Rejected \\
$\mathrm{FQ} \rightarrow \mathrm{CC}$ & $\mathrm{H}_{3 \mathrm{~b}}$ & n.s. & Rejected \\
$\mathrm{TQ} \rightarrow \mathrm{CSAT}$ & $\mathrm{H}_{4 \mathbf{a}}$ & $0.24(3.65)$ & Failed to Reject \\
$\mathrm{FQ} \rightarrow \mathrm{CSAT}$ & $\mathrm{H}_{4 \mathrm{~b}}$ & $0.21(3.32)$ & Failed to Reject \\
$\mathrm{TB} \rightarrow \mathrm{AC}$ & $\mathrm{H}_{5 \mathbf{a}}$ & $0.21(4.27)$ & Failed to Reject \\
$\mathrm{TB} \rightarrow \mathrm{CC}$ & $\mathrm{H}_{5 \mathrm{~b}}$ & $0.55(7.94)$ & Rejected \\
$\mathrm{TH} \rightarrow \mathrm{AC}$ & $\mathrm{H}_{6 \mathrm{a}}$ & $0.44(7.58)$ & Failed to Reject \\
$\mathrm{TH} \rightarrow \mathrm{CC}$ & $\mathrm{H}_{6 \mathrm{~b}}$ & $-0.40(-5.02)$ & Failed to Reject \\
$\mathrm{DEP} \rightarrow \mathrm{AC}$ & $\mathrm{H}_{7 \mathbf{a}}$ & n.s. & Rejected \\
$\mathrm{DEP} \rightarrow \mathrm{CC}$ & $\mathrm{H}_{7 \mathrm{~b}}$ & $0.35(7.75)$ & Failed to Reject \\
$\mathrm{CSAT} \rightarrow \mathrm{It} S$ & $\mathrm{H}_{8}$ & n.s. & Rejected \\
$\mathrm{AC} \rightarrow \mathrm{ItS}$ & $\mathrm{H}_{9}$ & $0.44(8.26)$ & Failed to Reject \\
$\mathrm{CC} \rightarrow \mathrm{ItS}$ & $\mathrm{H}_{10}$ & $0.16(3.80)$ & Failed to Reject
\end{tabular}
$\mathrm{TH}=$ Trust Honesty; $\mathrm{DEP}=\mathrm{Dependence;} \mathrm{AC}=\mathrm{Affective}$ Commitment; $\mathrm{CC}=\mathrm{Calculative}$ Commitment; ItS=Intention to Stay. 
of confirmatory analyses by adding these two paths to our model, our final model needs to be cross-validated using additional samples (Cudeck \& Brown 1983; MacCallum 1986). The relationships in the final model are depicted in Figure 6-2.

\subsection{Discussion}

Our study indicates that for the establishment of affective commitment in a supplier-customer relationship, it is very important that a customer has a lot of trust in the supplier's benevolence and honesty. If a customer beliefs that the supplier is benevolent, which means that he is interested in the customer's welfare and will not take any unexpected actions which will negatively influence the customer, then also more affective commitment will emerge. This similarly applies for honesty. The positive effect of trust on affective commitment is supported by several empirical studies (e.g., Geyskens et al. 1996; Morgan \& Hunt 1994; Venetis 1997). Also by paying attention to service outcome and constantly improving this technical quality, customers will not only be more affectively committed in the relationship, but also more satisfied. The positive effect of technical quality on affective commitment is also found by Venetis (1997). In her study on advertising agencies, however, the effect is mediated by a global measure of service quality. Furthermore, De Ruyter et al. (1997c) also report a positive relationship between service quality and affective commitment. Subsequently, higher levels of customer satisfaction also contribute to more affectively committed customers. Other ways of increasing customer satisfaction is by improving the functional quality of the service, that is the quality of the service process and developing trust in the supplier's honesty.

Our study also shows that affective commitment is not directly significantly influenced by functional quality. Apparently, the quality of the service outcome is more important in establishing affective commitment than the quality of the service process (Venetis 1997). However as mentioned before, functional quality results in higher levels of customer satisfaction, which in turn lead to affective commitment. Therefore, functional quality is an indirect antecedent of affective commitment. Furthermore, asymmetry in a relationship

\section{Figure 6-2: Relationships in Final Model}

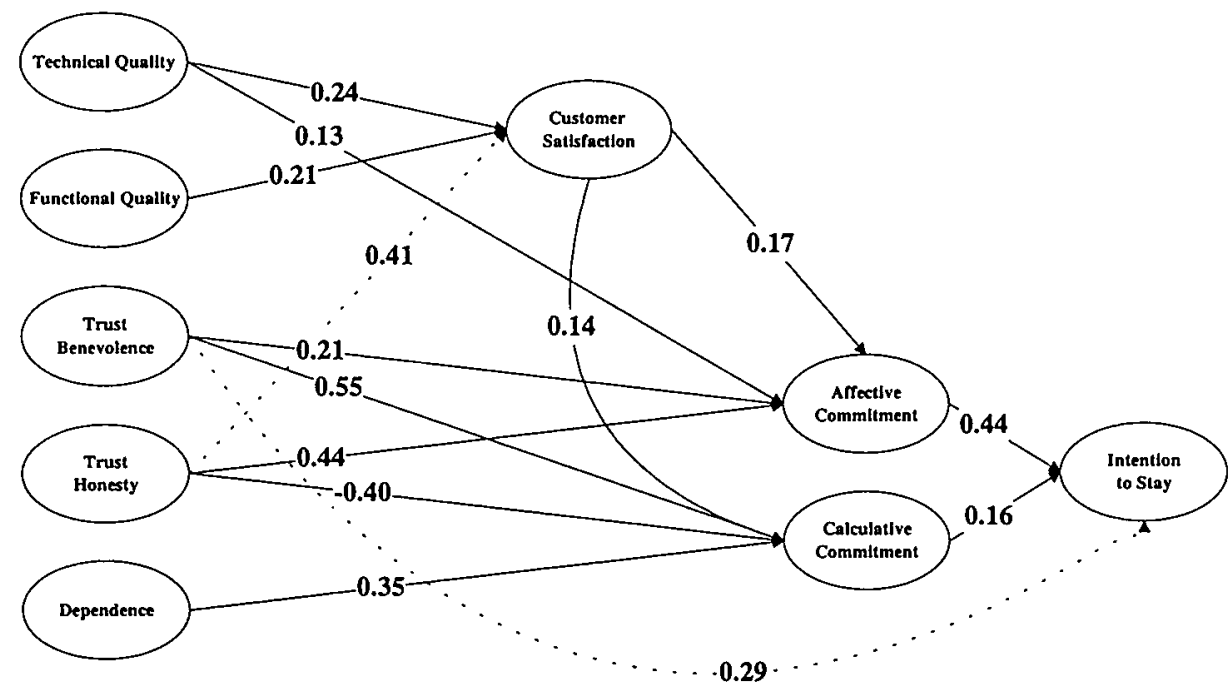


between supplier and customer does not automatically imply that a customer will be less affectively committed to the relationship.

Calculative commitment is not affected directly by quality. However, as both technical and functional quality are related to customer satisfaction, quality indirectly affects calculative commitment. Trust in the supplier's benevolence positively affects calculative commitment, whereas trust in the supplier's honesty reduces calculative commitment. The negative effect of trust on calculative commitment also emerges from an empirical study by Geyskens et al. (1996). Venetis (1997) fails to find a relationship between trust and calculative commitment in her study. Furthermore, we find that dependence shows a positive impact on calculative commitment. This relationship is corroborated by Geyskens et al. (1996).

The importance of affective commitment in business relationships is stressed by its strong relationship with customers' intentions to continue a relationship. More affectively committed partners show a stronger intention to stay than customers who feel more calculative commitment. This latter type of commitment is weakly positively related to the intention to stay. In a marketing channels context Kumar et al. (1994) report that affective commitment is the main determinant of intention to stay. This can also be observed from an empirical study by Venetis (1997). She reports a fairly strong relationship between affective commitment and intentions to stay, but fails to find a relationship between calculative commitment and intentions to stay. De Ruyter et al. (1997c) report similar findings, but mediate the relationship between affective commitment and intentions to stay with cooperation. Moreover, trust in benevolence significantly influences the intention to stay in the relationship. More trust in benevolence of a supplier leads to a stronger intention of customers to continue the relationship with that supplier. Surprisingly, this intention of continuation is not significantly influenced by customer satisfaction. However, because customer satisfaction leads to higher affective commitment, which in turn has the strongest influence on the intention to stay, it has an indirect effect on intention to stay in the relationship.

\subsection{Implications of this Study}

In this section we will be considering both the theoretical and the managerial implications of this study. In section 6.6.1 we will first discuss the theoretical implications of this study. Subsequently, section 6.6 .2 will be concerned with the managerial implications of this study.

\subsubsection{Theoretical Implications}

To begin with, our findings are based on one (service) organization. Future research will be needed to confirm the generalizability of our findings. Secondly, the constructs that were studied represent very complex phenomena. Future studies will have to determine which conceptualizations will be needed to yield the most reliable and best explanations. Thirdly, all concepts were measured at one point in time, thus essentially from a static perspective. It may be worthwhile to study customer-service organization relationships over time in order to be able to take into account the dynamics of business relationships (See Chapter 5). Finally, the use of paper-and-pencil self reports may have inflated the relationships between the constructs in our model. However, given the results of the construct validation this may not be a serious problem.

Moreover, previous research has suggested additional types of commitment in business relationships, such as moral commitment (Allen \& Meyer 1990; Kumar et al. 1994). Since the operationalization in our design has been limited to affective and calculative commitment, the obvious implication is to incorporate other types of commitment, particularly in research settings in which neither affective nor calculative commitment play a role of importance. Important questions remain as to the complexity of the antecedents of commitment. In this paper only a limited number were used. Additional research is needed as to other variables that lead to relationship commitment. One aspect that deserves a more in-depth study is the relation between commitment and various degrees of dependence asymmetry (Geyskens et al. 1996). Other variables that can be included in our conceptual framework are, for instance, the nature 
and frequency of interaction between parties, faimess, reciprocity, image of the service organization, the types of power strategies used in the relationship as well as more macroenvironment variables such as uncertainty and level of competition in industries and markets. Finally, the effects were estimated with regards to intentions. Actual behavior such as repeat "buying" behavior and word-of-mouth were not included in this study. However, they should be studied in order to complete the picture.

\subsubsection{Managerial implications}

There are several factors management of service providers can use to improve their specific service delivery process and to establish long-lasting relationships with their customers. Most important is the creation of affective commitment of customers in their relationship with the supplier. Affective commitment has the strongest effect on intention to stay in the relationship, and thus on future revenues. This affective commitment is positively influenced by higher levels of satisfaction of customers, and by the improvement of the technical quality of the service and trust in the supplier. The creation of trust in the relationship should be a focal point of attention for managers. It was shown that trust not only has a positive effect on affective commitment, but also on customer satisfaction and the intention to stay in the relationship. Trust arises if the manufacturer is honest and benevolent with the customer. To achieve trust, managers should try to instruct contact personnel to tell the truth, to give accurate information, to keep promises, to be sincere, and to give advice according to their best judgment. The service provider is benevolent if he is willing to offer assistance and support when the customer has a problem, when he is concerned about his welfare, and shows understanding for the customer's problems.

As mentioned, trust not only has a positive effect on affective commitment, but also on customer satisfaction. Customer satisfaction in turn has, through affective commitment, an indirect positive effect on intention to stay in the relationship. Management should try to avoid business relationships in which the partner only feels calculative commitment. Given the choice between developing closeness to the service provider through attraction or obligation, it is clear that management should cultivate the former over the latter. Our study indicates that calculative committed customers have a much weaker intention to stay than affective committed customers do. As soon as alternative suppliers emerge they probably will switch to alternative service providers. The way to avoid high calculative commitment is to strive for dependence symmetry and honesty towards the customer. A balanced and honest relationship will result in less calculatively and more affectively committed customers, more satisfied customers, and therefore in a long-lasting profitable relationship for both parties.

Furthermore, acknowledgment of the importance of client relationships as well as the identification of relationship constructs provides input for developing alternative segmentation strategies for service organizations (Van der Walt et al. 1994). Instead of traditional client criteria, such as client size and type of industry clients could also be segmented on the basis of commitment characteristics. Obviously, these client segments would require different relationship management tactics and strategies.

\subsection{Conclusion}

In this chapter of the thesis we tested the conceptual framework laid down in Chapter 4. This framework attempts to relate two research traditions: (1) the service quality/customer satisfaction research tradition and (2) the relationship marketing research tradition. Essentially, the framework, which was proposed in Chapter 4, introduces customer satisfaction as an antecedent of affective and calculative commitment. Furthermore, we assume that customer satisfaction mediates the relationship between service quality, technical and functional, and affective and calculative commitment. Moreover, we posited that quality is not only indirectly, but also directly related to commitment. Our research is mainly exploratory of nature and we used survey research to test the relationships in the conceptual 
framework. Our empirical study was conducted with the after-sales service department of a large, Dutch manufacturer of office equipment, which consisted of 12 departments. Each department is headed by its own manager and has its own "customer base".

The empirical research used a stratified sample on the basis of volume. The survey used a mail questionnaire. For data analysis purposes we used the partial aggregation approach as we were confronted with a relatively large number of indicators and constructs. This approach consists of two stages: (1) estimating the measurement model or confirmatory factor analysis and (2) estimating the structural model. The structural model is corrected for measurement error by means of the reliability coefficient derived from the first stage, the confirmatory factor analysis. In the structural model the error variance of the construct is fixed at 1reliability coefficient, and the path from the construct to the aggregate scale is fixed at the square root of the reliability.

Using confirmatory factor analysis we evaluated the construct validity of the constructs used in our study. All constructs exhibited sufficient construct validity in terms of unidimensionality, discriminant validity and convergent validity, and reliability. Our study suggests that both technical quality and functional quality exhibit a positive effect on affective commitment. Technical quality shows a direct as well as an indirect effect via customer satisfaction, while functional quality only shows an indirect effect via customer satisfaction. Furthermore, the same indirect effects can be found for calculative commitment. In addition, trust in partner's benevolence and trust in a partner's honesty positively influence affective commitment. Calculative commitment, on the other hand, is positively affected by trust in a partner's benevolence and negatively affected in by trust in a partner's honesty. Moreover, trust in a partner's honesty also positively affects customer satisfaction. Finally, intention to stay is positively affected by both affective and calculative commitment. However, in terms of standardized path coefficients the effect of affective commitment is stronger. Even the direct effect of trust in a partner's benevolence is stronger than the effect of calculative commitment. 


\section{Chapter 7 \\ Conclusions}

\section{Outline of the Chapter}

7.1 Introduction

7.2 Conclusions

7.2.1 Research Question 1: Organizational Antecedents to Service Quality

7.2.2 Research Question 2: Service Quality and the Relationship Paradigm

7.3 Implications

7.3.1 Theoretical Implications

7.3.2 Managerial Implications

7.4 Reflections on a Mirror Image 


\section{Conclusions}

\subsection{Introduction}

The research objectives of this thesis were twofold. First, we concentrated on organizational factors, which affect customer-contact service employee performance in terms of service quality. The performance of customer-contact service employees is quintessential for the organizational success of service organizations. Therefore, we formulated the first research question:

Research Question 1:

Which organizational factors affect the performance of customer-contact service employees?

Although several authors have reported a positive relationship between quality and profitability, there is still no clear view on the intervening process, which leads from (service) quality to profitability. Recently, it has been proposed that the maintenance of long-term relationships might clarify this relationship; this is referred to as the relationship paradigm. Several authors have explored frameworks, which have identified factors contributing to the creation and maintenance of long-term relationships. Our second research question deals with this issue:

Research Question 2:

How can service quality be related to the relationship paradigm? How does service quality affect the intention of customers to remain loyal in a long-term service relationship?

These research questions were formulated in Chapter 1 . In Chapter 2 we discussed the importance of service quality as a focal construct in this study. In Chapter 3 a conceptual framework was developed to answer the first research question and in Chapter 4 we formulated a conceptual framework to answer the second research question. In Chapter 5 the substantive relationships of the framework developed in Chapter 3 were empirically tested in an after-sales service setting. In Chapter 6 we subsequently tested the substantive relationships of the conceptual framework developed in chapter 4 in an after-sales service setting.

This chapter is structured as follows. In section 7.2 we will present the conclusions with regard to this thesis. In section 7.3 we will discuss the implications of this study. Finally, in section 7.4 we will provide a more holistic view on this study.

\subsection{Conclusions}

In this section the conclusions of our study will be presented. The conclusions will be structured using the two research questions as guideline.

\subsubsection{Research Question 1: Organizational Antecedents to Service Quality}

In Chapter 3 we focused on organizational antecedents to service quality. The Extended Model of Service Quality links internal or organizational antecedents to the gaps in the Conceptual Model of Service Quality. The design for the Extended Model of service Quality requires a relatively complex and elaborate design. The model uses data from: (1) customers, (2) service managers and (3) customer-contact service employees. Furthermore, the research design calls for two levels of analysis: (1) individuals and (2) organizational entities. Finally, 
the organizational entities may be viewed as sub-units and therefore are part of a larger organizational body. Thus, including a third level of analysis: the organization itself.

The model specification of the Extended Model of Service Quality also raises several concerns. It should be noted that the model is mainly of diagnostic value. The conceptualization of the internal gaps closely resembles a formalized, mechanistic, bureaucratic organization. Such an organizational configuration might not be appropriate for all service organizations. Moreover, the relationship between the antecedents and the internal gaps is not unambiguous. Most of the antecedents are of an ad hoc as well as a structural level. The Extended Model of Service Quality proposes a top-down approach, whereas Total Quality Management recommends the use of bottom-up procedures, such as QFD or its services counterpart SQD. The model might suffer from omission of relevant variables. Finally, the model essentially is static of nature and therefore the sequential order of variables cannot be determined unambiguously.

Empirical research has identified several shortcomings with regard to measurement properties of the internal gaps and the antecedents. Although the internal gaps (GAP2 to GAP4) show sufficient reliability in terms of coefficient $\alpha$, they are measured on attribute level only. Therefore, Smidts (1993) suggested to measure the internal gaps on item level; thus increasing reliability and specificity (diagnostic value). The majority of the antecedents to the internal gaps exhibit unacceptably low levels of reliability in terms of coefficient $\alpha$. Either these measures need to be improved or published scales with favorable psychometric properties need to be included in the framework. These results have been confirmed in our empirical pre-study. Furthermore, the proposed effects of the internal gaps (GAP1-GAP4) on GAP5 could not be found in our study. Finally, only a limited number of antecedents showed the hypothesized effect on the internal gaps.

Our need for an alternative model is based on four considerations. To begin with, the research design of the Extended Model of Service Quality is fairly complex and elaborate. A more limited approach might be advised. Furthermore, the measurement instruments, especially for the antecedents, need considerable improvement. The model specification of the Extended Model of Service Quality makes it closely resemble a formalized, mechanistic, bureaucratic organization. The relationship between the gaps and the antecedents are not unambiguous. Moreover, the antecedents in the model might show considerable interrelations, which is not allowed for in the model in its present form. The antecedents are both ad hoc and structural of nature. Finally, the model is static and needs a more dynamic approach. Therefore, a major revision should be considered. Two fields of research are particularly relevant for this revision: (1) marketing and (2) organizational theory. Marketing predominantly focuses on the customer as its object of study, while organizational theory focuses predominantly on the employee as its object of study. However, at the interface of the two disciplines valuable contributions can be found.

Service employees share several characteristics with salespersons. Both salespeople and service employees fulfill a boundary spanning role and form the link between the organization and the customer. Furthermore, both the performance of the salesperson and the performance of service employees are essential to the economic success of the organization. Finally, when dealing with customers both the service employee and the salesperson are called upon to perform innovative and creative activities to solve customers' problems. As a result of these characteristics service employees are particularly prone to role stress. Recently, two models have been proposed for the management of service employees. The first model suggests that service may be improved by industrializing the service; thus limiting the discretionary powers of service employees. The other model, also referred to as the "involvement" model, appeals to the ability of service employees to control their own activities using empowerment as its focal construct. In addition, we also have to take into account the supervisor and co-workers in the service organizations as major determinants of the performance of service employees.

Role theory posits that each individual performs a certain role in an organization. This role cannot be seen in isolation, but is related to other roles in the organization. Other individuals in the organization attempt to exert influences on the focal person by communicating role 
pressures or role expectations. Role conflict and role ambiguity occur when the role expectations differ between role senders and focal person. Role conflict occurs when the focal person is confronted with conflicting role expectations from different external agents, i.e. inter-sender role conflict. Role ambiguity refers to lack of clarity regarding the role to be performed. Role ambiguity and role conflict are the result of a dynamic process affected by personal factors, interpersonal factors and organizational factors.

We included both the "industrialization" approach and the involvement approach to service management in our conceptual model. The core of the "industrialization" model essentially is formalization. We assume that formalization will negatively affect role ambiguity, while formalization will positively affect role conflict. Formalization will create clarity regarding what the organization, the service manager and the colleagues expect from the service employee and thus reduce role ambiguity. Role conflict, on the other hand, may be increased by limiting the discretionary powers of the service employee. The service employee is required to work "by the rules" and the rules might not necessarily reflect the customer's point of view. Empowerment is included in the model as a proponent of the involvement model. Empowerment is operationalized in two dimensions: (1) autonomy and (2) competence. We expect that both authority and control will reduce role stress in terms of role ambiguity and role conflict.

In addition to formalization and empowerment we also included leadership behavior and group cohesiveness as antecedents to role stress. Leadership behavior consists of two dimensions: (1) initiating structure and (2) leader consideration. Both dimensions are expected to negatively influence role stress. As far as group cohesiveness is concerned we hypothesized that increased group cohesiveness will reduce both components of role stress. We have hypothesized that role ambiguity and role conflict lead to decreased levels of job satisfaction. The negative emotions associated with role stress will reduce job satisfaction. Several authors have suggested that there is a positive relationship between job satisfaction and job performance of service employees in terms of service quality. We have operationalized service quality as consisting of both an outcome (technical quality) and process component (functional quality).

To test the substantive relationships in our conceptual framework we used structural equation modeling in Chapter 5, more in particular the partial aggregation approach, as we used a large number of indicators and constructs in our empirical research. This approach entails specifying a measurement model or confirmatory factor analysis model first. Subsequently, the reliability coefficient derived from this stage is used to correct for measurement error in the structural model, the second stage of this approach. In the structural model the error variance of the construct is fixed at 1-reliability coefficient, and the path from the construct to the aggregate scale is fixed at the square root of the reliability.

Confirmatory factor analysis was applied to assess the construct validity both in the crosssectional and the longitudinal approach. All constructs exhibited sufficient construct validity in terms of unidimensionality, discriminant and convergent validity, and reliability. In the structural model we found that the autonomy component of empowerment showed a pervasive effect in the model. As the results differ only slightly between the cross-sectional approach and the longitudinal approach we will not address them separately. Autonomy affects the role stressors negatively and job satisfaction positively. We also found a negative effect of initiating structure on role ambiguity. Finally, for the longitudinal model we reported a positive effect of formalization on role conflict.

As far as the role stressors, job satisfaction and job performance are concerned, we found that it is role ambiguity that exerts a negative effect on job satisfaction. The relation between role conflict and job satisfaction is mediated by role ambiguity. Finally, job satisfaction shows a considerable positive effect on job performance in terms of service quality. We also found that the inclusion of autoregressive and lagged effects considerable improved the explanatory power of our model. The autoregressive effects are all significant and of considerable magnitude, indicating the effect of the corresponding construct in the first wave. We found 
three lagged effects. Firstly, formalization in the first wave positively affects job satisfaction in the second wave. Secondly, group cohesiveness in the first wave positively affects role ambiguity in the second wave. Thirdly, the competence component of empowerment in the first wave shows negative effect on job performance in terms of technical quality in the second wave.

Our results indicate that the autonomy component of empowerment exerted quite a pervasive effect in our model. The competence component of empowerment, on the other hand, showed no contemporaneous effect. The results regarding the relation between autonomy and role ambiguity are contrary to the results obtained by Hartline \& Ferrell (1993) in their empirical study. They find a positive effect of empowerment on role ambiguity and no relationship between empowerment and role conflict. Hartline \& Ferrell (1996) even report a positive relationship between empowerment and role conflict. In our cross-sectional approach we could observe no effect of formalization on the role stressors. In the longitudinal approach, however, a positive effect of formalization on role conflict emerged. Although the negative relationship between formalization and role ambiguity is confirmed by meta-analytical studies (Fisher \& Gitelson 1983; Jackson \& Schuler 1985), the relationship between formalization and role conflict is to a lesser extent determined (Jackson \& Schuler 1985; Nicholson \& Goh 1983; Organ \& Greene 1981; Rogers \& Molnar 1976). In boundary spanning positions, such as customer-contact service employees, the relationship between formalization and role conflict is often positive (Clopton 1984; Michaels et al. 1987, 1988). Finally, formalization showed a positive lagged effect on job satisfaction. This can be interpreted as a long-term effect of formalization. Although the short-term effect might be experienced as increasing role conflict, in the longer term it provides clarity and thereby job satisfaction. The negative effect of group cohesiveness on role stress is only supported in our cross-sectional design. We find that group cohesiveness may decrease role conflict, as their co-workers are able to support their colleagues. In the longitudinal model, however, group cohesiveness showed a positive effect on role ambiguity. The two dimensions of supervisory behavior show a negative effect on both role stressors (Fisher \& Gitelson 1983; Fry et al. 1986; Jackson \& Schuler 1985; Micheals et al. 1987). However, initiating structure seems to be stronger associated with role ambiguity than with role conflict (Jackson \& Schuler 1985). Our results confirm the negative relationship between initiating structure and role ambiguity, but we fail to find a negative relationship between initiating structure and role conflict. Our findings indicate that leadership consideration may be relatively independent of role stress (Jackson \& Schuler 1985), since no relationship between leadership consideration and the role stressors could be found.

It is generally hypothesized that role ambiguity and role conflict negatively affect job satisfaction (Brown \& Peterson 1993; Churchill et al. 1985; Katz \& Kahn 1978; Jackson \& Schuler 1985). However, empirical research suggests that role ambiguity might show a more dysfunctional effect on job satisfaction than role conflict (Singh 1993; Singh et al. 1996). This finding is confirmed by Hartline \& Ferrell (1996) who reported a negative relationship between role ambiguity and job satisfaction in a hotel context, but fail to find a negative relationship between role conflict and job satisfaction. Although the intuitive appeal of a strong, positive relationship between job satisfaction and job performance is high (Grönroos 1990a; Heskett 1987,1995 ), empirical research using meta-analytical procedures have produced only moderate correlations between the two constructs (Brown \& Peterson 1993; Iaffaldano \& Muchinsky 1985). This is based mainly on objective, outcome-related measures of performance (Hartline \& Ferrell 1996). It can be argued that job satisfaction is more closely related to behavioral-based performance than to outcome-based performance (Churchill et al. 1985; Schneider 1980). In our study we find a strong, positive relationship between job satisfaction and job performance in terms of technical quality and functional quality, two behavioral-based performance measures.

\subsubsection{Research Question 2: Service Quality and the Relationship Paradigm}

Although our conceptual model in Chapter 3 focuses on service quality as final outcome, research indicates that quality is nothing, but input to the process that ultimately leads to 
profitability. The PIMS program has established a positive relationship between quality and profitability in terms of ROI. This can be explained by using a two-pronged approach. In the first place, superior quality allows the firm to reap premium prices. In the second place, superior conformance quality leads to cost reductions. Empirical research supports the positive relationship between quality and price, but failed to find a relationship between quality and costs. Furthermore, quality positively affects market share and market share subsequently increases the profitability of the firm. A direct relationship between quality and profitability has also been reported by a number of studies. More recently, Fornell and his colleagues have proposed an alternative approach to the relationship between quality and profitability (Anderson et al. 1994; Fornell 1995; Fornell et al. 1996). They proposed that quality is positively related to customer satisfaction. Customer satisfaction leads to increased customer retention and customer loyalty. Rust cum suis propose that quality needs to be financially accountable and that it is possible to spent too much on quality (Rust et al. 1995). They suggest that quality improvements need to be evaluated using their return on quality concept.

The relationship paradigm suggests that it is beneficial for both the service provider and the customer to maintain a long-term relationship. The relationship can be viewed as consisting of five phases: (1) awareness, (2) exploration, (3) expansion, (4) commitment and (5) dissolution. The fourth phase, commitment is the most desirable one in the relationship between a service provider and customer. Commitment is essential in developing long-term relationship between service providers and customers. Two approaches to commitment dominate the relationship field. The first approach views commitment as largely affective of content. The second approach considers commitment to be more calculative of nature. Both affective and calculative commitment positively affect intention to maintain an existing relationship.

We have identified five antecedents to commitment. To begin with, we assumed that technical and functional quality positively affect customer satisfaction. Subsequently, we hypothesized that customer satisfaction increases both calculative and affective commitment. Trust, operationalized as honesty and benevolence, positively influences affective commitment, but negatively affects calculative commitment. Finally, dependence is assumed to have a negative effect on affective commitment and a positive effect on calculative commitment. Intention to stay is modeled as outcome to commitment. We posit that both calculative commitment and affective commitment positively affects the intention to stay. Moreover, we also assume a direct positive relationship between customer satisfaction and intention to stay.

In Chapter 6 of the thesis we tested the conceptual framework laid down in Chapter 4. This framework attempts to relate two research traditions: (1) the service quality/customer satisfaction research tradition and (2) the relationship marketing research tradition. Essentially, the framework, which was proposed in Chapter 4, introduces customer satisfaction as an antecedent of affective and calculative commitment. Furthermore, we assume that customer satisfaction mediates the relationship between service quality, technical and functional, and affective and calculative commitment. Moreover, we posited that quality is not only indirectly, but also directly related to commitment. Our research is mainly exploratory of nature and we used survey research to test the relationships in the conceptual framework. Our empirical study was conducted with the after-sales service department consisted of 12 departments. Each department is headed by its own manager and has its own "customer base".

For data analysis purposes we used the partial aggregation approach as we were confronted with a relatively large number of indicators and constructs. This approach consists of two stages: (1) estimating the measurement model or confirmatory factor analysis and (2) estimating the structural model. The structural model is corrected for measurement error by means of the reliability coefficient derived from the first stage, the confirmatory factor analysis. In the structural model the error variance of the construct is fixed at 1-reliability 
coefficient, and the path from the construct to the aggregate scale is fixed at the square root of the reliability.

Using confirmatory factor analysis we evaluated the construct validity of the constructs used in our study. All constructs exhibited sufficient construct validity in terms of unidimensionality, discriminant and convergent validity, and reliability. Our study suggests that both technical quality and functional quality exhibit a positive effect on affective commitment. Technical quality shows a direct as well as an indirect positive effect via customer satisfaction, while functional quality only shows an indirect positive effect via customer satisfaction. Furthermore, the same indirect effects can be found for calculative commitment. In addition, trust in a partner's benevolence and trust in a partner's honesty positively influence affective commitment. Calculative commitment, on the other hand, is positively affected by trust in a partner's benevolence and negatively affected by trust in a partner's honesty. Moreover, trust in a partner's honesty also positively affects satisfaction. Intention to stay is positively affected by both affective and calculative commitment. However, in terms of standardized path coefficients the effect of affective commitment is stronger. Even the direct effect of trust in a partner's benevolence is stronger than the effect of calculative commitment. Finally, the generalizabilty of our results is tentatively indicated by similar findings by two empirical studies in professional service settings (De Ruyter et al. 1997c; Venetis 1997). Both studies find a positive effect of service quality on affective commitment and a relatively stronger effect of affective commitment on intentions to stay as compared to calculative commitment.

Our study indicates that for the establishment of affective commitment in a suppliercustomer relationship, it is very important that a customer has a lot of trust in the supplier's benevolence and honesty. The positive effect of trust on affective commitment is found in several empirical studies (e.g., Geyskens et al. 1996; Morgan \& Hunt 1994). Technical quality is positively related to both affective commitment and customer satifaction. The positive effect of technical quality on affective commitment is also reported by Venetis (1997). De Ruyter et al. (1997c) also find a positive relationship between service quality and affective commitment. Customer satisfaction also leads to more affectively committed customers. Customer satisfaction can be improved by increasing the functional quality of the service and developing trust in the supplier's honesty. Our study also shows that affective commitment is not directly significantly influenced by functional quality. It seems that the quality of the service outcome is more important in establishing affective commitment than the quality of the service process (Venetis 1997). However, functional quality leads to higher levels of customer satisfaction, which in turn result in affective commitment.

Calculative commitment is not influenced directly by quality. However, as both technical and functional quality are related to customer satisfaction, quality indirectly affects calculative commitment. Trust in the supplier's benevolence increases calculative commitment, whereas trust in the supplier's honesty reduces calculative commitment. The negative effect of trust on calculative commitment is also found in an empirical study by Geyskens et al. (1996). Geyskens et al. (1996) also find that trust negatively affects calculative commitment. Furthermore, we find that dependence shows a positive relationship with calculative commitment. This relationship is supported by empirical research by Geyskens et al. (1996).

More affectively committed partners show a stronger intention to stay than customers who feel more calculative commitment. This latter type of commitment is weakly positively related to the intention to stay. In a marketing channels context Kumar et al. (1994) found that affective commitment is the main determinant of intention to stay. This can also be observed from an empirical study by Venetis (1997). She reports a fairly strong relationship between affective commitment and intentions to stay, but fails to find a relationship between calculative commitment and intentions to stay. De Ruyter et al. (1997c) report similar findings, but they mediate the relationship between affective commitment and intentions to stay with cooperation. Moreover, trust in benevolence significantly influences the intention to stay in the relationship. 


\section{3}

\section{Implications}

Section 7.3.1 deals with theoretical implications of this study, while in section 7.3.2 we will focus on the managerial implications of this study.

\subsubsection{Theoretical Implications}

Part of the strength of a research project lies in the recognition of its limitations. These limitations may serve as points for a future research agenda. The theoretical implications apply both to Chapter 5 and Chapter 6 . To begin with, our results are based on the results of a study with the after-sales service department of a large, Dutch manufacturer of office equipment. This approach is quite likely to have contributed to the internal validity of our study, however it questions the external validity of our findings. As a result, this study needs to be replicated in other after-sales service settings in order to generalize our findings.

All our measurement instruments are based on paper-and-pencil self-reports, so that the strength of the relationships between the constructs may be somewhat inflated by common method variance. However, we extensively pre-tested and cross-validated our measures and considering the results of the construct validation, it is unlikely that the results of our model are solely due to common method variance. Moreover, we attempted to minimize the biased responses to our measurement instruments. We assured the confidentiality of the respondents and had the questionnaires sent directly to the researchers.

Both our studies may suffer from omitted variables. In both conceptual models there is room for additional variables, be it mediating or mediator variables. Additionally, we used attitudinal variables and intentions, actual behavior was not included in our framework. In order to further validate our model we need to include behavioral variables, such as turnover of customercontact service employees and customers.

We mainly used global measures for our study linking organizational antecedents to service quality as a performance measure. However, several authors have proposed multifaceted or multidimensional scales for some important constructs in these frameworks. The differential effects of these facets or dimensions should be further explored.

Furthermore, we used an individual level of analysis (customer-contact service employees and customers). However, some variables in our conceptual models can be operationalized at higher level, unit or organizational level. As aggregation potentially biases results when data is not analyzed at the lowest level of analysis, a multiple-level design may be more appropriate. For example, service quality can be considered both from the individual level, unit level and organizational level. Customer evaluations of service quality can be linked up with organizational antecedents at the level of the individual customer-contact service employee, service unit or even service organization in cross-level design. Such as design can also be used to link service quality to relationship-based variables; thus linking organizational antecedents to the customer actually staying (or leaving) with the service organization.

Our research indicates that a longitudinal design shows quite some promise for service research. Its application to our conceptual model in Chapter 5 shows that especially autoregressive effects were quite substantial. We found only a limited number of lagged effects. Therefore, additional research using more waves and shorter lag times is necessary. Similarly, a longitudinal design could also clarify the dynamics of relationships. The results in chapter 6 are clearly limited, because of the cross-sectional design used. The use of experiments and/or quasiexperiments or a longitudinal research design might further advance service research in this respect.

Finally, limitations lie also in the compatibility of the procedure of structural equation modeling that was followed. Although the formulated model captures the observed relationships satisfactorily and allows us to test the hypotheses on the antecedents and consequences of role stressors, it should be noted that a statistical fit might also be achieved with models other than the ones we tested in our study (e.g., Bagozzi 1980a; Bollen. 1989). 


\subsubsection{Managerial Implications}

Research shows that the service quality evaluations of customer contact service employees and service quality evaluations of customers are highly correlated. This notion is also acknowledged by Heskett and his colleagues (Heskett 1995; Heskett et al. 1994, 1997). They propose that job satisfaction positively affects customer satisfaction and ultimately customer loyalty and profitability; they refer to this as the service profit chain. Our results, however, indicate that this causal "chain" may be overly simplistic in terms of abstraction. The results in Chapter 6 indicate that both technical quality and functional quality affect customer satisfaction. In addition we found that trust in a partner's honesty positively affects customer satisfaction. Customer satisfaction, on its turn, positively affects affective and calculative commitment. Affective commitment, and to a lesser extent calculative commitment, positively affect the intention to stay.

From Chapter 5 we can conclude that both technical quality and functional quality are strongly and positively affected by job satisfaction. Job satisfaction is influenced positively by the autonomy component of empowerment. Empowering customer-contact service employees will therefore have a positive effect on the intention to stay of customers of the service organizations. Both role conflict (indirectly) and role ambiguity (directly) negatively affect job satisfaction and will therefore negative affect relationship maintenance. Initiating structure negatively affects role ambiguity and may be especially important if empowerment of the customer-contact service employees is increased, for instance, by using self-directed work teams (Block 1987; Fisher 1993; Wellins et al. 1991). Initiating structure, maybe even formalization, will be needed to set the boundaries to the role creation originating from further empowerment. Finally, the effects of empowerment may not always be positive. In the longitudinal design we found that the competence component of empowerment negatively affects technical quality. In other words, feeling too competent might actually reduce performance in a strict, technical sense.

Formalization shows no effect in the cross-sectional model, however, in the longitudinal model we find that formalization positively affects role conflict and thus reduces job satisfaction. We also find a positive lagged effect of formalization on job satisfaction, indicating that formalization may serve a purpose by clarifying goals and expectations. In the cross-sectional approach we found a negative effect of group cohesiveness on role conflict, implying that group support might alleviate the effect of role conflict and thus increasing job satisfaction. In the longitudinal approach, however, we could not find a contemporaneous effect for group cohesiveness. However, group cohesiveness showed a positive effect on role ambiguity. This might be due to the development of group norms, which might conflict with management objectives and customer expectations.

There are several other factors service organizations can use to improve their specific service delivery process and to establish long-lasting relationships with their customers. The creation of trust in the relationship should be a focal point of attention for managers. It was shown that trust not only has a positive effect on affective commitment, but also on satisfaction and the intention to stay in the relationship. Trust arises if the manufacturer is honest and benevolent with the customer. To achieve trust, managers should try to instruct contact personnel to tell the truth, to give accurate information, to keep promises, to be sincere, and to give advice according to their best judgment. The service provider is benevolent if he is willing to offer assistance and support when the customer has a problem, when he is concerned about his welfare, and shows understanding for the customer's problems.

As mentioned, trust not only has a positive effect on affective commitment, but also on customer satisfaction. Satisfaction in turn has, through affective commitment, an indirect positive effect on the intention to stay in the relationship. Management should try to avoid business relationships in which the partner only feels calculative commitment. Given the choice between developing closeness to the service provider through attraction or obligation, it is clear that management should cultivate the former over the latter. Our study indicates that 
calculative committed customers have a much weaker intention to stay than affective committed customers do. As soon as alternative suppliers emerge they probably will switch service providers. A way to avoid high calculative commitment is to strive for dependence symmetry and honesty towards the customer. A balanced and honest relationship will result in less calculatively and more affectively committed customers, more satisfied customers, and therefore in a long-lasting profitable relationship for both parties.

Furthermore, acknowledgement of the importance of client relationships as well as the identification of relationship constructs provides input for developing alternative segmentation strategies for service organizations (Van der Walt et al. 1994). Instead of traditional client criteria, such as client size and type of industry clients could also be segmented on the basis of commitment characteristics. Obviously, these client segments would require different relationship management tactics and strategies.

\subsection{Reflections on a Mirror Image}

If we compare the conceptual models developed in Chapter 3 and Chapter 4 quite some similarities can be distinguished. To begin with, service quality and satisfaction are related in both models. In Chapter 4 service quality affects customer satisfaction and in Chapter 3 job satisfaction leads to service quality as a performance measure. Therefore, service quality can truly be considered the construct service research hinges on. However, there are dissimilarities between the two models as well. In Chapter 3 we prominently focused on role theory and its antecedents. In Chapter 4 trust and commitment as exponents of the relationship paradigm play a pivotal role. However, if we picture service quality not as a hinge, but rather as a mirror, this metaphor could be used to structure future research in services. This mirror image is implicitly recognized in the work of Heskett cum suis (Heskett 1995; Heskett et al. 1994, 1997; Schlesinger \& Heskett 1992). They propose that service employee job satisfaction is positively related to customer satisfaction and customer loyalty. Ultimately, they propose that customer loyalty will positively influence service organization profitability. Our research indicates that job satisfaction is positively related to customer-contact service employee performance in terms of service quality. Customer-perceived service quality, on its turn, is positively related to customer satisfaction, which positively affects both affective commitment and calculative commitment, and ultimately intention to stay.

If we would reflect the relationship paradigm on the relations between customer-contact service employee and service organization, the inclusion of trust and (organizational) commitment in the conceptual framework presented in Chapter 3 is unavoidable. Morgan \& Hunt (1994) have already suggested that the relationship paradigm needs an extension. They argue that the relationship approach should not only be applied to customers and suppliers, but also to other external parties, such as governmental agencies, competitors etc. More importantly, they also argue that the relationship should be used with regard to employees, functional departments and business units. Long-term relationships between the focal firm and its employees are posited to improve its performance. The extension of the relationship paradigm is depicted in Figure 7-1. The relationship between organizational commitment and turnover has been extensively researched (e.g., Hom \& Griffeth 1991; Lucas et al. 1987). This research tradition would need to be incorporated into the present model. Research will be needed to study the effects of organizational commitment, turnover intentions and actual turnover on service organization performance. Moreover, we argued that (voluntary) turnover might actually prove to have a detrimental effect on organizational performances in service organizations. However, further research is needed to test this hypothesis. 
Furthermore, in relationship marketing research commitment has been mainly conceptualized as a multidimensional constructed consisting at least of two dimensions: (1) affective commitment and (2) calculative commitment (Allen \& Meyer 1990; Meyer \& Allen 1991). Although this notion was first developed for organizational commitment, there is only limited empirical work. Further research will be needed in service organizations to investigate the differential effects of organizational commitment in terms of affective and calculative commitment.

Trust has mainly been used as a determinant of commitment in relationship marketing research. However, given the strong effect of trust on commitment the inclusion of trust in relationship models pertaining to customer-contact service employees and service organizations should be considered. More recently, the pivotal role of trust in work relationships has been emphasized by Lewicki \& Bunker (1996). Cummings \& Bromily (1996) even developed an Organizational Trust Inventory (OTI). Further conceptual and empirical work is needed to clarify the role of trust in organizations.

The use of the individual level clearly needs to be complement by as cross-level approach, which introduces groups, unit and organizations to our design. Along that line various authors have argued that relationships should also be explored between functional departments. De Ruyter \& Wetzels (1998b) examined several antecedents of relational attitude between marketing and financial departments. Additional research will be needed, since the nature of customer service is clearly cross-functional. The cross-functional nature of customer service may ultimately lead to a situation, in which service employees are confronted with an expansion of their tasks. Already customer service employees are requested to act as technicians, salespersons and consultants simultaneously. This obviously will affect role stress. Role ambiguity and role conflict may increase, as they are confronted by even more potentially conflicting goals and expectations. An alternative would be to compose account

\section{Figure 7-1: Extension of the Relationship Paradigm}

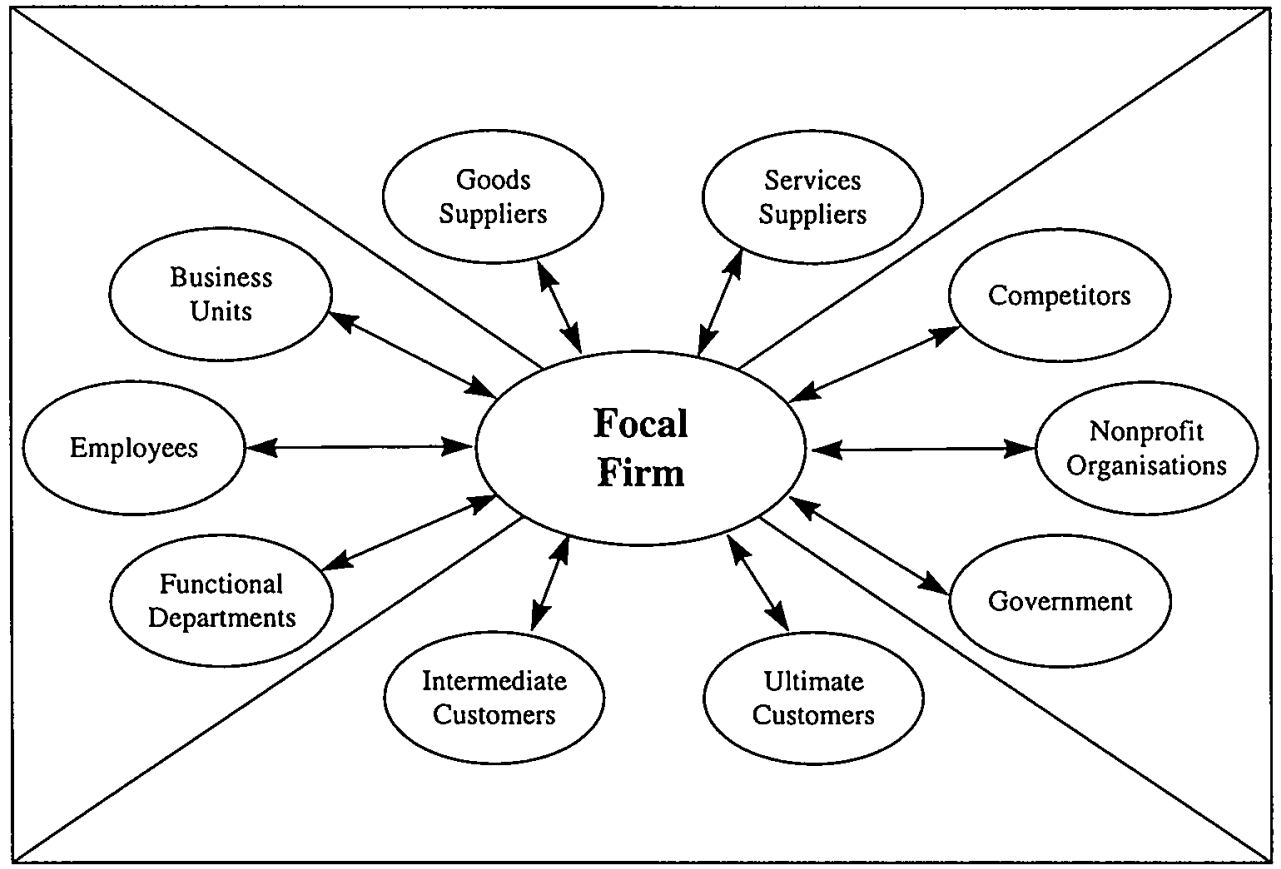


teams consisting of member of different functional departments. Each account team could then take care of a certain number of customers during their "relational life cycle". This would require that account teams would be assigned to their own customer base.

Empowerment plays an important role in this study. However, we have to emphasize that empowerment in this study is conceptualized as psychological empowerment. Procedures, tools and policies to implement empowerment were not considered in this study. Therefore, further research will needed to explore the possible implementation of empowerment in service organizations (Block 1987; Bowen \& Lawler 1995a,b; Fisher 1993; Wellins et al. 1991).

Finally, future research needs to take into account the various levels of analysis. Although, the relationship paradigm may be suitable both for internal purposes and external purposes, the effects of such an approach will manifest itself on individual levels (customers and service employees), units (self-directed work teams, functional departments), and organizations (suppliers, the focal service organization and customers). This clearly calls for as cross-level design, as it can be assumed that certain individual level variables exhibit effects on variables at higher levels (Klein et al. 1994; Rousseau 1985). For instance, role ambiguity affects job satisfaction at the level of individual service employee. However, the performance of service unit may also be affected by role ambiguity at the individual level. Further research will be needed to investigate these effects. 


\section{References}

A

Abbott, L. (1955), Quality and Competition: An Essay in Economic Theory, Columbia University Press, New York.

Adams, J.S. (1976), "The Structure and Dynamics of Behavior in Organizational Boundary Roles", in: M.D. Dunette (ed.), Handbook of Industrial and Organizational Psychology, Rand McNally College Publishing Company, Chicago, 1175-1199.

Adams, J.S. (1980), "Interorganizational Processes and Organization Boundary Activities", in: B.M. Staw \& L.L. Cummings (eds.), Research in Organizational Behavior, 2, JAI Press, Greenwich, Connecticut, 321355.

Aiken, M. \& J. Hage, (1966), "Organizational Alienation: A Comparative Analysis", American Sociological Review, 31 (August), 497-507.

Aldrich, H. (1971), "Organizational Boundaries and Inter-Organizational Conflict", Human Relations, 24, 279 293.

Allen, N.J. \& J.P. Meyer (1990), "The Measurement and Antecedents of Affective, Continuance, and Normative Commitment to the Organization", Journal of Occupational Psychology, 63 (1),1-18.

Anderson, E.W. (1993), "Firm, Industry and National Indices of Customer Satisfaction", in: T.A. Swartz, D.E. Bowen \& S.W. Brown (eds.), Advances in Services Marketing and Management: Research and Practice, 2, JAI Press, Inc., Greenwich, Connecticut \& London, England, 87-108.

Anderson, E.W. (1995), "An Economic Approach to Understanding How Customer Satisfaction Affects Buyer Perceptions of Value, Proceedings of the AMA Winter Conference, AMA, Chicago, 102-106.

Anderson, E.W. (1996), "Customer Satisfaction and Price Tolerance", Marketing Letters, 7 (3), 19-30.

Anderson, E.W. \& C. Fornell (1994), "A Customer Satisfaction Research Prospectus", in: R.T. Rust \& R.L. Oliver (eds.), Service Quality: New Directions in Theory and Practice, Sage Publications, Thousand Oaks, 119.

Anderson, J.C. \& D.W. Gerbing (1988), "Structural Equation Modeling in Practice: A Review and Recommended Two-Step Approach", Psychological Bulletin, 103 (1), 411-423.

Anderson, J.C. \& J.A. Narus (1990), "A Model of Distributor Firm and Manufacturer Firm Working Partnerships", Journal of Marketing, 54 (January), 42-58.

Anderson, J.C., D.W. Gerbing \& J.E. Hunter (1987), "On the Assessment of Unidimensionality Measurement: Internal and External Consistency Criteria", Journal of Marketing Research, 24 (November), 432-437.

Anderson, E.W. \& M.W. Sullivan (1993), "The Antecedents and Consequences of Customer Satisfaction for Firms", Marketing Science, 12 (2), 125-143.

Anderson, E.W. \& B. Weitz (1989), "Determinants of Continuity in Conventional Industrial Channel Dyads", Marketing Science, 4 (4), 310-323.

Anderson, E.W. \& B. Weitz (1992), "The Use of Pledges to Build and Sustain Commitment in Distribution Channels", Journal of Marketing Research, 29 (February), 18-34.

Anderson, E.W., C. Fornell \& D.R. Lehmann (1994), "Customer Satisfaction, Market Share, and Profitability: Findings from Sweden", Journal of Marketing, 58 (July), 53-66.

Anderson, N.H. (1981), Foundations of Information Integration Theory, Academic Press, New York.

Andrews F.M. \& S.B. Withey (1976), Social Indicators of Well-Being, Plenum Press, New York.

Argote, L. (1982), "Input Uncertainty and Organizational Coordination in Hospital Emergency Units", Administrative Science Quarterly, 27, 420-434.

Argyris, C. (1964), Integrating the Individual and the Organization, John Wiley \& Sons, New York.

Armstrong, J.S. \& T.S. Overton (1977), "Estimating Nonresponse Bias in Mail Surveys", Journal of Marketing Research, 14 (August), 396-402.

Assael, H. (1987), Consumer Behavior and Marketing Action, PWS-Kent, Boston.

Asubonteng, P., K.J. Mcleary \& J.E. Swan (1996), "SERVQUAL Revisited: A Critical Review of Service Quality", The Journal of Services Marketing, 10 (6), 62-81.

\section{B}

Babakus, E. \& G.W. Boller (1992), "An Empirical Assessment of the SERVQUAL Scale", Journal of Business Research, 24, 253-268.

Babakus, E. \& W.G. Mangold (1992), "Adapting the SERVQUAL Scale to Hospital Services: An Empirical Investigation", Health Service Research, 26 (6), 768-786.

Babbie, E. (1995), The Practice of Social Research, Wadsworth Publishing Company, Belmont.

Babin, B.J. \& J.S. Boles (1996), "The Effects of Perceived Co-Worker Involvement and Supervisor Support on Service Provider Role Stress, Performance and Job Satisfaction", Journal of Retailing, 72 (1), 57-75. 
Bagozzi, R.P. (1978), "Salesforce Performance and Satisfaction as a Function of Individual Difference, Interpersonal, and Situational Factors", Journal of Marketing Research, 15 (November), 517-531.

Bagozzi, R.P. (1980a), "Performance and Satisfaction in an Industrial Sales Force: An Examination of their Antecedents and Simultaneity", Journal of Marketing, 44 (Spring), 65-77.

Bagozzi, R.P. (1980b), Causal Models in Marketing, John Wiley \& Sons, New York.

Bagozzi, R.P. (1994), "Measurement in Marketing Research: Basic Principles of Questionnaire Design", in: R.P. Bagozzi (ed.), Principles of Marketing Research, Blackwell Publishers, London, 1-49.

Bagozzi, R.P. \& T.F. Heatherton (1994), "A General Approach to Representing Multifacted Personality Constructs: Application to State Self-Esteem", Structural Equation Modeling, 1, 35-67.

Bagozzi, R.P. \& L.W. Phillips (1991), "Assessing Construct Validity in Organizational Research", Administrative Science Quarterly, 36, 421-458.

Bagozzi, R.P. \& Y. Yi (1988), "On the Evaluation of Structural Equation Models", Journal of the Academy of Marketing Science, 16 (Spring), 74-94.

Bateson, J.E.G. (1977), "Do We Need Service Marketing?", in: Marketing Consumer Services: New Insights, Report No. 77-115, Marketing Science Institute, Cambridge.

Bateson, J.E.G. (1989), Managing Services Marketing: Text and Readings, The Dryden Press, Fort Worth.

Bateson, J.E.G. (1992), Managing Services Marketing: Text and Readings, The Dryden Press, Fort Worth.

Bateson, J.E.G. (1985), "Perceived Control and the Service Encounter", in: J.A. Czepiel, M.R. Solomon \& C.F. Surprenant (eds.). The Service Encounter: Managing Employee/Customer Interaction in the Service Businesses, Lexington Books, Lexington \& Toronto, 67-82.

Baumgartner, H. \& C. Homburg (1996), "Applications of Structural Equation Modeling in Marketing and Consumer Research: A Review", International Journal of Research in Marketing, 13 (2), 139-161.

Bearden, W.O. \& J.E. Teel (1983), "Selected Determinants of Consumer Satisfaction and Complaints Reports", Journal of Marketing Research, 20 (February), 21-28.

Bearden, W.O., S. Sharma \& J.E. Teel (1982), "Sample Size Effects on Chi Square and Other Statistics Used in Evaluating Causal Models", Journal of Marketing Research, 19 (November), 425-430.

Becker, H.S. (1960), "Notes on the Concept of Commitment", American Journal of Sociology 66, 32-40.

Bedeian, A.G. \& A.A. Armenakis (1981), "A Path-Analytic Study of the Consequences of Role Conflict and Ambiguity", Academy of Management Journal, 24 (2), 417-424.

Beehr, T.A. (1976), "Perceived Situational Moderators of the Relationship between Subjective Role Ambiguity and Role Strain", Journal of Applied Psychology, 61 (1), 35-40.

Behara, R.S. \& R.B. Chase (1993), "Service Quality Deployment: Quality Service by Design”, in: R.V. Sarin (ed.), Perspectives on Operations Management: Essays in Honor of Elwood S. Buffa, Kluwer Academic Publisher, Norwell.

Behrman, D.N. \& W.D. Perreault, Jr. (1984), "A Role Stress Model of the Performance and Satisfaction of Industrial Salespersons", Journal of Marketing, 48 (Fall), 9-21.

Bell, D. (1973), The Coming of Post-Industrial Society: A Venture in Social Forecasting, Basic Books, New York

Bellenger, D.N., E. Steinberg \& W. Stanton (1976), "The Congruence of Store Image and Self Image: As It Relates to Store Loyalty", Journal of Retailing, 52 (Spring), 17-32.

Belson, W.A. (1984), The Design and Understanding of Survey Questions, Gower Publishing Co. Ltd., Aldershot.

Bennis, W.G. (1966), Changing Organizations, McGraw-Hill, New York.

Bentler, P.M. (1990), "Comparative Fit Indexes in Structural Models", Psychological Bulletin, 107 (2), 238-246.

Bentler, P.M. \& D.G. Bonett (1980). "Significance Tests and Goodness of Fit in the Analysis of Covariance Structures", Psychological Bulletin, 88 (3), 588-606.

Bentler, P.M. \& C. Chou (1987), "Practical Issues in Structural Modeling", Sociological Methods \& Research, 16 (August), 78-117.

Berry, L.L. (1980), "Services Marketing Is Different", Business, 30 (May-June), 24-28.

Berry, L.L. (1981), "The Employee as Customer", Journal of Retail Banking, 3 (March), 33-40.

Berry, L.L. (1983), "Relationship Marketing", in: L.L. Berry, G.L. Shostack, \& G.D. Upah, (eds.), Emerging Perspectives on Services Marketing, American Marketing Association, Chicago, 25-28.

Berry, L.L. (1995), "Relationship Marketing of Services: Growing Interest, Emerging Perspectives", Journal of the Academy of Marketing Science, 23 (4), 236-245.

Berry, L.L. \& A. Parasuraman (1993), "Building a New Academic Field: The Case of Services Marketing", Journal of Retailing, 69 (1), 13-60.

Biddle, B.J. \& E.J. Thomas (1966), Role Theory: Concepts and Research, John Wiley \& Sons, New York.

Biong. H. (1993), "Satisfaction and Loyalty to Suppliers within the Grocery Trade", European Journal of Marketing, 27 (7), 21-38.

Bitner, M.J. (1990), "Evaluating Service Encounters: The Effects of Physical Surroundings and Employee Responses", Journal of Marketing, 54 (January), 71-84.

Bitner, M.J. (1992), "Servicescapes: The Impact of Physical Surroundings on Customers and Employees", Journal of Marketing, 56 (April), 57-71. 
Bitner, M.J. \& A.R. Hubbert (1994), "Encounter Satisfaction versus Overall Satisfaction: The Customer's Voice", in: R.T. Rust \& R.L. Oliver (eds.), Service Quality: New Directions in Theory and Practice, Sage Publications, Thousand Oaks, 72-94.

Bitner, M.J., J.D. Nyquist \& B.H. Booms (1985), "The Critical Incidents Technique as a Technique for Analyzing the Service Encounter", in: T.M. Bloch, G.D. Updah \& V.A. Zeithaml (eds.), Services Marketing in a Changing Environment, American Marketing Association, Chicago, 48-51.

Bitner, M.J., B.H. Booms \& M.S. Tetreault (1990), "The Service Encounter: Diagnosing Favorable and Unfavorable Incidents", Journal of Marketing, 54, (January), 71-84.

Blau, P.M. (1964), Exchange and Power in Social Life, John Wiley \& Sons, New York.

Block, P. (1987), The Empowered Manager, Jossey-Bass Publishers, San Francisco/London.

Bloemer, J.M.M. \& J.D.P. Kasper (1995), "The Complex Relationship between Consumer Satisfaction and Brand Loyalty", Journal of Economic Psychology, 16, (2), 311-329.

Bluedorn, A.C. (1982), "A Unified Model of Turnover from Organizations", Human Relations, 35 (2), 135-153.

Bojanic, D. (1991), "Quality Measurement in Professional Services Firms", Journal of Professional Services Marketing, 7 (2), 27-36.

Boles, J.C. \& B.J. Babin (1996), "On the Front Lines: Stress, Conflict, and the Customer Service Provider", Journal of Business Research, 37, 41-50.

Bollen, K.A. (1989), Structural Equations with Latent Variables, John Wiley \& Sons, New York.

Bolton, R.N. \& J.H. Drew (1991a), "A Longitudinal Analysis of the Impact of Service Changes on Customer Attitudes", Journal of Marketing, 55 (January), 1-9.

Bolton, R.N. \& J.H. Drew (1991b), "A Multistage Model of Customers' Assessments of Service Quality and Value", Journal of Consumer Research, 17 (March), 375-384.

Bommer, W.H., J.L. Johnson, G.A Rich, P.M. Podsakoff \& S.B. MacKenzie (1995), "On the Interchangeability of Objective and Subjective Measures of Employee Performance: A Meta-Analysis", Personnel Psychology, 48, 587-605.

Booms, B.H. \& M.J. Bitner (1981), "Marketing Strategies and Organization Structures for Service Firms", in: J.H. Donnelly \& W.R. George (eds.), Marketing of Services, American Marketing Association, Chicago, 4751.

Boulding, W., A. Kalra, R. Staelin \& V.A. Zeithaml (1993), "A Dynamic Process Model of Service Quality: From Expectations to Behavioral Intentions", Journal of Marketing Research, 30 (February), 7-27.

Bowen, D.E. (1986), "Managing Customers as Human Resources in Service Organizations", Human Resource Management, 25, 371-384.

Bowen, D.E. (1990), "Interdisciplinary Study of Service: Some Progress, Some Prospects", Journal of Business Research, 20 (January), 71-79.

Bowen, D.E. \& E.E. Lawler, III (1992), "The Empowerment of Service Workers: What, Why How and When", Sloan Management Review, 34 (Spring), 31-39.

Bowen, D.E. \& E.E. Lawler, III (1995a), "Empowering Service Employees", Sloan Management Review, 37 (Summer), 73-84.

Bowen, D.E. \& E.E. Lawler (1995b). "Organizing for Service: Empowerment or Production Line?", in: W.J. Glynn \& J.G. Barnes (eds.), Understanding Services Management, John Wiley \& Sons, Chichester, 269-294.

Bowen, D.E. \& B. Schneider (1985), "Boundary Spanning Role Employees and the Service Encounter: Some Guidelines for Management and Research", in: J.A. Czepiel, M.R. Solomon \& C.F. Surprenant (eds.), The Service Encounter: Managing Employee/Customer Interaction in the Service Businesses, Lexington Books, Massachusetts \& Toronto, 127-147.

Bowen, D.E. \& B. Schneider (1988), "Services Marketing and Management: Implications for Organizational Behavior", in: B.M. Staw \& L.L. Cummings (eds.), Research in Organizational Behavior: An Annual Series of Analytical Essays and Critical Reviews, 10, JAI Press, Inc., Greenwhich \& London, 43-80.

Bowen, D.E., C. Siehl \& B. Schneider (1989), "A Framework for Analyzing Customer Service Orientations in Manufacturing", Academy of Management Review, 14 (1), 75-95.

Brannick, M.T. \& R.W.R. Darling (1991), "Specifying Importance Weights Consistent with a Covariance Structure", Organizational Behavior and Human Decision Processes, 50, 395-410.

Bremer, H., J.A. Linde, H. Oppewal \& M. Vriens (1994), Het Belang van Attributen van Bankdiensten: Een Toepassing van Hiërarchische Conjuncte Analyse, Reasearch Memorandum 562, Instituut voor Economisch Onderzoek, Rijksuniversiteit Groningen.

Brems, H. (1948), "The Interdependence of Quality Variations, Selling Effort and Price", Quarterly Journal of Economics, 62, 418-440.

Brislin, R.W. (1980), "Translation and Content Analysis of Oral and Written Materials", in: H.C. Triandis \& J.W. Berry (eds.), Handbook of Cross-Cultural Psychology: Methodology. 2, Allyn and Bacon, Boston, 389444.

Broh, R.A. (1982), Managing Quality for Higher Profits, McGraw Hill, New York.

Brown, S.W. \& T.A. Swartz (1989), "A Gap Analysis of Professional Service Quality", Journal of Marketing, 53 (April), 92-98.

Brown, S.P. \& R.A. Peterson (1993), "Antecedents and Outcomes of Salesperson Job Satisfaction: Meta-analysis and Assessment of Causal Effects", Journal of Marketing Research, 30 (February), 63-77. 
Brown, T.J., G.A. Churchill \& J.P. Peter (1993), "Improving the Measurement of Service Quality", Journal of Retailing, 69 (Spring), 127-139.

Burns, T. \& G.M. Stalker (1961), The Management of Innovation, Tavistock Publications, London.

Butler, J.K., Jr. \& R.S. Cantrell (1984), "A Behavioral Decision Theory Approach to Modelling Dyadic Trust in Superiors and Subordinates", Psychological Reports, 55 (1), 19-28.

Buttle, F. (1996), “SERVQUAL: Review, Critique, Research Agenda”, European Journal of Marketing, 30 (1), 8-32.

Buzzell, R.D. \& B.T. Gale (1987), The PIMS Principles: Linking Strategy to Performance, The Free Press, New York/London.

Buzzell, R.D. \& F.D. Wiersema (1981a), "Successful Share-Building Strategies", Harvard Business Review, 59 (January-February), 135-144.

Buzzell, R.D. \& F.D. Wiersema (1981b), "Modelling Changes in Market Share: A Cross Sectional Analysis", Strategic Management Journal, 2 (January-March), 27-42.

Buzzell, R.D., B. Gale \& R. Sultan (1975), Market Share: A Key to Profitability", Harvard Business Review, 59 (January-February), 135-144.

C

Cadotte, E.R., R.B. Woodruff \& R.L. Jenkins (1987), "Expectations and Norms in Models of Consumer Satisfaction", Journal of Marketing Research, 24 (August), 305-314.

Cameron, K.S. \& Whetten, D.A. (1983), Organizational Effectiveness: A Comparison of Multiple Models, Academic Press, New York.

Campbell, J.P. (1977), "On the Nature of Organizational Effectiveness", in: P.S. Goodman, J.M. Pennings \& Associates, New Perspectives on Organizational Effectiveness, Jossey-Bass, San Francisco.

Capon, N., J.U. Farley \& S. Hoenig (1990), "Determinants of Financial Performance: A Meta Analysis", Management Science, $36(10), 1143-1159$.

Carman, J.M. (1990), "Consumer Perceptions of Service Quality: An Assessment of the SERVQUAL Dimensions", Journal of Retailing, 66 (1), 33-55.

Carroll, J.D. \& P.E. Green (1995), "Psychometric Methods in Marketing Research: Part I, Conjoint Analysis", Journal of Marketing Research, 32 (November), 385-391.

Carroll, J.D. \& P.E. Green (1997), "Psychometric Methods in Marketing Research: Part II, Multidimensional Scaling", Journal of Marketing Research, 34 (May), 193-204.

Chase, R.B. (1978), "Where Does the Customer Fit in a Service Operation", Harvard Business Review, 56 (November-December), 137-142.

Chase, R.B. (1981), "The Customer Contact Approach to Services: Theoretical Bases and Practical Extensions", Operations Research, 29 (4), 698-706.

Chase, R.B. (1986), A New Approach to Service System Design, University of Southern California (working paper).

Chase, R.B. \& D.A. Tansik (1983), "The Customer Contact Model for Organization Design", Management Science, $29(9), 1037-1050$.

Chiles, A.M. \& T.E. Zorn (1995), "Empowerment in Organizations: Employees' Perceptions of the Influences of Empowerment", Journal of Applied Communication Research, 23, 1-25.

Chonko, L.W. (1986), "Organizational Commitment in the Sales Force", Journal of Personal Selling and Sales Management, 6 (3), 19-27.

Churchill, G.A., Jr. (1979), "A Paradigm for Developing Better Measures of Marketing Contructs", Journal of Marketing Research, 16 (February), 64-73.

Churchill, G.A., Jr. \& C. Surprenant (1982), "An Investigation into the Determinants of Customer Satisfaction", Journal of Marketing Research, 19 (November), 491-504.

Churchill, G.A., Jr., N.M. Ford \& O.C. Walker, Jr. (1974), "Measuring Job Satisfaction of Industrial Salesmen", Journal of Marketing Research, 11 (August), 254-260.

Churchill, G.A., Jr., N.M. Ford \& O.C. Walker, Jr. (1976), "Organizational Climate and Job Satisfaction in the Salesforce", Journal of Marketing Research, 13 (November), 323-332.

Churchill, G.A., Jr., N.M. Ford \& O.C. Walker, Jr. (1990), Sales Force Management, Richard D. Irwin, Inc., Homewood/Boston.

Churchill, G.A., Jr., N.M. Ford, S.W. Hartley \& O.C. Walker, Jr. (1985), "The Determinants of Salesperson Performance: A Meta-Analysis", Journal of Marketing Research, 22 (May), 103-118.

Clark, C. (1940), The Conditions of Economic Progress, MacMillan, London.

Clopton, S.W. (1984), "Seller and Buying Firm Factors Affecting Industrial Buyers' Negotiation Behavior and Outcomes", Journal of Marketing Research, 21 (February), 39-53.

Cochran, W.G. (1963), Sampling Techniques, John Wiley \& Sons, Inc., New York.

Cohen, J. \& P. Cohen (1983), Applied Multiple Regression/Correlation Analysis for the Behavioral Sciences, Lawrence Erlbaum Associates, Publishers, Hillsdale/London.

Conger, J.A. \& R. Kanungo (1988), "The Empowerment Process: Integrating Theory and Practice", Academy of Management Review, 13 (3), 471-482. 
Cook, T.D. \& D.T. Campbell (1979), Quasi-Experimentation: Design and Analysis Issues for Field Settings, Rand McNally, Chicago.

Cook, K.S. \& R.M. Emerson (1978), "Power Equity and Commitment in Exchange networks", American SociologicalRreview, 43 (4), 721-739.

Cooper, L.G. (1983), "A Review of Multidimensional Scaling in Marketing Research", Applied Psychological Measurement, 7 (Fall), 427-450.

Cowan, A. (1969), Quality Control for the Manager, Pergamon Press, Oxford.

Cronbach, L.J. (1986), "Social Inquiry by and for Earthlings", in: D.W. Fiske \& R.A. Schweder (eds.), Metatheory in Social Science Pluralisms and Subjectivities, The University of Chicago Press, Chicago \& London.

Cronin, J.J., Jr. \& S.A. Taylor (1992), "Measuring Service Quality: A Reexamination and Extension", Journal of Marketing, 56 (July), 55-68.

Cronin, J.J., Jr. \& S.A. Taylor (1994), "SERVPERF versus SERVQUAL: Reconciling Performance-Based and Perceptions-Minus-Expectations Measurement of Service Quality", Journal of Marketing, 58 (January), 132139.

Crosby, L.A. \& N. Stevens (1987), "Effects of Relationship marketing on Satifaction, Retention, and Prices in the Life Insurance Industry", Journal of Marketing Research, 24 (November), 401-411.

Crosby, L.A., K. Evans \& D. Cowles (1990), "Relationship Quality in Services Selling: An Interpersonal Influence Perspective". Journal of Marketing, 54 (July), 68-81.

Crosby, P.B. (1979), Quality Is Free: The Art of Making Quality Certain, New American Library, New York.

Cudeck, R. \& M.W. Brown (1983), "Cross-validation of Covariance Structures", Multivariate Behavioral Research, 18 (2), 147-167.

Cummings, L.L. \& Ph. Bromiley (1996), "The Organization Trust Inventory (OTI): Development and Validation", in: R.M. Kramer \& T.R. Taylor (eds.), Trust in Organizations: Frontiers of Theory and Research, Sage Publications, Thousand Oaks, 114-139.

Cunningham, M.T. \& D.A. Roberts (1974), "The Role of Customer Service in Industrial Marketing", European Journal of Marketing, 8 (1), 15-28.

Curry, D.J. (1985), "Measuring Price and Quality Competition", Journal of Marketing, 49 (Spring), 106-117.

Czepiel, J.A. (1990), "Service Encounters and Service Relationships: Implications for Research", Journal of Business Research, 20 (January), 13-22.

Czepiel, J.A. \& R. Gilmore (1987), "Exploring the Concept of Loyalty in Services", in: J.A. Czepiel, C.A. Congram \& J. Shanahan (eds.), The Services Marketing Challenge: Integrating for Competitive Advantage, AMA, Chicago, 91-94.

Czepiel, J.A., M.R. Solomon, C.F. Surprenant \& E.G. Gutman (1985), Service Encounters: An Overview", in: J.A. Czepiel, M.R. Solomon \& C.F. Surprenant, (eds.), The Service Encounter: Managing Employee/Customer Interaction in the Service Businesses, Lexington Books, Lexington, Massachusetts \& Toronto, 3-15.

\section{$\mathbf{D}$}

Dabholkar, P.A., D.I. Thorpe \& J.O. Rentz (1996), "A Measure of Service Quality for Retail Stores: Scale Development and Validation", Journal of the Academy of Marketing Science, 24 (1), 3-16.

Danaher, P.J. \& J. Mattsson (1994), "Customer Satisfaction during the Service Delivery Process", European Journal of Marketing, 28 (5), 5-16.

Darlington, R.B. (1990), Regression and Linear Models, McGraw-Hill Publishing Company, New York.

Day, G.S. (1969), "A Two-Dimensional Concept of Brand Loyalty", Journal of Advertising Research, 9 (September), 29-36.

Day, G.S. (1994), Continuous learning About Markets", California Management Review, 36 (Summer), 9-31.

Day, G.S. \& D.B. Montgomery (1983), "Diagnosing the Experience Curve", Journal of Marketing, 47 (Spring), 44-58.

Day, R.L. (1984), "Modelling Choices among Alternative Responses to Dissatisfaction", in: T.C. Kinnear (ed.), Advances in Consumer Research, 11, 496-499.

DeMaris, A. (1992), Logit Modeling: Practical Applications, Quantitative Applications in the Social Sciences, 86, Sage Publications, Newbury Park, etc.

Desarbo, W.S., L. Huff, M.M. Rolandelli \& J. Choi (1994), “On the Measurement of Perceived Service Quality: A Conjoint Analysis Approach", in: R.T. Rust \& R.L. Oliver (eds.), Service Quality: New Directions in Theory and Practice, Sage Publications, Thousand Oaks, 201-223.

DeVellis, R.F. (1991), Scale Development: Theory and Applications, Applied Social Research Methods Series, 26, Sage Publications, Newbury Park.

Dick, A.S. \& K. Basu (1994) Customer Loyalty: Toward an Integrated Conceptual Framework, Journal of the Academy of Marketing Science, 22 (Spring), 99-113.

Donnelly, J.H., Jr. \& J.M. Ivancevich (1975), "Role Clarity and the Salesman", Journal of Marketing, 39 (January), $71-74$. 
Dorfman R. \& P.O. Steiner (1954), "Optimal Advertising and Optimal Quality" American Economic Review, 44 (December), 822-836.

Doyle, J.R., R.H. Green \& P.A. Bottomly (1997), "Judging Relative Importance: Direct Rating and Point Allocation Are Not Equivalent", Organizational Behavior and Human Decision Processses", 70 (April), 6572.

Dubinsky, A.J. \& S.W. Hartley (1986), "A Path-Analytic Study of a Model of Salesperson Performance", Journal of the Academy of Marketing Science, 14 (1), 36-46.

Dubinsky, A.J. \& B.E. Mattson (1979), "Consequences of Role Conflict and Ambiguity Experienced by Retail Salespeople", Journal of Retailing, 55 (Winter), 70-86.

Dwyer, F.R., P.H. Schurr \& S. Oh (1987), "Developing Buyer-Seller Relationships", Journal of Marketing, 51 (April), 11-27.

\section{$\mathbf{E}$}

Enis, B.M. \& K.J. Roering (1981), "Service Marketing: Different products, Similar Strategy", in: J.H. Donnelly \& W.R. George (eds.), Marketing of Services, American Marketing Association, Chicago, 1-4.

Evans, J.R \& B. Berman (1987), Marketing, MacMillan, New York.

\section{$\mathbf{F}$}

Fehr, B. (1988), "Prototype Analysis of the Concepts of Trust and Commitment", Journal of Personality and Social Psychology, 55 (4), 557-579.

Feigenbaum (1961), Total Quality Control: Engineering and Managment, McGraw-Hill, New York.

Feigenbaum A.V. (1983), Total Quality Control, McGraw-Hill, New York.

Ferrell, O.C. \& S.J. Skinner (1988), "Ethical Behavior and Bureaucratic Structure in Marketing Research Organizations", Journal of Marketing Research, 25 (February), 103-109.

Fick, G.R. \& J.R.B. Ritchie (1991), "Measuring Service Quality in the Travel and Tourism Industry, Journal of Travel Research, 3 (Fall), 2-9.

Fiol, C.M. \& M.A. Lyles (1985), "Organizational Learning", Academy of Management Review, 10 (4), 803-813.

Fishbein, M. (1967), "Selling as a Dyadic Relationship-New Approach", American Behavioral Scientist, 6, 7679.

Fisher, A.G.B. (1935), The Clash of Progress and Security, MacMillan, London.

Fisher, A.G.B. (1939), "Production, Primary, Secondary, and Tertiary", Economic Record, 15 (June), 24-38.

Fisher, C.D. \& R. Gitelson (1983), "A Meta-Analysis of the Correlates of Role Conflict and Ambiguity", Journal of Applied Psychology, 68 (2), 320-333.

Fisher, K. (1993), Leading Self-Directed Work Teams: A Guide to Developing New team Leadership Skills, McGraw-Hill, Inc., New York.

Fisk, R.P., S.W. Brown \& M.J. Bitner (1993), "Building a New Academic Field: The Case of Services Marketing", Journal of Retailing, 69 (1), 61-103.

Fitzsimmons, J.A. \& M.J. Fitzsimmons (1994), Service Management for Competitive Advantage, McGraw-Hill, Inc., New York.

Folkes, V.A. (1994), "How Consumers Predict Service Quality. What Do They Expect?" in: R.T. Rust \& R.L. Oliver (eds.), Service Quality: New Directions in Theory and Practice, Sage Publications, London, 108-123.

Folkes, V.S. (1984), "Consumer Reactions to Product Failure: An Attributional Approach", Journal of Consumer Research, 10 (March), 298-409.

Ford, N.M., O.C. Walker \& G.A. Churchill, Jr. (1975), "Expectation-Specific Measures of the Intersender Conflict and Role Ambiguity Experienced by Industrial Salesmen", Journal of Business Research, 3 (2), 95 112.

Fornell, C. (1992), "A National Customer Satisfaction barometer: The Swedish Experience", Journal of Marketing, 56 (January), 6-21.

Fornell, C. (1995), "The Quality of Economic Output: Empirical Generalizations about Its Distribution and Relationship to Market Share", Marketing Science, 14 (3), Part 2, G203-G211.

Fornell, C. \& D.F. Larcker (1981), "Evaluating Structural Equation Models with Unobservable Variables and Measurement Error", Journal of Marketing Research, 18 (February), 19-50.

Fornell, C. \& B. Wernerfelt (1987), "Defensive Marketing Strategy by Customer Complaint Management: A Theoretical Analysis", Journal of Marketing Research, 24 (November), 337-346.

Fornell, C. \& B. Wernerfelt (1988), "A Model for Customer Complaint Management", Marketing Science, 7 (Summer), 271-286.

Fornell, C, C.D. Ittner \& D.F. Larcker (1996), The Valuation Consequences of Customer Satisfaction, National Quality Center Research Center Working Paper, Nation Quality Research Center, Ann Arbor, MI.

Fornell, C., M.D. Johnson, E.W. Anderson, J. Cha \& B.E. Bryant (1996), "The American Customer Satisfaction Index: Nature, Purpose and Findings", Journal of Marketing, 60 (October), 7-18. 
Fry, L.W., C.M. Futrell, A. Parsuraman \& M.A. Chmielewski (1986), "An Analysis of Alternative Causal Models of Salesperson Role Perceptions and Work-Related Attitudes", Journal of Marketing Research, 23 (May), 153-163.

Fuchs, W.R. (1968), The Service Economy, Columbia University Press, New York.

G

Ganesan, S. (1994), "Determinants of Long-Term Orientation in Buyer-Seller Relationships", Journal of Marketing, 58 (April), 1-19.

Gardner, M.P. (1985), "Mood States and Consumer Behavior: A Critical Review", Journal of Consumer Research, 12 (December), 281-300.

Garvin, D.A. (1983), "Quality on the Line", Harvard Business Review, 61 (September-October), 65-73.

Garvin, D.A. (1984a), "Product Quality: An Important Strategic Weapon", Business Horizons, 27 (March-April), $40-43$.

Garvin, D.A. (1984b), "What Does 'Product Quality' Really Mean?", Sloan Management Review, 26 (Fall), 2543.

Garvin, D.A. (1987), "Competing on the Eight Dimensions of Quality", Harvard Business Review, 65 (November-December), 101-109.

Garvin, D.A. (1988), Managing Quality: The Strategic and Competitive Edge, The Free Press, New York.

George, W. (1984), "Internal Marketing for Retailers: The Junior Executive Employee", in: Developments in Marketing Science, Academy of Marketing Science, 322-325.

George, W. (1986), "Internal Communications Programs as a Mechanism for Doing Internal Marketing", in: C. Marshall, D. Schmalensee \& V. Venkatesan, Creativity in Services Marketing, American Marketing Association, Chicago.

George, W. (1990), "Internal Marketing and Organizational Behavior: A Partnership in Developing CustomerConscious Employee at Every Level", Journal of Business Research, 20 (January), 63-70.

Gerbing D.W. \& J.C. Anderson (1988), "An Updated Paradigm for Scale Development Incorporating Unidimensionality and Its Assessment", Journal of Marketing Research, 25 (May), 186-192.

Geyskens, I. \& J.B. Steenkamp (1995), "An Investigation into the Joint Effects of Trust and Interdependence on Relationship Commitment", EMAC Proceedings, May 16-19, Paris, 351-371.

Geyskens, I., J.B. Steenkamp, L.K. Scheer \& N. Kumar (1996), "The Effects of Trust and Interdependence on Relationship Commitment: A Trans-Atlantic Study", International Journal of Research in Marketing, 13 (4), 303-318.

Giarini, O (1991), "Notes on the Concept of Service Quality and Economic Value", in: S.W. Brown, E. Gummesson, B. Edvardsson \& B. Gustavsson, Service Quality: Multidisciplinary and Multinational Perspectives, Lexington Books, Lexington, 57-72.

Ginsberg, E. \& G. Vojta (1981), "The Service Sector of the U.S. Economy", Scientific American, 244 (March), 31-39.

Gist, M., T.N. Mitchell (1992), "Self-Efficacy: A Theoretical Analysis of Its Determinants and Malleability", Academy of management Review, 17 (2), 183-211.

Goodman, P. S., J.M. Pennings \& Associates (1977), New Perspectives on Organizational Effectiveness, JosseyBass, San Francisco.

Goolsby, J.R. (1992), "A Theory of Role Stress in Boundary Spanning Positions of Marketing Organizations", Journal of the Academy of Marketing Science, 20 (2), 155-164.

Green, P.E. \& V. Srinivasan (1978), "Conjoint Analysis in Consumer Research: Issues and Outlook", Journal of Consumer Research, 5 (September), 103-123.

Green, P.E. \& V. Srinivasan (1990), "Conjoint Analysis in Marketing: New Developments with Implications for Research and Practice", Journal of Marketing, 54 (October), 3-19.

Green, P.E. (1975), "Marketing Applications of MDS: Assessment and Outlook", Journal of Marketing, 39 (January), 24-31.

Green, S.B. (1991), "How many Subjects Does it Take to Do a Regression Analysis?", Multivariate Behavioral Research, 26, 499-510.

Gremler, D.D. \& S.W. Brown (1996), "Service Loyalty: Its Nature, Its Importance and Implications", in: B. Edvardsson, S.W. Brown. R. Johnston \& E. Scheuing (eds.), QUIS V: Advancing Service Quality: A Global Perspective, ISQA, New York, 171-181.

Griffin, A. \& J.R. Hauser (1993), "The Voice of the Customer", Marketing Science, 12 (1), 1-27.

Griffith, J. (1988), "Measurement of Group Cohesion in U.S. Army Units", Basic and Applied Psychology, 9 (2), $149-171$.

Grönroos, C. (1978), "A Service-oriented Approach to Marketing of Services", The European Journal of Marketing, $12(8), 588-601$.

Grönroos C. (1983), Strategic Management and Marketing in the Services Sector, Marketing Report No. 83-104, Marketing Science Institute, Cambridge, MA

Grönroos, C. (1984), "A Service Quality Model and Its Marketing Implications", European Journal of Marketing, 18 (4), 36-44. 
Grönroos, C. (1990a), Service Management and Marketing: Managing the Moments of Truth in Service Competition, Lexington Books, Lexington, MA/Toronto.

Grönroos, C. (1990b), "Relationship Approach to Marketing in Service Contexts: The Marketing and Organizational Behavior Interface", Journal of Business Research, 20 (January), 3-12.

Grönroos, C. (1993), "Toward a Third Phase in Service Quality Research: Challenges and Future Directions", in: T.A. Swartz, D.E. Bowen \& S.W. Brown (eds.), Advances in Services Marketing and Management: Research and Practice, 2, JAI Press, Inc., Greenwich, Connecticut \& London, England, 49-64.

Grönroos, C. (1994), "From Marketing Mix to Relationship Marketing: Towards a Paradigm Shift in Marketing", Management Decision, 32 (2), 4-20.

Grönroos, C. (1995), "Relationship Marketing: The Strategy Continuum", Journal of the Academy Science, 23 (4), 252-254.

Grove, S.J., R.P. Fisk \& M.J. Bitner (1992), "Dramatizing the Service Experience: A Managerial Approach", in: T.A. Swartz, D.E. Bowen, S.W. Brown (eds.), Advances in Services Marketing and Management: Research and Practice, 1, JAI Press, Greenwich \& London, 91-121.

Guiltinan, J.P. (1989), "A Classification of Switching Costs with Implications for Relationship Marketing", in: T.L. Childers \& R.P. Bagozzi (eds.), AMA Winter Educators' Conference: Marketing Theory and Practice, AMA, Chicago, 216-220.

Gummesson, E. (1991), "Service Quality: A Holistic View", in: S.W. Brown, E. Gummesson, B. Edvardsson \& B. Gustavsson (eds.), Service Quality: Multidisciplinary and Multinational Perspectives, Lexington books, Massachusetts \& Toronto, 3-22.

Gummesson, E. (1994),. "Service Management: An Evaluation and the Future", International Journal of Service Industry Management, 5 (1), 77-96.

Gundlach, G.T., R.S. Achrol \& J.T. Mentzer (1995), "The Structure of Commitment in Exchange", Journal of Marketing, 59 (January), 79-92.

\section{H}

Hallowell, R. (1996), "The Relationships of Customer Satisfaction, Customer Loyalty, and Profitability: An Empirical Study", Intermational Journal of Service Industry Management, 7, 27-42.

Hampton, R., A.J. Dubinsky \& S.J. Skinner (1986), "A Model of Sales Supervisor Leadership Behavior and Retail Salespeople's Job-Related Outcomes", Journal of the Academy of Marketing Science, 14 (3), $33-43$.

Hartline, M.D. \& O.C. Ferrell (1993), Service Quality Implementation: The Effects of organizational Socialization and Managerial Actions on Customer-Contact Employee Behaviors, Report No. 93-122, Academy of Marketing Science, Cambridge.

Hartline, M.D. \& O.C. Ferrell (1996), "The Management of Customer-Contact Service Employees", Journal of Marketing, 60 (October), 52-70.

Hartline, M.D. \& K.C. Jones (1996), "Employee Performance Cues in a Hotel Service Environment: Influence on Perceived Service Quality, Value and Word-of-Mouth Intentions", Journal of Business Research, 35, $207-$ 215.

Hartman, R.S. (1967), The Structure of Value: Foundations of a Scientific Axiology, Southern Illinois Press, Carbondale.

Hartman, R.S. (1973), The Hartman Value Profile (HVP): Manual of Interpretation, Research Concepts, Muskegon.

Hattie, J.R. (1985), "Methodology Review: Assessing Unidimensionality of Tests and Items", Applied Psychological Measurement, 9 (June), 139-164.

Hayduk, L.A. (1987), Structural Equation Modeling with LISREL: Essentials \& Advances, The John Hopkins University Press, Baltimore \& London.

Heide, J.B. \& G. John (1990), "Alliances in Industrial Purchasing: The Determinants of Joint Action in BuyerSupplier relations", Journal of Marketing Research, 27 (February), 24-36.

Heide, J.B. \& G. John (1992), "Do Norms Really Matter?", Journal of Marketing, 56 (April), 32-44.

Helson, H. (1959), "Adaptation Level Theory", in: S. Koch (ed.), Psychology: A Study of Science, 1, McGrawHill, New York.

Henkoff, R. (1994), "Service is Everybody's Business", Fortune, 24 June, 48-60.

Hensel, J.S. (1990), "Service Quality Improvement and Control", Journal of Business Research, 20 (January), 43-54.

Herche, J. \& B. Engelland (1996), "Reversed-Polarity Items and Scale Unidimensionality", Journal of the Academy of Marketing Science, 24 (4), 366-374.

Heskett, J.L. (1986), Managing in the Service Economy, Harvard Business School Press, Boston.

Heskett, J.L. (1987), "Lessons in the Service Sector", Harvard Business Review, 65 (March-April), 118-126.

Heskett, J.L. (1995), "Strategic Services Management: Examining and Understanding it", in: W.J. Glynn \& J.G. Barnes (eds.), Understanding Services Management: Integrating Marketing, Organisational Behaviour and Human Resource Management, John Wiley \& Sons, Chichester, 449-473.

Heskett, J.L., W.E. Sasser, Jr. \& L.A. Schlesinger (1997), The Service Profit Chain: How Leading Companies Link Profit and Growth to Loyalty, Satisfaction, and Value, The Free Press, New York. 
Heskett, J.L., G.W. Loveman, W.E. Sasser, Jr. \& L.A. Schlesinger (1994), "Putting the Service Profit Chain to Work", Harvard Business Review, 72 (March-April), 164-174.

Hirschman, A.O. (1970), Exit, Voice and Loyalty - Responses to Decline in Firms, Organizations, and States, Harvard University Press, Cambridge.

Hirschman, E.C. \& M.B. Holbrook (1982), "Hedonic Consumption: Emerging Concepts, Methods and Propositions", Journal of Marketing, 46, 92-101.

Hoelter, J.W. (1983), "The Analysis of Covariance Structures: Goodness-of-fit Indices", Sociological Methods and Research, 11 (February), 325-344.

Holbrook, M.B. (1994) "The Nature of Customer Value: An Axiology of Service in the Consumption Experience", in: R.T. Rust \& R.L. Oliver, (eds.), Service Quality: New Directions in Theory and Practice, Sage Publications, London, $21-71$.

Holbrook, M.B. \& K.P. Corfman (1985), "Quality and Value in the Consumption Experience: Phaedrus Rides Again", in: J. Jacoby \& J.C. Olson (eds.), Perceived Quality: How Consumers View Stores and Merchandise, Lexington Books, Lexington \& Toronto, 31-57.

Hom, P.W. \& R.W. Griffeth (1991), "Structural Equations Modeling Test of a Turnover Theory: Cross-Sectional and Longitudinal Analyses", Journal of Applied Psychology, 76 (3), 350-366.

House, R.L. (1971), "A Path Goal Theory of Leader Effectiveness", Administrative Science Quarterly, 16 (September), 321-329.

House, R. J. \& G. Dessler (1974), "The Path-Goal Theory of Leadership: Some Post Hoc and A Priori Tests", in: J.G. Hunt \& L.L. Larson (eds.), Contingency Approaches to Leadership, Southern Illinois University Press, Carbondale, 29-55.

House, R.J. \& J.R. Rizzo (1972), "Role Conflict and Ambiguity as Critical Variables in a Model of Organizational Behavior", Organizational Behavior and Human Performance, 7, 467-505.

House, R.L., A.C. Filley \& S. Kerr (1971), "Relation of Leader Consideration and Iniating Structure to R\&D Subordinates Satisfaction", Administrative Science Quarterly, 16 (March), 19-30.

Hu, L. \& P.M. Bentler (1995). "Evaluating Model Fit", in: R.H. Hoyle (ed.), Structural Equation Modeling: Concepts, Issues, and Applications, Sage Publications, Inc., Thousand Oaks, 76-99.

Hunt, S.D., R.D. Sparkman \& J.B. Wilcox (1982), "The Pretest in Survey Research: Issues and Preliminary Findings", Journal of Marketing Research, 19 (May), 269-273.

Hunt, S.D., L.B. Chonko \& V.R. Wood (1985), "Organizational Commitment and Marketing" , Joumal of Marketing, 49 (Winter) 112-126.

I

Iacobucci, D., K.A. Grayson \& A.L. Ostrom (1994), "The Calculus of Service Quality and Customer Satisfaction: Theoretical and Empirical Differentiation", in: T.A. Swartz, D.E. Bowen \& S.W. Brown (eds.), Advances in Services Marketing and Management: Research and Practice, 3, JAI Press, Greenwich \& London, 1-67.

Iacobucci, D., A.L. Ostrom, B.M. Braig \& A. Bezjian-Avery (1996), “A Canonical Model of Consumer Evaluations and Theoretical Bases of Expectations", in: T.A. Swartz, D.E. Bowen \& S.W. Brown (eds.), Advances in Services Marketing and Management: Research and Practice, 5, JAI Press, Greenwich \& London, 1-44.

Iaffaldano, M.T. \& P.M. Muchinsky (1985), "Job Satisfaction and Job Performance: A Meta Analysis", Psychological Bulletin, 97 (2), 251-273.

Ironson, G.H., P.C. Smith, M.T. Brannick, W.M. Gibson \& K.B. Paul (1989), "Construction of a Job in General Scale: A Comparison of Glabal, Composite and Specific Measures", Journal of Applied Psychology, 74 (2), 193-200.

Ittner, C.D. \& D.F. Larcker (1996), "Measuring the Impact of Quality Initiatives on Firm Financial Performanc, in: S. Ghosh \& D. Fedor, Advances in the Management of Organizational Quality, 1, JAI Press, Greenwich \& London, 1-37.

\section{J}

Jaccard, J., D. Brinberg \& L.J. Ackerman (1986), "Assessing Attribute Importance: A Comparison of Six Methods", Journal of Consumer Research, 12 (March), 463-468.

Jackson, B.B. (1985), "Building Customer Relations that Last", Harvard Business Review, 63 (NovemberDecember), 120-128.

Jackson, R.W. \& P.D. Cooper (1988), “Unique Aspects of Marketing Industrial Services", Industrial Marketing Management, 17, 111-118

Jackson, S.E. \& R.S. Schuler, (1985), "A Meta-Analysis and Conceptual Critique of Research on Role Ambiguity and Role Conflict in Work Settings", Organizational Behavior and Human Performance, 36, 1678. 
Jacobson, R. \& D.A. Aaker (1987), "The Strategic Role of Product Quality", Journal of Marketing, 51 (October), 31-44.

Jacoby, J. \& R.W. Chestnut (1978), Brand Loyalty: Measurement and Management, John Wiley and Sons, Inc., New York.

Jacoby, J. \& J.C. Olson (1985), Perceived Quality: How Consumers View Stores and Merchandise, Lexington Books, Massachusetts/Toronto.

Jain, A.K., C. Pinson \& N.K. Malhotra (1987), "Customer Loyalty as a Construct in the Marketing of Banking Services", International Journal of Bank Marketing, 5 (3), 49-72.

James, L.R. \& A.P. Jones (1976), "Organizational Structure: A Review of Structural Dimensions and Their Conceptual Relationships with Individual Attitudes and Behavior", Organizational Behavior and Human Performance, 16, 74-113.

James L.R., S.S. Mulaik \& J.M. Brett (1982), Causal Analysis, Sage Publications, Beverly Hills.

John, G. (1984), "An Empirical Investigation of Some Antecedents of Opportunism in a Marketing Channel", Journal of Marketing Research, 21 (August), 278-289.

Johns, G. (1981), "Difference Score Measures of Organizational Behavior Variables: A Critique", Organizational Behavior and Human Performance, 27 (June), 443-463.

Johnston, M.W., C.M. Futrell \& J. Sager (1988), "Performance and Job Satisfaction Effects on Salesperson Turnover: A Replication and Extension", Journal of Business Research, 16 (March), 67-83.

Johnston, M.W., P.R. Varadarajan, C.M. Futrell, \& J. Sager (1987), "The Relationship between Organizational Commitment, Job Satisfaction, and Turnover", Journal of Personal Selling and Sales Management, 7 (November), 29-38.

Johnston, M.W., A. Parasuraman, C.M. Futrel, \& W.C. Black (1990), “A. Longitudinal Assessment of the Impact of Selected Organizational Influences on Salespeople's Organizational Commitment During Early Employment", Journal of Marketing Research, 27 (August), 333-344.

Jones, G.R. (1990), "Governing Customer-Service Organization Exchange", Journal of Business Research, 20 (January), 23-30.

Jöreskog, K.G. (1971), "Statistical Analysis of sets of Congeneric Tests", Psychometrika, 36 (June), 109-133.

Jöreskog, K.G. \& D. Sörbom (1989), LISREL 7: A Guide to the Program and Applications, Jöreskog \& Sörbom/SPSS Inc., Chicago.

Jöreskog, K.G. \& D. Sörbom (1993), LISREL ${ }^{\otimes}$ 8: Structural Equation Modeling with the SIMPLIS Command Language, Scientific Software International, Chicago/Lawrence Erlbaum Associates, Hillsdale.

Juran, J.M. (1974), "Basic Concepts", in: J.M. Juran, F.M. Gryna, Jr. \& R.S. Bingham, Jr. (eds.), Quality Control Handbook, McGraw-Hill, New York, 2-1 - 2-24.

\section{$\mathbf{K}$}

Kahn, R.L., D.M. Wolfe, R.P. Quinn, J.D. Snoek \& R.A. Rosenthal (1964), Organizational Stress: Studies in Role Conflict and Ambiguity, John Wiley \& Sons, Inc., New York.

Kahn, R.L. \& R.P. Quinn (1970), "Role Stress: A Framework for Analysis", in: A. McLean (ed.), Occupational Mental Health, Rand-McNally, New York.

Kanouse, D.E. \& L.R. Hanson, Jr. (1971), "Negativity in Evaluations", in: E.E. Jones, D.E. Kanouse, H.H. Kelley, R.E Nisbett, S. Valins \& B. Weiner (eds.), Attribution: Perceiving the Causes of Behavior, General Learning, Morristown, 47-62.

Kasper, H. \& J. Lemmink (1989), "After Sales Service Quality: Views between Industrial Customers and Service Managers", Industrial Marketing Management, 18, 199-208.

Kasper, H. \& H. Schreuder (1985), "Consumer reporting: A Conceptual Framework for the Organizational Level", Journal of Consumer Policy, 8, 267-285.

Katz, D. \& R.L. Kahn (1978), The Social Psychology of Organizations, John Wiley \& Sons, New York.

Keaveney, S.M. (1995), "Customer Switching Behavior in Service Industries: An Exploratory Study", Journal of Marketing, 59 (April), 71-82.

Keeley, M. (1977), "Subjective Performance Evaluation and Person-Role Conflict under Conditions of Uncertainty", Academy of Management Journal, 20 (2), 301-314.

Keller, R.T. (1978), "Boundary-Spanning Activity, Role Dynamics and Job Satisfaction: A Longitudinal Study", Journal of Business Research, 6, 147-158.

Keller, R.T \& W.E. Holland (1975), "Boundary-Spanning Roles in A Research and Development Organization: An Empirical Investigation", Academy of Management Journal, 18 (2), 388-393.

Keller, R.T., A.D. Szilagyi, Jr. \& W.E. Holland (1976), "Boundary Spanning Activity and Employee Reactions", Human Relations, 29 (7), 699-710.

Kelley, S.W., K.D. Hoffman \& M.A. Davis (1993), "A Typology of Retail Failures and Recoveries", Journal of Retailing, 69 (1), 429-452.

Kemery, E.R., A.G. Bedeian, K.W. Mossholder \& J. Touliatos (1985), "Outcomes of Role Stress: A Multisample Constructive Replication", Academy of Management Journal, 28 (2), 363-375.

Kenny, D.A. (1979), Correlation and Causality, John Wiley \& Sons, New York.

Keppel, G. (1991), Design \& Analysis: A Researcher's Handbook, Prentice-Hall, Inc, Upper Saddle River. 
Kerlinger, F.N. (1986), Foundations of Behavioral Research, Holt, Rinehart \& Winston, New York.

Kessler, R.C. \& D.F. Greenberg (1981), Linear Panel Analysis: Models of Quantitative Change, Academic Press, New York.

King, L.A. \& D.W. King (1990), "Role Conflict and Role Ambiguity: A Critical Assessment of Construct Validity", Psychological Bulletin, 107 (1), 48-64.

Klaus, P.G. (1985), "Quality Epiphenomenon: The Conceptual Understanding of Quality in Face-to-Face Service Encounters", in: J.A. Czepiel, M.R. Solomon \& C.F. Surprenant (eds.), The Service Encounter: Managing Employee/Customer Interaction in the Service Businesses, Lexington Books, Lexington \&Toronto, 17-33.

Klein, K.J., F. Dansereau \& R.J. Hall (1994). "Level Issues in Theory Development, Data Collection, and Analysis", Academy of Management Review, 19 (2), 195-229.

Klemperer, P. (1987) "Markets with Consumer Switching Costs", The Quarterly Journal of Economics, 102 (May), 375-394.

Koepp, S. (1987), "Pul-eeze! Will Somebody Help Me?", Time, 2 February, 28-34.

Kordupleski, R., R.T Rust \& A.J Zahorik (1993), "Why Improving Quality Doesn't Improve Quality", California Management Review, 35 (Spring), 82-95.

Kumar, A. \& W.R. Dillon (1987), "The Interaction of Measurement and Structure in Simultaneous Equation Models with Unobservable Variables", Journal of Marketing Research, 24 (February), 98-105.

Kumar, N., J.D. Hibbard \& L.W. Stern (1994), The Nature and Consequences of Marketing Channel Intermediary Commitment, Report No. 94-115, Marketing Science Institute, Cambridge.

Kumar, N., L.K. Scheer \& J.E.M. Steenkamp (1995), "The Effects of Perceived Interdependence on Dealer Attitudes", Journal of Marketing, 32 (August), 348-356.

Kumar, N., L.W. Stern \& R.S. Achrol (1992), "Assessing Reseller Performance from the Perspective of the Supplier", Journal of Marketing Research, 29 (May), 238-253.

Kunst, P. \& J. Lemmink (1993), Management of Services: Organizational Consequences of Customers Perceived Quality, Working Paper 93-012, University of Limburg, Maastricht.

Kyj, M. (1989), "International Customer Service as a New Competitive Tool", International Journal of Physical Distribution and Materials Management, 19 (10), 4-9.

\section{$\mathbf{L}$}

LaLonde, B.J. \& P.H. Zinszer (1976), Customer Service: Meaning and Measurement, National Council of Physical Distribution Management, Chicago.

Langeard, E., J. Bateson, C. Lovelock \& P. Eiglier (1981), Marketing of Services: New Insights from Customers and Managers, Report No. 81-104, Marketing Sciences Institute, Cambridge.

Lapierre, J. (1996), "Service Quality: The Construct, Its Dimensionality and Its Measurement", in: T.A. Swartz, D.E. Bowen \& S.W. Brown (eds.), Advances in Services Marketing and Management: Research and Practice, 5, JAI Press, Greenwich \& London, 45-70.

Lapierre, J. \& P. Filiatrault (1996) "The Foundations of Research on the Quality of Professional Services to Organizations" in: P. Kunst \& J. Lemmink, Managing Service Quality, 2, 97-108.

Larsson, R. \& D.E. Bowen (1989), "Organization and Customer: Managing Design and Coordination of Services", Academy of Management Review, 14 (2), 213-233.

Lawrence, P.R. \& J.W. Lorsch (1967), Organization \& Environment: Managing Differentiation and Integration, Harvard University Press, Boston.

Lee, B.A. \& C.A. Zeiss (1980), "Behavioral Commitment to the Role of Sport Consumer: An Exploratory Analysis", Sociology and Social Research, 64 (April), 405-419.

Leffler, K.B. (1982), "Ambiguous Changes in Product Quality", American Economic Review, 72 (December), 956-967.

Lehtinen, U. \& J.R. Lehtinen (1982), Service Quality: A Study of Quality Dimensions, Service Management Institute, Helsinki (unpublished working paper).

Lehtinen, U., J. Ojasalo \& K. Ojasalo (1996), “On Service Quality Models, Service Quality Dimensions and Customers' Perceptions", in: P. Kunst \& J. Lemmink, Managing Service Quality, 2, 109-115.

Leifer, R. \& A. Delbecq (1978), "Organizational/Environmental Interchange: A Model of Boundary Spanning Activity", Academy of Management Review, 3 (1), 40-50.

Leland, H.E. (1977), "Quality Choice and Competition", American Economic Review, 67, 127-137.

Lele, M.M. (1986), "How Service Needs Influence Product Strategy", Sloan Management Review, 28 (1), 63-70.

Lele, M.M. \& J.N. Sheth (1987), The Customer Is Key: Gaining An Unbeatable Advantage through Customer Satisfaction, John Wiley \& Sons, New York.

Lemmink, J. (1991), Kwaliteitsconcurrentie tussen Ondernemingen: Een Empirisch Onderzoek naar Produktkwaliteitsverbeteringen van Industriële Ondernemingen, Marketing-mix Reacties van Concurrenten en Gepercipieerd Succes, Proefschrift, Rijksuniversiteit Limburg, Maastricht.

Lemmink, J. (1992), "Metingen ten behoeve van Kwaliteitsmanagement: Een Kritische Beschouwing van het SERVQUAL Model", in: A.E. Bronner, P. Ester, P.S.H. Leeflang, A.J. Olivier, W.F. van Raaij \& B. 
Wierenga (eds.), Recente ontwikkelingen in het Marktonderzoek: Jaarboek van de Nederlandse Vereniging van Marksonderzoekers 1992-'93, Uitgeverij de Vrieseborch, Haarlem, 223-235.

Lemmink, J. \& R.S. Behara (1992), "Q-Matrix: A Multidimensional Approach to Using Service Quality Measurements", in: P. Kunst \& J. Lemmink (eds.), Quality Management in Services, Van Gorcum, Assen \& Maastricht, 79-88.

Lemmink, J., J.C. de Ruyter \& M.G.M. Wetzels (1998), "The Role of Value in the Service Delivery Process of Hospitality Services", Joumal of Economic Psychology (forthcoming)

Lemmink, J., M. Wetzels \& K. Koelemeijer (1997), "Manufacturer-Distributor Relationships and Channel Service Quality", International Journal of Logistics Management, 7 (2), 33-42.

Levitt, T. (1969), The Marketing Mode, McGraw-Hill, New York.

Levitt, T. (1972), "Product-Line Approach to Service", Harvard Business Review, 50 (September-October), 41 52.

Levitt, T. (1976), "Industrialization of Service", Harvard Business Review, 54 (September-October), 63-74.

Levitt, T. (1981), "Marketing Intangible Products and Product Intangibles", Harvard Business Review, 59, 94 102.

Levy, M. \& A. Sharma (1995), "Relationships among Measures of Retail Person Performance", Journal of the Academy of Marketing Science, 21 (3), 231-238.

Lewicki, R.J. \& B.B. Buncker (1996), "Developing and Maintaining Trust in Work Relationships", in: R.M. Kramer \& T.R. Taylor (eds.), Trust in Organizations: Frontiers of Theory and Research, Sage Publications, Thousand Oaks, 114-139.

Lewis, C.I. (1946), An Analysis of Knowledge and Valuation, Open Court, La Salle.

Lewis, R.C. \& B.H. Booms (1983), "The Marketing Aspects of Service Quality", in: L.L. Berry, G.L. Shostack \& G. Upah (eds.), Emerging Perspectives on Services Marketing. American Marketing Association, 99-107.

Liljander, V. \& T. Strandvik (1993), "Estimating Zones of Tolerances in Perceived Service Quality", International Journal of Service Industry Management, 4 (2), 6-28.

Liljander, V. \& T. Strandvik (1994), "A Comparison of Episode Performance and Relationship Performance for a Discrete Service", Proceedings of the 3rd Dienstleistungs Workshop, 25-26 February, Berlin.

Liljander, V. \& T. Strandvik (1995a), "The Nature of Customer Relations in Services", in: T.A. Swartz, D.E Bowen \& S.W Brown (eds), Advances in Services Marketing and Management: Research and Practice, 4, JAI Press, Greenwich \& London, 141-167.

Liljander, V. \& T. Strandvik (1995b), "The Relationship Between Service Quality, Satisfaction and Intentions", in P. Kunst \& J. Lemmink (eds.), Managing Service Quality, Paul Chapman Publishing Ltd., 1, 45-63.

Locke, E.A. (1970), "Job Satisfaction and Job Performance: A Theoretical Analysis", Organizational Behavior and Human Performance, 5, 484-500.

Lodge, M. (1981), Magnitude Scaling: Quantitative Measurement of Opinions, Sage Publications, Beverly Hills.

Loehlin, J.C. (1987), Latent Variable Models, Lawrence Erlbaum Associates, Hillsdale.

Long, J.S. (1994), "Confirmatory Factor Analysis: A Preface to LISREL", in: M.S. Lewis-Beck (ed.), Factor Analysis and Related Techniques, International Handbooks of Quantitative Applications in the Social Sciences, 5, Sage Publications/Toppan Publishing, London, 247-328.

Long, J.S. (1994), "Covariance Structure Models: An Introduction to LISREL", in: M.S. Lewis-Beck (ed.), Factor Analysis and Related Techniques, International Handbooks of Quantitative Applications in the Social Sciences, 5, Sage Publications/Toppan Publishing, London, 329-328.

Lord, F.M. (1963), "Elementary Models for Measuring Change", in: C.W. Harris (ed.), Problems in Measuring Change, University of Wisconsin Press, Madison, 22-38.

Lott, A.J. \& B.E. Lott (1965), "Group Cohesiveness as Interpersonal Attraction: A Review of relationships with Antecedent and Consequent Variables", Psychological Bulletin, 64 (4), 259-309.

Lovelock, C.H. (1981), "Why Marketing Management Needs to Be Different for Services", in: J.H. Donnelly \& W.R. George (eds.), Marketing of Services, American Marketing Association, Chicago, 5-9.

Lovelock, C.H. (1983), "Classifying Services to Gain Strategic Marketing Insights", Journal of Marketing, 47 (Summer), 9-20.

Lovelock, C.H. (1984), Services Marketing: Text, Cases \& Readings, Prentice-Hall, Englewood Cliffs.

Lucas, G.H., Jr., E. Babakus \& T.N. Ingram (1990), "An Empirical Test of the Job Satisfaction-Turnover Relationship: Assessing the Role of Job Performance", Journal of the Academy of Marketing Science, 18 (3), 199-208.

Lucas, G.H., Jr., A. Parasuraman, R. Davis \& B. Enis (1987), "An Empirical Study of Salesforce Turnover", Journal of Marketing, 51 (July), 34-59.

Luchs, R. (1986), "Successful Businesses Compete on Quality, Not Costs", Long Range Planning, 19, 12-17.

Lundstrom, W.J. \& L.M. Lamont (1976), "The Development of a Scale to Measure Consumer Discontent", Journal of Marketing Research, 13 (November), 373-381.

Lundvall, D.M. \& J.M. Juran (1974), "Quality Costs", in: J.M. Juran, F.M. Gryna, Jr. \& R.S. Bingham, Jr. (eds.), Quality Control Handbook, McGraw-Hill, New York, 5-1 - 5-22.

Lysonski, S. (1985), "A Boundary Theory Investigation of the Product Manager's Role", Journal of Marketing, 49 (Winter), 26-40.

Lytle, R.S. \& M.P. Mokwa (1992), "Evaluating Health Care Quality; The moderating Role of Outcomes", Joumal of Health Care Marketing, 12 (1), 4-14. 


\section{$\mathbf{M}$}

Mabc, P.A. \& S.G. West (1982), "Validity of Self-Evaluation of Ability: A Review and Meta-Analysis", Journal of Applied Psychology, 67, 280-296.

MacCallum, R. (1986), "Specification Searches in Covariance Structure Modeling", Psychological Bulletin, 100 (1), 107-120.

MacCallum, R, M. Roznowski \& L.B. Necowitz (1992), "Model Specification in Covariance Structure Analysis: The Problem of Capitalization on Chance", Psychological Bulletin, 111 (3), 490-405.

Mangold, W.G. \& E. Babakus (1991), "Service Quality: The Front-Stage vs. the Back-Stage Perspective", The Journal of Services Marketing, 5 (4), 59-70.

Mano, H. \& R.L. Oliver (1993), "Assessing the Dimensionality and Structure of the Consumption Experience: Evaluation, Feeling, and Satisfaction", Journal of Consumer Research, 20 (December), 451-466.

March, J.G. \& H.A. Simon (1958), Organizations, John Wiley \& Sons, New York.

Markus, G.B. (1979), Analyzing Panel Data, Quantitative Applications in the Social Sciences, 18, Sage Publications, Newbury Park.

Marsh, H.W. \& D. Hocevar (1985), "Application of Confirmatory Factor Analysis to the Study of Self-Concept: First- and Higher Order Factor Models and Their Invariance Across Groups", Psychological Bulletin, 97 (3), $562-582$.

Marsh, H.W., J.R. Balla \& R.P. McDonald (1988), "Goodness-of-Fit Indexes in Confirmatory Factor Analysis: The effect of Sample Size", Psychological Bulletin, 103 (3), 391-410.

Marsh, H.W., J. R. Balla \& H.K. Tai (1996), "An Evaluation of Incremental Fit Indices: A Clarification of Mathematical and Empirical Properties", in: G.A. Marcoulides \& R.E. Schumacker (eds.), Advanced Structural Equation Modelling: Issues and Techniques, Mahwah, NJ, Lawrence Erlbaum Associates, $315-$ 353.

Mathieu, J.E. \& D.M. Zajac (1990), “A Review and Meta-Analysis of the Antecedents, Correlates and Consequences of Organizational Commitment", Psychological Bulletin, 108 (2), 171-194.

Mattsson, J. (1991), Better Business by the ABC of Values, Studentlitteratur, Chartwell-Bratt, Lund.

Mazis, M.B., O.T. Ahtola \& R.E. Klippel (1975), "A Comparison of Four Multi-attribute Models in the Prediction of Consumer Attitudes", Journal of Consumer Research, 2 (June), 38-52.

McGregor, D. (1960), The Human Side of the Enterprise, McGraw-Hill, New York.

Menard, S. (1991), Longitudinal Research, Quantitative Applications in the Social Sciences, 76, Sage Publications, Newbury Park.

Merton, R.K. (1940), "Bureaucratic Structure and Personality", Social Forces, 18, 560-568.

Merton, R.K. (1957), Social Theory and Social Structure, The Free Press, New York.

Meyer, J.P. \& N.J. Allen (1991), "A Three-Component Conceptualization of Organizational Commitment", Human Resource Management Review, 1 (1) 61-89.

Meyer, J.P., S.V. Paunonen, I.R. Gellatly, R.D. Goffin \& D.N. Jackson (1989), "Organizational Commitment and Job Performance: It is the Nature of Commitment that Counts", Journal of Applied Psychology, 74 (1), 152-156.

Micheals, R.E. \& A.L. Dixon (1994), "Sellers and Buyers on the Boundary: Potential Moderators of Role StressJob Outcome Relationships", Journal of the Academy of Marketing Science, 22 (1), $62-73$.

Micheals, R.E., W.L. Cron, A.J. Dubinsky \& E.A. Joachimsthaler (1988), "Influence of Formalization on the Organizational Commitment and Work Alienation of Salespeople and Industrial Buyers", Journal of Marketing Research, 30 (November), 376-383.

Micheals, R.E., R.L. Day \& E.A. Joachimsthaler (1987), "Role Stress Among Industrial Buyers: An Integrative Model", Journal of Marketing, 51 (April), 28-45.

Miller, A., K. Springen, J. Gordon, A. Murr, B. Cohen, T. Barnett \& L. Drew (1988), "Stress on the Job", Newsweek, 25 April, 40-45

Mills, P.K. (1983), "Self-Management: Its Control and Relationship to Other Organizational Propertics", Academy of Management Review, 8 (3), 445-453.

Mills, P.K. (1985), "The Control Mechanisms of Employees at the Encounter of Service Organizations", in: J.A. Czepiel, M.R. Solomon \& C.F. Surprenant (eds.), The Service Encounter: Managing Employee/Customer Interaction in the Service Businesses, Lexington Books, Lexington \& Toronto, 163-177.

Mills, P.K. (1986), Managing Service Industries: Organizational Practices in a Post-industrial Economy, Ballinger, Cambridge.

Mills, P.K. (1990), "On the Quality of Services in Encounters: An Agency Perspective", Journal of Business Research, 20 (January), 31-42.

Mills, P.K., R.B. Chase \& N. Margulies (1983), "Motivating the Client/Employee System as a Service Production Strategy", Academy of Management Review, 8 (2), 301-310.

Mills, P.K. \& Margulies, N. (1980), "Toward a Core Typology of Service Organizations", Academy of Management Review, 5 (2), 118-131.

Mills, P.K. \& D.J. Moberg (1982), "Perspectives on the Technology of Service Operations", Academy of Management Review, 7 (3), 467-478.

Mills, P.K., J.L. Hall \& J.K. Leidecker (1983), "Flexiform: A Model for Professional Service Organizations", Academy of Management Review, 8 (1), 118-131. 
Mindak, W. \& R. Folger (1990), "Introduction: Toward Integration of Marketing and Organizational Behavior in the Service Economy", Journal of Business Research, 20 (January), 1-2.

Mintzberg, H. (1983), Structures in Fives, Prentice Hall, Englewood Cliffs.

Mobley, W.H., R.W. Griffeth, H.H. Hand \& B.M. Meglino (1979), "Review and Conceptual Analysis of the Employee Turnover Process", Psychological Bulletin, 86 (2), 493-522.

Mohr, L.A. \& M.J. Bitner (1995a), "The Role of Employee Effort in Satisfaction with Service Transactions", Journal of Business Research, 32, 239-252.

Mohr, L.A. \& M.J. Bitner (1995b), "Process Factors in Service Delivery: What Employee Effort Means to Customers", in: T.A. Swartz, D.E. Bowen \& S.W. Brown (eds.), Advances in Services Marketing and Management: Research and Practice, 4, JAI Press, Inc., Greenwich/London, 91-117.

Monroe, K.B. \& W.B. Dodds (1988), "Research Program for Establishing the Validity of the Price-Quality Relationship", Journal of the Academy of Marketing Science, 16 (Spring), 151-168.

Moorman, C., G. Zaltman \& R. Despande (1992), "Relationships Between Providers and Users of Marketing Research: The Dynamics of Trust Within and Between Organizations", Journal of Marketing Research, 29 (August), 314-29.

Morgan, R.M. \& S.D. Hunt (1994), "The Commitment-trust Theory of Relationship Marketing", Journal of Marketing, 58 (July), 20-38.

Morrow, P. (1983), "Concept Redundancy in Organizational Research: The Case of Work Commitment", Academy of Management Review, 8 (3) 486-500.

Mowday, R.T., L.W. Porter \& R.M. Steers (1979), "The Measurement of Organizational Commitment", Journal of Vocational Behavior, 14 (April), 224-247.

Mowday, R.M., L.W. Porter \& R.M. Steers (1982), Employee-Organization Linkages: The psychology of Commitment, Absenteeism, and Turnover, Academic Press, New York.

\section{$\mathbf{N}$}

Netemeyer, R.G., M.W. Johnston \& S. Burton (1990), "Analysis of Role Conflict and Role Ambiguity in a Structural Equations Framework", Journal of Applied Psychology, 75 (2), 148-157.

Neter, J., W. Wasserman \& G.A. Whitmore (1988), Applied Statistics, Allyn \& Bacon, Inc., Boston.

Neter, J., W. Wasserman \& M.H. Kutner (1990), Applied Linear Statistical Models: Regression, Analysis of Variance and Experimental Designs, Richard D. Irwin, Inc, Burr Ridge.

Newman, J.W. \& R.A. Werbel (1973), "Multivariate Analysis of Brand Loyalty for Major Household Appliances", Journal of Marketing Research, 10 (November), 404-409.

Nicholson, P.J., Jr. \& S.C. Goh (1983), "The Relationship of Organization Structure and Interpersonal Attitudes to Role Conflict and Ambiguity in Different Work Environments", Academy of Management Journal, 26 (1), 148-155.

Normann, R. (1991), Service Management: Strategy and Leadership in Service Business, John Wiley \& Sons, Chichester.

Nunnally, J.C. \& I.H. Bernstein (1994). Psychometric Theory, New York: McGraw-Hill.

\section{$\mathbf{O}$}

Ofir, C. \& A. Khuri (1986), "Multicollinearity in Marketing Models: Diagnostics and Remedial Measures", International Journal of Research in Marketing, 3, 181-205.

Oldham, G.R. \& J.R. Hackman (1981), "Reactions between Organizational Structure and Employee Reactions: Comparing Alternative Frameworks", Administrative Science Quaterly, 26, 66-83.

Oliver, R.L. (1980), "A Cognitive Model of the Antecedents and Consequences of Satisfaction Decisions", Journal of Marketing Research, 17 (November), 460-469.

Oliver, R.L. (1981), "Measurement and Evaluation of Satisfaction Processes in Retail Settings", Journal of Retailing, 57 (Fall), 25-48.

Oliver (1993a), "A Conceptual Model of Service Quality and Service Satisfaction: Compatible Goals, Different Concepts ", in: T.A. Swartz, D.E. Bowen \& S.W. Brown (eds.), Advances in Services Marketing and Management: Research and Practice, 3, JAI Press, Greenwich \& London, 65-85.

Oliver, R.L. (1993b), "Cognitive, Affective, and Attribute Bases on the Satisfaction Response", Journal of Consumer Research, 20 (December), 418-430.

Oliver, R.L. (1994), "Conceptual Issues in the Structural Analysis of Consumption, Satisfaction and Quality: Evidence in a Service Setting", in: C.T. Allen \& D. Roedder John (eds.), Advances in Consumer Research, 21, Association for Consumer Research, Provo, 16-22.

Oliver R.L. (1997), Satisfaction: A Behavioral Perspective on the Consumer, The McGraw-Hill Companies, Inc., New York

Oliver, R.L. \& A.P. Brief (1977-1978), "Determinants and Consequences of Role Conflict and Ambiguity Among Retail Sales Mangers", Journal of Retailing, 53 (4), 47-58, 90. 
Oliver, R.L. \& W.S. DeSarbo (1988), "Response Determinants in Satisfaction Judgments", Journal of Consumer Research, 14 (March), 495-507.

Oliver, R.L. \& J.E. Swan (1989a), "Consumer Perceptions of Interpersonal Equity and Satisfaction in Transactions: A Field Survey Approach", Journal of Marketing, 53 (April), 21-35.

Oliver, R.L. \& J.E. Swan (1989b), "Equity and Disconfirmation Perceptions as Influences on Merchant and Product Satisfaction", Journal of Consumer Research, 16 (December), 372-383.

Olson, R.G. (1967), "The Good", in: P. Edwards (ed.), The Encyclopedia of Philosophy, 3, MacMillan, New York, 367-370.

Organ, D.W. \& C.N. Greene (1981), "The Effects of Formalization on Professional Involvement: A Compensatory Process Approach", Administrative Science Quarterly,26 (June), 237-252.

Osterhus, T.L. (1997), "Pro-Social Consumer Influence Strategies: When and How Do They Work", Journal of Marketing, 61 (October), 16-29.

Ostrowski, P.L., T. O'Brien \& G. Gordon (1993), "Service Quality and Customer Loyalty in the Commercial Airline Industry", Journal of Travel Research, 32 (Fall), 16-24.

\section{$\mathbf{P}$}

Parasuraman, A. (1995), "Measuring and Monitoring Service Quality", in: W.J. Glynn \& Barnes, J.G. (eds.), Understanding Services Management: Integrating Marketing, Organisational Behaviour and Human Resource Management, John Wiley \& Sons, Chichester, 143-177.

Parasuraman, A., L.L. Berry \& V.A. Zeithaml (1990), An Empirical Examination of Relationships in an Extended Service Quality Model, Report No. 92-122, Academy of Marketing Science, Cambridge, MA.

Parasuraman, A., L.L. Berry \& V.A. Zeithaml (1991), "Refinement and Reassessment of the SERVQAL Scale", Journal of Retailing, 67 (Winter), 420-450.

Parasuraman, A., L.L. Berry \& V.A. Zeithaml (1993), "More on Improving Service Quality Measurement", Journal of Retailing, 69 (Spring), 140-147.

Parasuraman, A., V.A. Zeithaml \& L.L. Berry (1985), "A Conceptual Model of Service Quality and Its Implications for Further Research", Journal of Marketing, 49 (Fall), 41-50.

Parasuraman, A., V.A. Zeithaml \& L.L. Berry (1988), "SERVQUAL: A Multiple-item Scale for Measuring Consumer Perceptions of Service Quality", Journal of Retailing, 64 (Spring), 12-40.

Parasuraman, A., V.A. Zeithaml \& L.L. Berry (1990), An Empirical Examination of Relationship in an Extended Service Quality Model, Report No. 90-122, Marketing Science Institute, Cambridge.

Parasuraman, A., L.L. Berry \& V.A. Zeithaml (1994a), Moving Forward in Service Quality Research: Measuring Different Levels of Customer Expectations, Comparing Alternative Scales, and Examining the Performance-Behavioral Intentions Link, Marketing Science Institute Working Paper, Report No. 94-114.

Parasuraman, A., V.A. Zeithaml \& L.L. Berry (1994b), "Reassessment of Expectations as a Comparison Standard in Measuring Service Quality: Implications for Further Research", Journal of Marketing, 58 (January), 111-124.

Parasuraman, A., V.A. Zeithaml \& L.L. Berry (1994c), "Alternative Scales for Measuring Service Quality: A Comparative Assessment Based on Psychometric and Diagnostic Criteria", Journal of Retailing, 70 (3), 201 230.

Parkington, J.P. \& B. Schneider (1979). "Some Correlates of Experienced Job Stress: A Boundary Role Study", Academy of Management Journal, 22 (2), 270-281.

Paulin, M. \& J. Perrien (1996) "Measurement of Service Quality: The Effect of Contextuality" in: P. Kunst \& J. Lemmink, Managing Service Quality, 2, 79-96.

Pedhazur, E.J. \& L. Pedhazur Schmelkin (1991), Measurment, Design, and Analysis, Lawrence Erlbaum Associates, Publishers, Hillsdale, Hove \& London.

Perrault, W.D. \& F.A. Russ (1974), "Physical Distribution Service: A Neglected Aspect of Marketing Management", MSU Business Topics, 22 (3), 37-45.

Peter, J.P., G.A. Churchill, Jr. \& T.J., Brown (1993), "Caution in the Use of Difference Scores in Consumer Research", Journal of Consumer Research, 19 (March), 655-662.

Peterson, R.A. \& W.R Wilson (1985), "Perceived Risk and Price-Reliance Schema as Price-Perceived Quality Mediators", in: J. Jacoby \& J.C. Olson (eds.), Perceived Quality: How Consumers View Stores and Merchandise, Lexington Books, Inc., Lexington, 247-267.

Peterson, R.A. \& W.R. Wilson (1992), "Measuring Customer Satisfaction: Fact and Artifact", Journal of the Academy of Marketing Science, 20 (1), 61-71

Phillips, L.W., D.R. Chang \& R.D. Buzzel (1983), "Product Quality, Cost Position and Business Performance: A Test of some Key Hypotheses", Journal of Marketing, 47 (Spring), 26-43.

Pirsig, R.M. (1974), Zen and the Art of Motorcycle Maintenance, Bantam Books, New York.

Pirsig, R.M. (1992), Lila: An Inquiry into Morals, Bantam Books, New York.

Podsakoff, P.M., L.J. Williams \& W.D. Todor (1986), "Effects of Organizational Formalization on Alienation Among Professionals and Nonprofessionals", Academy of Management Journal, 29 (4), 819-831. 
Podsakoff, P.M., W.D. Todor, R.A. Grover \& V.L. Huber (1984). "Situational Moderators of Leader Reward and Punishment Behaviors: Fact or Fiction", Organizational Behavior and Organizational Performance, 34, 21-63.

Porter, M.E. (1980), Competitive Strategy: Techniques for Analyzing Industries and Competitors, The Free Press, New York.

Prakash, V. \& J.W. Lounsbury (1984), "The Role of Expectations in the Determination of Consumer Satisfaction", Journal of the Academy of Marketing Science, 12 (Summer), 1-17.

Prakash, V. (1984), "Validity and Reliability of the Confirmation of Expectations Paradigm As a Determinant of Consumer Satisfaction", Journal of the Academy of Marketing Science, 12 (Fall), 63-67.

Price, L.L., E.J. Arnould \& P. Tierney (1995), "Going to Extremes: Managing Service Encounters and Assessing Provider Performance", Journal of Marketing, 59 (April), 83-97.

Pugh, D.S., D.J. Hickson, C.R. Hinings \& C. Turner (1968), "Dimensions of Organization Structure", Administrative Science Quarterly, 13, 63-105.

$\mathbf{R}$

Rakowski, J.P. (1982), "The Customer Service Concept", Review of Business and Economic Research, 17 (Winter), 55-66.

Ramanujam, V. \& N. Venkatraman (1984), "An Inventory and Critique of Strategy Research Using the PIMS Database", Academy of Management Review, 9 (January), 138-151.

Rao, A.R. \& K.B. Monroe (1989), "The Effect of Price, Brand Name, and Store Name on Buyers' Perceptions of Product Quality: An Integrative Review", Journal of Marketing Research, 26 (August), 351-357.

Rathmell, J.M. (1966), "What Is Meant by Services?", Journal of Marketing, 30 (October), 32-36.

Rathmell, J.M. (1974), Marketing in the Services Sector, Winthrop, Cambridge.

Reeves, C.A. \& D.A. Bednar (1994), "Defining Quality: Alternatives and Implications", Academy of Management Review, 19 (3), 419-445.

Regan, W.J. (1963), "The Service Revolution", Journal of Marketing, 47 (July), 57-62.

Reichheld, F.F. \& W.E. Sasser, Jr. (1990), "Zero Defection: Quality Comes 10 Services", Harvard Business Review, 68 (September-October), 105-111.

Reichheld, F.F. (1996), "Learning from Customer Defections", Harvard Business Review, 74 (March-April), 5669.

Reidenbach, R.E \& B. Sandifer-Smalwood (1990), "Exploring Perceptions of Hospital Operations by a Modified SERVQUAL Approach", Journal of Health Care Marketing, 10 (4), 47-55.

Richins, M.L. (1983), "Negative Word-of-Mouth by Dissatisfied Consumers", Journal of Marketing, 47 (Winter), 68-78.

Riddle, D.I. (1986), Service-Led Growth: The Role of the Service Sector in World Development, Preager Publishers, New York.

Rizzo, J.R., R.J. House \& S.I. Lirtzman (1970), "Role Conflict and Ambiguity in Complex Organisations", Administrative Science Quarterly, 15, 150-163.

Rogers, D.L. \& J. Molnar (1976), "Organizational Antecedents of Role Conflict and Ambiguity in Top-Level Administrators", Administrative Science Quarterly, 21 (December), 598-610.

Rousseau, D.M. (1978). "Characteristics of Departments, Positions, and Individuals: Contexts for Attitudes and Behavior", Administrative Science Quarterly, 23, 521-540.

Rousseau, D.M. (1985), "Issues of Level in Organizational Research: Multi-Level and Cross-Level Perspectives", in: L.L. Cummings \& B.M. Staw (eds.), Research in Organizational Behavior: An Annual Series of Analytical Essays and Critical Reviews, 7, JAI Press, Greenwich \& London, 1-37.

Ruekert, R.W., O.C. Walker, Jr. \& K.J. Roering (1985), "The Organization of Marketing Activities: A Contingency Theory of Structure and Performance", Journal of Marketing, 49 (Winter), 13-25.

Rushing, W.A. (1966), "Organizational Rules and Surveillance: Propositions in Comparative Organizational Analysis", Administrative Science Quarterly, 10, 423-443.

Rust, R.T. \& R.L. Oliver (1994), "Service Quality: Insights and Managerial Implications from the Frontier", in: R.T. Rust \& R.L. Oliver (eds.), Service Quality: New Directions in Theory and Practice, Sage Publications, Thousand Oaks, 1-20.

Rust, R.T. \& A.J. Zahorik (1993), "Customer Satisfaction, Customer Retention, and Market Share", Journal of Retailing, 69 (Spring), 193-215.

Rust, R.T., A.J. Zahorik \& T.L. Keiningham (1995), "Return on Quality (ROQ): Making Service Quality Financially Accountable", Journal of Marketing, 59 (April), 58-70.

Rust, R.T., A.J. Zahorik \& T.L. Keiningham (1996), Service Marketing, Harper Collins College Publishers, New York.

Ruyter, de K. \& M. Wetzels (1995), "Two Sides of the Same Story: Measuring Different Quality Perceptions of the Dyadic Service Encounter with the SERVCON Instrument", Total Quality Management, 7 (6), 595-603.

Ruyter, de K. \& M. Wetzels (1997), "On the Perceived Dynamics of Retail Service Quality", Journal of Retailing and Consumer Services, 4 (2), 83-88. 
Ruyter, de K. \& M. Wetzels (1998a), "On the Complex Nature of Patient Evaluations of General Practice Service", Journal of Economic Psychology (forthcoming).

Ruyter, de K. \& M. Wetzels (1998b), "The Marketing-Finance Interface: A relational Exchange Perspective", Journal of Business Research (forthcoming).

Ruyter, de K. \& M. Wetzels (1998c), "Commitment in Auditor-Client Relationships: Antecedents and Consequences", Accounting, Organizations and Society (forthcoming).

Ruyter, de K. \& M. Wetzels (1998d), "Marketing Service Relationships: The Role of Commitment", Journal of Business and Industrial Marketing (forthcoming).

Ruyter, de J.C., D. Perkins \& M.G.M. Wetzels (1995), "Consumer-Defined Service Expectations and Post-Purchase Dissatisfaction in Moderately-Priced Restaurants: A Cross-Cultural Study", Journal of Consumer Satisfaction, Dissatisfaction and Complaining Behavior, 7, 177-187.

Ruyter, de K., J. Lemmink, M. Wetzels \& J. Mattsson (1997a), "Carry-Over Effects in the Formation of Satisfaction: The Role of Value in a Hotel Service Delivery Process", in: T.A Swartz, D.E. Bowen \& D. Iacobucci, Advances in Services Marketing: Research and Practice, 7, JAI Press, Greenwich \& London, 61-77.

Ruyter, de J.C., M.G.M. Wetzels, J. Lemmink \& J. Mattsson (1997b), "The Dynamics of the Service Delivery Process: A Value-Based Approach", International Journal of Research in Marketing, 14 (3), 231-243.

Ruyter, de K., M. Wetzels \& M. Thijssen (1997c), "Van accountant naar accountmanager: een onderzoek naar de rol van commitment in relaties tussen accountants en cliënten", Maandblad voor voor Accountancy en Bedrijfseconomie, 71 (oktober), 531-541.

Ruyter, de J.C., J.M.A. Bloemer \& P. Peters (1997d), "Merging Service Quality and Service Satisfaction: An Empirical Test of an Integrative Framework", Joumal of Economic Psychology, 18 (4), 387-406.

$\mathbf{S}$

Sager, J.K. (1991), "A Longitudinal Assessment of Change in Sales Force Turnover", Journal of the Academy of Marketing Science, 19 (1), 25-36.

Sager, J.K. (1994), "A Structural Model Depicting Salespeople's Job Stress", Journal of the Academy of Marketing Science, 22 (1), 74-84.

Sasser, E. (1976), "Match Supply and Demand in Service Industries", Harvard Business Review, 56 (NovemberDecember), 133-148.

Sasser, W.E., Ir., R.P. Olson \& D.D. Wyckoff (1978), Management of Service Operations: Text and Cases, Allyn \& Bacon, Boston.

Saxe, R. \& B.A. Weitz (1982), "The SOCO Scale: A Measure of the Customer Orientation of Salespeople", Journal of Marketing Research, 19 (August), 343-351.

Scanzoni, J. (1979), "Social Exchange and Behavior Interdependence", in: R.L. Burgess \& T.L. Huston (eds.), Social Exchange in Developing Relationships, Academic Press, Inc., New York, $61-98$.

Schlesinger, L.A. \& J.L. Heskett (1991), "Enfranchisement of Service Workers", California Management Review, 33 (4), 83-100.

Schlesinger, L.A. \& J.L. Heskett (1992), "De-Industrializing the Service Sector: A New Model for Service Firms" in: T.A. Swartz, D.E. Bowen \& S.W. Brown (eds), Advances in Services Marketing and Management: Research and Practice, 1, JAI Press,Greenwich \& London, 159-176.

Schmitt, N. \& D.M. Stults (1985), "Factors Defined by Negatively Keyed Items: The Result of Careless Respondents", Applied Psychological Measurement, 9 (December), 367-373.

Schneider, B. \& D.E. Bowen (1984), "New Services Design, Development and Implementation and the 'Employee", in: W.R. George \& C.E. Marshall (eds.), Developing New Services, American Marketing Association, Chicago, 82-101.

Schneider, B. \& D.E. Bowen (1985), "Employee and Customer Perceptions of Service in Banks: Replication and Extension", Journal of Applied Psychology, 70, 423-433.

Schneider, B. (1980), "The Service Organization: Climate is Crucial", Organizational Dynamics, 9 (Autumn), $52-65$.

Schneider, B. (1985), "Organization Behavior", Annual Review of Psychology, 36, 536-611.

Schneider, B. (1986), "Notes on Climate and Culture", in: C. Marshall, D. Schmalensee \& V. Venkatesan, Creativity in Services Marketing, American Marketing Association, Chicago.

Schneider, B., J.J. Parkington \& V.M. Buxton (1980), "Employee and Customer Perceptions of Service in Banks", Administrative Science Quarterly, 25 (June), 252-267.

Schocffler, S., R.D. Buzzell \& D.F. Heany (1974), "Impact of Strategic Planning on Profit Performance", Harvard Business Review, 56 (September-October), 104-114.

Schriesheim, C.A., R.J. House \& S. Kerr (1976), "Leader Initiating Structure: A Reconciliation of Discrepant Research Results and Some Empirical Tests", Organizational Behavior and Human Performance, 15 (April), 159-172.

Schuler, R.S. (1980), "Definition and Conceptualization of Stress in Organizations", Organizational Behavior and Human Performance, 25, 184-215.

Schuler, R.S., R.J. Aldag \& A.P. Brief (1977), "Role Conflict and Ambiguity: A Scale Analysis", Organizational Behavior and Human Performance, 20, 111-128. 
Schwab, D.P. \& L.L. Cummings (1970), "Theories of Performance and Satisfaction: A Review", Industrial Relations, 9, 408-430.

Seashore, S. (1954), Group Cohesiveness in the Industrial Work Group, Institute for Social Research, Ann Arbor.

SeInes, F. (1993), "An Examination of the Effect of Product Performance on Brand Reputation, Satisfaction and Loyalty", European Journal of Marketing, 27 (9), 19-35.

Settoon, R.P., N. Bennett \& R.C. Liden (1996), "Social Exchange in Organizations: Perceived Organizational Support, Leader-Member Exchange, and Employee Reciprocity", Journal of Applied Psychology, 81 (3), 219-227.

Shamir, B. (1992), "Between Service and Servility: Role Conflict in Subordinate Service Roles", in: J.E.G. Bateson (ed.), Managing Services Marketing: Text and Readings, The Dryden Press, Fort Worth, 286-296.

Sharma, S., R.M. Durand \& O. Gur-Arie (1981), "Identification and Analysis of Moderator Variables", Journal of Marketing Research, 18 (August), 291-300.

Sheaves, D.E. \& J.G. Barnes (1996), "The Fundamentals of Relationships: An Exploration of the Concept to Guide Marketing Implementation" in: T.A. Swartz, D.E. Bowen \& S.W. Brown, Advances in Services Marketing and Management: Research and Practice, 5, JAI Press, Greenwich \& London, 215-245.

Shelp, R.K. (1981), Beyond Industrialization: Ascendancy of the Global Service Economy, Preager Publishers, New York.

Shemwell, D.J., J.J. Cronin \& W.R. Bullard (1994), "Relational Exchange in Services: An Empirical Investigation of Ongoing Customer Service-Provider Relationships", International Journal of Service Industry Management, 5 (3), 57-68.

Sheridan, J.E. \& J. Slocum (1975), "The Direction of the Causal Relationship between Job Satisfaction", Organizational Behavior and Human Performance, 14 (October), 150-172.

Sheth, J.N. \& A. Parvatiyar (1994), "The Evolution of Relationship Marketing", International Business Review, $4(4), 397-418$.

Shimp, T.A. \& S. Sharma (1987), "Consumer Ethocentrism: Construction and Validation of the CETSCALE", Journal of Marketing Research, 24 (August), 280-289.

Shostack (1985), "Planning the Service Encounter", in: J.A. Czepiel, M.R. Solomon \& C.F. Surprenant (eds.), The Service Encounter: Managing Employee/Customer Interaction in the Service Businesses, Lexington Books, Lexington \& Toronto, 243-263.

Shostack, G.L. (1977a), "Breaking Free from Product Marketing", Journal of Marketing, 41 (April), 73-80.

Shostack, G.L. (1977b), "Banks Sell Services - Not Things", The Bankers Magazine, 160 (Winter), 40.

Silvia, S.E.M. \& R.C. MacCallum, (1988), "Some Factors Affecting the Success of Specification Searches in Covariance Structure Modeling", Multivariate Behavioral Research, 23, 297-326.

Singh, J. (1991), "Understanding the Structure of Consumers' Satisfaction Evaluations of Service Delivery", Journal of the Academy of Marketing Science, 19 (Summer), 223-244.

Singh, J. (1993), "Boundary Role Ambiguity: Facets, Determinants, and Impacts", Journal of Marketing, 57 (April), 11-31.

Singh, J. \& G.K. Rhoads (1991), "Boundary Role Ambiguity in Marketing-Oriented Positions: A Multidimensional, Multifaceted Operationalization", Journal of Marketing Research, 28 (August), 328-338.

Singh, J., W. Verbeke \& G.K. Rhoads (1996), "Do Organizational Practices Matter in Role Stress Processes? A Study of Moderating Effects for Marketing-Oriented Boundary Spanners", Journal of Marketing, 60 (July), 69-86.

Slater, S.F. \& J.C. Narver (1995), "Market Orientation and the Learning Organization", Journal of Marketing, 59 (July), 63-74.

Smidts, A. (1993), "De Kwaliteit van SERVQUAL: Een Toepassing bij Zeven Dienstverlenende Organisaties", in: A.E. Bronner, P. Ester, P.S.H. Leeflang, A.J. Olivier, W.F. van Raaij \& B. Wierenga (eds.), Recente ontwikkelingen in het Marktonderzoek: Jaarboek van de Nederlandse Vereniging van Marktonderzoekers 1993-'94, Uitgeverij de Vrieseborch, Haarlem, 165-185.

Smith, P.C., L.M. Kendall \& C.L. Hulin (1969), The Measurement of Satisfaction in Work and Retirement, Rand Mcnally, Chicago.

Snyder, D.R. (1986), "Service Loyalty and Its Measurement: A Preliminary Investigation" in: M. Venkatesan, D.M. Schmalensee \& C. Marshall (eds.), Creativity in Service Marketing: What's New, What Works, What's Developing, AMA, Chicago, 44-48.

Solomon, M.R., C.F. Surprenant, J.A. Czepiel \& E.G. Gutman (1985), “A Role Theory Perspective on Dyadic Interactions: The Service Encounter", Journal of Marketing, 49 (Winter), 99-111.

Spector, P.E. (1994), "Summated Rating Scale Construction: An Introduction", in M.S. Lewis-Beck (ed.), Basic Measurement, International Handbooks of Quantitative Applications in the Social Sciences, 4, Sage Publications/Topan Publishing, 229-300.

Spiro, R.L. \& B.A. Weitz (1990), “Adaptive Selling: Conceptualization, Measurement and Nomological Validity", Journal of Marketing Research, 27 (February), 61-69.

Spreitzer, G.M. (1995), "Psychological Empowerment in the Workplace: Dimensions, Measurement and Validation", Academy of Management Journal, 38 (5), 1442-1465.

Spreng, R.A. \& A.K. Singh (1993), "An Empirical Assessment of the SERVQUAL Scale and the Relationship between Service Quality and Satisfaction", Michigan State University (unpublished manuscript). 
Stahl, M.J. \& G.M. Bounds (1991), Competing Globally through Customer Value, Quorum Books, New York.

Staw, B.M. (1984), "Organizational Behavior: A Review and Reformulation of the Field's Outcome Variables", Annual Review of Psychology, 35, 627-666.

Steenkamp, J.B.E.M. (1989), Product Quality: An Investigation into the Concept and how it is perceived by Consumers, Van Gorcum, Assen/Maastricht.

Steenkamp, J.B.E.M. \& H.C.M. van Trijp (1991), "The Use of LISREL ${ }^{\circledR}$ in Validating Marketing Constructs", International Journal of Research in Marketing 8 (4) (November), 283-299.

Steers, R.M. (1977), Organizational Effectiveness: A Behavioral View, Goodyear Publishing Company, Santa Monica.

Steiger, J.H. (1990), "Structural Model Evaluation and Modification: An Interval Estimation Approach", Multivariate Behavioral Research, 25, 173-180.

Stogdill, R.M. (1963), Manual for the Leader Behavior Description Questionnaire - From XII, Bureau of Busines Research, The Ohio State University, Columbus.

Storbacka, K., T. Strandvik \& C. Grönroos (1994), "Managing Customer Relationships for Profit: The Dynamics of Relationship Quality", International Journal of Service Industry Management, 5 (5), 21-38.

Strandvik, T. \& Liljander, V. (1994), "A Comparison of Episode Performance and Relationship Performance for a Discrete Service", Proceedings of the $3^{\text {rd }}$ Service Marketing Workshop, February 25-26, Berlin.

Suchanek, M. (1998), Exploring the Sales Control Function: Control Systems that Drive Sales Performance (unpublished Ph.D. thesis).

Surprenant, C.F. \& M.R. Solomon (1987), "Predictability and Personalization in the Service Encounter", Journal of Marketing, 51 (April), 86-96.

Swan, J.E. \& I.F. Trawick (1981), "Disconfirmation of Expectations and Satisfaction with a Retail Service", Journal of Retailing, 57 (Fall), 49-67.

Swartz, T.A., D.E. Bowen \& S.W. Brown (1992), "Fifteen Years after Breaking Free: Services Then, Now and Beyond", in: T.A. Swartz, D.E. Bowen \& S.W. Brown, Advances in Services Marketing and Management, 1, JAI Press, Greenwich \& London, England, 1-21.

Szymanski, D.M., S.G. Bharadwaj \& P.R. Varadarajan (1993), "An Analysis of the Market Share-Profitability Relationship", Journal of Marketing, 57 (July), 1-18.

T

Tabachnik, B.G. \& L.S. Fidell (1996), Using Multivariate Statistics, Harper Collins College Publishers, New York.

Tansik, D.A. (1990), "Balance in Service Systems Design", Journal of Business Research, 20 (January), 55-62.

Tansik, D.A (1990), "Managing Human Resource Issues for High Contact Personnel", in: D.E. Bowen, R.B. Chase \& T.G. Cummings (eds.), Service Management Effectiveness, Jossey-Bass, San Francisco, 152-176.

Taylor, P.W. (1961), Normative Discourse, Prentice Hall, Englewood Cliffs.

Taylor, S.A. (1995), "Service Quality and Consumer Attitudes: Reconciling Theory and Measurement", in: T.A. Swartz, D.E. Bowen \& S.W. Brown (eds.), Advances in Services Marketing and Management: Research and Practice, 4, JAI Press, Greenwich \& London, 1-36.

Taylor, S.A. \& T.L. Baker (1994), “An Assessment of the Relationship between Service Quality and Customer Satisfaction in the Formation of Customers' Purchase Intentions", Journal of Retailing, 70 (2), 163-178.

Teas, K.R. (1980), "An Empirical Test of Linkages Proposed in the Walker, Churchill and the Ford model of Salesforce Motivation and Performance", Journal of the Academy of Marketing Science, 8 (1), 58-72.

Teas, R.K. (1983), "Supervisory Behavior, Role Stress and Job Satisfaction of Industrial Salespeople", Journal of Marketing Research, 20 (February), 84-91.

Teas, R.K. (1993), "Expectations, Performance, Evaluation and Consumers Perceptions of Quality", Journal of Marketing, 57 (October), 18-34.

Teas, R.K. (1994), "Expectations as a Comparison Standard in Measuring Service Quality: An Assessment of a Reassessment", Journal of Marketing, 58 (January), 132-139.

Tett, R.P. \& J.P. Meyer (1993). "Job Satisfaction, Organizational Commitment, Turnover Intention, and Turnover: Path Analyses Based on Meta-Analytic Findings", Personnel Psychology, 46, 259-293.

Thibaut, J.W. \& H.H. Kelley (1959), The Social Psychology of Groups, John Wiley \& Sons, New York.

Thomas, D.R.E. (1978), "Strategy Is Different in Service Business", Harvard Business Review, 56 (JulyAugust), 158-165.

Thomas, K.W. \& B.A. Velthouse (1990), "Cognitive Elements of Empowerment: An 'Interpretive' Model of Intrinsic Task Motivation", Academy of Management Review, 15 (4), 666-681.

Thompson, J.D. (1967), Organizations in Action, McGraw-Hill Book Company, New York.

Thompson, L. \& G.B. Spanier (1983), "The End of Marriage and Acceptance of Marital Termination", Journal of Marriage and Family, 16 (February), 103-13.

Tryfos, P. (1996), Sampling Methods for Applied Research, John Wiley \& Sons, Inc., New York.

Tse, D.K. \& P.C. Wilton (1988), "Models of Consumer Satisfaction Formation: An Extension", Journal of Marketing Research, 25 (May), 204-12.

Tuchman, B.W. (1980), "The Decline of Quality", New York Times Magazine, November 2, 38-41, 104. 
Tucker, F.G. (1983), "Creative Customer Service Management", International Journal of Physical Distribution and Materials Management, 13 (3), 35-50.

Tucker, L.R. \& Lewis (1973), "The Reliability Coefficient for Maximum Likelihood Factor Analysis", Psychometrika, 38, 1-10.

$\mathbf{V}$

Van de Ven, A.H. \& D.L. Ferry (1980), Measuring and Assessing Organizations, John Wiley \& Sons, New York.

Van Sell, M., A.P. Brief. \& R.S. Schuler (1981), "Role Conflict and Role Ambihuity: Integration of the Literature and Directions of Future Research", Human Relations, 34 (1), 43-71.

Venetis, K.A. (1997), Service Quality and Customer Loyalty in Professional Business Service Relationships: An Empirical Investigation into the Customer-Based Quality Concept in the Dutch Advertising Industry, Dissertation, Maastricht University, Maastricht

Vogels, R., J. Lemmink \& H. Kasper (1989), "Some Methodological Remarks on the SERVQUAL Model", in: G.J. Avlonitis, N.K. Papavasiliou \& A.G. Kouremenos, Marketing Thought and Practice in the 1990's, EMAC Conference Proceedings, April, Athens, The Athens School of Economics and Business Science, 1, 789-800.

Vriens, M., H.C.A. Roest, G.L.M. de Kort \& Th.M.M. Verhallen (1997), "Meten van Kwaliteit van Dienstverlening en Strategische Marketing Planning", in: A.E. Bronner, P. Dekker, A.J. Olivier, W.F. van Raaij, M. Wedel \& B. Wierenga (eds.), Recente ontwikkelingen in het Marktonderzoek: Jaarboek 1998 van de Nederlandse Vereniging voor Marktonderzoeker en Informatiemanagement, Uitgeverij de Vrieseborch, Haarlem, 239-254.

Vries, de W., J.D.P. Kasper \& P.J.C van Helsdingen (1997), Dienstenmarketing, Educatieve Partners Nederland, Houten.

Vroom, V.R. \& P.W. Yetton (1973), Leadership and Decision-making, University of Pittsburgh Press, Pittsburgh.

W

Walker, O.C., Jr., G.A. Churchill, Jr. \& N.M. Ford (1975), "Organizational Determinants of the Industrial Salesman's Role Conflict and Ambiguity" Journal of Marketing, 39 (January), 32-39.

Wall, J.A. \& J.S. Adams (1974), "Some Variables Affecting Constituent's Evaluations of and Behavior Toward a Boundary Role Occupant", Organizational Behavior and Human Performance, 11, 390-408.

Wall, T.D. \& R. Payne (1973), "Are Deficiency Scores Deficient?", Journal of Applied Psychology, 58 (3), 322326.

Walt, van der S.D., D. Scott \& A.G. Woodside (1994), "CPA Service Providers: A Profile of Client Types and Their Assessment of Performance", Journal of Business Research, 31, 225-233.

Wanous, J.P. (1974), "A Causal-Correlational Analysis of the Job Satisfaction and Performance Relationship", Journal of Applied Psychology, 59 (April), 139-144.

Weatherly, K.A. \& D.A. Tansik (1993a). "Tactics Used by Customer Contact Workers: Effects of Role Stress, Boundary Spanning and Control", International Journal of Service Industry Management, 4 (3), 4-17.

Weatherly, K.A. \& D.A. Tansik (1993b), "Managing Multiple Demands: A Role Theory Examination of the Behaviors of Customer Contact Service Workers", in: T.A. Swartz, D.E. Bowen \& S.W. Brown (eds.), Advances in Services Marketing and Management: Research and Practice, 2, JAI Press, Greenwich \& London, 279-300.

Webster, F.E. (1992), "The Changing Role of Marketing in the Corporation", Journal of Marketing, 56 (October), 1-17.

Wellins, R.S., W.C. Byham \& J.M. Wilson (1991), Empowered Teams: Creating Self-Directed Work Groups that Improve Quality, Productivity and Participation, Jossey-Bass Publishers, San Francisco.

Wener, R.E. (1985), "The Environmental Psychology of Service Encounters", in: J.A. Czepiel, M.R. Solomon \& C.F. Surprenant (eds.), The Service Encounter: Managing Employee/Customer Interaction in the Service Businesses, Lexington Books, Lexington \& Toronto, 101-112.

Werts, C.E. \& R.L. Linn (1970), "A General Linear Model for Studying Growth, Psychological Bulletin, 73, 1722.

Westbrook R.A. \& R.L. Oliver (1991), "The Dimensionality of Consumption Emotion Patterns and Consumer Satisfaction", Journal of Consumer Research, 18 (June), 84-91.

Westbrook, R.A. (1980), "A Rating Scale for Measuring Product/Service Satisfaction", Journal of Marketing, 44 (Fall), 68-72.

Wetzels, M.G.M., J.C. de Ruyter, J. Lemmink \& K. Koelemeijer (1995), "Measuring Customer Service Quality in International Marketing Channels: A Multimethod Approach", Journal of Business and Industrial Marketing, 10 (5), 50-59. 
Williams, L.J. \& J.T. Hazer (1986), “Antecedents and Consequences of Satisfaction and Commitment in Turnover Model: A Reanalysis Using Latent Variable Structural Equation Methods", Journal of Applied Psychology, 71 (2), 219-231.

Williams, L.J. \& P.M. Podsakoff (1989), "Longitudinal Filed Methods for Studying Reciprocal Relationships in Organizational Behavior: Toward Improved causal Analysis", in: L.L. Cummings \& B.M. Staw (eds.), Research in Organizational Behavior: An Annual Series of Analytical Essays and Critical Reviews, 11, JAI Press, Greenwich \& London, 247-292.

Woodruff, R.B., E.R. Cadotte \& R.L. Jenkins (1983), "Modeling Consumer Satisfaction Processes Using Experience-Based Norms", Journal of Marketing Research, 20 (August), 296-304.

Woodside, A.G., L.L. Frey \& R.T. Daly (1989), "Linking Service Quality, Customer Satisfaction, and Behavioral Intention", Journal of Health Care Marketing, 9 (December), 5-17.

Wyckham, R.G., P.T. Fitzroy \& G.D. Mandry (1975), "Marketing of Services: An Evaluation of the Theory", European Journal of Marketing, 9 (1), 95-99.

\section{$\mathbf{Z}$}

Zahorik, A.J. \& R.T. Rust (1992), "Modeling the Impact of Service Quality on Profitability: A Review", in: T.A. Swartz, D.E. Bowen \& S.W. Brown, Advances in Services Marketing and Management: Research and Practice, 1, JAI Press, Greenwich \& London, 247-276.

Zeithaml, V.A. (1981), "How Consumer Evaluation Processes Differ between Goods and Services", in: J.H. Donnelly \& W.R.George (eds.), Marketing of Services, American Marketing Association, Chicago, 186-190.

Zeithaml, V.A. (1988), "Consumer Perceptions of Price, Quality, and Value: A means-End Model and Synthesis of Evidence", Journal of Marketing, 52 (July), 2-22.

Zeithaml, V.A. \& M.J. Bitner (1996), Services Marketing, The McGraw-Hill Companies, Inc, New York etc.

Zeithaml, V.A., A. Parasuraman. \& L.L. Berry (1985), "Problems and Strategies in Services Marketing", Journal of Marketing, 49 (Spring), 33-46.

Zeithaml, V.A., A. Parasuraman \& L.L Berry (1988), "Communication and Control Process in the Delivery of Service Quality", Journal of Marketing, 52 (April), 35-48.

Zeithaml, V.A., A. Parasuraman \& L.L. Berry (1990), Delivering Service Quality: Balancing Customer Perceptions and Expectations, The Free Press, New York.

Zeithaml, V.A., L.L. Berry \& A. Parasuraman (1993), "The Nature and Determinants of Customer Expectations of Service", Journal of the Academy of Marketing Science, 21 (1), 1-12.

Zeithaml, V.A., L.L. Berry \& A. Parasuraman (1996), "The Behavioral Consequences of Service Quality", Journal of Marketing, 60 (April), 31-61

Zemke, R. \& D. Schaaf (1989). The Service Edge: 101 companies that profit from customer care, New American Library, New York.

Zhu, S. \& N.H. Anderson (1991), "Self Estimation of Weight Parameter in Multi-attribute Analysis", Organizational Behavior and Human Decision Processes, 48, 35-54. 


\title{
Appendix I \\ Original SERVQUAL-Instrument
}

\section{Expectations}

\begin{abstract}
Directions
This survey deals with your opinions of -..--..- services. Please show the extent to which you think firms offering -......-- services should possess the features described by each statement. Do this by picking one of the seven numbers next to each statement. If you strongly agree that these firms should possess a feature, circle the number 7. If you strongly disagree that these firms should possess a feature, circle 1 . If your feelings are not strong, circle one of the numbers in the middle. There are no right or wrong answers ... all we are interested in is a number that best shows your expectations about firms offering -.....-.--- services.
\end{abstract}

\section{TANGIBLES}

E1 They should have up-to-date equipment.

E2 Their physical facilities should be visually appealing.

E3 Their employees should be well dressed and appear neat.

E4 The appearance of the physical facilities of these firms should be in keeping with the type of services provided.

\section{RELIABILITY}

E5 When these firms promise to do something by a certain time, they should do so.

E6 When customers have problems, these firms should be sympathetic and reassuring.

E7 These firms should be dependable.

E8 They should provide their services at the time they promise to do so.

E9 They should keep their records accurately.

\section{RESPONSIVENESS}

E10 They shouldn't be expected to tell customers exactly when services will be performed. (-)

E11 It is not realistic for customers to expect prompt service from employees of these firms. (-)

E12 Their employees don't always have to be willing to help customers. (-)

E13 It is okay if they are too busy to respond to customer requests promptly. (-)

\section{ASSURANCE}

E14 Customers should be able to trust employees of these firms.

E15 Customers should be able to feel safe in their transactions with these firms' employees.

E16 Their employees should be polite.

E17 Their employees should get adequate support from these firms to do their jobs well.

\section{EMPATHY}

E18 These firms should not be expected to give customers individual attention. (-)

E19 Employees of these firms cannot be expected to give customers personal attention. (-)

E20 It is unrealistic to expect employees to know what the needs of their customers are. (-)

E21 It is unrealistic to expect these firms to have their customers' best interests at heart. (-)

E22 They shouldn't be expected to have operating hours convenient to all their customers.(-)

\section{Perceptions}

\section{Directions}

The following set of statements relate to your feelings about XYZ. For each statement, please show the extent to which you believe XYZ has the feature described by the statement. Once again, circling a 7 means that you strongly agree that XYZ has that feature, and circling a 1 means that you strongly disagree. You may circle any of the numbers in the middle that show how strong your feelings are. There are no right or wrong answers.-.-. all we are interested in is a number that best shows your perceptions about XYZ.

\section{TANGIBLES}

P1 XYZ has up-to-date equipment.

P2 XYZ's physical facilities are visually appealing.

P3 XYZ's employees are well dressed and appear neat.

P4 The appearance of the physical facilities of $X Y Z$ is in keeping with the type of services provided. 


\section{RELIABILITY}

P5 When XYZ promises to do something by a ccrtain time, it does so.

P6 When you have problems, $X Y Z$ is sympathetic and reassuring.

P7 $\mathrm{XYZ}$ is dependable.

P8 $\quad X Y Z$ provides its services at the time it promises to do so.

P9 XYZ keeps its records accurately.

\section{RESPONSTVENESS}

P10 XYZ does not tell customers exactly when services will be performed. (-)

P11 You do not receive prompt service from XYZ's employees. (-)

P12 Employees of XYZ are not always willing to help customers. (-)

P13 Employees of XYZ are too busy to respond to customer requests promptly. (-)

\section{ASSURANCE}

P14 You can trust employees of XYZ.

P15 You feel safe in your transactions with XYZ's employees.

P16 Employees of XYZ are polite.

P17 Employees get adequate support from $X Y Z$ to do their jobs well.

\section{EMPATHY}

P18 XYZ does not give you individual attention. (-)

P19 Employees of XYZ do not give you personal attention. (-)

P20 Employees of XYZ do not know what your needs are. $(-)$

P21 XYZ does not have your best interests at heart. (-)

P22 XYZ does not have operating hours convenient to all their customers. (-)

Source: Parasuraman et al. (1988, 38-40). 


\title{
Appendix II \\ Modified SERVQUAL Instrument
}

\author{
Expectations
}

\section{Directions}

Based on your experiences as a customer of telephone repair services, please think about the kind of telephone company that would deliver excellent quality of repair service. Think about the kind of telephone company with which you would be pleased to do business. Please show the extent to which you think such a telephone company would possess the feature described by each statement. If you feel a feature is not at all essential for excellent telephone companies such as the one you have in mind, circle the number "I". If you feel a feature is absolutely essential for excellent telephone companies, circle "7". If your feelings are less strong, circle one of the numbers in the middle. There are no right or wrong answers - all we are interested in is a number that truly reflects your feelings regarding telephone companies that would deliver excellent quality of service.

Note: Each of the statements was accompanies by a 7-point scale anchored at the ends by the labels "Strongly" Disagree" (=1) and "Strongly Agree" (=7). Intermediate scale points were not labeled. Also, the headings (TANGIBLES, RELIABILITY, etc.), shown here to indicate which statements fall under each dimension, were not included in the actual questionnaire.

\section{TANGIBLES}

E1 Excellent telephone companies will have modern-looking equipment.

E2 The physical facilities at excellent telephone companies will be visually appealing.

E3 Employees of excellent telephone companies will be neat-appearing.

E4 Materials associated with the service (such as pamphlets or statements) will be visually appealing in an excellent telephone company.

\section{RELIABILITY}

E5 When excellent telephone companies promise to do something by a certain time, they will do so.

E6 When customers have a problem, excellent telephone companies will show a sincere interest in solving it.

E7 Excellent telephone companies will perform the service right the first time.

E8 Excellent telephone companies will provide their services at the time they promise to do so.

E9 Excellent telephone companies will insist on error-free records.

\section{RESPONSIVENESS}

E10 Employees of excellent telephone companies will tell customers exactly when services will be performed.

E11 Employees of excellent telephone companies will give prompt service to customers.

E12 Employees of excellent telephone companies will always be willing to help customers.

E13 Employees of excellent telephone companies will never be too busy to respond to customer requests.

ASSURANCE

E14 The behavior of employees of excellent telephone companies will instill confidence in customers.

E15 Customers of excellent telephone companies will feel safe in their transactions.

E16 Employees of excellent telephone companies will be consistently courteous with customers.

E17 Employees of excellent telephone companies will have the knowledge to answer customer questions.

\section{EMPATHY}

E18 Excellent telephone companies will give customers individual attention.

E19 Excellent telephone companies will have operating hours convenient to all their customers.

E20 Excellent telephone companies will have employees who give customers personal attention.

E21 Excellent telephone companies will have the customers' best interests at heart.

E22 The employees of excellent telephone companies will understand the specific needs of their customers. 


\section{Perceptions}

\section{Directions}

The following set of statements relate to your feelings about XYZ Telephone Company's repair service. For each statement, please show the extent to which you believe $X Y Z$ has the feature described by the statement. Once again, circling a " $I$ " means that you strongly disagree that XYZ has that feature, and circling a "7"means that you strongly agree. You may circle any of the numbers in the middle that show how strong your feelings are. There are no right or wrong answers - all we are interested in is a number that best shows your perceptions about XYZ's repair service.

\section{TANGIBLES}

P1 XYZ has modern-looking equipment.

P2 XYZ's physical facilities are visually appealing.

P3 XYZ's employees are neat-appearing.

P4 Materials associated with the service (such as pamphlets or statements) are visually appealing at XYZ.

\section{RELIABILITY}

P5 When XYZ promises to do something by a certain time, it does so.

P6 When you have a problem, XYZ shows a sincere interest in solving it.

P7 XYZ performs the service right the first time.

P8 $\quad X Y Z$ provides its services at the time it promises to do so.

P9 XYZ insists on error-free records.

\section{RESPONSIVENESS}

P10 Employees of XYZ tell you exactly when services will be performed.

P11 Employees of $X Y Z$ give you prompt service.

P12 Employees of XYZ are always willing to help you.

P13 Employees of XYZ are never too busy to respond to your requests.

\section{ASSURANCE}

P14 The behavior of employees of XYZ instills confidence in customers.

P15 You feel safe in your transactions with XYZ.

P16 Employees of $X Y Z$ are consistently courteous with you.

P17 Employees of XYZ have the knowledge to answer your questions.

\section{EMPATHY}

P18 XYZ gives you individual attention.

P19 XYZ has operating hours convenient to all its customers.

P20 XYZ has employees who give you personal attention.

P21 XYZ has your best interests at heart.

P22 Employees of XYZ understand your specific needs. 


\section{Appendix III \\ Behavioral Intentions Battery}

WORD-OF-MOUTH COMMUNICATIONS

1. Say positive things about $X Y Z$ to other people

2. Recommend $\mathrm{XYZ}$ to someone who seeks your advice

3. Encourage friends and relatives to do business with $\mathrm{XYZ}$.

PURCHASE INTENTIONS

4. Consider $\mathrm{XYZ}$ your first choice to buy ... services.

5. Do more business with $\mathrm{XYZ}$ in the next few years.

6. Do less business with $\mathrm{XYZ}$ in the next few years.

PRICE SENSITIVITY

7. Take some of your business to a competitor that offers more attractive prices.

8. Continue to do business to a competitor that offers more attractive prices.

9. Pay a higher price than competitors charge for the benefits you currently receive from XYZ.

COMPLAINING BEHAVIOR

10. Switch to a competitor if you experience a problem with XYZ's service.

11. Complain to other consumers if you experience a problem with XYZ's service.

12. Complain to external agencies, such as the Better Business Bureau, if you experience a problem with XYZ's service.

13. Complain to XYZ's employees if you experience a problem with XYZ's service.

Adapted from: Zeithaml et al. $(1996,38)$. 


\section{Appendix IV \\ Measures for Extended Model of Service Quality}

Gap 2

\section{Directions}

Listed below are statements summarizing five features concerning various aspects of a telephone company's performance with customers. We want to know the extent to which your company has standards that cover the ways these aspects are delivered. If you have no company standards to cover a statement circle I. If you have company standards that cover all aspects of the statement, circle 7. Circle the number between 1 and 7 that best describes the extent to which your company has performance standards for the aspects mentioned in each statement.

1.

2. The ability of the company to perform the promised service dependably and accurately.

3. The willingness of the company to help customers and provide prompt service.

4. The knowledge and courtesy of the company's employees and their ability to convey trust and confidence

5. The caring, individualized attention the company provides its customers

\section{Directions}

Performance standards in companies can be formal ... written, explicit, and communicated to employees. They can also be informal -.- verbal, implicit, and assumed to be understood by employees. Circle the number that best describes the extent to which performance standards are formalized in your company. If there are no standards in your company, check the appropriate box.

1. The appearance of the company's physical facilities, equipment, personnel, and communication materials.

2. The ability of the company to perform the promised service dependably and accurately.

3. The willingness of the company to help customers and provide prompt service.

4. The knowledge and courtesy of the company's employees and their ability to convey trust and confidence.

5. The caring, individualized attention the company provides its customers.

Note: As implied above, two facets of Gap 2 were measured ... extent to which standards existed and the degree of formality of those standards. The sum of the two facets was employed as an overall measure of Gap 2.

\section{Gap 3}

\section{Directions}

Listed below are the same five statements concerning a company's performance. Employees and units sometimes experience difficulty in achieving the standards established for them. For each statement below, circle the number that best represents the degree to which your branch or organizational unit and its employees are able to meet the performance standards established. Remember, there are no right or wrong answers ... we need your candid assessments for this question to be helpful.

1. The appearance of the company's physical facilities, equipment, personnel, and communication materials.

2. The ability of the company to perform the promised service dependably and accurately.

3. The willingness of the company to help customers and provide prompt service.

4. The knowledge and courtesy of the company's employees and their ability to convey trust and confidence.

5. The caring, individualized attention the company provides its customers. 


\section{Gap 4}

\section{Directions}

Advertising and salespeople often make promises about the level of service a company will deliver. In some organizations, it is not always possible to fulfill these promises. Circle the number that best describes your perception of how well these promises are fulfilled by your company.

1. The appearance of the company's physical facilities, equipment, personnel, and communication materials.

2. The ability of the company to perform the promised service dependably and accurately.

3. The willingness of the company to help customers and provide prompt service.

4. The knowledge and courtesy of the company's employees and their ability to convey trust and confidence.

5. The caring, individualized attention the company provides its customers.

\section{Antecedents to Internal Gaps}

\section{Directions}

Listed below are a number of statements intended to measure your perceptions about your company and its operations. Please indicate the extent to which you disagree of agree with each statement by circling one of the seven numbers next to each statement. If you strongly disagree, circle 1. If you strongly agree, circle 7. If your feelings are not so strong, circle one of the numbers in the middle. There are no right or wrong answers. Please tell us honestly how you feel.

Note: Each of the statements was accompanied by a seven-point scale anchored at the ends by the labels Strongly disagree $(=1)$ and Strongly Agree $(=7)$. Intermediate scale points were not labeled.

\section{CONSTRUCTS INFLUENCING GAP 1}

\section{MARKETING RESEARCH ORIENTATION (MRO)}

MRO1 We regularly collect information about the needs or our customers.

MRO2 We rarely use marketing research information that is collected about our customers. (-)

MRO3 We regularly collect information about the service quality expectations of our customers.

MRO4 The managers in our company rarely interact with customers. (-)

\section{UPWARD COMMUNICATION (UC)}

UC1 The customer contact personnel in our company frequently communicate with management.

UC2 Managers in our company rarely seek suggestions about serving the customer contact personnel. ()

UC3 The managers in our company frequently have face to face interactions with customer contact personnel.

UC4 The primary means of communication in our company between contact personnel and upper level managers is through memos. (-)

LEVELS OF MANAGEMENT (LOM)

LOM1 Our company has too many levels of management between contact personnel and top management.

\section{CONSTRUCTS INFLUENCING GAP 2}

\section{MANAGEMENT COMMITMENT TO SERVICE QUALITY (MCSQ)}

MCSQ1 Our company does not commit the necessary resources for service quality. (-)

MCSQ2 Our company has internal programs for improving the quality of service to customers.

MCSQ3 In our company, managers who improve quality of service are more likely to be rewarded than other managers.

MCSQ4 Our company emphasizes selling as much as or more than it emphasizes serving customers. (-)

GOAL SETTING (GS)

GS1 Our company has a formal process for setting quality of service goals for employees.

GS2 In our company, we try to set specific quality of service goals.

TASK STANDARDIZATION (TS)

TS1 Our company effectively uses automation to achieve consistency in serving customers.

TS2 Programs are in place in our company to improve operating procedures so as to provide consistent service.

\section{PERCEPTION OF FEASIBILITY (POF)}

POF1 Our company has the necessary capabilities to meet customer requirements for service.

POF2 If we gave our customers the level of service the really want, we would go broke. (-)

POF3 Our company has the operating systems to deliver the level of service customers demand. 


\section{CONSTRUCTS INFLUENCING GAP 3}

\section{TEAMWORK (TEAM)}

TEAM1 I feel that I am part of a team in my branch or organizational unit.

TEAM2 Everyone in my branch or organizational unit contributes to a team effort in servicing customers.

TEAM3 I feel a sense of responsibility to help my fellow employees do their jobs well.

TEAM4 My fellow employees an I cooperate more often than we compete.

TEAM5 I feel that I am an important member of this company.

\section{EMPLOYEE-JOB FIT (EFIT)}

EFIT1 I feel comfortable in my job in the sense that I am able to perform the job well.

EFIT2 My company hires people who are qualified to do their jobs.

TECHNOLOGY-JOB FIT (TFIT)

TFIT1 My company gives me the tools and equipment that I need to perform my job well.

PERCEIVED CONTROL (PC)

PC1 I spend a lot of time in my job trying to resolve problems over which I have little control. (-)

PC2 I have the freedom in my job to truly satisfy my customers'needs.

PC3 I sometimes feel a lack of control over my job because too many customers demand service at the same time. (-)

PC4 One of my frustrations on the job is that I sometimes have to depend on other employees in serving my customers. (-)

\section{SUPERVISORY CONTROL SYSTEMS (SCS)}

SCS1 My supervisor's appraisal of my job performance includes how well I interact with customers.

SCS2 In our company, making a special effort to serve customers well does not result in more pay or recognition. (-)

SCS3 In our company, employees who do the best job serving their customers are more likely to be rewarded than other employees.

\section{ROLE CONFLICT (RC)}

RC1 The amount of paperwork in my job makes it hard for me to effectively serve my customers.

RC2 Our company places so much emphasis on selling to customers that it is difficult to serve customers properly.

RC3 What my customers want me to do and what management wants me to do are usually the same thing. (-)

RC4 My company and I have the same ideas about how my job should be performed.

ROLE AMBIGUITY (RA)

RA1 I receive a sufficient amount of information from management concerning what I am supposed to do in my job. $(-)$

RA2 I often feel that I do not understand the services offered by my company.

RA3 I am able to keep up with changes in my company that affect my job. (-)

RA4 I feel that I have not been well trained by the company in how to interact effectively with customers.

RA5 I am not sure what aspects of my job my supervisor will stress most in evaluating my performance.

\section{CONSTRUCTS INFLUENCING GAP 4}

\section{HORIZONTAL COMMUNICATION (HC)}

HC1 The people who develop our advertising consult employees like me about the realism of promises made in the advertising.

HC2 I am not aware in advance of the promises made in the company's advertising campaigns. (-)

HC3 Employees like me interact with operations people to discuss the level of service the company can deliver to customers.

HC4 The company's policies on serving customers are consistent in the different offices that service customers.

PROPENSITY TO OVERPROMISE (PTO)

PTO1 Intense competition is creating more pressure inside this company to generate new business.

PTO2 Our key competitors make promises the cannot possibly keep in an effort to gain new customers. 


\section{Appendix V \\ Measurements Scales Used in Empirical Study Chapter 5}

\begin{tabular}{|c|c|c|}
\hline Construct & Item & \\
\hline \multirow[t]{6}{*}{ Formalization } & 1. & $\begin{array}{l}\text { If a written rule does not cover some situation, we make up } \\
\text { informal rules as we go along. (-) }\end{array}$ \\
\hline & 2. & $\begin{array}{l}\text { There are many things in my business that are not covered by } \\
\text { some formal procedure for doing it. }(-)\end{array}$ \\
\hline & 3. & $\begin{array}{l}\text { Usually, my contact with my company and its representatives } \\
\text { involves doing things "by the rule book". }\end{array}$ \\
\hline & 4. & $\begin{array}{l}\text { Contact with my company and its representatives are on a formal } \\
\text { preplanned basis. }\end{array}$ \\
\hline & 5. & $\begin{array}{l}\text { I ignore the rules and reach informal agreements to handle some } \\
\text { situations. (-) }\end{array}$ \\
\hline & 6. & $\begin{array}{l}\text { When rules and procedures exist in my company they are usually } \\
\text { written agreements. }\end{array}$ \\
\hline
\end{tabular}

Source: Ferrell \& Skinner (1987)

\begin{tabular}{lll}
\hline $\begin{array}{l}\text { Empowerment } \\
\text { Competence }\end{array}$ & 1. & $\begin{array}{l}\text { I permit employees to use their own judgment in solving } \\
\text { problems. }\end{array}$ \\
& 2. & $\begin{array}{l}\text { I encourage initiative in my employees. } \\
\text { Source: Hartline \& Ferrell (1993) }\end{array}$ \\
3. & I allow employees a high degree of initiative. & I trust employees to exercise good judgment.
\end{tabular}

\begin{tabular}{lll}
\hline Empowerment & 1. & I allow employees complete freedom in their work. \\
Autonomy & 2. & I let employees do their work the way they think best. \\
& 3. & I assign tasks, then let employees handle them. \\
& 4. & I turn employees loose on a job, and let them go to it. \\
5. & I permit employees to set their own work pace.
\end{tabular}

Source: Hartline \& Ferrell (1993)

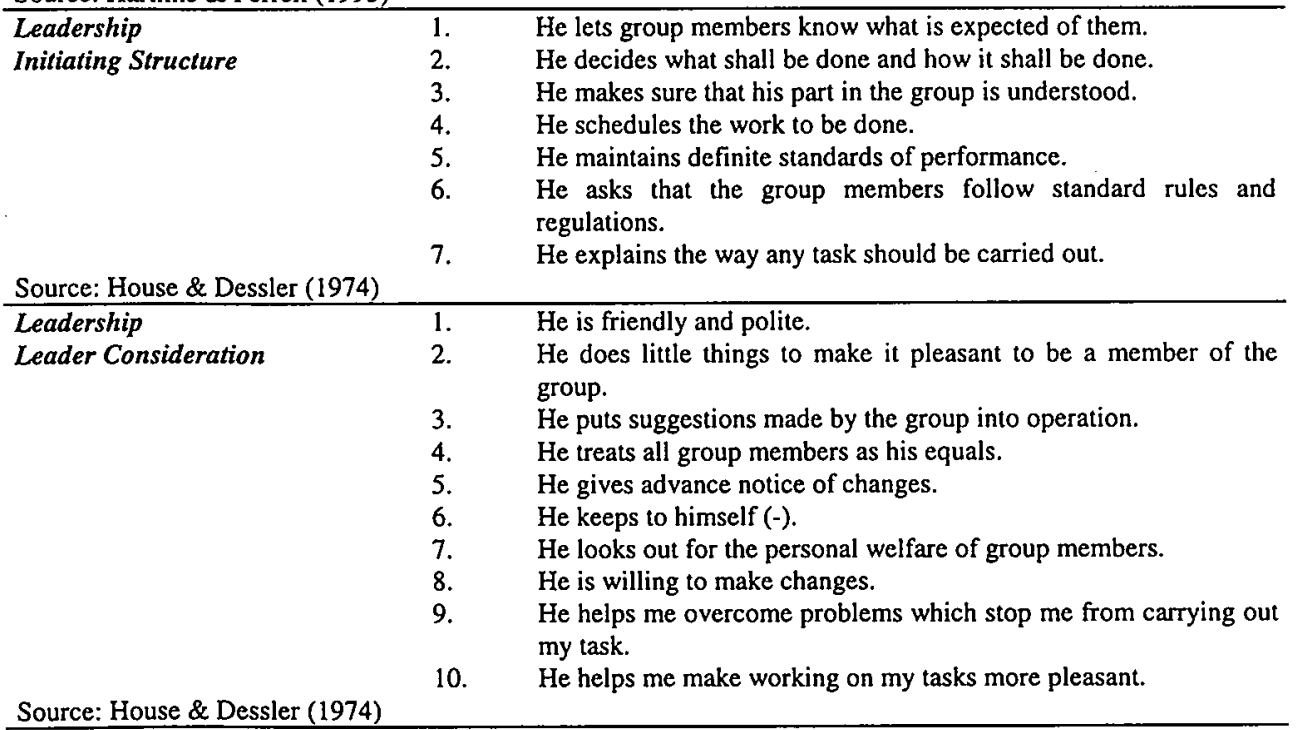




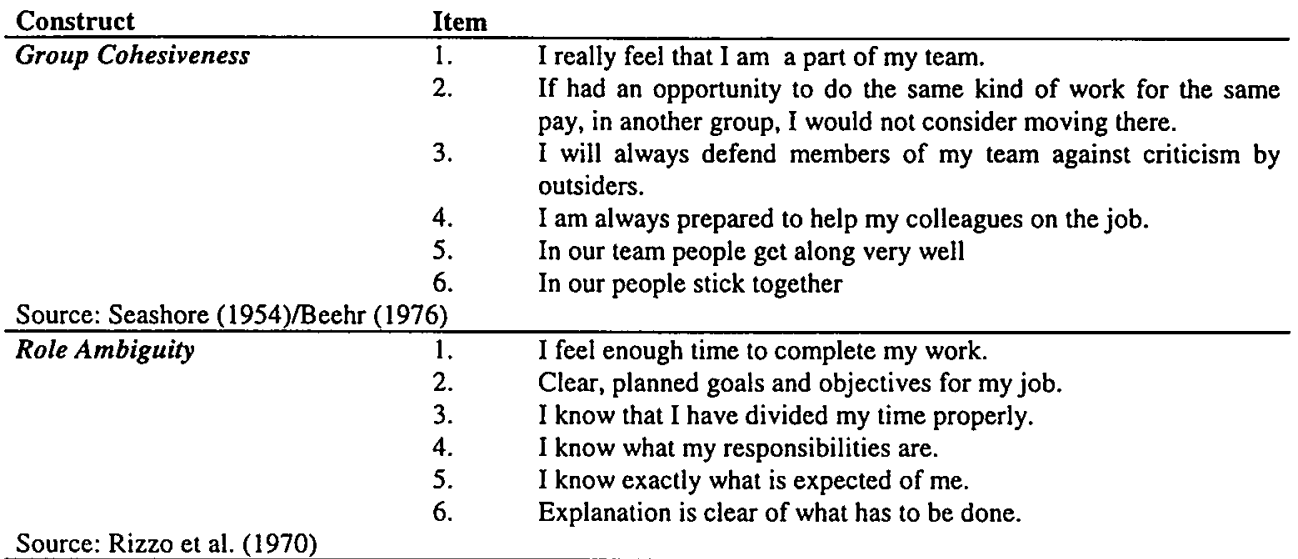

\begin{tabular}{lll}
\hline Role Conflict & 1. & I have to do things that should be done differently. \\
2. & I receive an assignment without the manpower to complete it. \\
3. & I have to buck a rule or policy in order to carry out an assignment. \\
4. & I work with two or more groups who operate quite differently. \\
5. & I receive incompatible requests from two of more people. \\
6. & $\begin{array}{l}\text { I do things that are apt to be accepted by one person and not } \\
\text { accepted by other. }\end{array}$ \\
7. & $\begin{array}{l}\text { I receive an assignment without adequate resources and materials } \\
\text { to execute it. }\end{array}$ \\
Source: Rizzo et al. (1970) & 8. & I work on unnecessary things.
\end{tabular}

\begin{tabular}{lll}
\hline Job Satisfaction & 1. & Your overall job. \\
2. & Your fellow workers. \\
3. & Your supervisor (s). \\
4. & Your organization's policies. \\
5. & The support provided by your organization. \\
6. & Your salary or wages. \\
7. & Your opportunities for advancement with this organization. \\
8. & Your organization's customers.
\end{tabular}

Source: Churchill et al. (1974)

\begin{tabular}{lll}
\hline Technical Quality & 1. & Quality of $A B C$ machines.. \\
& 2. & Quality of $A B C$ replacement parts. \\
3. & On time delivery of $A B C$ machines. \\
& 4. & Failure frequency of $A B C$ machines.
\end{tabular}

Source: Instrument developed for this study

\begin{tabular}{|c|c|c|}
\hline 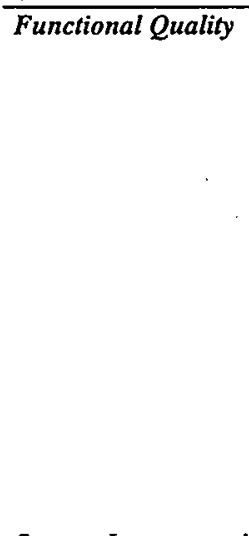 & $\begin{array}{l}2 . \\
3 . \\
4 . \\
5 . \\
6 . \\
7 . \\
8 . \\
9 \\
10 . \\
11 . \\
12 . \\
13 .\end{array}$ & $\begin{array}{l}\text { Accessibility by phone of } A B C \text { planning department in case of } \\
\text { failure. } \\
\text { Understanding for the problem by } A B C \text { planning employee. } \\
\text { Knowledge of the problem by the } A B C \text { planning employee. } \\
\text { Adherence to made by the } A B C \text { planning employee. } \\
\text { Phone support by the } A B C \text { planning employee } \\
\text { Time needed to for the } A B C \text { service engineer to arrive. } \\
\text { Time needed to take care of the service failure by the } A B C \text { service } \\
\text { engineer. } \\
\text { Competence of the } A B C \text { service engineer. } \\
\text { Explaining the nature of the repairs needed by the } A B C \text { service } \\
\text { engineer } \\
\text { Availability of replacement parts for } A B C \text { machine. } \\
\text { The ABC service engineer arrived on the agreed time. } \\
\text { Attitude of the } A B C \text { clerical employee over the phone. } \\
\text { Timely delivery of } A B C \text { supplies }\end{array}$ \\
\hline
\end{tabular}




\section{Appendix VI \\ Detailed Results of Confirmatory Factor Analyses for Cross- Sectional Study}

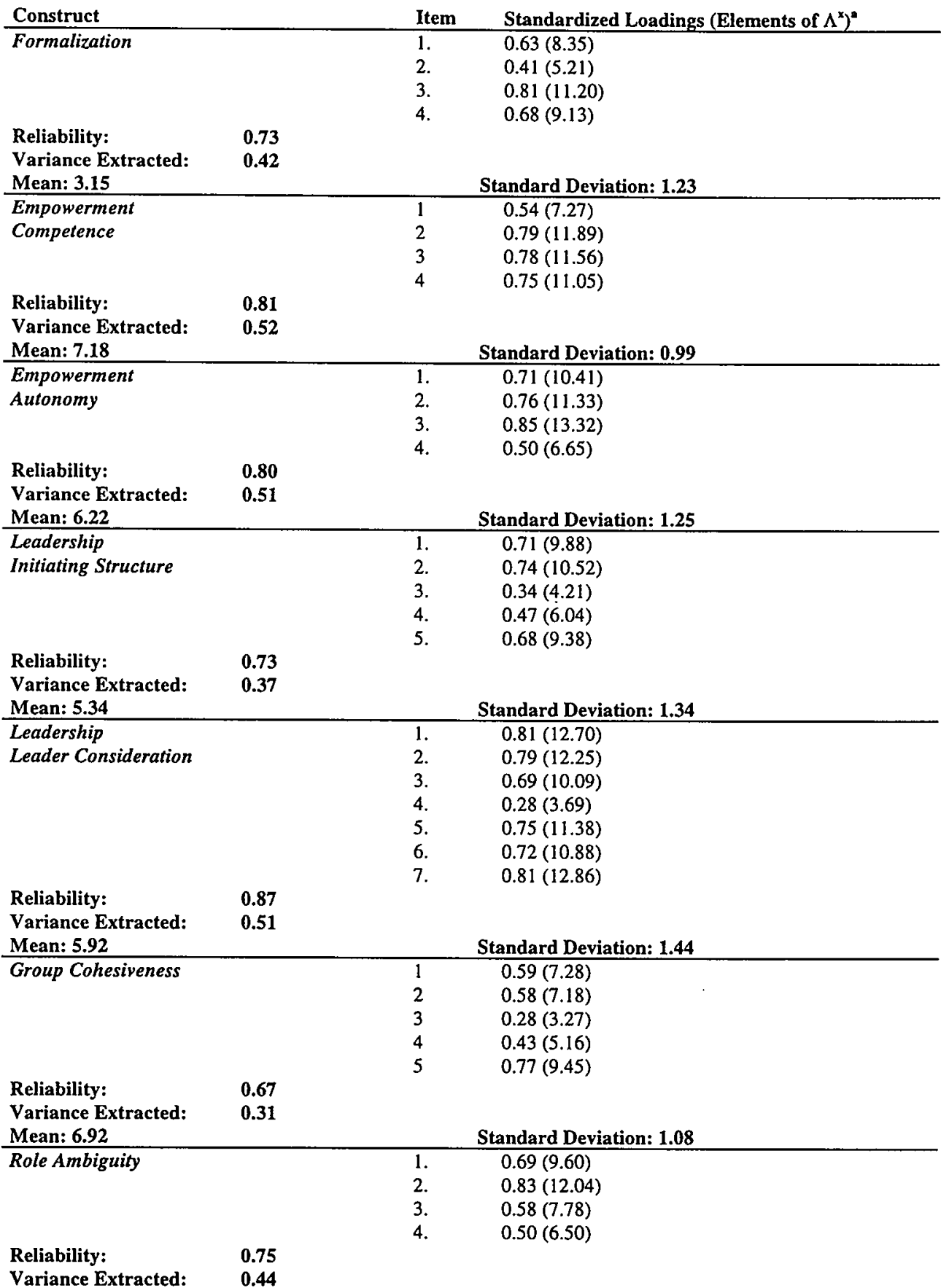

Mean: 3.62

Standard Deviation: 1.18 


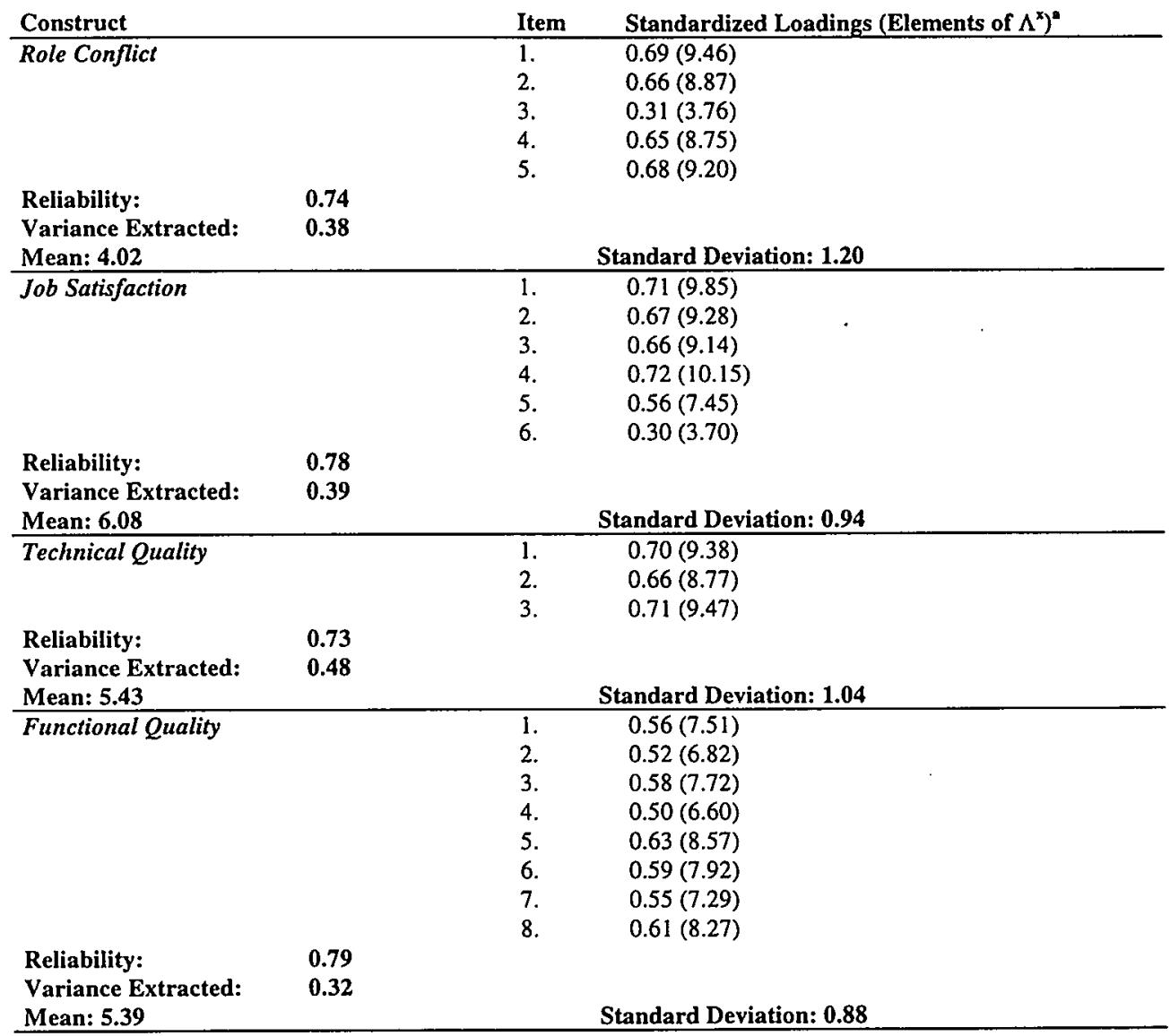




\section{Appendix VII \\ Measurement Scales Used in Empirical Study Chapter 6}

\begin{tabular}{lll} 
Construct & Item & \\
\hline Technical Quality & 1. & Quality of $\mathrm{ABC}$ machines.. \\
& 2. & Quality of $\mathrm{ABC}$ replacement parts. \\
& 3. & On time delivery of $\mathrm{ABC}$ machines. \\
& 4. & Failure frequency of $\mathrm{ABC}$ machines.
\end{tabular}

Source: Instrument developed for this study

\begin{tabular}{|c|c|c|}
\hline Functional Quality & $\begin{array}{l}2 . \\
3 . \\
4 . \\
5 . \\
6 . \\
7 . \\
\\
8 . \\
9 . \\
10 . \\
11 . \\
12 . \\
13 .\end{array}$ & $\begin{array}{l}\text { Accessibility by phone of } A B C \text { planning department in case } \\
\text { of failure. } \\
\text { Understanding for the problem by } A B C \text { planning employee. } \\
\text { Knowledge of the problem by the } A B C \text { planning employee. } \\
\text { Adherence to made by the } A B C \text { planning employee. } \\
\text { Phone support by the } A B C \text { planning employee } \\
\text { Time needed to for the } A B C \text { service engineer to arrive. } \\
\text { Time needed to take care of the service failure by the } A B C \\
\text { service engineer. } \\
\text { Competence of the } A B C \text { service engineer. } \\
\text { Explaining the nature of the repairs needed by the } A B C \\
\text { service engineer } \\
\text { Availability of replacement parts for } A B C \text { machine. } \\
\text { The ABC service engineer arrived on the agreed time. } \\
\text { Attitude of the } A B C \text { clerical employee over the phone. } \\
\text { Timely delivery of } A B C \text { supplies }\end{array}$ \\
\hline
\end{tabular}

Source: Instrument developed for this study

Satisfaction 1.

Source: --

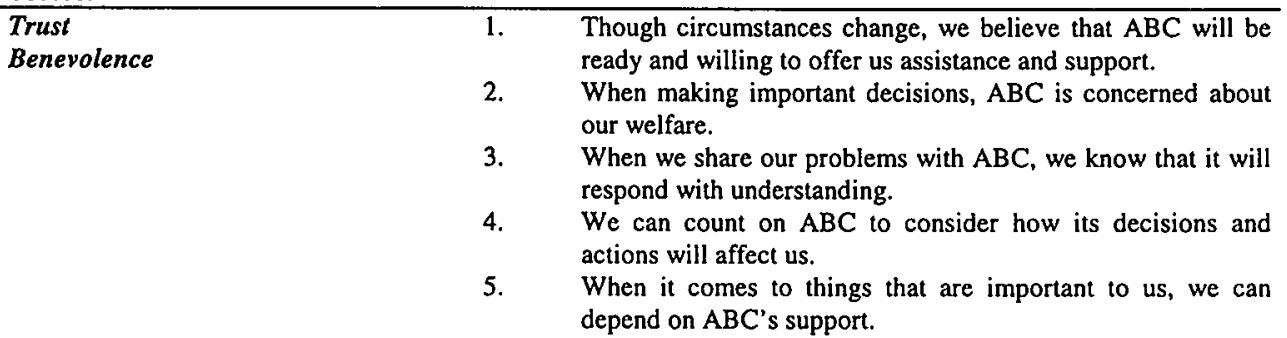

Source: Kumar et al (1995)

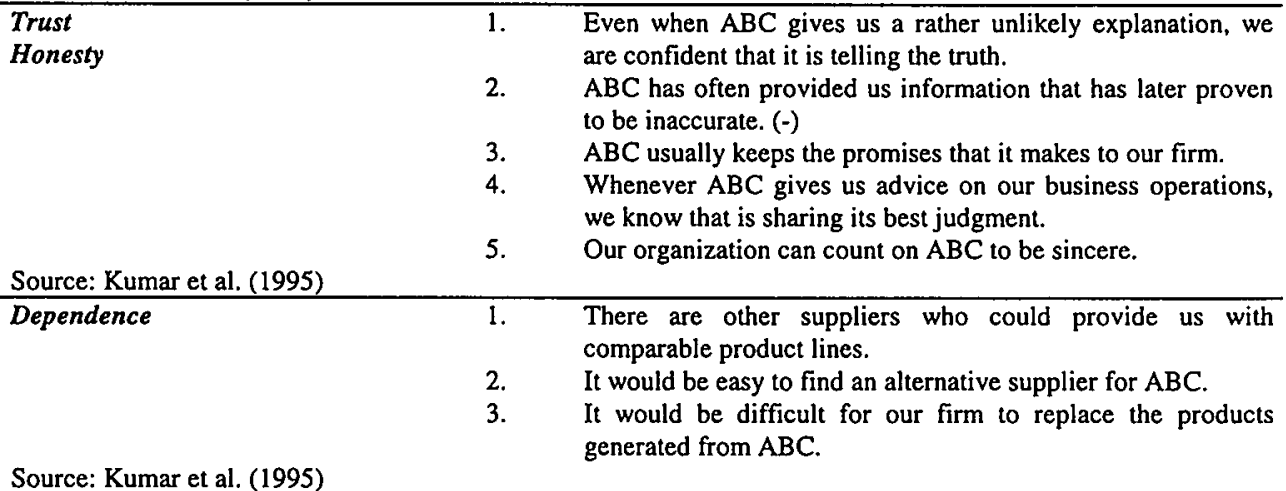




\begin{tabular}{|c|c|c|}
\hline Construct & Item & \\
\hline \multirow[t]{4}{*}{ Affective Commitment } & 1. & $\begin{array}{l}\text { It is pleasant working with } A B C \text {; that's why we continue to } \\
\text { represent them. }\end{array}$ \\
\hline & 2. & $\begin{array}{l}\text { We want to remain a member of the } A B C \text { customer network, } \\
\text { because we genuinely enjoy our relationship with } A B C \text {. }\end{array}$ \\
\hline & 3. & $\begin{array}{l}\text { Our decision to remain a } A B C \text { customer is based on our } \\
\text { attraction to the things } A B C \text { stands for as a company. }\end{array}$ \\
\hline & 4. & $\begin{array}{l}\text { We like working with } A B C \text {, and want to remain a } A B C \\
\text { customer. }\end{array}$ \\
\hline \multicolumn{3}{|l|}{ Source: Kumar et al. (1994) } \\
\hline \multirow[t]{4}{*}{ Calculative Commitment } & 1. & $\begin{array}{l}\text { There is just too much time, energy, and expense involved in } \\
\text { switching to another supplier, that is why we stay with ABC. }\end{array}$ \\
\hline & 2. & $\begin{array}{l}\text { Right now, staying with } A B C \text { is a matter of necessity since no } \\
\text { feasible alternative exists. }\end{array}$ \\
\hline & 3. & $\begin{array}{l}\text { It would be hard for us to transfer the investments we have } \\
\text { made in support of } A B C \text { to another supplier, so we continue } \\
\text { to represent them. }\end{array}$ \\
\hline & 4. & $\begin{array}{l}\text { It is too difficult to switch to another supplier because of the } \\
\text { lack of good alternatives; therefore we stay with ABC; } \\
\text { otherwise, we'd consider leaving. }\end{array}$ \\
\hline \multicolumn{3}{|l|}{ Source: Kumar et al. (1994) } \\
\hline \multirow[t]{3}{*}{ Intention to Stay } & 1. & $\begin{array}{l}\text { The renewal of our relationship with } \mathrm{ABC} \text { is virtually } \\
\text { automatic. }\end{array}$ \\
\hline & 2. & $\begin{array}{l}\text { Considering all the benefits and drawbacks, we feel that we } \\
\text { will still be a } A B C \text { customer in two years. }\end{array}$ \\
\hline & 3. & $\begin{array}{l}\text { It is highly unlikely that we will want to terminate our } \\
\text { relationship with } A B C \text { in the next } x \text { years. }\end{array}$ \\
\hline
\end{tabular}

Source: Kumar et al. (1995) 


\section{Appendix VIII \\ Detailed Results of Confirmatory Factor Analyses}

Construct

Technical Quality

Item Standardized Loadings (Elements of $\left.\Lambda^{x}\right)^{a}$

$1 . \quad 0.85(23.66)$

2. $\quad 0.95(25.24)$

3. $\quad 0.61(15.36)$

Reliability: $\quad 0.84$

Variance Extracted: $\quad 0.63$

Mean: 5.77

Standard Deviation: 1.21

Functional Quality

Reliability: $\quad 0.91$

$\begin{array}{ll}1 . & 0.66(17.34) \\ 2 . & 0.76(20.95)\end{array}$

3. $\quad 0.81(22.67)$

4. $\quad 0.71(18.87)$

5. $\quad 0.70(18.71)$

6. $\quad 0.66(17.26)$

$7 . \quad 0.75(20.26)$

$8 . \quad 0.74(20.18)$

9. $\quad 0.67(17.53)$

Variance Extracted: $\quad 0.52$

Mean: 6.18

Standard Deviation: 1.12

Customer Satisfaction ${ }^{b}$

Mean: 7.35

Trust

Benevolence

Standard Deviation: 1.15

$\begin{array}{ll}1 . & 0.80(22.53) \\ 2 . & 0.78(21.70) \\ \text { 3. } & 0.78(21.63) \\ \text { 4. } & 0.80(22.45) \\ \text { 5. } & 0.88(26.24)\end{array}$

Reliability: $\quad 0.92$

Variance Extracted: $\quad \mathbf{0 . 7 0}$

Mean: 6.07

Trust

Standard Deviation: 1.40

Honesty

1. $\quad 0.37(8.54)$

2. $\quad 0.68(17.69)$

3. $\quad 0.70(18.33)$

4. $\quad 0.86(24.16)$

Reliability: $\quad 0.80$

Variance Extracted: $\quad 0.51$

Mean: 6.82

Standard Deviation: 1.22

Dependence

$1 . \quad 0.72(11.83)$

2. $0.85(12.73)$

Reliability:

0.80

Variance Extracted: $\quad 0.53$

Mean: 4.13

Standard Deviation: 1.43

Affective Commitment

$0.90(27.24)$

2. $0.91(27.95)$

3. $\quad 0.80(22.85)$

4. $\quad 0.89(27.07)$

Reliability: $\quad 0.95$

Variance Extracted: $\quad \mathbf{0 . 8 3}$

Mean: 6.29

Calculative Commitment

Standard Deviation: 1.48

$\begin{array}{ll}1 . & 0.60(14.66) \\ 2 . & 0.85(23.16) \\ 3 . & 0.73(18.91) \\ 4 . & 0.78(20.65)\end{array}$

Reliability: $\quad 0.87$

Variance Extracted: $\quad 0.64$ 


\begin{tabular}{llll} 
Construct & & Item & Standardized Loadings (Elements of $\left.\Lambda^{\boldsymbol{x}}\right)^{\mathbf{2}}$ \\
\hline Intention to Stay & & 1. & $0.64(15.55)$ \\
& & 2. & $0.86(22.24)$ \\
& 3. & $0.59(14.14)$ \\
Reliability: & $\mathbf{0 . 7 7}$ & & \\
Variance Extracted: & $\mathbf{0 . 5 2}$ & & \\
Mean: 6.18 & & & Standard Deviation: 1.54 \\
\hline
\end{tabular}

a Corresponding t values between brackets.

b Single item measure with reliability set at 0.95 . 


\section{Nederlandse Samenvatting}

Het toegenomen belang van de dienstverlenende sector uit zich zowel op nationaal als op wereldwijd niveau. Twee disciplines hebben zich met name beziggehouden met het management van dienstverlenende organisaties: (1) marketing en (2) organisatie theorie. Het perspectief van beide disciplines is verschillend. Marketing richt zich met name op de klant (c.q. consument), terwijl de organisatie theorie zich met name richt op de medewerker (c.q. organisatie). Deze verschillende perspectieven bieden een snijvlak in de vorm van de service encounter. De service encounter kan gedefinieerd worden als de tijdsspanne, in welke de klant direct interacteert met de dienstverlenende organisatie.

De essentie van de service encounter wordt in de meeste diensten nog gevormd door de interactie tussen de dienstverlener in de eerste lijn en de klant (c.q. consument). Marketing richtte zich tot op heden voornamelijk op het conceptualiseren en het meten van kwaliteit van de dienstverlening (en daarmee samenhangend klanttevredenheid). Verder is men zich gaan realiseren, dat het onderhouden van lange termijn relaties zowel voordelen oplevert voor de klant als ook voor dienstverlenende organisatie. De bijdrage van de organisatie theorie komt met name voort uit systeemtheorie en de daaruit voortvloeiende boundary spanning activities. Deze boundary spanning activities worden in dienstverlenende organisatie voornamelijk door dienstverleners in de eerste lijn uitgevoerd. Met name role stress is voor dienstverleners in de eerste lijn een belangrijke belemmerende factor voor een goed functioneren. Verder blijkt, dat met name job satisfaction (tevredenheid van de medewerker met zijn functie) en job performance (prestatie van de medewerker in zijn functie) negatief beïnvloed worden door role stress. Job performance zal in deze dissertatie geoperationaliseerd worden als subjectieve maatstaf, namelijk kwaliteit van de dienstverlening zoals gepercipieerde door de dienstverlener in de eerste lijn.

Deze dissertatie kent twee onderzoeksvragen. De eerste onderzoeksvraag richt zich op de organisatie factoren die prestaties van dienstverleners in de eerste lijn beïnvloeden. Het zijn met name de dienstverleners in de eerste lijn, die essentieel zijn voor het succes van dienstverlenende organisaties. De eerste onderzoeksvraag luidt derhalve:

Onderzoeksvraag 1:

\section{Welke organisatie factoren beïvloeden de prestatie van dienstverleners in de eerste lijn?}

Hoewel verschillende onderzoekers aangeven, dat er een positieve relatie bestaat tussen kwaliteit en winstgevendheid, is er nog steeds geen duidelijk beeld hoe deze relatie precies tot stand komt. Onlangs werd voorgesteld, dat het onderhouden van lange termijn relaties een verklarende factor voor het positieve verband tussen kwaliteit en winstgevendheid zou kunnen zijn. Hiernaar wordt in het algemeen verwezen als het relatieparadigma. De tweede onderzoeksvraag luidt derhalve:

Onderzoeksvraag 2:

Hoe kan het concept kwaliteit van de dienstverlening gerelateerd worden aan het relatieparadigma? Hoe beinvloedt kwaliteit van de dienstverlening de intentie om klant te blijven in een lange termijn relatie?

Onderzoeksvraag 1 komt conceptueel aan de orde in hoofdstuk 3 en de resultaten van het bijbehorende empirische onderzoek worden in hoofdstuk 5 gerapporteerd. Onderzoeksvraag 2 
wordt conceptueel in hoofdstuk 4 behandeld en het bijbehorende empirisch onderzoek wordt in hoofdstuk 6 gepresenteerd. Uit bovenstaande onderzoeksvragen blijkt, dat kwaliteit van de dienstverlening de verbindende schakel vormt tussen beide onderzoeksvragen. In de eerste onderzoeksvraag fungeert kwaliteit van de dienstverlening in termen van job performance als resultaat, terwijl in de tweede onderzoeksvraag kwaliteit van de dienstverlening uit het perspectief van de klant als antecedent optreedt.

In hoofdstuk 2 van deze dissertatie zullen we dan ook eerst stilstaan bij kwaliteit van de dienstverlening als focal construct van deze dissertatie. In hoofdstuk 2 wordt na het bespreken van verschillende benaderingen van kwaliteit ingegaan op het concept kwaliteit van de dienstverlening. Deze benadering onderscheidt zich van andere benaderingen door als uitgangspunt de perceptie van de klant te kiezen. Deze definitie is het uitgangspunt voor het Conceptual Model of Service Quality. Op basis van dit model wordt kwaliteit van de dienstverlening geoperationaliseerd als een vergelijking tussen perceptie en verwachting. Het SERVQUAL meetinstrument werd ontwikkeld aan de hand van deze conceptualisatie. Het meetinstrument heeft verschillende modificaties ondergaan. Deze modificaties hebben met name betrekking op de verwachtingscomponent van het instrument en het toevoegen van een wegingsfactor. SERVQUAL kent zowel conceptuele als operationele tekortkomingen. De conceptuele tekortkomingen liggen voornamelijk op het gebied van construct validity, met name het onderscheidend vermogen van kwaliteit van de dienstverlening en klanttevredenheid. Onlangs werd echter gesuggereerd, dat kwaliteit van de dienstverlening een antecedent vormt van klanttevredenheid. Hoewel ervan uitgegaan kan worden, dat kwaliteit van de dienstverlening uit meer dan één dimensie bestaat, is er geen consensus over het precieze aantal dimensies. Verder hebben een aantal auteurs ook het statische karakter van SERVQUAL aangekaart. Tenslotte vraagt de positieve relatie tussen kwaliteit van de dienstverlening en intenties duidelijk om een integratie met het relatieparadigma. Met betrekking tot de operationele tekortkomingen van SERVQUAL zien we, allereerst dat het blijkbaar moeilijk is om de resultaten van de originele onderzoeken te repliceren en dan met name de factorstructuur van het instrument. Introductie van wegingsfactoren heeft nauwelijks tot verbeteringen in het empirisch onderzoek geleid. Verder heeft met name het gebruik van verschilscores tot problemen veroorzaakt. Veelal wordt voorgesteld om dit verschil op één schaal te meten, de zogenaamde non-difference score.

In hoofdstuk 3 van de dissertatie wordt het conceptuele raamwerk voor de eerste onderzoeksvraag ontwikkeld. Eerder onderzoek aan de hand van het Extended Model of Service Quality werd gekenmerkt door een groot aantal conceptuele en operationele tekortkomingen. Conceptuele tekortkomingen hangen met name samen met de complexiteit van dit model. Ook is het model voornamelijk van diagnostische waarde. Verder veronderstelt het model, dat dienstverlenende organisaties formeel, mechanistisch en bureaucratisch werken. Ook is de relatie tussen de antecedenten en de interne gaps niet zonder problemen. De empirische onderzoeken laten zonder meer teleurstellende resultaten zien. De betrouwbaarheden van de antecedenten zijn laag en de interne gaps (GAP1-GAP4) vertonen geen significant effect op GAP5, kwaliteit van de dienstverlening.

Met dit model als uitgangspunt werd een alternatief model ontwikkeld. Centraal hierbij staat het concept role stress. Role stress bestaat uit twee componenten: (1) role ambiguity (onduidelijkheid over de te vervullen rol) en (2) role conflict (conflicten met betrekking tot de te vervullen rol; verschillende partijen hebben verschillende, vaak tegenstrijdige, wensen ten aanzien van de medewerker). De volgende vier constructen worden onderscheiden als antecedenten van role ambiguity en role conflict: (1) formalisatie, (2) empowerment, (3) leiderschap en (4) group cohesiveness. Als uitkomsten van role stress modeleren wij job satisfaction en job performance geoperationaliseerd als technische en functionele kwaliteit. Wat formalisatie betreft, verwachten we dat er een negatief verband tussen formalisatie en role 
ambiguity bestaat en een positief verband tussen formalisatie en role conflict. Empowerment, dat uit twee dimensies bestaat, autonomy (bevoegdheid om zelf beslissingen te nemen) en competence (deskundigheid), wordt verondersteld negatief samen te hangen met zowel role ambiguity als ook role conflict. Leiderschap bestaat eveneens uit twee dimensies, initiating structure (het scheppen van een kader/structuur, waarin de medewerker kan acteren) en leader consideration (aandacht voor de medewerker). We nemen aan, dat beide negatief samenhangen met role ambiguity en role conflict. Verder wordt verondersteld, dat group cohesiveness (samenhang van de groep/team) negatief samenhangt met role ambiguity en role conflict. Role ambiguity en role conflict worden vervolgens verondersteld een negatieve invloed op job satisfaction uit te oefenen. Tenslotte nemen wij aan, dat job satisfaction positief samenhangt met de twee componenten van job performance, technische kwaliteit (kwaliteit van het resultaat van de dienstverlening) en functionele kwaliteit (kwaliteit van het proces van de dienstverlening).

In hoofdstuk 4 van de dissertatie wordt het conceptuele raamwerk voor de tweede onderzoeksvraag ontwikkeld. Verschillende empirische studies hebben een positieve relatie tussen kwaliteit en winstgevendheid gevonden. Onlangs is meer zicht gekomen op het onderliggende mechanisme van deze relatie. Met name het positieve verband tussen kwaliteit en klanttevredenheid enerzijds, en loyaliteit anderzijds, speelt hierbij een prominente rol. Dit sluit nauw aan bij het zogenaamde relatieparadigma. Het relatieparadigma houdt in, dat het onderhouden van een lange termijn relatie zowel voordelen biedt voor de dienstverlener als ook voor de klant. Commitment of betrokkenheid is een van de belangrijke concepten in deze onderzoeksstroming. Met betrekking tot commitment worden twee dimensies onderscheiden: (1) affectief commitment (betrokkenheid op de basis van affect) en (2) calculatief commitment (betrokkenheid op basis van een afweging tussen baten en kosten). In ons conceptuele model onderscheiden we vier antecedenten van commitment: (1) kwaliteit van de dienstverlening, (2) klanttevredenheid, (3) vertouwen en (4) afhankelijkheid. In de eerste plaats veronderstellen we een positieve relatie van kwaliteit van de dienstverlening met klanttevredenheid. Vervolgens verwachten wij een positieve relatie tussen klanttevredenheid en affectief commitment en calculatief commitment. Vertrouwen, geoperationaliseerd aan de hand van de dimensies honesty (vertrouwen in eerlijkheid van de partner) en benevolence (vertrouwen in de welwillendheid van de partner) wordt ook verondersteld een positief verband te vertonen met beide commitment componenten. Voorts veronderstellen we, dat afhankelijkheid een negatief effect op affectief commitment heeft en een positief effect op calculatief commitment. Vervolgens verwachten wij, dat zowel affectief commitment als calculatief commitment een positief effect heeft op de intentie om loyaal aan de service organisatie te blijven. Tenslotte, veronderstellen we een direct positief effect van klanttevredenheid op de intentie om loyaal aan de service organisatie te blijven.

In hoofdstuk 5 worden de resultaten van het empirische onderzoek op basis van het coneeptuele model in hoofdstuk 3 beschreven. Het onderzoek vond plaats bij de after-sales service van een grote producent van kantoorapparatuur in Nederland. Ongeveer 250 service medewerkers namen deel aan het onderzoek. De psychometrische eigenschappen van de gebruikte meetinstrumenten werden allereerst onderzocht middels confirmatorische factoranalyse. Alle gebruikte meetinstrumenten vertonen gunstige psychometrische eigenschappen. Vervolgens werden de hypothesen getoetst middels structural equation modeling. Er werd in het empirisch onderzoek zowel gebruik gemaakt van een cross-sectionele als een longitudinale onderzoeksopzet met twee metingen of waves. De verschillen tussen beide waren verwaarloosbaar en zullen derhalve niet afzonderlijk besproken worden. De autonomy component van empowerment vertoont een negatief verband met zowel role ambiguity als ook role conflict. Verder vertoont autonomy een direct, positief verband met job satisfaction. Initiating structure, een dimensie van leiderschap, vertoont eveneens een negatief verband met role ambiguity. In de longitudinale opzet vinden we 
verder ook een positief verband van formalisatie met role conflict. Vervolgens is het role ambiguity, dat een sterk negatief verband met job satisfaction laat zien. Het effect van role conflict op job satisfaction verloopt via role ambiguity. Tenslotte, vertoont job satisfaction een sterk positief verband met job performance. We zien dus, dat autonomy, de bevoegdheid om zelf beslissingen te nemen, een negatief effect vertoont op zowel role conflict als role ambiguity. Verder is het opvallend, dat van de role stress variabelen alleen role ambiguity een negatief verband heeft met job satisfaction. Ook nemen we waar, dat job satisfaction een positief verband heeft met job performance in termen van technische en functionele kwaliteit. In het longitudinale model introduceren we autoregressive effects (effecten tussen identieke constructen over de tijd) en lagged effects (vertraagde effecten). Alle autoregressive effects zijn significant en van substantiële grootte. We vonden echter slechts drie lagged effects of vertraagde effecten. Ten eerste, formalisatie in de eerste wave beïnloedt job satisfaction in de tweede wave positief. Dit betekent dus, dat het vertraagde effect van formalisatie op job satisfaction positief is. Ten tweede, group cohesiveness in de eerste wave vertoont een positief effect op role ambiguity in de tweede wave. Tenslotte, heeft de competence dimensie van empowerment in de eerste wave een negatief effect op technische kwaliteit (job performance) in de tweede wave.

In hoofdstuk 6 worden de resultaten van het empirische onderzoek op basis van het conceptuele model in hoofdstuk 4 beschreven. Het onderzoek vond opnieuw plaats bij de after-sales service van een grote producent van kantoorapparatuur in Nederland. Bijna 600 klanten namen deel aan het onderzoek. De psychometrische eigenschappen van de gebruikte meetinstrumenten werden allereerst onderzocht middels confirmatorische factoranalyse. Alle gebruikte meetinstrumenten vertonen gunstige psychometrische eigenschappen. Vervolgens werden de hypothesen getoetst middels structural equation modeling. Middels empirisch onderzoek vonden we, dat zowel technische kwaliteit als ook functionele kwaliteit een positieve samenhang met affectief commitment vertonen. Technische kwaliteit laat zowel een direct als indirect positief verband zien, terwijl functionele kwaliteit slechts een indirect positief verband laat zien. Verder laten zowel technische kwaliteit als ook functionele kwaliteit via klanttevredenheid een indirect verband met calculatief commitment zien. De benevolence component van vertrouwen vertoont een positief verband met zowel affectief als calculatief commitment. De honesty component daarentegen laat een positief verband met affectief commitment zien, maar een tegengesteld verband met calculatief commitment. Verder zien we ook een positief verband tussen honesty en klanttevredenheid. De intentie om loyaal aan de service organisatie te blijven wordt positief beïnvloed door zowel affectief commitment als ook calculatief commitment. We vinden echter wel een relatief sterker verband voor affectief dan voor calculatief commitment. Dat betekent, dat met name affectief commitment een positieve bijdrage levert tot het onderhouden van een lange termijn relatie. Tenslotte, vinden we ook we een positief verband tussen de benevolence component van vertrouwen en intentie om loyaal te blijven.

Hoofdstuk 7 tenslotte wordt deze dissertatie met een conclusie afgesloten. Hoofdstuk 7 bevat de belangrijkste conclusies van deze dissertatie. Naast de conclusies bevat hoofdstuk 7 ook theoretische en management implicaties van dit onderzoek. De belangrijkste theoretische implicaties van deze dissertatie kunnen als volgt samengevat worden. Beide empirische onderzoeken vonden slechts bij één service organisatie plaats. Verder onderzoek is nodig om de algemene geldigheid van onze resultaten aan te tonen. Het is mogelijk, dat een aantal relevante variabelen niet in ons model opgenomen zijn (omitted variables). Verder maken we gebruik van één niveau van analyse, terwijl meerdere niveaus onderscheiden kunnen worden (individu, groep, organisatie). Het gebruik van een longitudinale opzet is sterk aan te bevelen, gezien de resultaten van dit onderzoek. Verder onderzoek is echter noodzakelijk naar het juiste vertragingseffect. 
Ons onderzoek laat de volgende management implicaties zien. Kwaliteit van de dienstverlening is inderdaad een focal construct voor het management van dienstverlenende organisaties. We zien, dat klanttevredenheid positief beïnvloed wordt door zowel technische kwaliteit als functionele kwaliteit (beide percepties uit het oogpunt van de klant). Klanttevredenheid op zijn beurt heeft een positief effect op affectief commitment en calculatief commitment. Affectief commitment heeft vervolgens een sterk positief effect op intentie om loyaal te blijven aan de service organisatie. Als we kwaliteit als prestatiemaatstaf voor de service medewerkers in de eerste lijn nemen dan zien we, dat met name job satisfaction een positief effect vertoont op job performance in termen van technische en functionele kwaliteit (hier als prestatiemaatstaf voor service medewerkers in de eerste lijn). Role ambiguity is de belangrijkste determinant van job satisfaction. Dit houdt in, dat onduidelijk over de te vervullen taken tot een vermindering van job satisfaction leidt. Autonomy, de bevoegdheid om zelf beslissingen te nemen, heeft een negatief effect op role ambiguity; draagt dus bij tot minder role ambiguity. Autonomy vertoont ook een negatief effect op role conflict en draag zo ook indirect bij tot de reductie van role ambiguity. Verder laat ook initiating structure een negatief verband met role ambiguity zien. Dat houdt in, dat het scheppen van kaders en structuren door de service manager leidt tot een vermindering van de role ambiguity door de service medewerker in de eerste lijn. Vervolgens zien we, dat empowerment ook een direct, positief verband met job satisfaction heeft. Onze resultaten ondersteunen grotendeels het bestaan van de service profit chain. De onderliggende gedachte bij de service profit chain is, dat tevreden medewerkers loyaal blijven aan de service organisatie en zo een positieve bijdrage leveren aan de klanttevredenheid en loyaliteit van de klanten. Met andere woorden, tevreden (service) werknemers, leiden tot tevreden (service) klanten. Vervolgens zal de verhoogde loyaliteit van de klanten een positief effect hebben op de winstgevendheid van de service organisatie. 


\section{Curriculum Vitae}

Martin G.M. Wetzels was born 20 March 1969 in Heerlen, the Netherlands. After completing secondary school ("Sophianum" in Gulpen, the Netherlands) he studied Economics at the University of Limburg, Maastricht. During his studies he specialized in Marketing and Marketing Research. In 1992 he joined the department of Marketing \& Marketing Research as a Research Assistant. In 1993 he obtained his Master's Degree (with distinction) at the Faculty of Economics and Business Administration of the University of Limburg. In September 1993 he started to work for the Department of Marketing \& Marketing Research as a Lecturer. In September 1994 he started work on his Dissertation. His main research interests are: service quality, customer satisfaction./dissatisfaction, customer value, quality management in service organizations, services marketing, marketing research, cross-functional cooperation and relationship marketing. His work has been published in the International Journal of Research in Marketing, the Journal of Economic Psychology, Accounting, Organization and Society, the Journal of Business Research, the European Journal of Marketing, Advances in Services Marketing and Management, the Joumal of Business and Industrial Marketing, Maandblad voor Accountancy en Bedrijfseconomie, the Journal of Retailing and Consumer Services, the International Journal of Service Industry Management and the Journal of Customer Satisfaction, Dissatisfaction and Complaining Behavior. Finally, he has contributed more than twenty papers to conference proceedings. 